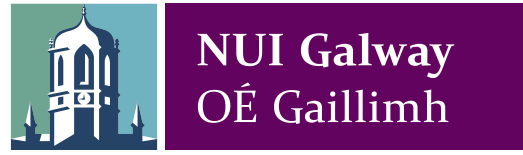

\title{
DEVELOPING AND IMPLEMENTING DEMENTIA POLICY IN IRELAND
}

\author{
EDITED BY EAMON O'SHEA, \\ SUZANNE CAHILL AND MARIA PIERCE
}




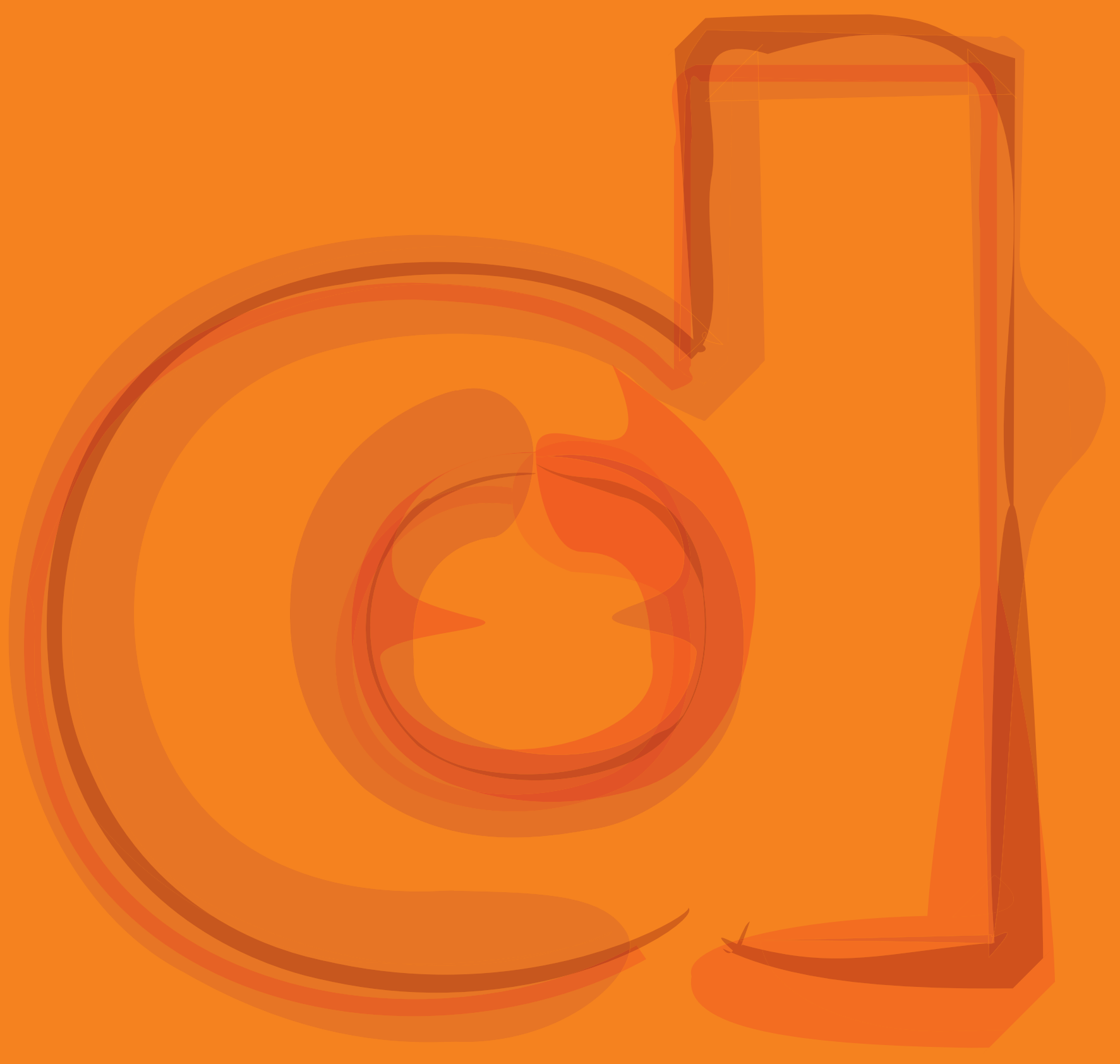




\section{DEVELOPING AND IMPLEMENTING DEMENTIA POLICY IN IRELAND}

EDITED BY EAMON O'SHEA, SUZANNE CAHILL AND MARIA PIERCE 


\section{ACKNOWLEDGEMENTS}

The editors would like to thank The Atlantic Philanthropies for investing in this project and for their encouragement and support for dementia in the past decade. Mary Sutton and Tom Costello deserve special mention for their long-term contribution to funding dementia programmes and interventions in Ireland. We are very grateful to the various contributors to this report who generously gave their time and expertise to the project. Thanks to Mary Manning for writing the foreword to the report. We have also had many informal conversations with staff in various health and social care organisations and we thank them for their insight and advice. Similarly, conversations with people with dementia and their families have also contributed to the ideas shared in this report. We would like to acknowledge the work of Elaine Howard and Mary McGuire of Genio and the wider HSE \& Genio Dementia Programme which has informed the content of Chapter 5. We would like to thank Marie Lynch, Mary McGuire, Sinead Grennan, Tony Foley, Matthew Gibb, Maureen O'Connor, Dympna Brady, Corina Naughton, Michael Brennan for contributing information for Chapter 6. Special thanks to Tom Pierse who steered the whole process through to completion. Thanks also to Martha Killilea who provided great assistance with references and proof reading as well as Christine De Largy who ensured that everything worked smoothly. 


\section{FOREWORD}

The Developing and Implementing Dementia Policy in Ireland report follows on from Creating Excellence in Dementia Care: A Research Review of Ireland's National Dementia Strategy, a seminal piece of work that was highly instrumental in informing the development of the National Dementia Strategy (NDS).

I have no doubt the current publication will have an equal and meaningful impact, both in terms of reflecting on and informing how we address dementia in Ireland.

The National Dementia Office (NDO), established to oversee the implementation of the NDS, is playing a key role in integrating the different elements of the strategy; ensuring a holistic approach and its integration into the wider health and social care system. The NDS was published at the end of 2014 and we are just over half-way through implementation. For the NDO, the key learnings to date are that leadership at a high level is crucial, not only to drive the dementia agenda but to bring all stakeholders together and promote collaborative and partnership working.

While progress is being made, there is a need to ensure we are focused on fostering change, creating a system that is receptive to meeting the real needs of people with dementia and their families. This can be achieved in part by education and training and by increasing public awareness. But it also requires an examination, focused effort and investment in changing processes and pathways to ultimately change the culture of care.

No one organisation is going to tackle dementia alone. We all need to work together, bringing our unique insights and skill sets to get the balance right.

We also crucially need to continue to ensure that the development of dementia policy and practice is underpinned by a solid evidence-base and, most importantly, that the person with dementia and their families are central in informing and influencing future dementia policy and practice in Ireland.

The insights and reflections on various aspects of dementia and dementia care, both nationally and internationally, as outlined in this report will be important to inform future developments in dementia policy in Ireland.

The range of authors who have contributed to the report is a reflection on the expertise we have across disciplines in dementia research in this country. I would like to congratulate all contributors to the report and in particular acknowledge the work of the three editors: Dr. Maria Pierce; Prof. Suzanne Cahill; and Prof. Eamon O'Shea.
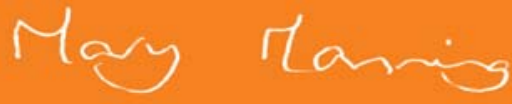

Mary Manning

General Manager

National Dementia Office 


\section{EXECUTIVE SUMMARY}

A lot has happened in dementia care nationally and internationally since 2012 when we wrote Creating Excellence in Dementia Care: a Research Review for Ireland's National Dementia Strategy. That report provided the government with a critical baseline of research and policy analysis upon which to build its initial dementia strategy. The Irish National Dementia Strategy was published in December 2014 and, almost immediately after, systems were put in place to support its implementation. There has been action on a number of fronts since then, especially in relation to: raising public and professional awareness and understanding of dementia; workforce training and education; intensive home care packages; and timely diagnosis and intervention. A new National Dementia Office has also been established staffed by dedicated health care professionals and others committed to social change and to improving and expanding dementia services. While the transformation of care for people with dementia is on-going, real progress has been achieved within a relatively short period of time.

The current report is not intended as an evaluation of the National Dementia Strategy or its aftermath in relation to implementation. Rather, it is a reflection on various aspects of care for people with dementia in Ireland and internationally with a view to informing future developments in dementia policy in the country. Some chapters are analytical and build on the earlier work contained in the Creating Excellence Report, others are retrospective analyses focusing on innovations in the organisation and delivery of care, while the remainder are prospective, sometimes aspirational narratives on what should happen in the future. The international dimension of dementia is explicitly covered in the report. We believe, like in other countries such as Australia, Scotland, France and Norway, that have now advanced to their second and in some cases third or fourth Dementia Strategies, that there should be a second National Dementia Strategy in Ireland. The ideas presented in this report can lay the foundations for the next iteration of the National Dementia Strategy.

The baseline dementia prevalence estimates in this report are based on the EuroCoDe and EURODEM dementia prevalence rates. Applying these prevalence rates to the 2016 Census of Population, the number of people with dementia in Ireland is estimated to be 55,266 . The number of people with dementia is expected to grow at an average rate of 3.6 per cent per year over the next thirty years. By 2036, the number of people with dementia in the country will have doubled to 115,426 . In about thirty years from now, in 2046 , the number will have almost trebled to 157,883 . These figures are estimates, and will no doubt be influenced by migration and fertility patterns, along with on-going preventative programmes. However, the upward trend is incontrovertible and the implications for the health and social care system are profound in terms of the need to respond to the increase in numbers through the provision of additional services and supports. 
People with dementia are a diverse group. For that reason, prevalence estimates are disaggregated in this report by age, disability and ethnicity. People within the dementia cohort are not always treated equally and some people may face additional difficulties. Younger people with dementia, people with dementia and intellectual and sensory disability and those with dementia coming from minority ethnic communities may experience additional discrimination leading to more severe disabilities. Raising the issue of diversity may help to open up discussion about the need for more nuanced understandings of dementia and its experience, as well as drawing more attention to the unique and complex challenges posed by gender, age, disability and ethnicity. It can also highlight the importance of responding to these issues through personalised approaches to supporting people with dementia.

It is difficult to estimate the precise number of informal caregivers of people with dementia in Ireland and to generate a breakdown on spousal and non-spousal (generally adult children) caregivers, whom, in terms of commitment to care and motivation, we believe are two very different groups. However, extrapolating from the Enhancing Care in Alzheimer's Disease (ECAD) study, we estimate that there are approximately 60,000 informal caregivers providing care for people with dementia living in the community in Ireland. This figure is likely to be an underestimate, as many family caregivers will continue to have a central role in dementia care even when their relative with dementia is admitted to hospital or transferred into long-stay residential care. The type of care that informal caregivers of people with dementia undertake is wideranging and may vary from providing direct, hands-on practical or personal care, to organising care delivered by others, to supporting and assisting with decision-making. Informal caregiving is dynamic, incremental and unpredictable, as well as impacting physically and psychologically on the well-being of the carer. Dementia care is often provided by a wide variety of sources (formal and informal) so the way in which services are coordinated is important for caregivers. Responding to the complexities of care requires the development and nurturing of a philosophy whereby informal and formal carers are equal partners, supporting the person with dementia to live a dignified life. The challenge of providing care and support to a person with dementia is contingent on knowing what may and may not be acceptable to that person. Caregivers are important conduits of information in that regard.

How we think about dementia and talk about people who have dementia is important for the development of dignity-promoting care and support systems. In the past, dementia was thought of largely as a cognitive brain disorder, often hidden, or when visible managed by deficit based policies focused on medication and control. This thinking tended to marginalise the individual who was often seen as a 'non-person' or a body purely to be managed. In contrast, dementia nowadays tends to be framed in broader social terms with an emphasis on the preservation and promotion of personhood and citizenship and the provision of services and supports that engage and empower the individual. Increasingly it is recognized that the complexities associated with dementia mean that no single speciality or organisation has the expertise to deal with its multiple challenges. The emerging consensus is for the development of a biopsychosocial model of care that reflects the medical, social, behavioural, psychological and emotional needs of the person with dementia and their caregivers.

For a broader model of care to prosper and for the individual to be helped flourish, dementia must become more fully integrated into other health policy areas, including prevention and risk reduction areas. Future policy must focus on the recognition and promotion of the human rights of the individual and their family members. We must continue to personalise care, recognising that people with dementia are active agents and citizens who need to remain socially engaged and involved in meaningful relationships and in activities that promote their dignity and enhance their quality of life. If the principles of citizenship and personhood are to be implemented in Irish care settings, there is a need for clear guidelines to be developed on what exactly these principles mean to the individual, family members, health service professionals, front line care staff and care regulators. Without guidelines, personhood and citizenship will remain vague and potentially unattainable concepts leading to sub-optimal care for people with dementia.

The personalisation of services for people with dementia is at an early stage of development in Ireland. Recent initiatives, funded by the Atlantic Philanthropies and developed through HSE \& Genio cooperation, have led to changes in how home care services are designed, coordinated and delivered for people with dementia. The introduction of Intensive Home Care Packages for people with dementia is part of the process of expanding the use of personalisation into the wider system. However, while piloting and 
demonstrating new models of care is very useful, systemic change requires more than 'tinkering' on the margins. We can learn from other areas such as the disability sector, where moves towards personalisation have gone through a lengthy and incremental process over several decades, incorporating the deinstitutionalisation and normalisation movement. If we can learn from this experience, a similar transformation in dementia care need not be so protracted.

For personalisation to work well, changes to the way in which resources are allocated are required. At a simple level, allowing people the freedom to 'bundle' their hours into one single block rather than having short periods of support at times that do not suit them might yield considerable benefits. Change is also required to facilitate the person and family to have a much greater say in how resources are used. This, for example, could be through some form of personal budget, which has been shown to have benefits for people with dementia and their family carers if the right supports are available to purchase. It is also important to shift away from a singular focus on 'hours of care', with little regard for what happens during those hours. A recalibration from task-centred instrumental care to a more holistic personalised care model that takes greater account of the individual's social, emotional, psychological and spiritual needs is necessary. This is part of the deeper philosophical change that is required in dementia care in Ireland, where time spent adding value to a person's life is recognised and regarded as equally important and worth paying for as time spent helping them with personal care. Changes in service delivery, such as a single point of contact, continuity in provision and confidence in a timely response have been shown to yield significant benefits for people with dementia and their caregivers.

For future service transformation, education will be a very important element in the change process. We are only at the beginning of the journey of challenging entrenched and stereotypical, nihilistic attitudes about dementia and people with dementia. A fundamental philosophical shift is required within each and every citizen: a shift that goes beyond the intellectual and challenges many of our fundamental values, beliefs and assumptions. Most importantly, we need to eliminate the erroneous notion that dementia strips people of all autonomy and personhood and that the ability to exercise autonomy and the ability to make rational decisions are one and the same thing. More choice, control, and agency needs to be returned to the individual living with dementia who for too long has been relegated to the status of a diseased and atrophied brain. Public information campaigns, such as Understand Together, are very important in creating the basis for these more fundamental shifts in attitudes towards people with dementia and their carers.

While considerable progress has been made in the number and diversity of dementia educational programmes available in Ireland in recent years, the majority of people with dementia still do not routinely receive person-centred care. Therefore, we cannot afford to be complacent in regard to on-going investment in education and training in dementia. Transitioning to a culture where person-centred care becomes the norm will, however, require more than simply training front line staff. It will necessitate senior managers valuing and nurturing their staff, helping to create a care culture that rewards them for positive risk taking and for delivering creative personalised care services and interventions that promote peoples' human rights. It will also require a reconfiguration in the balance of power between service providers and the individual living with dementia in favour of the latter.

Post diagnostic support (PDS) is increasingly recognised as an essential element in the care infrastructure for people with dementia and their caregivers. It is not only provision that is important, but the timing is also critical. For example, both pharmacological supports (drugs) and non-pharmacological supports (social and environmental) have maximum effect at an early stage in the course of the disease. Managing the emotional and psychological impact of the disease can be very distressing but, with the right supports, relevant coping strategies can be developed that help reduce anxiety and improve quality of life. Many individuals experiencing the symptoms of dementia, even if fortunate to obtain a diagnosis, may not be offered follow-up services or supports at a time when their information needs are highest. In the early stages, people with dementia require interventions that enhance social contact, reduce isolation, increase social engagement and overcome the limitations imposed by the condition. Post-diagnostic supports are important, therefore, to enable people with dementia and their caregivers to come to terms with the disease, maximise their autonomy, plan for the future and live well with dementia. The availability of a dedicated contact person is also important for continuity and the development of personalised care within an integrated system of provision. People with dementia and their carer need someone to help them 
navigate their way through existing services and supports. It is our contention that it is irrelevant what that contact person is called, provided he/she is a named and trained person, who commands respect within the local health and social care system and can signpost the individual with dementia and their family caregiver to the appropriate services and supports. We believe that the government's current commitment to timely diagnosis should be accompanied by guaranteed post-diagnostic supports (as in Scotland). An immediate investment in post-diagnostic support would yield significant long-term dividends for people with dementia and their families.

Promoting autonomy, maintaining independence and preserving the personhood of the individual newly diagnosed with dementia should be the goal of the post-diagnostic support system. For the person to live well with dementia, ensuring that they remain socially engaged and closely connected to family, friends and social networks within local communities is very important. The negative attitudes of others can result in people newly diagnosed not wanting to disclose their diagnosis for fear of being devalued, or not wanting to socialise for fear of being subjected to condemnation and ridicule. For that reason, education and psychosocial interventions, including peer support programmes, must become an important part of the post-diagnostic health and social care system to help people cope with the symptoms of the disease and its implications. Whilst anti-dementia drugs are clearly important and may, in the short term, hold promise for a minority of people diagnosed with dementia, we also believe that cognitive stimulation should be central to any new post-diagnostic support system. This is one area where the evidence is clear and compelling in terms of potential benefit to the individual diagnosed with dementia. The potential benefits of cognitive rehabilitation are also promising. Moreover, innovation in reminiscence, music therapy and exercise should be supported and evaluated as part of a wider strategy of developing the evidence base for a model of care in Ireland that put a high value on psychosocial needs.

Living at home in the community for as long as possible is a universal and desirable goal for all of us, yet home care provision for individuals with dementia in Ireland is currently weak and many people living at home in the community with dementia continue to have unmet needs. When older people are asked what they want in relation to home care, their answer is a system that allows them to live well in their own familiar environment. They want better and timely information, choice, personalised care, integrated care and more practical supports for family carers. Changing the current imbalance between home care and residential care will require new rights-based legislation, which is currently being considered by the Department of Health. Providing good quality care that is tailored to the individual needs of older people will be expensive, requiring a significant expansion of services, co-ordination, integration and regulation. Home carers will also have to be better trained and valued more highly, allowing them to be paid more, have better working conditions and more sustainable career pathways. Such incentives may ultimately attract more people into the profession. Solving the problem of inadequate home care is, therefore, going to cost money at many different levels.

Therefore, while expanding rights to community-based care is a necessary condition for progress in dementia care in Ireland, it is not a sufficient condition. The funding issue also needs to be addressed. Funding for long-term care in Ireland has historically come from general taxation. However, funding from this source has not delivered the money required to support an optimal community-based response for people with dementia. Cost sharing mechanisms have been used in many countries, including Ireland, to supplement revenues from taxation in different areas of health and social care, including dementia. While there may be some scope for increased funding for home-based care for people with dementia in the future though co-payments, the bulk of funding will still need to come though general taxation. And, in any case, we need to be careful about over reliance on cost sharing in community-based care if we want to encourage people to remain at home rather than seek admission to long-stay care.

An alternative option for funding the home care needs of people with dementia is long-term care social insurance. Under a social insurance system, individuals would pay into a fund over their lifetime in the labour market in return for automatic entitlement should they need benefits at some time in the future. A designated social insurance fund would allow for a more protected, community-based funding model than currently exists. It would also encourage transparency in priority-setting and service delivery. Back in 2002, when the issue of funding long-term care in this country was last examined in detail, Mercer (2002) favoured 
a social insurance approach arguing that a new social scheme would generate additional resources and would establish a clear link between contribution and benefit (Brown, 2016). Fears about the potential costs of a new scheme prevented any further consideration of a switch to social insurance. However, it is now timely to examine this issue again. Consideration of an alternative funding model for long-term care is urgently required if we really want to change the care system for people with dementia in Ireland. Rights without resources will not solve the current problems of home care.

The WHO's Global Action Plan on the public health response to dementia, described by some as the start of a new era for people living with dementia, was released at the World Health Assembly in May 2017. The Plan identifies seven priority areas for action on dementia, namely: (i) dementia as a public health policy; (ii) dementia awareness and friendliness; (iii) dementia risk reduction; (iv) diagnosis, treatment and care; (v) support for dementia carers; (vi) information systems for dementia; and (vii) dementia research and innovation. The new Global Action Plan sets targets for each priority area over a nine year period (2017-2025) and requests governments across the world to commit to and prioritise all seven actions and report to the WHO on a regular basis. When compared with other countries, Ireland should be proud of already being in the lead with regard to addressing the majority of these key priority areas. However, further work now needs to be undertaken on risk reduction programmes (action three) and information systems (action six), where core sets of dementia indicators (data) are required for collection. The Global Action Plan is strongly embedded in rights based principles linked to the UN Convention on the Rights of Persons with Disabilities. The ratification of the Convention by Ireland requires urgent attention, as does the linking of its priority areas to Articles in the UN Convention, especially Article 12, which refers to the right of persons with disabilities to enjoy legal capacity on an equal basis with others in all aspects of life.

Finally, it is important that the energy and commitment recently witnessed in Ireland to reframe dementia policy and improve and expand dementia services is sustained and that the country continues to build on the success of its inaugural National Dementia Strategy by developing a second Strategy. This will be made easier given the actions, targets and requirements set out in the Global Action Plan and given the fact that a new infrastructure is already in place in Ireland through the National Dementia Office. However, tackling some of the fiscal and funding challenges, as discussed in this report, will be required to achieve ambitious goals in relation to personhood, citizenship and person-centred care. This report has provided new insights and reflections on what that ambition might look like, but our contribution is not meant to be definitive, as we believe that an opportunity also needs to be given to all of the key stakeholders involved in dementia care in Ireland, especially people with dementia, to inform and influence future policy development and implementation.

What is clear from the contributions in this report is that timely diagnosis will remain very important in any new Strategy, supported by a post-diagnostic system that emphasises knowledge, information, peer support, cognitive interventions, continuity of care and integration, leading to higher levels of selfdetermination, choice and control on the part of people with dementia. Personalisation needs to be expanded to ensure that services and supports adequately reflect the wishes and preferences of people with dementia rather than the providers of care. Flexibility in provision and enhanced communication are the bulwarks of person-centred care, but without significant investment in education and training neither will be achieved. Primary prevention should also be deeply embedded in any new Strategy. So too should the voice and realities of people with dementia in acute care settings and in residential care. This includes generating alternative placement options between home care and residential care for people with dementia. Unfortunately, it will be impossible to achieve stated principles and goals in dementia without additional resources. Therefore, a new social insurance funding model will be necessary to support the development of a sustainable, high-quality, response to the needs of an increasing number of people with dementia in Ireland. 


\section{AUTHOR BIOGRAPHIES}

Eamon O'Shea is the Director of the Centre for Economic and Social Research on Dementia (CESRD) and a Professor in the School of Business and Economics at the National University of Ireland, Galway.

Suzanne Cahill has been the Director of the Dementia Services Information and Development Centre at St James's hospital between 1999 and 2017. She is also an Adjunct Professor in the School of Social Work and Social Policy at Trinity College Dublin.

Dr. Maria Pierce is an Adjunct Faculty Member, Faculty of Science and Health, Dublin City University, Dublin.

Glenn Rees is the Chair of Alzheimer's Disease International (ADI).

Kate Irving is a Professor of Clinical Nursing at the School of Nursing and Human Sciences in Dublin City University and Community Health Organisation Area 9.

Dr. Fiona Keogh is a Senior Research Fellow at the Centre for Economic and Social Research on Dementia, National University of Ireland Galway.

Dr. Patricia Carney is a researcher at the Centre for Economic and Social Research on Dementia, National University of Ireland Galway.

Dr. Tom Pierse is a researcher at the Centre for Economic and Social Research on Dementia, National University of Ireland Galway.

Niamh Hennelly is a PhD Candidate at the Centre for Economic and Social Research on Dementia, NUI Galway, Ireland. 


\section{TABLE OF CONTENTS}

ACKNOWLEDGEMENTS $\quad 2$

FOREWORD 3

EXECUTIVE SUMMARY 5

\section{CHAPTER 1: Introduction}

1.1 Introduction

1.2 Policy Background

1.3 Influences on the Irish National Dementia Strategy

$\begin{array}{ll}1.4 \text { Key Aspects of the Strategy } & 19\end{array}$

\begin{tabular}{ll}
\hline 1.5 A New Beginning & 20
\end{tabular}

1.6 Implementation Issues $\quad 21$

$\begin{array}{ll}1.7 \text { Report Structure } & 23\end{array}$

\section{CHAPTER 2: Prevalence of Dementia in Ireland}

2.1 Introduction 27

2.2 Prevalence and Projections of Dementia 28

$\begin{array}{ll}2.3 \text { Sensitivity Analysis } & 29\end{array}$

2.4 Regional Estimates of Dementia 32

2.5 Community/Residential Mix of Dementia 34

2.6 Incidence 34

2.7 Prevalence of Dementia by Age, Gender, Disability and Ethnicity 35

$\begin{array}{ll}2.8 \text { Conclusion } & 37\end{array}$

CHAPTER 3: Informal Caregiving to People with Dementia

3.1 Introduction 41

3.2 Informal Caregiving in Ireland 42

3.3 Cost and Impact of Informal Care 43

3.4 Supporting Informal Caregivers $\quad 44$

3.5 Caregiving Relationships and the Promotion of Personhood and Citizenship 46

3.6 Conclusion 47

CHAPTER 4: Models for Care for People with Dementia

4.1 Introduction $\quad 51$

4.2 Models for Understanding Dementia 52

4.2.1 The Social Model $\quad 52$

4.2.2 The Biopsychosocial Model $\quad 53$

4.2.3 Citizenship and Rights-Based Approach 54

4.2.4 A Public Health Approach $\quad 55$

4.3 Lessons from Other Countries $\quad 56$

4.4 The Way Forward 56

$\begin{array}{ll}4.5 \text { Conclusion } & 57\end{array}$ 
CHAPTER 5: Personalised Care for People with Dementia in Ireland

$\begin{array}{ll}5.1 \text { Introduction } & 61\end{array}$

5.2 HSE \& Genio Dementia Programme $\quad 62$

5.3 Personhood and Personalised Supports $\quad 62$

5.4 Dementia Consortia - a Mechanism for Service Integration 63

$\begin{array}{ll}\text { 5.5 Mobilising Community Support } & 64\end{array}$

\begin{tabular}{ll}
\hline 5.6 Community Supports Model & 65
\end{tabular}

5.7 Key Findings from the HSE and Genio Programme 67

5.8 Policy and Practice Implications of Personalisation 68

\section{CHAPTER 6: Education and Dementia}

$\begin{array}{ll}6.1 \text { Introduction } & 73\end{array}$

$\begin{array}{ll}\text { 6.2 Personhood and Person-Centred Care } & 73\end{array}$

\begin{tabular}{ll}
\hline 6.3 Changing Perceptions about Dementia & 74
\end{tabular}

6.4 Delivering Person-Centred Care $\quad 75$

\begin{tabular}{ll}
\hline 6.5 Education and Training Needs & 76
\end{tabular}

$\begin{array}{ll}6.6 \text { Current Educational Responses } & 78\end{array}$

\begin{tabular}{ll}
\hline 6.6.1 Dementia Awareness & 78
\end{tabular}

6.6.2 Dementia Skilled $\quad 78$

\begin{tabular}{ll}
\hline 6.6.3 Dementia Expert & 79
\end{tabular}

$\begin{array}{ll}6.7 \text { Measuring Impact } & 79\end{array}$

\begin{tabular}{lr}
\hline 6.8 Conclusion & 80
\end{tabular}

CHAPTER 7: Post-Diagnostic Support for People with Dementia

$\begin{array}{ll}7.1 \text { Introduction } & 87\end{array}$

7.2 Post-diagnostic Support - Features and Definitions 88

\begin{tabular}{ll}
\hline 7.3 The Importance of Diagnosis & 88
\end{tabular}

\begin{tabular}{ll}
\hline 7.4 Framework for Examining the Evidence & 89
\end{tabular}

$\begin{array}{ll}7.5 \text { Information, Advice and Peer Support } & 90\end{array}$

$\begin{array}{ll}7.6 \text { Cognitive Therapies } & 91\end{array}$

\begin{tabular}{ll}
\hline 7.7 Psychoeducational Interventions for Carers & 91
\end{tabular}

$\begin{array}{ll}7.8 \text { Psychosocial Interventions } & 92\end{array}$

$\begin{array}{ll}7.9 \text { Conclusion } & 93\end{array}$

CHAPTER 8: The Economics and Financing of Dementia in Ireland

$\begin{array}{ll}8.1 \text { Introduction } & 97\end{array}$

\begin{tabular}{ll}
\hline 8.2 The Societal Impact of Dementia & 98
\end{tabular}

8.3 Spending on Dementia Care 98

\begin{tabular}{ll}
\hline 8.4 Home Care Provision & 101
\end{tabular} 


\section{TABLE OF CONTENTS}

$\begin{array}{ll}\text { 8.5 Economics and the Boundary of Care in Dementia } & 102\end{array}$

8.6 Funding Long-Term Care 103

\begin{tabular}{ll}
\hline 8.7 Conclusion & 105
\end{tabular}

CHAPTER 9: Dementia: an International Priority

$\begin{array}{ll}9.1 \text { Introduction } & 109\end{array}$

\begin{tabular}{ll}
\hline 9.2 Dementia Risk Reduction & 110
\end{tabular}

\begin{tabular}{ll}
\hline 9.3 Global Action Plan on Dementia & 110
\end{tabular}

\begin{tabular}{ll}
\hline 9.4 Mobilising Government & 112
\end{tabular}

\begin{tabular}{ll}
\hline 9.5 Agents of Change & 112
\end{tabular}

9.5.1 The Human Face of Dementia 112

$\begin{array}{ll}\text { 9.5.2 Evidence Base } & 113\end{array}$

$\begin{array}{ll}\text { 9.5.3 Human Rights } & 113\end{array}$

\begin{tabular}{ll}
\hline 9.5.4 Dementia-Friendly Communities & 113
\end{tabular}

$\begin{array}{ll}9.6 \text { Key Alliances } & 114\end{array}$

\begin{tabular}{ll}
\hline 9.6.1 WHO and National Governments & 114
\end{tabular}

$\begin{array}{ll}\text { 9.6.2 ADI, WHO and DAI } & 114\end{array}$

\begin{tabular}{ll}
\hline 9.6.3 Researchers & 114
\end{tabular}

$\begin{array}{ll}9.7 \text { Principles to Action to Impact } & 114\end{array}$

9.8 Conclusion 116

CHAPTER 10: Conclusion: Towards a Second Dementia Strategy

10.1 Dementia in Ireland 119

$\begin{array}{ll}\text { 10.2 The National Dementia Strategy } & 120\end{array}$

$\begin{array}{ll}10.3 \text { Current Gaps } & 121\end{array}$

$\begin{array}{ll}\text { 10.4 Future Directions for Policy and Practice } & 125\end{array}$

$\begin{array}{lr}\text { REFERENCES } & 130\end{array}$ 


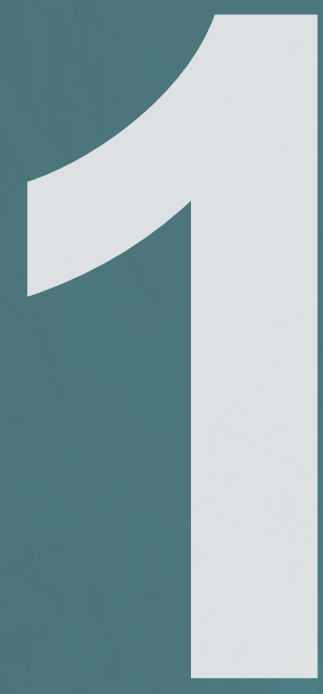

Introduction

Eamon O'Shea, Suzanne Cahill, Maria Pierce, Niamh Hennelly and Patricia Carney 
$-12 y=-1=$

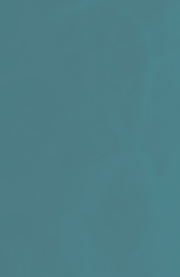

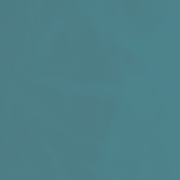

atititis 


\subsection{Introduction}

A lot has happened in dementia care nationally and internationally, since we wrote Creating Excellence in Dementia Care: a Research Review for Ireland's National Dementia Strategy in 2012. That report provided the government with a critical baseline of research and policy analysis upon which to build its initial dementia strategy. The Irish National Dementia Strategy was published in December 2014 and almost immediately after, systems were put in place to support its implementation through the creation of the National Dementia Office. There has been action on a number of fronts, especially in relation to raising public and professional awareness and understanding of dementia, workforce training and education, intensive home care packages and timely diagnosis and intervention. This current report is not intended as an evaluation of the National Dementia Strategy or its aftermath in relation to implementation. Certainly, the transformation of care for people with dementia has begun and real progress has been achieved, even if the pace of that progress has been far from consistent and the specific areas where changes introduced have remained somewhat confined.

This report should be seen as a reflection on various aspects of care for people with dementia in Ireland. Some chapters are analytical and build on the earlier work contained in the Creating Excellence report, others are retrospective analyses focusing on innovations in the organisation and delivery of care, while the remainder are prospective, sometimes aspirational, narratives on what should happen in the future. We believe that like in other countries such as Australia, Scotland, France and Norway that have now advanced to their second and in some cases third or fourth Dementia Strategies, there should be a second National Dementia Strategy in Ireland and that the ideas presented in this report can help in the formulation and implementation of future policy for people with dementia in the country. 


\subsection{Policy Background}

Historically, dementia care in Ireland has been under-funded and under-prioritised (Cahill, 2010). The care system has slowly moved away from institutionalisation, workhouses for the destitute and large-scale unregulated county homes to newer more enlightened models with a stronger focus on community care (Timonen and Doyle, 2008). The Care of the Aged Report (Inter-Departmental Committee on the Care of the Aged, 1968), was the first policy document that explicitly referenced older people remaining in their own homes. These commitments to community care were magnified in The Years Ahead: a Policy for the Elderly (Robins, 1988). The Years Ahead also contained some of the first dementia specific policy recommendations. These centred on elements such as screening for dementia, the need for dementiaspecific carers, additional day care and day hospital facilities, specialist hostels to support people with severe dementia and developing the provision of psychiatry in old age. Although clinically driven these policy documents have provided a solid baseline for current developments in dementia services.

An Action Plan for Dementia (O'Shea and O'Reilly, 1999) commissioned by the National Council for Ageing and Older People, was Ireland's first non-governmental dementia plan. It envisioned a person-centred, best practice social model of dementia care highlighting the need for major improvements in care in the community. It prioritised several key areas: increased public awareness, earlier diagnosis, psychosocial approaches to complement existing care, community based-services and small-scale residential care units. The government's 2001 Health Strategy (Dept. of Health, 2001) pledged to implement the Plan, but this hope was never realised. Despite pressure from various stakeholder groups, the setting up of two National Dementia Working Groups and the publication of a call for implementation (O'Shea, 2007) dementia failed to become a priority for government. The attention of policymakers at that time was focused mainly on the regulation of nursing homes in Ireland, including establishing the statutory provision of long-term care with the Nursing Homes Act (1990) and the development of national quality standards for residential care settings for older people in Ireland (HIQA, 2008).

Eventually, in 2011 a promise was given by the incoming government to develop a National Dementia Strategy (Dept. of Health, 2014). However this was signalled as a no cost strategy, due to the precarious condition of the State's finances at that time. Fortunately, from 2011 to 2016, dementia care in Ireland benefited from a substantial charitable investment of over $€ 33$ million from The Atlantic Philanthropies (O'Shea and Carney, 2016). Atlantic Philanthropies funded major multi-sectoral programmes throughout the country in key areas such as: service transformation, including end-of-life care; advocacy and awareness; education and training; brain health, prevention and diagnosis; and measurement, research and evaluation (O'Shea and Carney, 2016). A key legacy of Atlantic Philanthropies' investment was the development and strengthening of cooperation and partnerships across stakeholders in dementia care in Ireland. These alliances accelerated action in the areas of advocacy and policy, culminating in the development of Ireland's first National Dementia Strategy in 2014.

\subsection{Influences on the Irish National Dementia Strategy}

The Creating Excellence in Dementia Care Report (Cahill et al., 2012) was a major influence on the Irish National Dementia Strategy as it provided the required evidence base on which to plan future services. There is an explicit reference in the Strategy to the importance of the Report and to the information contained therein on best practice in dementia care locally and internationally. In addition to the Excellence report, the Strategy's development was informed by several other critical processes including: a review of international dementia policies; a review of Irish policy contexts; a public consultation; two roundtable discussions with clinicians; two workshops with people with dementia and carers; and the input of the National Dementia Strategy Advisory Group (Dept. of Health, 2014). Reports are available on the public consultation, roundtable discussions and workshops (Dept. of Health, 2012b; Alzheimer Society of Ireland, 
2013a; b). The Advisory Group contained experts working within the Department of Health in clinical and non-clinical roles, representatives from the Alzheimer Society of Ireland, academics, and experts from specialist groups, including those responsible for young onset dementia and end-of-life care. All of this consultation informed the development of the Strategy which was officially launched by the Department of Health and overseen by An Taoiseach and An Tánaiste in government buildings in December 2014. Thus, from its inception, strong political leadership of Ireland's first national dementia strategy was evident.

\subsection{Key Aspects of the Strategy}

The Strategy contains 8 key principles and 14 priority actions, while a further 21 additional actions and 31 objectives are dispersed throughout the document. The Strategy is based on two overarching principles, personhood and citizenship. The inclusion of these concepts as principles is a major breakthrough in the effort to develop a counter-policy frame to the traditional biomedical model that has dominated the dementia landscape in Ireland (Hennelly and O'Shea, 2017) where 'the person' tended to be seen as 'the dementia' (McLean, 2007) and where policy tended to be deficit-based, focused on what the person with dementia cannot do. This shift is also reflective of a wider international movement towards more holistic, person-centred models of dementia care where personhood is no longer regarded as being synonymous with mental capacity, but rather is created and sustained through meaningful interpersonal relationships (Kitwood, 1997). By developing policy for dementia, which is firmly embedded in these principles, the Strategy commits to seeing 'the person' in every individual irrespective of how advanced their dementia is and to ensuring that the person remains central to how dementia care services in Ireland are designed, developed and delivered. An analysis of the public submissions made in developing the Strategy shows that the majority of stakeholders also recognise the importance of personhood (Hennelly and O'Shea, 2017) and the uniqueness of the individual. The other guiding principles of the Strategy are concerned with integrating dementia into existing and future health policies, supporting people with dementia to remain in their own homes, ensuring that services and communications are accessible to the person with dementia, and the need for partnership among many different groups in the delivery of services. The Strategy emphasises that the stated principles should underpin and inform services and supports for people with dementia and their carers across all health and social care services in Ireland.

The six Priority Action Areas of the Strategy are: better awareness and understanding of dementia; timely diagnosis and intervention; integrated services; supports and care for people with dementia and their carers; training and education; research and information systems; and leadership. Better Awareness and Understanding aims to educate society as a whole on dementia, on modifiable risk factors and on reducing the stigma attached to dementia. Timely Diagnosis and Intervention is focused on educating GPs and other health care service personnel on all aspects of dementia from timely diagnosis to management of medication. It also aims to develop dementia care pathways to streamline existing services and supports. The third Priority Action Area Integrating Services and Supports involves a review of existing services for people with dementia in order to identify gaps in services and prioritise how these will be dealt with. It will also examine how to configure existing resources to allow people with dementia to remain living in their own homes for as long as possible. The action area of Training and Education overlaps partially with two of the others and relates to the training and upskilling of all health care professionals working with people with dementia. Research and Information Systems is concerned with gathering more information (both clinical and non-clinical) on dementia in Ireland, including using the Single Assessment Tool and hospital in-patient data to develop a better understanding of dementia and inform future dementia policy and decision-making. The final action area, Leadership, seeks to position responsibility for dementia within the Department of Health and to name a key worker within every primary care area to co-ordinate care for each person with dementia. This action area also requires the Department of Health to report directly to the Cabinet Committee on Social Policy, a committee chaired by An Taoiseach. 


\subsection{A New Beginning}

The publication of the National Dementia Strategy was a milestone for dementia care in Ireland. It followed years of lobbying, advocacy and policy failures in dementia, resulting in those living with dementia and their family members remaining an invisible and much neglected group of people. A key to the Strategy's success was its comprehensive consultation process. The development of the Strategy included extensive and varied types of consultation. This process brought together key stakeholders in dementia care in Ireland and gathered a broad spectrum of views, insights and issues in dementia care in Ireland. The consultation was equally important in developing a sense of ownership or 'buy in' from those interested stakeholders and of national solidarity. As with the development of other international strategies the importance of including people with dementia was recognised and actualised (O'Shea et al., 2016). People with dementia were directly involved in workshops organised as part of the development of the Strategy and their representitive organizations including the Alzheimer Society of Ireland and the Dementia Services Information and Development Centre were members of the Working Group.

The overarching principles of the strategy are to support personhood and citizenship, while another key principle of the Strategy focusses on supporting the person with dementia to "retain skills as much as possible" (Dept. of Health, 2014 p.13) and to have choice in relation to a range of long term care options (Dept. of Health, 2014 p.24). These commitments reflect a global movement towards a rights (Kelly and Innes, 2013) and strengths based model which seeks to promote autonomy (Boyle, 2008), support, empower and listen to the voice and wishes of the person with dementia (Bartlett and O'Connor, 2010; Batsch, 2016). Writing these principles into a policy document is simple but ensuring that they are operationalized and permeate health and social care services is a lot more challenging and requires a paradigm shift in the culture of dementia care and in how service provision is currently designed, structured and delivered. It necessitates a move away from a provider driven, service-led model to a person-centred individualized, outcomes-focused model, where the primary focus is on supporting the person with dementia to have more control over their everyday life, remain socially engaged through the course of the disease, retain their social identity beyond that of 'dementia patient' (O'Connor and Purves, 2009) and live well with dementia (O'Shea et al., 2016). This approach described in different ways including person-centred care, individualised care and relationship centred care, is based on notions of interdependence and that the individual's mood, behaviour and quality of life is influenced 'not only by [the] neuropathology' (O'Connor and Purves, 2009, p 13) but by a whole range of other pertinent factors.

While the Strategy echoes these important sentiments throughout its principles and objectives, the focus on personhood and person-centeredness, along with the other overarching focus on citizenship, lose traction within the priority actions of the Strategy. None of the priority actions contain any reference to implementing person-centred care or a person-centred system (Hennelly and O'Shea, 2017) and although committed to citizenship none of the priority areas contain reference to individual rights as, for example, the right to self determination, autonomy, control or real choice over home versus residential care. It is clear that the Strategy is dedicated, at a philosophical level, to systemic changes in dementia over an extended period of time. However, the Strategy is very weak on detail and on identifying what is challenging and what is required to bring about this change. The key to ensuring that change actually happens is only referenced in five lines of text under additional actions in the final pages of the Strategy (Hennelly and O'Shea, 2017) which probably relate more to leadership and systems rather than to on the ground real change which might help to improve the daily lives of all those living with the symptoms of dementia and those who support them.

In the past dementia tended to become lost between health and social care and between mental health and physical health (Banerjee, 2013). A key strength of the Strategy is the establishment of a National Dementia Office as where ownership of a policy area exists, action is likely to take place (Banerjee, 2013) and budgetary resources tend to follow. A second key strength of the Strategy is its focus on integrating dementia into existing and future government policy. For example the Strategy supports commitments made in Future Health (Dept. of Health, 2012a) in relation to supporting people to remain living in their own homes for as long as possible. It also commits to implementing the Strategy alongside the National 
Carer's Strategy, the HSE reform programme, Healthy Ireland, the National Physical Activity Plan and the National Positive Ageing Strategy. It pledges to implement, through the HSE, the National Consent Policy and to promote awareness of the Assisted Decision-Making Capacity Act. This pan-governmental integration of policy is vital to ensuring that dementia remains at the forefront of health policy and that there is more awareness and understanding of dementia across health care professionals and the general public. It is also vital towards ensuring that dementia shares resources with other chronic diseases where risk reduction programmes are similar and where economies of scale can be availed of. However, without continued effort to integrate and embed dementia across relevant policy initiatives, it is at risk of remaining in its own silo, thereby reducing its potential impact. The evidence on cross-cutting inter-departmental support for the Strategy is not strong and needs to be addressed quickly.

A further weakness of the Strategy is its lack of an explicit consideration of outcomes. There are references within the Strategy to developing "performance indicators to measure progress in implementing the Strategy" (Dept. of Health, 2014, p.35) but these are contained within the additional actions and remain vague throughout. Policy implementation requires measurable, realistic outcomes and key performance indicators. Without these, it is difficult to regulate for change. Equally, a lack of concrete, measurable outcomes makes it difficult for those implementing the Strategy to interpret what exactly is required to effect change and for those formally evaluating it to comment on what has and has not been achieved.

Additionally, the priority actions of the Strategy do not contain any timelines in which these actions will be realised nor does it contain any reference to how much money is available for each action and how in the future the current pilotted programmes and services will be sustainable. Ideally, a Strategy should contain specific information on how its key actions will be prioritied and resourced. For example, the third national French Alzheimer Plan contained a detailed funding summary broken down into themes, measures to be taken under each theme and how much funding is assigned to each (Alzheimer Europe, 2016). This approach has proven successful in leveraging real change in each of the priorities referenced in that country (Haeffner-Cavaillon et al., 2015). In Ireland, it was left to the National Dementia Office to address implementation, outcomes and timelines post the publication of the Strategy. To its credit, much progress has been made in respect of implementation, given the ambiguity of the Strategy. In terms of prioritisation, it might have been useful, for example, if the Irish National Dementia Strategy had prioritised home care provision above everything else and allocated additional funding to support this primary goal.

\subsection{Implementation Issues}

Currently, the key focus is on implementation, and the continued development of policy for people with dementia. Historically, the Irish experience with implementation has been poor. For example, policy documents in the ageing field have consistently pointed to community-based care as being the way forward for dependent older people, while funding has continued to be biased towards residential care; funding for residential care is currently three times as much as home care in Ireland (HSE, 2015). The attachment to the traditional residential model of care has been impossible to shift thus far, in spite of the community narrative emanating from government circles for the past fifty years. This bias is probably not unique to Ireland - for example Boyle (2010) argues that in the UK, despite the rhetoric of community care policy, there is a lack of relevant services to support people with moderate to severe dementia to live at home in the community. O'Shea et al. (2016) have also shown how much easier it has been in Ireland to formulate policy rather than to implement it.

Money matters for implementation, especially when combined with commitment, conviction, communication, monitoring, evaluation and good management. The Atlantic Philanthropies financial support for the implementation of National Dementia Strategy was vital in ensuring that action followed quickly after the publication of the Strategy. The Strategy is currently more than half way through its implementation with a total budget of $€ 27.5$ million, $€ 12$ million of which was provided by Atlantic Philanthropies on the agreement that the rest was matched by the Department of Health (O'Shea and 
Carney, 2016). Four areas have been allocated funding: Health and Well-Being (€2.7 million), Primary Care ( $€ 1.2$ million), establishing the National Dementia Office ( $€ 1.5$ million) and Intensive Home Care Packages (€22.1 million). Spending on Health and Well-Being is covered under the action area of Better Awareness and Understanding. Work in this area has involved a major national survey exploring public attitudes to dementia and an extensive national public awareness campaign called Understand Together which has involved radio, TV and social media. Funding in primary care relates to Timely Diagnosis and Intervention, which focuses on GP training and health service professional training including establishing the PREPARED project (the Primary Care Education, Pathways and Research in Dementia). The National Dementia Office falls under the remit of Leadership and is responsible for the overall implementation of the Strategy. The intensive home care packages are being provided to fulfil the objectives of the action area of Integrated Services, Supports and Care.

Not all of the priority action areas have received additional funding. Change for some areas in dementia involves zero cost or the reconfiguration of existing resources. There are also some exceptionally vulnerable groups for which the Strategy offers no immediate improvements or solutions. These include people with young onset dementia for whom there are no dedicated services and those with more moderate to advanced dementia resident in general nursing homes. In many nursing homes, building design is far from ideal: bedrooms may be cramped, bathrooms shared, noise is rife, access to outdoor areas very limited, antipsychotic medication may be used excessively and activity programmes may be rigidly scheduled without any due attention given to residents' individual preferences.

The Irish National Dementia Strategy was a much needed catalyst for the improvement and expansion of dementia care services in Ireland. It has highlighted many deficiencies in current dementia care provision and the need for better, more integrated care for people with dementia and their carers. The Strategy also supports the need for a greater understanding of dementia amongst the public. A well-informed public can ensure that the individual experiencing the symptoms and their family members can remain more part of mainstream society, be better integrated and continue to be socially engaged. The most important thing now is to ensure that momentum is maintained and accelerated, particularly as there will be no further funding from philanthropic sources to support future implementation and to address other priority areas. Without additional resources, it will be very difficult for the National Dementia Office to deliver on expectations in regard to home care, particularly if these are not copper-fastened by new rights-based legislation and overseen by the WHO's new global action plan (2016).

Raising public awareness is very important, yet in the absence of adequate care services in the home and from home, people may continue to feel lost and unsupported. The timely diagnosis of dementia is also equally important but in the absence of post-diagnostic services, people living with dementia may continue to withdraw and disengage while family members may lack confidence and the knowledge needed to plan for a more dignified future for their relative. Equally important is the need to regulate for enhanced personhood in the system of care for people with dementia. Principles and ideologies written down without being operationalized and monitored and without evidence of changes to practice are of no value to people with dementia or their caregivers. We need to learn from the successes and failures of the implementation of this Strategy to inform the development of the next one. Ireland must follow in the footsteps of countries like France, Australia, Norway and Scotland who continue their commitment to improving the lives of people with dementia and their carers through strong, adequately resourced dementia policy articulated in successive dementia strategies. This Report is designed to provide reflection and guidance on future policy as we begin to think about a second Strategy for dementia. 


\subsection{Report Structure}

Chapter 2 provides new estimates for the number of people with dementia in Ireland, including the number of people with dementia living at home and in residential care. New estimates for incidence are also presented in this chapter. This is followed in Chapter 3 by a comprehensive account of informal care for people with dementia in Ireland, outlining the estimated number of carers involved, what they do and the costs and consequences of their labour. Chapter 4 outlines models of care for dementia in Ireland with particular reference to rights and the biopsychosocial model of care. This chapter provides an important anchor for future iterations of the National Dementia Strategy in Ireland. Chapter 5 reflects on the advent and implications of personalised care in Ireland and the lessons learnt for future policy in this area. Education and training are key to the evolution of a person-centred, personalised, approach to care in Ireland based on the principles of personhood and citizenship. Chapter 6 provides insight into educational and training needs in the country and the relevance of new and sustained investment in this area in the future. Chapter 7 examines the role of post-diagnostic support for people with dementia and their caregivers, providing guidelines for future directions in this area of policy. Chapter 8 highlights the contribution of economics in dementia care, especially in regard to balance of care decision-making and the cost-effectiveness of various interventions in various settings. The issue of funding models for dementia care in Ireland is also addressed in this chapter. This is an important topic given the acknowledged failures in relation to policy implementation in the country, especially in regard to home care provision for people with dementia. The concluding chapter reflects on the lessons of the earlier contributions and highlights the importance of a second Strategy in dementia to accelerate the on-going transformation of care in the country. 


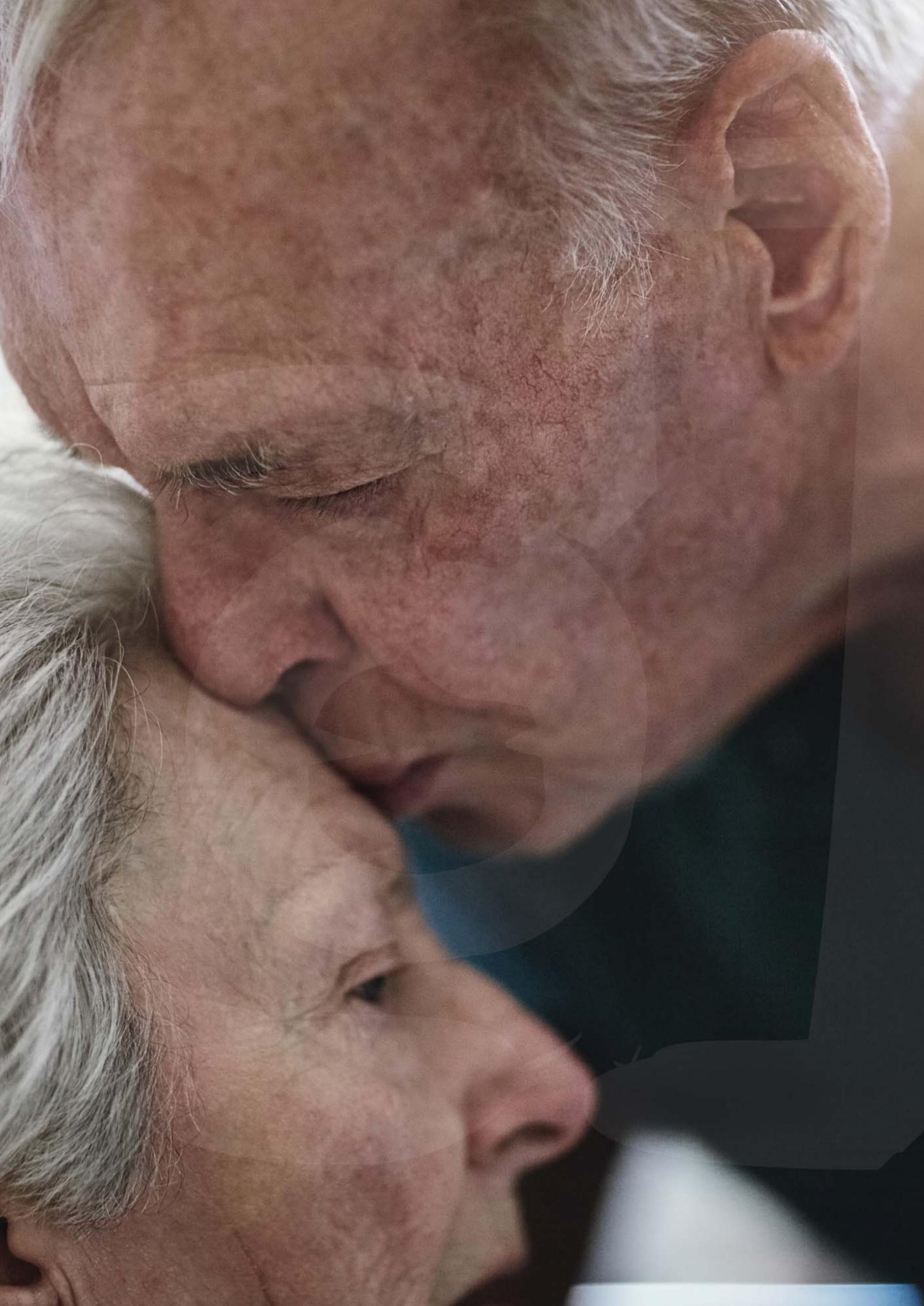




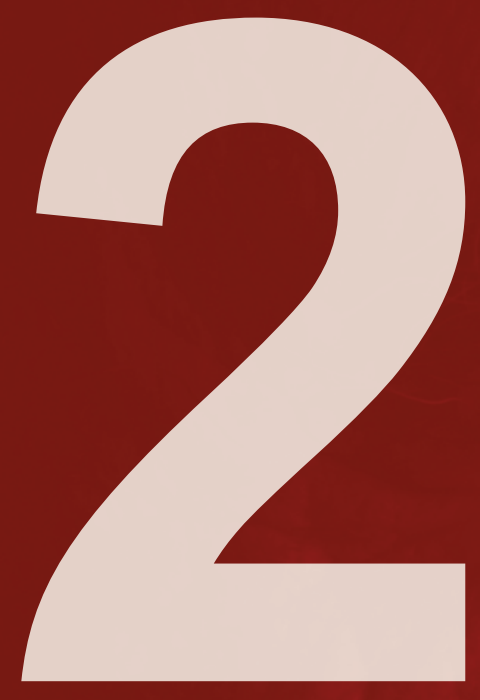

Prevalence of Dementia in Ireland

Maria Pierce and Tom Pierse 



\subsection{Introduction}

Ireland's population in 2016 stood at 4,757,976, of whom 637,567 people were aged 65 years and over. We can state these figures with confidence, as they are taken directly from the Census of Population (CSO, 2016). Estimating the number of people with dementia is less straightforward, as the Census cannot directly provide us with such a figure. This is where epidemiological studies come into play. There are no Irish epidemiological studies to inform estimates of the prevalence of dementia in Ireland, a situation similar to many other European countries (Kiejna et al., 2010; Misiak et al., 2013). This is not surprising as epidemiological studies are costly, complex and time consuming to undertake (Gordon et al., 1997). The main purpose of this chapter is to provide estimates of the number of people with dementia in Ireland, based on the most recent census, using international epidemiological studies as proxies for Irish prevalence and incidence rates.

In the absence of Irish epidemiological studies, previous estimates of dementia prevalence for Ireland (O'Shea, 2007; Pierce et al., 2014; Cahill et al., 2012; Diaz-Ponce, 2008) used a methodology based on a meta-analysis of data (i.e. combined data) from European epidemiological studies. This same methodology has been adopted in this chapter to provide updated estimates of the prevalence of dementia in Ireland for 2016. Specifically, this involves the application of EuroCoDe dementia prevalence rates (Alzheimer Europe, 2009) to 2016 Census data that is age and gender-disaggregated. The use of EuroCoDe dementia prevalence rates is not without its difficulties. In recognition of the uncertainties attached to the methodology used for producing the estimates, a sensitivity analysis is included in this chapter.

People with dementia are key users of a range of generic and dementia-specific health and social care services as well as other social services. Estimates of the number of people with dementia, where they live and the care settings in which they are being supported, are critical to the planning and development of health and social care services. Given that Ireland now has a National Dementia Strategy with a range of new community services being implemented, estimates of the number of people with dementia are important for providing the baseline for future service planning and development. The current availability of services and supports for people with dementia and the form that they take varies across the country; therefore, in addition to national level estimates, it is useful to have estimates at regional and local level to identify potential demand for services.

Although overall national and regional estimates of dementia prevalence are useful for service planning, people with dementia are not one homogenous group. This chapter disaggregates prevalence estimates by age and gender. It provides estimates of the number of people with an intellectual disability and dementia and gives consideration to ethnicity. By disaggregating the prevalence estimates in this way, this chapter seeks, albeit in a limited way, to recognise and highlight the differential impact that dementia has and the implications of this for services. It is, however, beyond the scope of this chapter to discuss the resource implications in any great detail. 


\subsection{Prevalence and Projections of Dementia}

The baseline dementia prevalence estimates provided in this chapter are based on the EuroCoDe dementia prevalence rates (Figure 2.1). These are supplemented with the EURODEM estimates of the prevalence of dementia in the 30-59 age group.

Figure 2.1:EuroCoDe Dementia Prevalence Rates

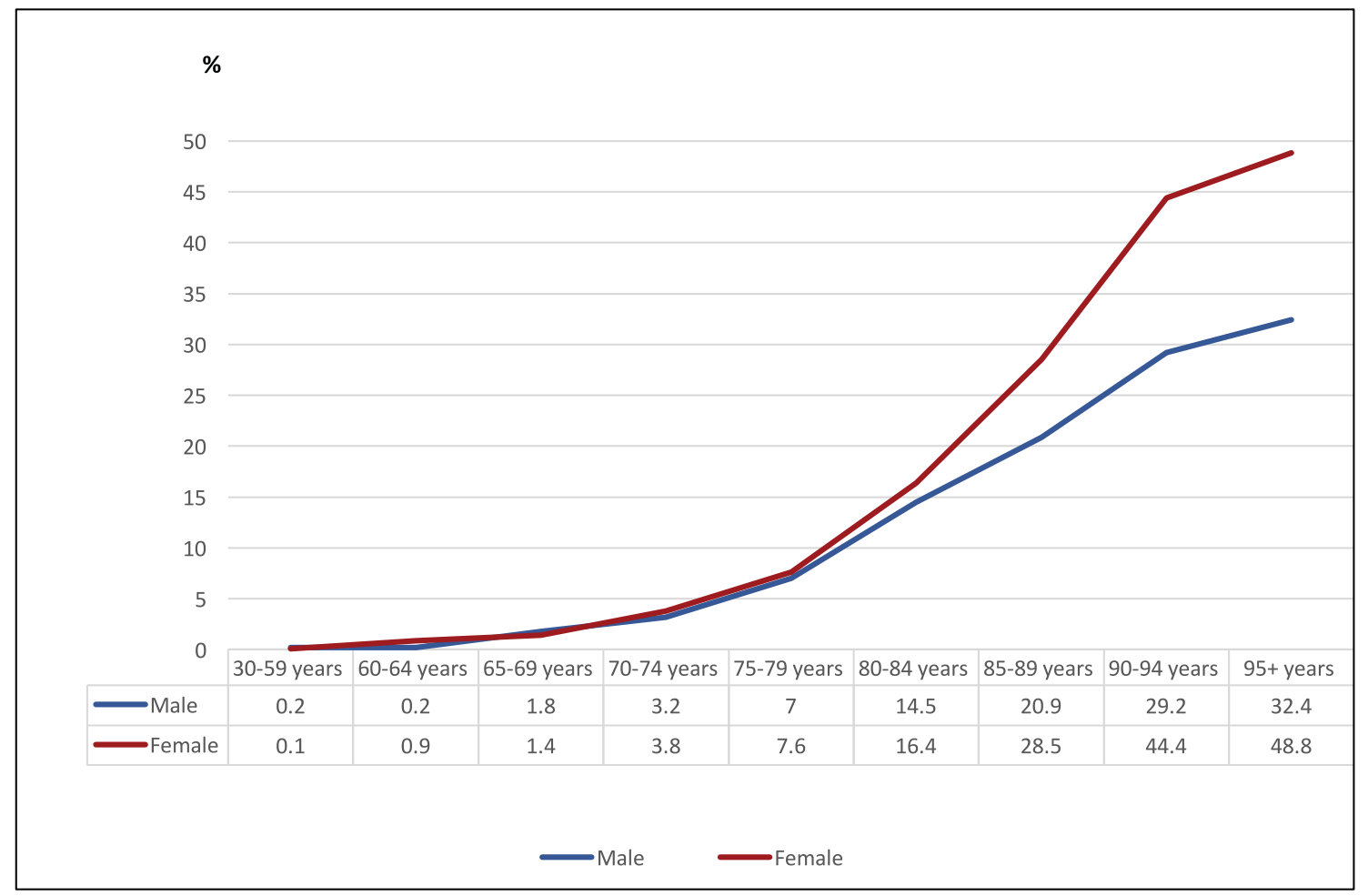

Applying these prevalence rates to the Census of Population data disaggregated by age and gender, the number of people with dementia in Ireland in 2016 is estimated to be 55,266 (Table 2.1). This is close to the number previously projected for 2016 (Pierce et al., 2014), where it was estimated that by 2016 there would be 54,793 people with dementia in the country.

Table 2.1: Estimated number of people with dementia in Ireland (2016) using EuroCoDe dementia prevalence rates

\begin{tabular}{|l|c|c|c|c|c|c|}
\hline \multirow{2}{*}{ Age groups } & \multicolumn{4}{|c|}{ Population (Census 2016) } & \multicolumn{3}{c|}{$\begin{array}{c}\text { Persons with dementia (estimated using } \\
\text { EuroCoDe age/gender-related dementia } \\
\text { prevalence rates) }\end{array}$} \\
\cline { 2 - 7 } & Male & Female & Total & Male & Female & Total \\
\hline $30-59$ years & 986,600 & $1,018,403$ & $2,005,003$ & 1,973 & 1,018 & 2,992 \\
\hline $60-64$ years & 118,698 & 120,158 & 238,856 & 237 & 1,081 & 1,319 \\
\hline $65-69$ years & 104,961 & 106,275 & 211,236 & 1,889 & 1,488 & 3,377 \\
\hline $70-74$ years & 79,501 & 82,771 & 162,272 & 2,544 & 3,145 & 5,689 \\
\hline $75-79$ years & 54,117 & 61,350 & 115,467 & 3,788 & 4,663 & 8,451 \\
\hline $80-84$ years & 35,196 & 45,841 & 81,037 & 5,103 & 7,518 & 12,621 \\
\hline $85-89$ years & 16,676 & 28,186 & 44,862 & 3,485 & 8,033 & 11,518 \\
\hline $90-94$ years & 5,234 & 12,740 & 17,974 & 1,528 & 5,657 & 7,185 \\
\hline $95+$ years & 1,152 & 3,567 & 4,719 & 373 & 1,741 & 2,114 \\
\hline Total & & & & 20,922 & 34,344 & 55,266 \\
\hline
\end{tabular}


For future projections of people with dementia, we continue to rely on the most recently available population projections from the Central Statistics Office (CSO, 2013). Based on these projections, Table 2.2 shows that there is expected to be a sustained increase in the number of people with dementia in Ireland over the next thirty years. The number of people with dementia is expected to grow at an average rate of 3.6 per cent per year. By 2036, the number of people with dementia in the country will have doubled; within thirty years from now in 2046, the number will have almost trebled.

Table 2.2: Projected growth in the number of people with dementia in Ireland by age group, 2016-2041 (M2F1)

\begin{tabular}{|l|c|c|c|c|c|c|c|}
\hline Age group & $\mathbf{2 0 1 6}$ & $\mathbf{2 0 2 1}$ & $\mathbf{2 0 2 6}$ & $\mathbf{2 0 3 1}$ & $\mathbf{2 0 3 6}$ & $\mathbf{2 0 4 1}$ & $\mathbf{2 0 4 6}$ \\
\hline $30-59$ & 2,992 & 2,933 & 2,871 & 2,854 & 2,847 & 2,879 & 2,991 \\
\hline $60-64$ & 1,319 & 1,449 & 1,615 & 1,738 & 1,905 & 2,044 & 1,896 \\
\hline $65-69$ & 3,377 & 3,681 & 4,108 & 4,586 & 4,986 & 5,438 & 5,774 \\
\hline $70-74$ & 5,689 & 6,842 & 7,575 & 8,518 & 9,543 & 10,395 & 11,381 \\
\hline $75-79$ & 8,451 & 10,206 & 12,564 & 14,055 & 15,925 & 17,971 & 19,693 \\
\hline $80-84$ & 12,621 & 14,015 & 17,861 & 22,348 & 25,375 & 29,104 & 33,195 \\
\hline $85+$ & 20,817 & 26,514 & 32,427 & 41,764 & 54,845 & 68,632 & 82,953 \\
\hline Total & 55,266 & 65,641 & 79,021 & 95,863 & 115,426 & 136,462 & 157,883 \\
\hline
\end{tabular}

\subsection{Sensitivity Analysis}

Besides the baseline EuroCoDe dementia prevalence rates, there are several other dementia prevalence rates from which to choose and which can be applied to Census data to generate an estimate of dementia prevalence in Ireland. In preparing the estimates in Table 2.1, we applied the EuroCoDe dementia prevalence rates to 2016 Census data mainly because previous estimates for dementia prevalence rates in Ireland also relied on these rates, or on the EuroDem dementia prevalence rates, their precursor. Applying the same dementia prevalence rates to Census data from different years ensures that there is continuity over time in relation to these estimates. It means that changes in the estimated number of people with dementia in Ireland are related to changes in the age and gender structure of the population, rather than differences in the dementia prevalence rates applied.

However, there is no consensus regarding which prevalence rates are the best to apply, and there are several uncertainties attached to these rates. The main sources of uncertainty relate to differences in the methods used to calculate the number of people with dementia in any particular country and the range of studies/countries included in any subsequent meta-analysis. There are also indications from several developed countries that the incidence of dementia may be declining slowly over time, although this is not a consistent finding across all studies and it cannot be assumed that this trend will be the same across countries (ADI, 2015). The potential fall in the risk of dementia in older adults in more economically developed countries may be due to better primary prevention of cardiovascular risk factors and improved levels of education within the population (Manton et al., 2005; Schrijvers et al., 2012; Matthews et al., 2013). There is also growing recognition of the potential of older adults to strengthen some cognitive abilities, leading to changes in individual behaviours as people age (Blazer et al., 2015). However, rising levels of diabetes and obesity may offset, partly or fully, some of the gains from a more active public health approach to risk reduction and prevention, especially in relation to cardiovascular disease. It is also possible, of course, that rising rates of obesity and diabetes may decrease life expectancy so that people with these conditions may be less likely to live to ages where the risk of dementia increases (Hurd et al., 2015). 
Given the absence of consensus and related uncertainty about which method to use to estimate dementia prevalence estimates for Ireland, a sensitivity analysis has been undertaken to explore the extent to which estimates of the number of people with dementia in Ireland might vary when different dementia prevalence rates are applied to 2016 Census data. To undertake the sensitivity analysis, two alternative sources of dementia prevalence rates were considered, the first source being from Alzheimer Disease International (ADI) and the second from the UK, our nearest neighbouring country.

In 2005, ADI convened a group of experts to review all available epidemiological data and reach a consensus estimate of prevalence in each of 14 WHO regions, one of which is Western Europe (Ferri et al., 2005). Since then, driven primarily by the expanding evidence base, this group of experts has reappraised the prevalence of dementia and produced global and regional updates (Prince et al., 2013; ADI, 2015; 2009). For the purposes of this sensitivity analysis, we have selected the dementia prevalence rates for the Western Europe region from the latest update provided by this group (ADI, 2015). These are illustrated in Figure 2.2.

Figure 2.2: ADI Dementia Prevalence Rates (ADI, 2015)

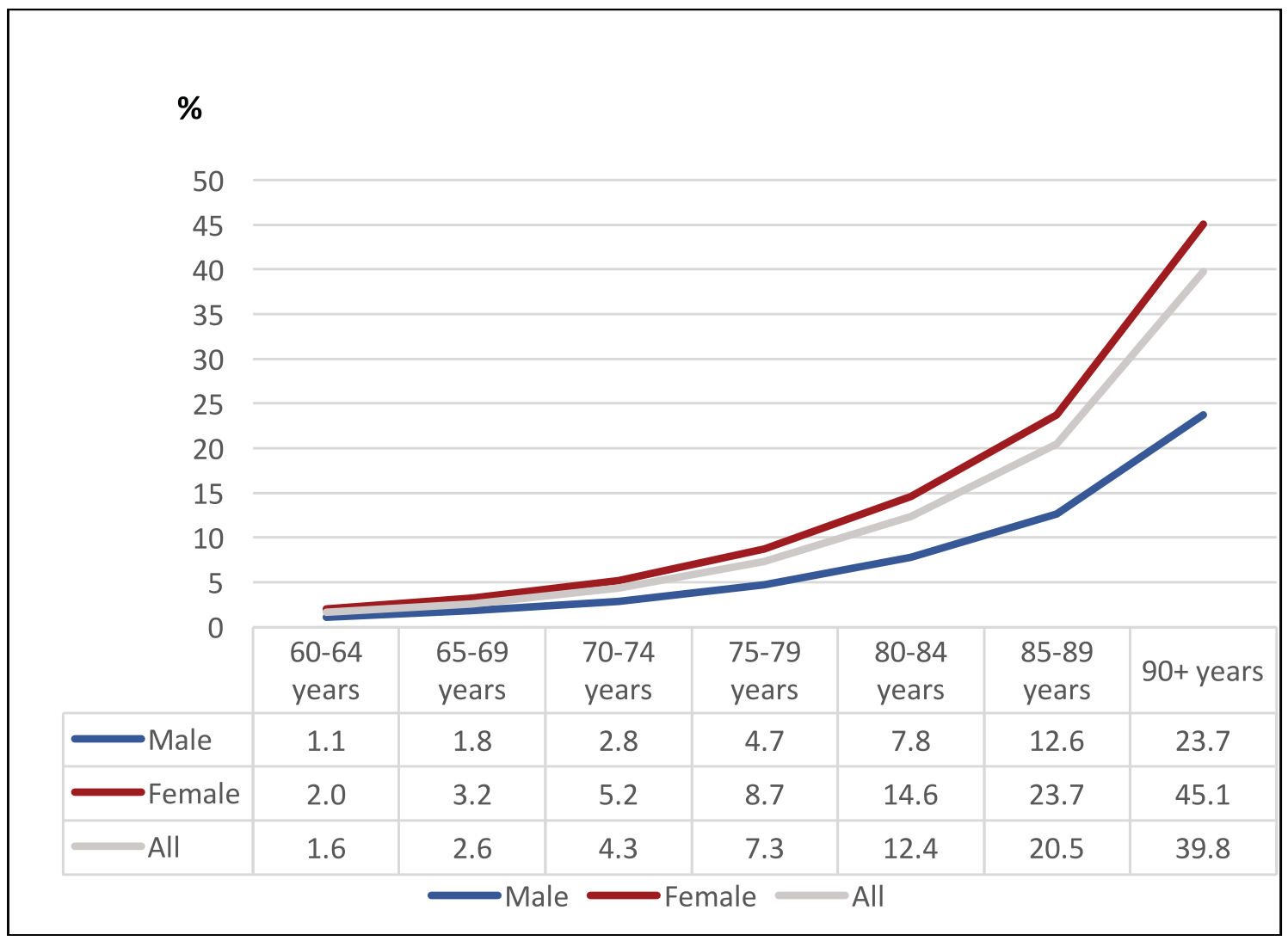

When these age/gender disaggregated prevalence rates are applied to the Census of Population 2016 data, this provides an estimate of 50,497 people with dementia aged 60 years and over in Ireland (Table 2.3). Including an estimate of 2,992 people aged 35-59 years with dementia brings the total number up to 53,489 . 
Table 2.3: Estimated number of people with dementia in Ireland (2016) using ADI (Western Europe) and UK dementia prevalence rates

\begin{tabular}{|l|c|c|c|c|c|c|}
\hline & \multicolumn{3}{|c|}{} & \multicolumn{3}{c|}{$\begin{array}{c}\text { UK age/gender-related dementia prevalence } \\
\text { rates }\end{array}$} \\
& \multicolumn{3}{|c|}{$\begin{array}{c}\text { ADI age/gender-related dementia prevalence } \\
\text { rates for Western Europe (ADI, 2015) }\end{array}$} & \multicolumn{2}{c|}{$\begin{array}{c}\text { Alzheimer Society source: } \\
\text { Prince et al, 2014) }\end{array}$} \\
\cline { 2 - 7 } & Male & Female & Total & Male & Female & Total \\
\hline $60-64$ years & 1,306 & 2,403 & 3,709 & 1,068 & 1,081 & 2,150 \\
\hline $65-69$ years & 1,889 & 3,401 & 5,290 & 1,574 & 1,913 & 3,487 \\
\hline $70-74$ years & 2,226 & 4,304 & 6,530 & 2,465 & 2,483 & 4,948 \\
\hline $75-79$ years & 2,543 & 5,337 & 7,881 & 2,868 & 4,049 & 6,917 \\
\hline $80-84$ years & 2,745 & 6,693 & 9,438 & 3,625 & 5,363 & 8,989 \\
\hline $85-89$ years & 2,101 & 6,680 & 8,781 & 2,518 & 5,694 & 8,212 \\
\hline $90+$ years & 1,513 & 7,354 & 8,868 & 1,515 & 5,773 & 7,288 \\
\hline Sub-total & 14,324 & 36,173 & 50,497 & 15,633 & 26,357 & 41,991 \\
\hline $30-59$ years & 1,973 & 1,018 & 2,992 & 1,973 & 1,018 & 2,992 \\
\hline Total & & & 53,489 & & & 44,983 \\
\hline
\end{tabular}

In the UK, the Alzheimer's Society commissioned a Delphi Consensus of experts to provide estimates of the number of people with dementia in the UK (Alzheimer's Society, 2007), and these estimates were updated in 2014 (Prince et al., 2014).The process is described in detail in Dementia UK: Update (Prince et al., 2014). The dementia prevalence rates generated from this study are presented in Figure 2.3.

Figure 2.3: Dementia UK Alzheimer Society prevalence rates (Prince et al, 2014)

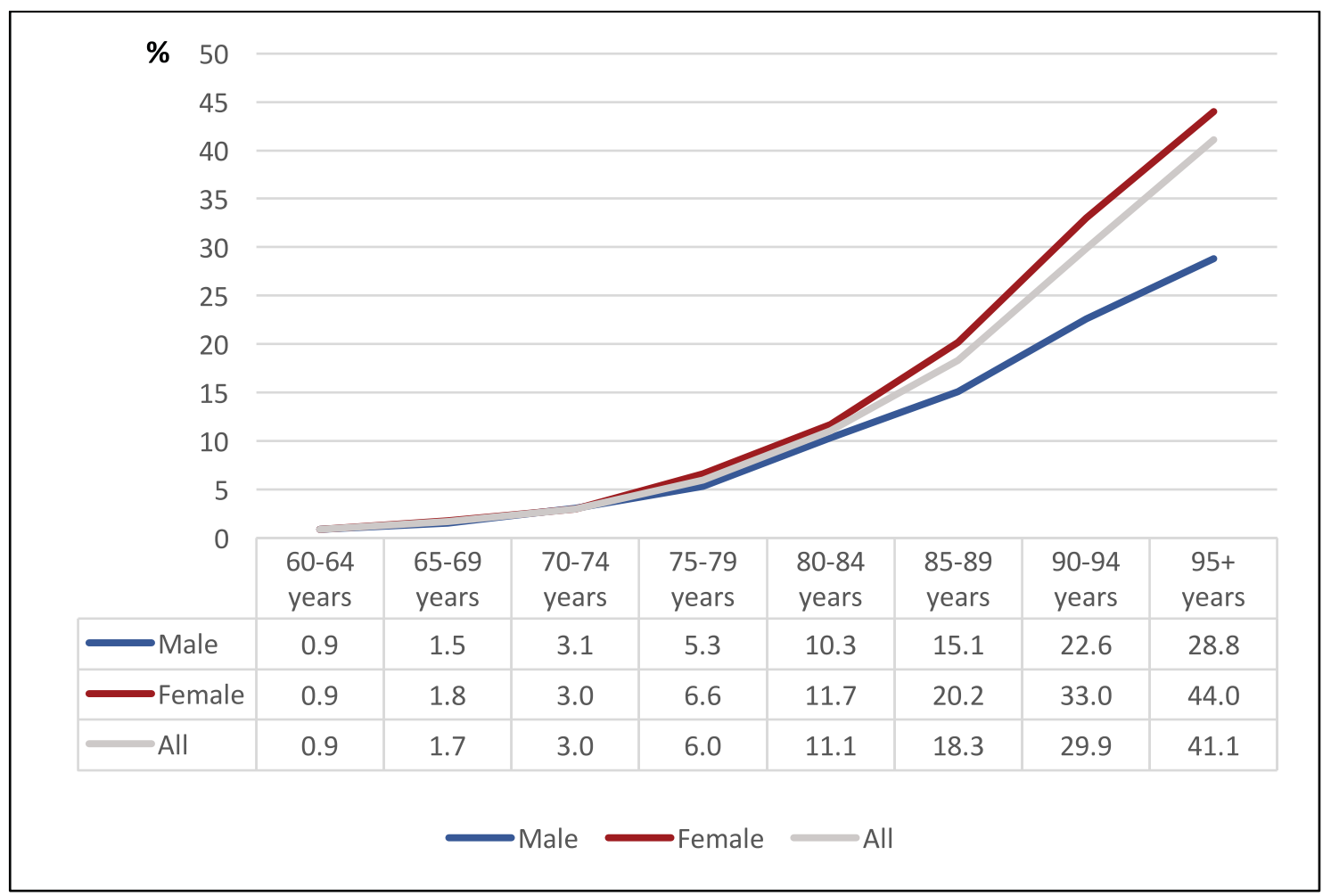


When the dementia prevalence rates from the UK report (Prince et al., 2014) are applied to Ireland's 2016 Census data, it is estimated that there are 41,991 people with dementia aged 60 years and over in Ireland (Table 2.3). Including an estimate of 2,992 people aged 35-59 years with dementia brings the figure to $44,983$.

Not surprisingly, when the different rates are applied to 2016 Census data, the prevalence estimates generated vary from those using EuroCoDe dementia prevalence rates. The estimate of approximately 53,000 generated using ADI rates (ADI, 2015) is close to the figure of 55,000 estimated using the EuroCoDe dementia prevalence rates. However, the figure generated using the UK prevalence rates is substantially lower at approximately 45,000. The largest differences are likely to be in the number of milder cases (Boersma et al., 1998; Helmer et al., 2006).

\subsection{Regional Estimates of Dementia}

In 2015, the health services in Ireland were restructured and nine Community Healthcare Organisations ( $\mathrm{CHO}$ ) established for the organisation and management of health services outside of acute services. Table 2.4 presents estimates of the number of people with dementia in each $\mathrm{CHO}$ area in 2016 using the baseline EuroCoDe dementia prevalence rates. While $\mathrm{CHO} 4$ (Cork and Kerry) is the $\mathrm{CHO}$ with the highest estimated absolute number of people with dementia, there are higher rates of dementia in CHOs 1, 2, and 3, which largely cover the Western seaboard. The CHOs are further broken down into Local Health Office (LHO) areas, of which there are 32 in total. Table 2.5 shows the proportion of the population estimated to be living with dementia in each LHO area. It further emphasises the high proportion of the population along the western seaboard with dementia.

Table 2.4: Estimated number of people with dementia by $\mathrm{CHO}$ areas, 2016

\begin{tabular}{|l|c|c|c|c|}
\hline CHO area & $\begin{array}{c}\text { Population of all } \\
\text { ages (2016) }\end{array}$ & $\begin{array}{c}\text { Population aged 65+ } \\
\text { years (2016) }\end{array}$ & $\begin{array}{c}\text { No. of people with } \\
\text { dementia including } \\
\text { early onset (2016) }\end{array}$ & $\begin{array}{c}\text { People with } \\
\text { dementia as a \% of } \\
\text { total population }\end{array}$ \\
\hline CHO 1 & 391,281 & 59,787 & 5,182 & $1.30 \%$ \\
\hline CHO 2 & 453,109 & 68,558 & 5,943 & $1.30 \%$ \\
\hline CHO 3 & 384,998 & 55,935 & 4,849 & $1.30 \%$ \\
\hline CHO 4 & 690,575 & 98,877 & 8,571 & $1.20 \%$ \\
\hline CHO 5 & 510,333 & 74,302 & 6,441 & $1.30 \%$ \\
\hline CHO 6 & 383,169 & 57,237 & 4,961 & $1.30 \%$ \\
\hline CHO 7 & 707,714 & 76,576 & 6,638 & $0.90 \%$ \\
\hline CHO 8 & 619,281 & 74,534 & 6,461 & $1.00 \%$ \\
\hline CHO 9 & 621,405 & 71,761 & 6,220 & $1.00 \%$ \\
\hline Total & $4,761,865$ & 637,567 & 55,266 & $1.20 \%$ \\
\hline
\end{tabular}


Table 2.5: Estimated number of people with dementia by LHO areas, 2016

\begin{tabular}{|c|c|c|c|c|c|}
\hline & LHO & $\begin{array}{l}\text { Population of } \\
\text { all ages (2016) }\end{array}$ & $\begin{array}{c}\text { Population } \\
\text { aged 65+ } \\
\text { years (2016) }\end{array}$ & $\begin{array}{c}\text { No. of people } \\
\text { with dementia } \\
\text { including early } \\
\text { onset (2016) }\end{array}$ & $\begin{array}{c}\text { People with dementia as a \% of } \\
\text { total population }\end{array}$ \\
\hline \multirow[t]{3}{*}{ CHO 1} & $\begin{array}{c}\text { Cavan } \\
\text { Monaghan }\end{array}$ & 133,342 & 18,546 & 1,608 & $1.20 \%$ \\
\hline & Donegal & 162,044 & 25,434 & 2,205 & $1.40 \%$ \\
\hline & SligoLeitrim & 95,895 & 15,807 & 1,370 & $1.40 \%$ \\
\hline \multirow[t]{3}{*}{$\mathrm{CHO} 2$} & Galway & 255,824 & 34,400 & 2,982 & $1.20 \%$ \\
\hline & Mayo & 130,507 & 22,909 & 1,986 & $1.50 \%$ \\
\hline & Roscommon & 66,778 & 11,249 & 975 & $1.50 \%$ \\
\hline \multirow[t]{3}{*}{$\mathrm{CHO} 3$} & Clare & 104,692 & 15,934 & 1,381 & $1.30 \%$ \\
\hline & Limerick & 171,894 & 24,729 & 2,144 & $1.20 \%$ \\
\hline & $\begin{array}{c}\text { Tipperary } \\
\text { North, East } \\
\text { Limerick }\end{array}$ & 108,412 & 15,272 & 1,324 & $1.20 \%$ \\
\hline \multirow[t]{5}{*}{$\mathrm{CHO} 4$} & Cork North & 92,726 & 13,610 & 1,180 & $1.30 \%$ \\
\hline & Cork North Lee & 192,106 & 23,943 & 2,075 & $1.10 \%$ \\
\hline & Cork South Lee & 200,984 & 25,947 & 2,249 & $1.10 \%$ \\
\hline & Cork West & 57,052 & 10,343 & 897 & $1.60 \%$ \\
\hline & Kerry & 147,707 & 25,034 & 2,170 & $1.50 \%$ \\
\hline \multirow[t]{4}{*}{$\mathrm{CHO} 5$} & $\begin{array}{l}\text { Carlow } \\
\text { Kilkenny }\end{array}$ & 136,083 & 18,717 & 1,622 & $1.20 \%$ \\
\hline & $\begin{array}{l}\text { Tipperary } \\
\text { South }\end{array}$ & 93,911 & 14,428 & 1,251 & $1.30 \%$ \\
\hline & Waterford & 130,617 & 19,172 & 1,662 & $1.30 \%$ \\
\hline & Wexford & 149,722 & 21,985 & 1,906 & $1.30 \%$ \\
\hline \multirow[t]{3}{*}{$\mathrm{CHO} 6$} & $\begin{array}{l}\text { Dublin South } \\
\text { East }\end{array}$ & 123,704 & 17,507 & 1,518 & $1.20 \%$ \\
\hline & Dun Laoghaire & 136,074 & 23,577 & 2,044 & $1.50 \%$ \\
\hline & Wicklow & 123,391 & 16,153 & 1,400 & $1.10 \%$ \\
\hline \multirow[t]{4}{*}{ CHO 7} & $\begin{array}{l}\text { Dublin South } \\
\text { City }\end{array}$ & 149,935 & 16,339 & 1,416 & $0.90 \%$ \\
\hline & $\begin{array}{l}\text { Dublin South } \\
\text { West }\end{array}$ & 160,898 & 21,268 & 1,844 & $1.10 \%$ \\
\hline & Dublin West & 155,343 & 14,532 & 1,260 & $0.80 \%$ \\
\hline & $\begin{array}{l}\text { Kildare, West } \\
\text { Wicklow }\end{array}$ & 241,538 & 24,437 & 2,118 & $0.90 \%$ \\
\hline \multirow[t]{4}{*}{$\mathrm{CHO} 8$} & Laois Offaly & 162,658 & 20,199 & 1,751 & $1.10 \%$ \\
\hline & $\begin{array}{l}\text { Longford } \\
\text { Westmeath }\end{array}$ & 129,643 & 17,194 & 1,490 & $1.10 \%$ \\
\hline & Louth & 128,064 & 15,990 & 1,386 & $1.10 \%$ \\
\hline & Meath & 198,916 & 21,151 & 1,833 & $0.90 \%$ \\
\hline \multirow[t]{4}{*}{$\mathrm{CHO} 9$} & Dublin North & 259,152 & 32,609 & 2,827 & $1.10 \%$ \\
\hline & $\begin{array}{l}\text { Dublin North } \\
\text { Central }\end{array}$ & 154,583 & 19,389 & 1,681 & $1.10 \%$ \\
\hline & $\begin{array}{l}\text { Dublin North } \\
\text { West }\end{array}$ & 207,670 & 19,763 & 1,713 & $0.80 \%$ \\
\hline & Total & $4,761,865$ & 637,567 & 55,266 & $1.20 \%$ \\
\hline
\end{tabular}




\subsection{Community/Residential Mix of Dementia}

We do not know for certain how many people with dementia are living at home in the community in Ireland. Our best estimate is based on the assumption that 63 per cent of people with dementia are living in the community (Cahill et al., 2012), suggesting that there were 34,818 people with dementia living in the community in 2016, the majority of whom remain undiagnosed. There is also uncertainty about how dementia cases are distributed according to severity levels. Data from four community projects within the HSE \& Genio Dementia Programme (Genio, 2015) suggests that 32 per cent of people with dementia are likely to be on the boundary of care between community and residential care ( $O$ 'Shea and Monaghan, 2017). Applying this percentage to the estimated figure of 34,818 people living at home for the whole of Ireland suggests that just under 8,000 people with dementia living at home have upper levels of severity that require significant attention from the health and social care system.

People living on their own with dementia may be particularly vulnerable given the uneven provision of social care in the country. Evidence from other countries, while highly variable (de Witt and Ploeg, 2016), suggests that between one-fifth and one-third of people with dementia in the community are likely to live alone (Schneider et al., 2003; Miranda-Castillo et al., 2010a). In Ireland, this would amount to between 7,000 and 11,500 people with dementia living alone. This does not mean that all of these people are vulnerable, some of them are likely to have low to mild cognitive impairment suggesting that they are capable of living on their own with minimal risk. However, there is evidence that people with dementia living alone have potentially more unmet needs than those living with others (Miranda-Castillo et al., 2010b) and a higher risk of premature admission into long-stay residential care than those living with a caregiver (Cepoiu-Martin et al., 2016).

Having estimated the number of people with dementia living at home, we are left with a residual population of people with dementia of 20,448 (or about 37 per cent of the total number of people with dementia), the vast majority of whom are likely to live in residential care, with the remainder being cared for in acute care, having been admitted there from either home or residential long-stay care. The corresponding figure for a comparable country like Scotland is 40 per cent living in care homes or acute care (Alzheimer Scotland, 2007). There is a lot of uncertainty as to the precise number of people with dementia living in residential care in Ireland. Like in the community, it is likely that dementia may remain hidden and never diagnosed in long stay care. The most recent Long-Stay Activity Statistics (Dept. of Health, 2013) suggests that just under two fifths of all long-stay residents have dementia, suggesting a figure of 11,100 people based on current bed capacity of around 30,000 (Wren et al., 2017). That figure seems on the low side, given international evidence that the proportion of people with dementia in long-stay care lies between onehalf and two-thirds of all residents in the USA and Europe (Cahill et al., 2010). This would suggest that the number of people with dementia in Irish nursing homes lies between 15,000 and 20,000 people. Research from Ipsos MRBI on behalf of AIB and Nursing Homes Ireland (AIB, 2014) suggests that 47 per cent of all residents have dementia, which is very close to the lower 15,000 estimate based on international rates.

\subsection{Incidence}

The number of people with dementia in any given year depends on the number of new cases of the condition and deaths of people with the condition. Incidence of dementia refers to the number of new cases of dementia per year. Knowing how many new cases of dementia there could potentially be in any year is useful for planning health and social care services for people who are at the early stage of dementia, particularly diagnostic and post-diagnostic supports. Similar to prevalence rates, there is considerable uncertainty regarding dementia incidence rates in Ireland. O'Shea (2007) previously estimated that there were 4,000 new cases of dementia per year. This was estimated by applying a Delphi consensus dementia incidence rate estimate of 8.8 people per 1,000 of those aged over 60 in the population (Ferri et al., 2006) to 2006 Irish Census population data. Applying the same rate to the 2016 Census data, which has a much older age structure than ten years earlier, provides an estimate of 7,752 new cases per year in Ireland. 
However, there have been several studies that have conducted meta-analysis of Western European dementia incidence rates; applying these aggregated rates would generate even higher estimates of new cases per annum (ADI, 2015; Ziegler-Graham et al., 2008; Launer et al., 1999).

According to CSO mortality statistics, dementia was recorded as a cause of death in 2,115 cases in Ireland in 2015, which accounts for 7 per cent of all deaths registered in 2015 . This is very likely to be an underestimate since an earlier research review on dementia in Ireland revealed that dementia has traditionally been hidden in many national sources of information that are relevant to dementia (Cahill et al., 2012). In the UK, mortality statistics now classify dementia and Alzheimer's disease as the leading cause of death in England and Wales, accounting for 11.5 per cent all deaths registered in 2015. This is mainly due to the reclassification of cancers as separate diseases. The rise in the number of deaths attributed to dementia is due to people living longer and surviving other illnesses, increased reporting of dementia on death certificates resulting from a better understanding of dementia and improvements in diagnosis, and changes in the way in which cause of death was recorded (ONS, 2016). If the UK death rate was applied to total Irish deaths in 2015, the number of deaths from dementia would have been 3,445.

\subsection{Prevalence of Dementia by Age, Gender, Disability and Ethnicity}

Previously in this chapter, an overall estimate of the number of people with dementia living in Ireland has been presented as well as estimates for each $\mathrm{CHO}$. Yet, people with dementia are not one homogenous group. This section disaggregates the prevalence estimates by age (younger and older), gender, disability, and ethnicity (each of which are grounds covered by Irish equality legislation). However, it is beyond the scope of this chapter to discuss in any great detail the implications of each for dementia care.

As Table 2.1 shows, like in other Western countries, the majority of people with dementia in Ireland are women. For example, of the 55,266 people estimated to have dementia in Ireland, almost two-thirds are women. A range of dementia-related challenges facing women have been identified in the literature (Corfield, 2017). For example, involving people with dementia in decision-making is considered to be a key attribute of person-centred care (Wilberforce et al., 2017). However, women are more likely to be assessed as lacking capacity than men, likely due to gender stereotyping (Boyle, 2013); similarly, women can be left out of decisions that are being made about their lives and about their care due to gender bias (Boyle, 2013; Bamford, 2011). In addition, while the Irish pension system has begun to address barriers to equal access for women and men, the current cohort of older women in Ireland are much less likely than men to have been employed in the labour market in their earlier years. They are, therefore, more likely to be solely dependent on state pensions, at greater risk of poverty (Duvvury et al., 2012) and hence have less access to resources that could potentially be used to buy in private market supports. Corfield (2017) highlights the need to incorporate a gender perspective into national dementia strategies, which involves not only incorporating gender-disaggregated prevalence rates, but includes a detailed analysis of this data and its implications for women and men.

Increasing age is the strongest risk factor for dementia, and the vast majority of people with dementia are over 65 years. But, as Table 2.1 shows, there are just over 4,000 people under 65 years of age affected by this condition, and the circumstances and experiences of dementia for a younger person are often different from those of an older person (ADI, 2015; Sansoni et al., 2016). For example, younger people with dementia can experience great difficulty in accessing care and support, as dementia services are generally designed to meet the needs of much older people. These services may not be appropriate for the needs of younger people with dementia. Appropriate or not, age criteria may mean that younger people with dementia cannot even access these services in the first place. The financial consequences of early onset dementia may also be catastrophic, especially for people of working age who may have to exit the labour market and/or have dependent children and mortgages. 
The experience of dementia can also be different for a person with an intellectual disability. For people with intellectual disabilities, especially those with Down syndrome, prevalence of dementia is higher than for the general population. The National Disability Survey reported that there were approximately 5,500 people with Down syndrome in Ireland in 2006 (CSO, 2008). Of these, Cahill et al. (2012) estimated that there were approximately 700 people with Down syndrome and dementia, based on an overall prevalence of 13.3 per cent (Tyrell et al., 2001). A more recent Irish study following up 77 people with Down syndrome over a 20 year period reported that 97.4 per cent of those followed had developed dementia over the period, with a mean age of dementia diagnosis of 55 years (MCCarron et al., 2017). The study mapped risk for people with Down syndrome of developing dementia as follows: 23 per cent at age 50, 45 per cent at age 55 and 88 per cent by age 65 years.

Sensory disabilities, i.e. visual and hearing impairments, are common among people with dementia. Like dementia, sight loss is increasingly prevalent with age, and as Ireland's population ages, there will be an increasing number of people with both dementia and sight loss. This is significant, since where sight loss and dementia co-exist, the effects are more severe than those resulting from either dementia or sight loss alone (Jones and Trigg, 2007). In the UK PrOVIDe study of older people, nearly one-third of those in whom vision could be measured were visually impaired (Bowen et al., 2017). Interestingly, almost one-half had their vision corrected with up-dated spectacle prescriptions.

Hearing loss is also age-related. Although figures are not yet available from the 2016 Census, data from the previous Census shows that, in 2011, 92,060 people in Ireland were deaf or had a serious hearing impairment, some 53,438 of whom were 65 years of age or over. This is significant as it has been established that people with hearing loss, both in midlife and later life, are at a greater risk of developing dementia (Livingston et al., 2017). This includes not only people with severe hearing loss but also those with mild or moderate hearing loss.

Visual impairment and hearing loss can also be regarded as co-morbidities. Prevalence of co-morbid conditions in people with dementia is high and most will usually have at least one other chronic medical condition. In addition to visual impairment, other common co-morbidities include but are not limited to cardiovascular-related conditions, chronic pain, depression and diabetes (Browne et al., 2017; Bunn et al., 2014; Bunn et al., 2017). The ability to self-manage some chronic conditions, such as diabetes, will depend on the severity of the dementia. A critical point comes when memory aids cease to be effective. At this juncture the role of the carer in managing co-morbidities needs to increase. In the health system, people with dementia are less likely to receive the same access or quality of care as those without dementia (Bunn et al., 2014). Care guidelines are mostly condition specific and often do not take account of the particular needs of people with dementia (Bunn et al., 2014). People with dementia who do not have the support of a family member are particularly vulnerable to poor access to care (Bunn et al., 2017).

Ireland is an ethnically diverse country. Approximately 20 per cent of people living in Ireland were born outside of Ireland in more than 50 countries, both EU and non-EU. With respect to the former, relatively large numbers come from Poland, Lithuania and Latvia as well as the UK, with Nigeria and India topping the list of countries for those born in Africa and Asia. While place of birth is only a proxy measure of ethnicity, it gives some indication of the ethnic diversity in Ireland. People from different ethnic or cultural backgrounds have not to date been identified in dementia prevalence estimates in Ireland. The identification of ethnic groups from Census data is a complex undertaking (Fanning and Pierce, 2004). Nevertheless, a question on ethnic or cultural background was introduced for the first time in the 2006 Census. The 2011 Census shows that, of those aged 30 years and over in Ireland who stated their ethnic or cultural background, 319,971 had a background other than White Irish (e.g. Traveller community, any other non-Irish White background, Black or Black Irish, Asian or Asian Irish). There is no evidence from Ireland in relation to dementia prevalence among minority ethnic groups, but assuming that dementia prevalence is the same as the population in Ireland as a whole, it is estimated that they are approximately 2,000 people with dementia in Ireland from an ethnic or cultural background other than 'White Irish'.

This is likely to be an underestimate as ethnic or cultural background is understated in the Irish Census and it is likely that prevalence of dementia is higher among some minority ethnic groups as risk factors for dementia such as heart disease, high blood pressure and diabetes are more common (Moriarty et al., 2011; 
All-Party Parliamentary Group on Dementia, 2013). Of the estimated 2,000 people, those from 'Any other White background' make up the largest group. Although the numbers in the other ethnic groups are low, health professionals in Ireland are coming across people with dementia from minority ethnic communities in their work and this is going to become a more frequent occurrence with the ageing of minority ethnic communities. One example of how organisations are already responding to this comes from The Alzheimer Society of Ireland, who in association with Pavee Point, delivered dementia awareness training in 2010/2011 to over 20 primary health care workers (predominantly Traveller women) who work with the Traveller Community in the Dublin area. Faced with the challenge of tailoring services to ethnically diverse populations of people with dementia, a key learning from other countries is that staff will need help in moving towards more individualised approaches to care that recognise people's ethnicity. Language and communication has been identified as a priority for staff training, which includes raising awareness that people with dementia from minority ethnic communities who have learned English as a second language may lose their ability to speak English as their dementia progresses (Moriarty et al., 2011). This may also affect a small number of native Irish speakers, particularly those from Gaeltacht areas in the country.

\subsection{Conclusion}

We have no way of knowing the exact number of people that are living with dementia in Ireland. In this chapter, using reasonable assumptions and building on previous approaches to measurement, we estimate that there were 55,266 people with dementia living in Ireland in 2016. This estimate was generated using the EuroCoDe dementia prevalence rates and is not far off the estimate of 53,489 generated using the most recent ADI dementia prevalence rates for Western Europe. Applying dementia prevalence rates from the Dementia UK: Update, reduces the estimate to 44,483 .

We acknowledge that these estimates are crude. However, estimates of the number of people with dementia in Ireland, now and in the future, serve as an indicator of general trends. These estimates are critical in raising consciousness about dementia and to informing service planning, including designing diagnostic services and post-diagnostic supports and planning future models of care, both locally and nationally, underpinned by the principles of personhood and citizenship. We know that there are a large number of people living in the community with dementia; some local areas have higher prevalence rates than others due to variations in the age structure of the population within and across regions. We also know that the number of people with dementia is growing every year.

Although necessary for service planning and resource allocation, generating an overall dementia prevalence estimate for Ireland brings with it the risk of thinking about people with dementia as one homogenous group, which is at odds with the principle of personhood that underpins Ireland's National Dementia Strategy. Each person with dementia is unique and, irrespective of the dementia sub-type, age, or comorbidities, no two people with dementia will ever have the same experience.

This chapter has used gender-disaggregated prevalence estimates to highlight the gendered dimension of dementia. It has presented prevalence estimates disaggregated by age, disability and ethnicity to highlight the differing impact of dementia, especially for those who may experience marginalisation such as younger people with dementia, people with intellectual and sensory disability and dementia and people with dementia from minority ethnic communities. Raising the issue of diversity may help to open up discussion about more nuanced and multidimensional understandings of dementia and its experience and draw more attention to the specific challenges posed by gender, age, disability and ethnicity and the importance of this in achieving personalised approaches to supporting people with dementia. 



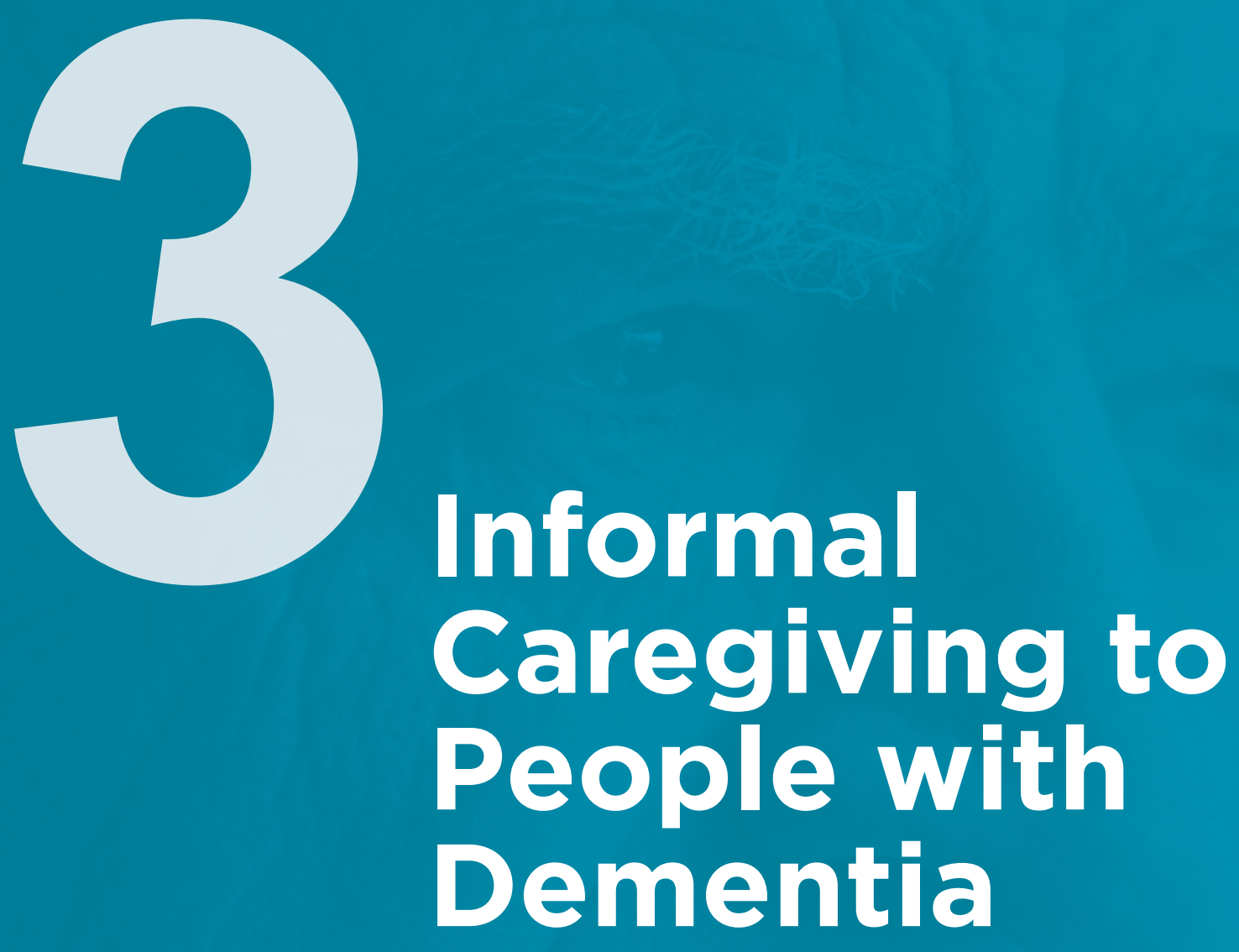

Maria Pierce, Suzanne Cahill and Patricia Carney 


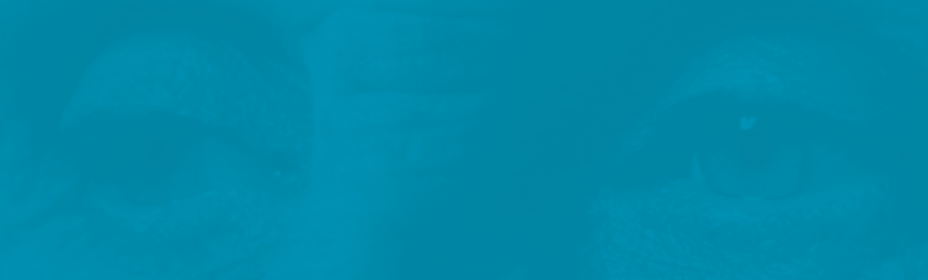




\subsection{Introduction}

In Chapter 2, it was estimated that there are 55,266 people with dementia in Ireland, of whom approximately 35,000 live in the community. This number is forecast to double over the next 20 years. The National Dementia Strategy (NDS) recognises the need to plan for the growing number of people with dementia who will require health and social care services (Dept. of Health, 2014). The NDS reaffirms a longstanding policy commitment to community care and is also underpinned by the principles of personhood and citizenship, all of which appertain to individuals with dementia, their informal caregivers, service providers, policymakers, and society as a whole.

The focus of this chapter is on informal caregivers, which includes family members, friends, neighbours and other individuals who provide regular unpaid care and/or support to people with dementia. Of these, family caregivers usually provide most of the care to people with dementia, especially those living in the community. The chapter begins by providing an estimate of the number of informal caregivers providing support and care to people with dementia in Ireland. It then addresses the question of who bears the main responsibility for caring, what motivates carers to take on this care and what is the nature and extent of informal caregiving.

Livingston et al. (2017) remind us that informal caregivers are frequently the most important resource for people with dementia. Family members and friends take on the role of caregiving for a variety of reasons, but whatever the motivation, there is a risk that informal caregivers will be overlooked by governments and policymakers because they are not seen to have any fiscal impact. Governments are well aware of the job that informal caregivers do, but they are less anxious to support them in any way in case it draws attention to the opportunity cost of caring and the monetary implications of the opportunities foregone. This chapter reports on estimates of the costs of informal caregiving. Although methodologically difficult, placing a monetary value on the contribution that informal caregivers of people with dementia make goes some way to making their care work visible. It gives policymakers and governments an indication of how much care work falls to informal caregivers and of the opportunity costs associated with informal caregiving.

Many family caregivers find caregiving rewarding and are strongly committed to the role but they also want recognition from the State for the significant contribution they make (O'Shea, 2003). Caregiving incurs significant financial, emotional and social costs and the impact of caring on family caregivers is examined in this chapter and its implications for the person with dementia, the family caregiver and for the wider society. Supporting family carers is a goal of Ireland's NDS. A range of services and interventions to support family carers providing care to people with dementia have been developed in Ireland. A brief outline of these supports is presented, which are considered in the context of the existing evidence on the effectiveness of such interventions. Consideration is also given to how resilience might be related to supporting family carers.

Finally, this chapter turns to concepts of personhood and citizenship. It considers the role that family caregivers can play in sustaining the personhood of the person with dementia, the role that health professionals have in supporting family caregivers to do so, and uses an ethics of care analysis to explore this. 


\subsection{Informal Caregiving in Ireland}

It is difficult to estimate the exact number of informal caregivers of people with dementia in Ireland. The Census of Population and the Quarterly National Household Survey (QNHS) provide valuable information on informal caregivers generally (CSO, 2012; 2010); and The Irish Longitudinal Study on Ageing (TILDA) on informal caregivers of older people (Kamiya et al., 2012). However, none provide information on the informal caregivers of people with dementia, which is a particularly complex area of caregiving.

Extrapolating from the Enhancing Care in Alzheimer's Disease (ECAD) study, which found that communitydwelling people with dementia had an average of 1.7 caregivers (Gillespie et al., 2013), it can be estimated that there are approximately 60,000 informal caregivers providing care for the 35,000 people with dementia living in the community in Ireland. Most family caregivers will continue to have a central role when a person with dementia is admitted to hospital or transferred to long-stay residential care. For example, the Irish De-Stress study found that over half of caregivers whose spouse had moved into long-stay residential care visited their spouse every day (Brennan et al., 2017). Combining community-based family caregivers with those who continue their caring role when their relative is in long term care, the number of informal caregivers for people with dementia is, therefore, likely to be well in excess of 60,000.

In informal caregiving a hierarchy tends to exist, with gender, kinship obligations and the relationship of the informal caregiver to the person with dementia often determining who adopts the caring role (Qureshi and Walker, 1989; Kramer and Kipnis, 1995). For people in a married or cohabiting relationship, the spouse or partner often assumes responsibility for the majority of care and this role tends to be taken on automatically and incrementally (Ungerson, 1987) without any conscious negotiation. Spousal/partner carers of people with dementia are often, but not always, older themselves and often do not enjoy good health (Cahill and Shapiro, 1998). For example, in the Irish De-Stress study, of the spousal carers of people with dementia, most of whom were women, three-quarters were over 65 years of age, and a quarter over 75 years and most $(70 \%)$ had two or more health conditions, were on medication and had visited a health care professional at least once in the previous month (Brennan et al., 2017). When a spouse/partner is unable to provide care or when the person with dementia is widowed or separated/divorced, adult children, usually daughters more often than sons, are the next most likely to take on the main responsibility for care, followed by other family members, often daughters-in-law. Geographical proximity, reluctance or refusal by other family members to provide care, and fear of premature admission to nursing homes are some of the reasons why adult children take on the caring role (Opie et al., 1992) but many drift into this role, sometimes because they lack a justifiable excuse such as labour market employment or child care responsibilities which might otherwise exempt them from caring (Ungerson, 1987). A recent Irish survey found that 53 per cent of family carers in receipt of carer's allowance and providing care to a person with dementia were the adult children of the care recipients (Lafferty et al., 2016).

Some informal caregivers, particularly those who have close emotional bonds with the person with dementia, will be motivated to care by love and affection, and take on caring willingly seeing it as an extension of their relationship with the person. Marriage has been referred to as the pre-eminent caregiving relationship (Ungerson, 1987); wives and husbands are most likely to want to care for people with dementia (Cahill, 1999; Cahill, 2000). Others may be less willing to take on the responsibility, but do so out of a sense of duty, guilt and obligation or because there is no one else willing or available to do it (Cahill, 1999). Either way, the level of commitment to caring for a relative with dementia is often high among family caregivers, as illustrated by the time devoted to and length of time spent caring. In the De-Stress study, the majority of spousal carers (79\%) reported that they provided 81-100 per cent of the care for their spouse with dementia and nearly half reported spending nearly all of their waking time looking after their spouse with dementia. In that study the average length of time spent caring for a spouse with dementia was five years, but caregiving could last for much longer, up to 19 years (Brennan et al., 2017).

The type of care that informal caregivers of people with dementia are involved in can be wide-ranging and may include providing direct, hands-on practical or personal care, organising care delivered by others, and assisting with decision-making. Informal caregiving is dynamic, often unpredictable and changes over time. 
For example, when a person has mild dementia, family caregivers may be involved in assisting the person with dementia adapt to their memory loss and cognitive problems and support the person in everyday decision-making. However, as the condition progresses and particularly in the later stages, caregiving responsibilities are likely to become more extensive and challenging, can extend around the clock, and may become extremely labour intensive. There may come a time when family caregivers are faced with making decisions on behalf of the person with dementia, experienced by family caregivers as difficult and unpredictable (Fetherstonhough et al., 2017). The challenge of providing care and support to a person with dementia is contingent on knowing what may and may not be acceptable to that person (Barnes and Brannelly, 2008) and at all times promoting the individual's dignity (Manthorpe et al., 2010).

Living arrangements are a significant aspect of informal caregiving. While spouses or partners will typically be co-residing with people with dementia living in the community, the picture can be quite different and complex for adult children or other informal caregivers who may be living in a separate household and essentially running two homes, or living at a distance or even in another country. Each of these living arrangements presents unique challenges for family caregivers. A small group of adult children may also have their parent with dementia move to live in their home, which can generate its own complexities especially if caring for a parent with dementia is combined with child care and sometimes part time or full time labour market employment.

According to a Dutch study of informal caregivers, when involved, neighbours and friends, are more likely to be involved in caregiving at the earlier stages of dementia. The amount of care they provide decreases significantly in the later stages of dementia (defined in the study as having symptoms for more than one year) and then informal care is mainly provided by the spouse and children of the person with dementia (Zwaanswijk et al., 2013).

\subsection{Cost and Impact of Informal Care}

The financial costs associated with providing informal care to a person with dementia living in the community are substantial (Zhu et al., 2015; Jones et al., 2015; Jacobs et al., 2013; O'Shea and Monaghan, 2016b; Rattinger et al., 2015; Connolly et al., 2014; ADI, 2015). The main informal cost of care is the caregiver's time which is the time spent providing care or supervising the person and can be estimated as actual or potential income/salary lost by the caregiver (Leng Woo et al., 2017). In Ireland, 48 per cent of the estimated $€ 1.69$ billion per annum cost of dementia is attributable to informal care (Connolly et al., 2014). These findings are similar to those from other cost of illness studies (ADI, 2015). Similar to the other costs of care (e.g. medications, medical care), the costs of informal care have been shown to increase significantly as the condition progresses (Hux et al., 1998). A longitudinal study following 72 people with dementia living in the community in Ireland over two years, estimated a 115 per cent increase in informal care costs over the time period, mainly driven by the growth in daily hours of supervision (Gillespie et al., 2015). In comparison, formal health and social care costs increased by an estimated 21 per cent over the same time period, leading the authors to conclude that formal care services did not respond to the increased level of dependence in people with dementia but instead left it to families to fulfil the care. However, ADI (2015) have shown that where direct social care sector costs increase, the cost of informal care decreases.

Leicht et al. (2013) highlight the direct relationship between difficulties in activities of daily living and both formal and informal care costs. Cognitive decline impacts on costs differently to functional decline, with the former impacting informal costs disproportionately compared to medical and non-medical costs whereas functional decline impacts non-medical costs to a greater extent than informal or medical costs (Rapp et al., 2012). In their study, medical visits such as inpatient or outpatient hospital visits and physician or allied health professional visits were included under medical costs. Non-medical costs included costs associated with the use of day-care, alarm services, home help and day/night surveillance. 
Caregiving can be rewarding and there are positive aspects to caring for a person with dementia (Andrén and Elmståhl, 2005; Hilbrand et al., 2016; Motenko, 1989; Mayor et al., 2009; Brennan et al., 2017; Hogstel et al., 2005). A Dutch study found that almost half of the caregivers (48.2\%) got positive utility (or immediate reward) from informal care and on average happiness would decline if they were to hand informal caring over to someone else (Brouwer et al., 2005). However, as far as we are aware no study to date has placed an economic value on the rewards of caregiving in relation to dementia. In contrast, there is extensive evidence showing that for family carers, caring for a person with dementia can be demanding, both physically and psychologically. In the already cited Irish study, Brennan et al. (2017) classed 13 per cent of spousal carers participating as having a moderate to severe level of psychological distress. Another Irish survey found that when compared to family carers of people without dementia, family carers providing care to people with dementia experienced greater symptoms of depression and stress (Lafferty et al., 2016). This is consistent with findings from studies in other countries (Reed et al., 2014; Morgan, 1997; Lapatin et al., 2012; Yaffe et al., 2002; Draper et al., 1992; Ory et al., 1999).

Livingston et al. (2017) report studies from other countries showing that about 40 per cent of family caregivers of people with dementia have clinically significant depression or anxiety, with others reporting psychological symptoms that are less severe. This finding holds true for spousal caregivers in Ireland, but there are differences among caregivers with male and older spousal carers reporting less depression and anxiety then female and younger carers (Brennan et al., 2017).

The issue of supporting informal caregivers to attend to their own physical and mental health is therefore important. Increased levels of caregiver stress have been linked to negative health outcomes and greater use of health care services (Son et al., 2007). Higher levels of caregiver stress and burden are two key factors in the decision to admit a relative with dementia to long-stay care (Eska et al., 2013; Brodaty and Donkin, 2009; Banerjee et al., 2003; Gaugler et al., 2005; Sutcliffe et al., 2016). Most families want their relative with dementia to remain living at home for as long as possible, but if the informal carers' health breaks down, the whole system of care is likely to collapse and, depending on the severity of the dementia, the individual may be admitted to hospital or to long-term residential care where the financial cost of care is likely to be far higher. An Irish study examining the potential gains from delaying entry to nursing home care estimated that costs of keeping a person with dementia at home with an increased level of care was $€ 207$ per week to the formal care service provider (O'Shea and Monaghan, 2016a). This is a potential cost saving of $€ 800$ per week when compared to the cost of long-stay residential care, assuming a cost of $€ 1,000$ per week. Valuing informal care inputs pushed the cost of home care above residential care provision, significantly so if valuation was done using a replacement cost methodology.

\subsection{Supporting Informal Caregivers}

When deconstructed, caregiver burden usually means the informal carer being physically and emotionally exhausted and no longer able to provide the level of care required (Cahill and Shapiro, 1997; Argyle et al., 2010; Bobersky, 2013). Caregiver burden tends to be associated with the multiple around the clock unique demands dementia care places on a family member including the need to support a person in undertaking activities of daily living or who may be incontinent or disoriented in time; monitor their safety and at any time day or night, respond to behaviours that challenge such as agitation, paranoia, hoarding and searching. A range of interventions have been developed with the aim of reducing caregiver burden and depression and delaying long-stay residential care admission.

Whilst informal caregivers often become expert themselves at deciding how best to support and promote the wellbeing of their relative with dementia, different interventions and support services have been developed to support family carers providing care to people with dementia. These include psychoeducational interventions, a commonly used intervention to support family carers, which comprise a broad range of activities that combine education and other activities such as counselling and supportive 
interventions. In Ireland, a range of organisations and programmes including the Dementia Services Information and Development Centre, the Alzheimer Society of Ireland, the Dementia Elevator Programme, and projects within the Genio \& HSE Dementia Programme have been developing education and training for family carers, each of which take different formats. The evidence from systematic reviews suggests that psycho-educational interventions offer benefits for family carers relating to self-efficacy, psychological wellbeing and reduced caregiver burden and that most benefits accrue when education forms part of a multicomponent intervention. However, it is unclear whether there is any impact on the delay in admission of people with dementia to long-stay residential care (Vandepitte et al., 2016; Olazaran et al., 2010; Parker et al., 2008; Selwood et al., 2007; Elvish et al., 2013; Pusey and Richards, 2001; Jensen et al., 2015).

Other interventions developed specifically to support informal caregivers include case management, behavioural management therapies (Cooper et al., 2007; Vernooij-Dassen et al., 2011), physical activity and psychosocial support (Cooper et al., 2007; Olazaran et al., 2010; Parker et al., 2008; Elvish et al., 2013). While a considerable number of systematic reviews now exist assessing evidence on the effectiveness of such interventions, the extent to which interventions can lead to an improvement of care and cost savings is not always clear, as with case management (Pimouguet et al., 2010), although evidence suggests that some interventions such as behavioural management therapies and physical activity can reduce subjective caregiver burden for family carers of people with dementia (Orgeta and Miranda-Castillo, 2014). More successful interventions tend to be those that are tailored to the needs of the individual and aim to address subjective burden; that involve the caregiver and care recipient as active participants; and that are longerterm as opposed to shorter-term (Brodaty and Donkin, 2009).

A commonly used service to support informal caregivers of people with dementia is respite care, whereby care is temporarily provided to a person with dementia by people other than the primary informal caregiver as either in-home respite, day care or overnight residential respite. Traditionally, the rationale for respite is to give the primary caregiver a break from their caregiving responsibilities (to rest, catch up on other tasks, see friends and family or take a holiday). The evidence base for the effectiveness of respite care is not particularly strong (Lee and Cameron, 2004), and it is the high value that family caregivers place on this type of support that is used as the main justification for respite services. Where it is taken up, informal caregivers express high levels of satisfaction with it (Bamford, 2013). A dyadic approach to the development of interventions and support services, where the focus is on both the person with dementia and the informal caregivers, is particularly welcome. This was the approach taken in the development of responsive respite supports by community projects funded under the HSE \& Genio Dementia Programme and evaluations. These supports were well received by family caregivers, as well as having wider implications, as discussed in Chapter 5.

Not all family caregivers are negatively affected by caring for a person with dementia. People have differing experiences of caring and their levels of resilience also varies (Teahan et al., 2017). Resilience, defined by Windle (2010) as 'the process of effectively negotiating, adapting to, or managing significant sources of stress or trauma', is important because caring for a person with dementia can be challenging and a person's resilience can influence both their own wellbeing and the quality of care they provide to the person for whom they are caring. Drawing on a review of the literature, Cherry et al. (2013) developed a framework consisting of three inter-related domains of factors influencing carers' resilience. These factors encompassed: social and cultural factors; properties of the care relationship; and carers' psychological factors. Teahan et al. (2017) developed a similar framework but within each of the three domains identified some additional factors, e.g. time spent caring. Promoting resilience in family carers of people with dementia is the aim of an Irish project informed by this framework and using participatory action research to develop an innovative EnCaRe (Enhancing Carers' Resilience) programme. As Cherry et al. (2013) argue, resilience frameworks can be used by practitioners to help them identify caregivers who are vulnerable and to tailor support on the factors that cause them to be vulnerable and that are amenable to change. 


\subsection{Caregiving Relationships and the Promotion of Personhood and Citizenship}

The final part of this chapter will now turn to a discussion of caregiving as a relational practice and the importance of relationships in the promotion of personhood for people with dementia which has been underlined in the literature (Wilberforce et al., 2017) and is an underlying principle of Ireland's NDS.

In discussions about dementia, the concept of 'personhood' was first introduced in the 1990s (Kitwood and Bredin, 1992) and further developed by Kitwood (1997) to mean that status or standing bestowed on one person by another in the context of human relationships (Kitwood, 1997). Personhood in many ways dislodged the biomedical model (see Chapter 4) as the prominent approach to understanding dementia, since Kitwood (1997) argued that the individual's subjective experience of dementia was significantly influenced by the quality and type of social interactions experienced in various care settings and that some of the decline and deterioration associated with dementia occurred not because of the diseased brain but rather due to a disabling physical and social environment (Kitwood, 1997). Preserving personhood or humanising the individual with dementia was central to that person's wellbeing and to promoting a good quality of life.

Understanding the nature and quality of relationships between persons with dementia and their informal caregivers and how these relationships can influence personhood was the focus of a Norwegian study by Smebye et al. (2012). The study drew attention to the complexity of relationships between family caregivers and persons with dementia, and distinguished between family relationships that sustained and those that diminished personhood. They found that close emotional relationships between family caregivers and persons with dementia sustained personhood, and provided the context for the provision of person-centred care. Family relationships that diminished personhood were those in which the family caregiver reluctantly took on the role of caregiving, and rather than being motivated by love and affection, took on the caring role out of a sense of duty and obligation. Other family relationships that diminished personhood were those that were task-centred, i.e. where family carers gave practical help but refrained from expressing their emotions or affection and other than provide practical help did little else to promote personhood. Care provided in the context of these relationships did not meet the criteria of person-centred care.

Relationships between family caregivers and persons with dementia are only one aspect of caregiving relationships. Informal caregiving does not occur in a separate world to paid formal caregiving, and where formal caregivers are involved, they interface with and usually work side by side with informal caregivers (Seavey, 2005). Thus, caregiving relationships often involve a minimum of three people and the relationship between the family caregiver and the formal caregiver is pivotal to the provision of person-centred care to the person with dementia. Smebye et al. (2012) found that in relationships that promote personhood of the person with dementia, reciprocity and exchange of information between the formal and informal caregivers were important and family carers and formal carers collaborated and reinforced each other's efforts.

Smebye et al. (2012) make a distinction between individualised care and person-centred care. The former focuses on tailoring care to specific individual needs, and this kind of care only becomes person-centred when there is a focus on promoting personhood in social relationships. Caring for a person with dementia whether formal or informal is highly skilled work and requires knowledge of dementia, expertise in responding to behaviours that challenge and an in-depth understanding of the person's life story and biography. Ideally, formal and informal caregivers should become partners in care supporting the individual with dementia to live a dignified life and a life where that person still feels in control. The key to successful caring arrangements is for practitioners and carers to develop trusting relationships and deliver care that is negotiated and agreed upon with the care receiver (Barnes and Brannelly, 2008). 
Foregrounding social relationships is also central to an ethic of care approach, which highlights the interdependencies between formal caregivers, informal caregivers and the person with dementia, and also recognises the often complex and ethical difficulties of providing care to people with dementia (Brannelly, 2006). It is based on Tronto (1993) model of caring, which has four phases and four ethical elements. The four phases are: caring about; taking care of; caregiving; and care receiving and meeting these involves cognitive, emotional and action strategies. The four ethical elements that are necessary for effective caring are: attentiveness; responsibility; competency; and responsiveness of the care recipient and these also require certain attitudes and skills. Whether or not an ethics of care has been adopted becomes evident in practice. Brannelly (2006) describes ethical care as 'a negotiated, collaborative version of care', and is demonstrated when formal and informal caregivers incorporate and work to the preferences of the person with dementia. When adopted, an ethic of care increases the opportunity for participation and inclusion of the person with dementia and thus strengthens opportunities for enhanced citizenship (Brannelly, 2006).

\subsection{Conclusion}

In this chapter we estimate that over 60,000 informal caregivers are likely to be providing care to a relative living with dementia in the community in Ireland. We have discussed why and how these people, mainly women, become caregivers, the complexities of care relationships, especially the blending of formal and informal care and the substantial contribution informal caregivers make through their unpaid work to sustaining community care and to the economy. Dementia care is different from other forms of caregiving (Ory et al., 1999). While there are positive aspects to caring for a person with dementia, the evidence shows that caregiving is demanding both physically and psychologically. Carers of persons living with dementia, many of whom are spouses, often have their own age-related chronic health problems (Brennan et al, 2017) which may further restrict them and lead to their own health decline. Supporting informal caregivers by way of interventions such as psychoeducational interventions and respite is, therefore, vital and these tend to be most successful when tailored to the needs of the individual, address subjective burden and take a dyadic approach. Some family caregivers are more vulnerable than others and resilience frameworks can be used to develop and tailor interventions to caregivers and their vulnerabilities with a view to promoting sustainability.

The recent Citizens' Assembly vote showed that 60 per cent of members believe that the family should be the main carer, but that the state should have some responsibility. Determining the level of this responsibility and its quality is critical to sustaining community care and to supporting the wellbeing and respecting the human rights of informal caregivers, and in turn the quality of care they provide to people with dementia. Most informal caregivers want to care, but they also want recognition of the significant contribution they make to the state which can be by way of regular formal support services or cash benefits. Personalised supports have been shown to support family carers to continue to care for longer and while these supports are not always cheap they represent good value for money especially for those on the boundary between community and residential care (O'Shea and Monaghan, 2016).

Caregiving as discussed in this chapter entails both caring for and caring about: it is an activity as well as an identity and is both personal and political. In discussing care, governments tend to concentrate on the 'caring about' and alleged 'community' aspects of family caregiving without giving sufficient attention and recognition to the hard physical work dementia care often entails. Caregiving is complex and presents everyday ethical dilemmas for people with dementia, their family caregivers and formal carers, who work side by side with each other in an interdependent relationship. This requires us to move towards developing an ethic of care whereby informal and formal carers are partners in care, supporting the person with dementia to live a dignified life while enhancing their personhood and their citizenship. 

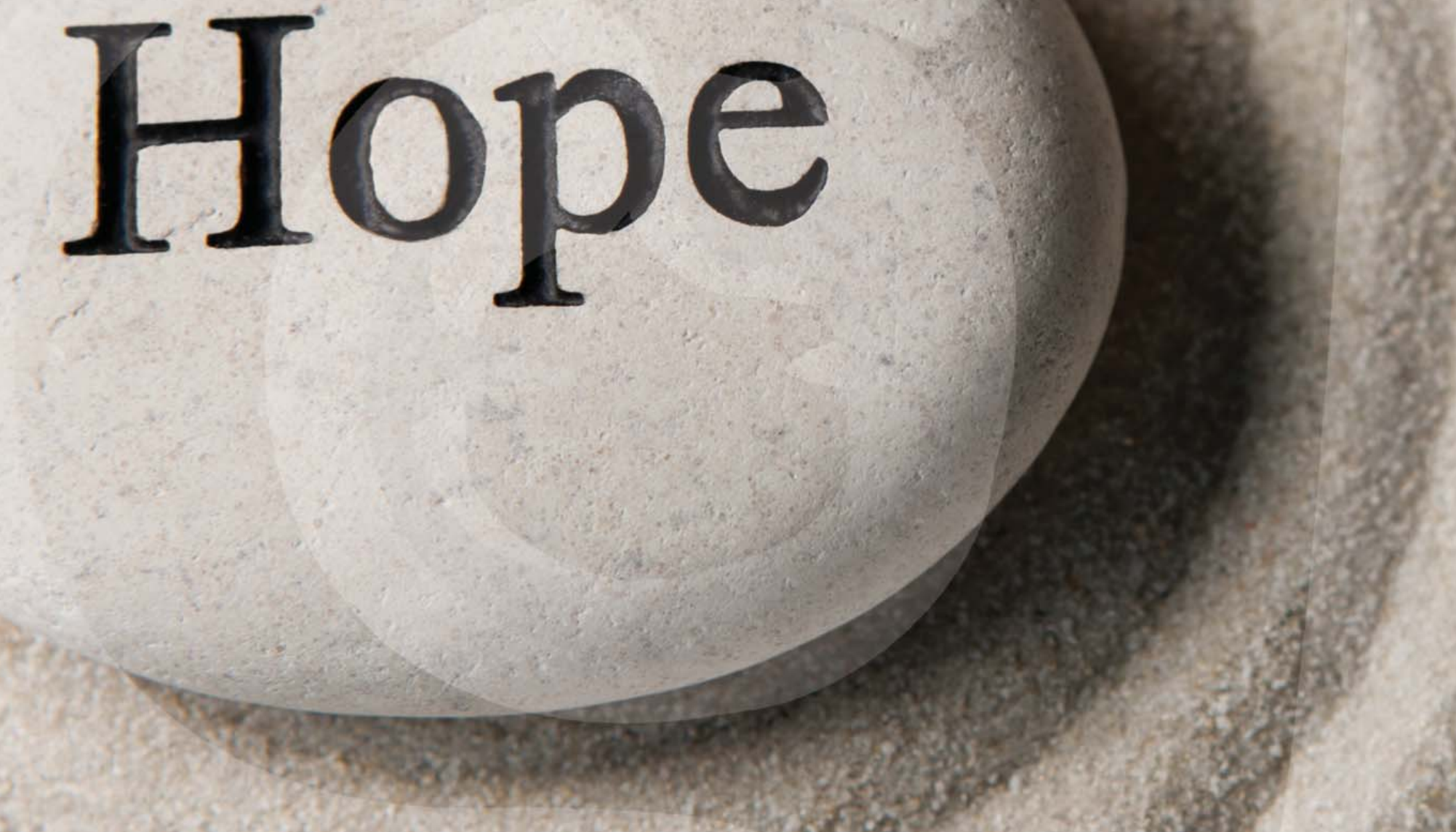

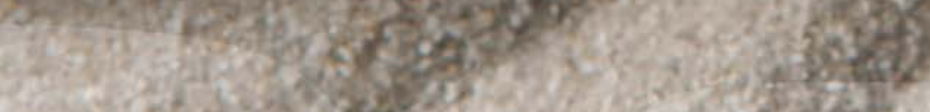

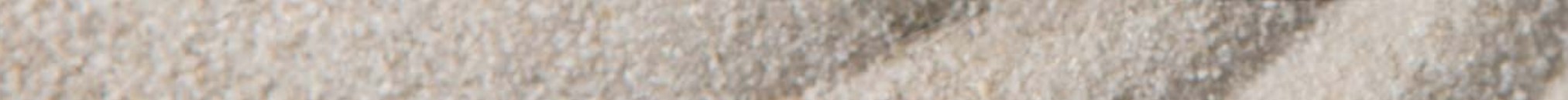

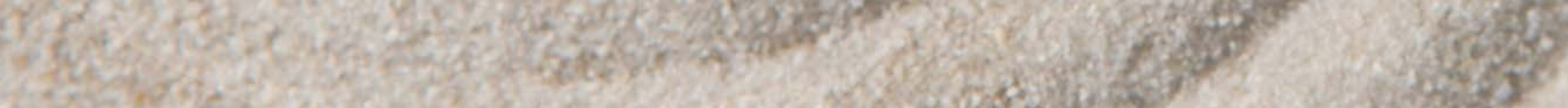
W

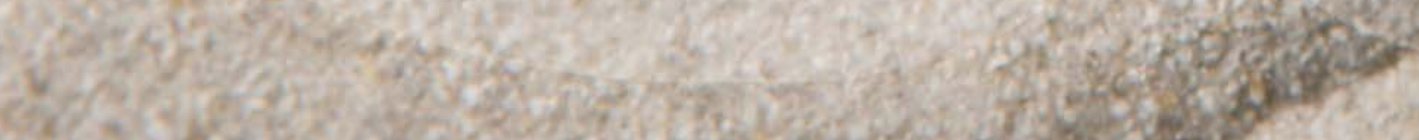
WF 


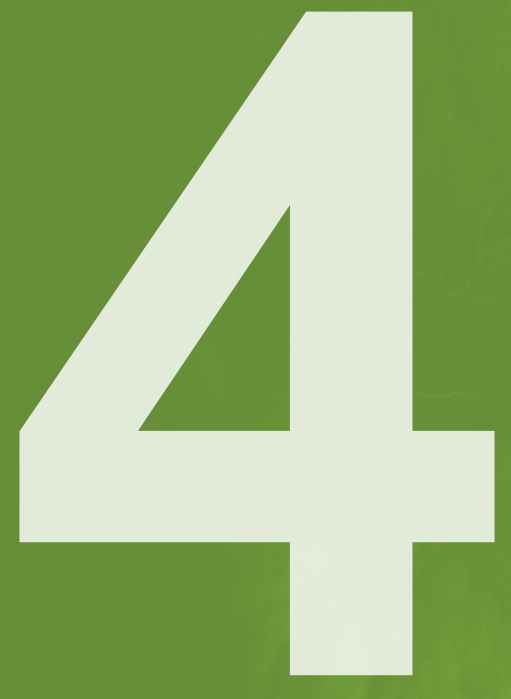

Models of

Care for

People with

Dementia

Suzanne Cahill 


\subsection{Introduction}

Over the coming years as Ireland's population ages, dementia prevalence and incidence are expected to rise exponentially (see Chapter 2). In preparation for this expansion in numbers and in the absence of an immediate cure, Ireland like other countries has responded to the challenge of dementia by developing its own national dementia strategy (Dept. of Health, 2014). Underpinned by the overarching principles of personhood and citizenship, and using a population health approach with a focus on: (i) timely diagnosis and GP training; (ii) increasing community awareness and education; and (iii) delivering and evaluating intensive home care supports. The country has for the first time in its history received ring-fenced funding to develop services for people with dementia and their family members likely to be supporting them.

For Ireland, this is an excellent opportunity to support a group of people who in the past have been significantly disadvantaged, in a system where dementia has remained largely invisible. At the time of writing, approximately three years after the launch of this Strategy, it is timely to move the debate forward and ask some critical questions which may help to guide future policy and practice development. These include how dementia is currently framed in Ireland and what exactly is the philosophical foundation underpinning its first national dementia strategy? How can different models for conceptualizing dementia help us to better understand its complexities and drive change in policy and practice? What model of dementia care should the country be aspiring towards in order to underpin future policy direction and what can Ireland learn from other nations now further advanced in developing public policy on dementia? This chapter addresses these important questions and makes several recommendations for future policy development in Ireland. 


\subsection{Models for Understanding Dementia}

In Ireland, the biomedical model has traditionally informed the dominant discourse on dementia and has significantly shaped policy and practice responses where until recently, systems are said to have been paternalistic and clinician led (O'Shea and Carney, 2016), services task-centered and inflexible (Cahill et al., 2014) and supports institutional and custodial with a strong funding bias towards residential care and where the older person's rights to autonomy, choice and control have been restricted (Donnelly et al., 2016). In recent years the biomedical framing of dementia has been challenged with the growing realization that by recasting dementia in broader social terms, much can be done to improve the individual's quality of life.

\subsubsection{The Social Model}

A counter-frame for recasting dementia is the social model: a perspective which draws on the social model of disability (Bond, 2001). This model does not diminish the importance of biomedical approaches, but recognizes that dementia is also a disability (Bartlett, 2000; Kitwood, 1997a), some solutions to which can be found in the environment and in particular in tackling and dismantling the social, attitudinal and environmental barriers society at times erects against those who have dementia (Thomas and Milligan, 2015; Shakespeare et al., 2017).

By locating the 'problem' of dementia as residing outside the individual and seeing it not exclusively based in the 'neurological impairment', the social model demonstrates what can be achieved with relevant physical (environmental) and social (attitudinal) manipulation. It argues that with the right interventions and supports, some of the 'excess disabilities' (Sabat, 1994) individuals experience can be eliminated or minimized and the person and family member can be supported to live a good life in a more inclusive society (WHO, 2012). So, for example, by adapting the physical environment and making it more accessible and 'dementia friendly' (through cueing, signage, and land marking), the individual can be supported to live more independently. Likewise by challenging the negative attitudes of others to dementia (the social environment), the individual is likely to feel more confident in participating in everyday life.

The social model also emphasizes the way in which the individual and their family members interpret their experiences of living with dementia: the meaning their situation has for them and the efforts they make to participate as social citizens in society (Bond, 2001). In this way the subjective experience of an individual's response to the dementia is central to the social model (Bond, 2001). Dementia is only one of a number of ways in which an individual's personal and social capacities may change. The social model asserts that the person with dementia is the expert and should be carefully listened to and encouraged to actively participate in all decision-making relevant to their health and welfare.

In Ireland, the launch of the HSE's 'Understand Together' campaign (National Dementia Office, 2017), one of three work streams of the National Dementia Strategy Implementation Programme, is a good example of the social model of dementia in action. 'Understand Together' is a public awareness, support and information campaign led by the HSE and delivered in partnership with the Alzheimer Society of Ireland and Genio. The programme is designed to challenge stigma, educate the public about risk reduction and signpost individuals and families to appropriate services. It points to the importance of a community development approach to dementia; the need to develop dementia friendly communities and to identify both locally and nationally dementia champions, i.e. people with excellent knowledge and skills in the care of those with dementia.

Another useful example of the social model underpinning dementia services in Ireland is reflected in the 'integrated services and supports' work stream of the National Dementia Strategy. This new and much needed joint investment by the HSE and The Atlantic Philanthropies in Intensive Home Care Packages has been designed to test the feasibility of using this type of support to enable people with dementia with high support needs to be discharged home from hospital or to be helped remain living at home in the community 
for longer. It reflects a welcome shift in policy direction, in a country where traditionally dementia has been over-medicalized (O'Shea and Carney, 2016) and where home care services have been inflexible, fragmented and underdeveloped (Bobersky, 2013).

There are many other examples of the social model of dementia operating in the Irish service landscape. These include: (i) the development and expansion of Alzheimer Cafes; (ii) the introduction of dementia advisor services; (iii) the delivery of more personalised and flexible home and community-based care and support services through the HSE \& Genio Dementia Programme; and (iv) the availability in some few geographical areas of cognitive stimulation therapy services. Examples such as these provide evidence of a more humanitarian, preventive and person-centered model of dementia care gradually gaining traction in a country, where in the past, dementia services were strongly clinically based and highly technical.

\subsubsection{The Biopsychosocial Model}

In more recent years, the influences of the biomedical model and social model have been brought together by the insightful contributions made by a number of social scientists (see for example Hughes, 2011; 2014; Sabat, 2012; Spector et al., 2016; Revolta et al., 2016) who, building on Tom Kitwood's pioneering work (Kitwood, 1993a; b; 1997b;) point to the relevance of a biopsychosocial framework for conceptualizing dementia and the importance of considering a broad range of factors - biological, psychological, social, economic, cultural and environmental - which are likely to influence the subjective experience of dementia. The biopsychosocial expands on the social model by placing a greater emphasis on the myriad of factors (social and non-social) likely to impact on the individual's experience of an illness. It takes a 'whole person' approach to dementia and recognizes the multiple domains, behavioral, functional, physical, psychological and emotional likely to be affected by dementia. In so doing the biopsychosocial model demonstrates that no single specialty has the expertise to respond to the multiple challenges dementia poses, rather the optimal approach, to enable the individual live well, is through involvement of multiple skilled personnel including, nurse practitioners, doctors, occupational therapist, social workers, psychologist, speech and language therapists and physiotherapist. The model also extends beyond health professionals and into the social sphere.

An early multi-disciplinary assessment leading to an integrated care plan is critical to the support of the individual and their family members. This plan should detail the type of interventions e.g. pharmacological, environmental and psychosocial required. Assessment should be on-going and be outcomes-focused. The primary focus should be on the person and on those particular outcomes relevant for that person. Care plans and goals should be based on an exchange model that encourages health service professionals to engage in ongoing dialogue with the person with dementia and their family members. Critically important too is the training of all health service professionals in biopsychosocial approaches (Revolta et al., 2016; Spector et al., 2016) to enable them to incorporate information from biological, psychological and social domains into treatment plans which may potentially lead to significant improvements in care.

The biopsychosocial model is well aligned with the newly emerging philosophy of reablement (Mishra and Barratt, 2016) an approach which challenges negative discourse (George, 2010) and rather than honing in on deficits and decline, builds on strengths and retained abilities and promotes autonomy, independence, choice and control. The approach is person-centred and strengths based. It is not necessarily clinician led but requires close collaboration between medical personnel, allied health care staff, the individual, care workers and family members. The biopsychosocial model when applied to the everyday life of a person diagnosed with dementia whether living at home, in an acute care setting or in residential care also promotes acceptance, inclusion and awareness. It highlights what people living with dementia can still experience and achieve irrespective of the severity of dementia. It shifts the focus from frameworks that are task focused and ignore subjectivity to those that are value driven and holistic. 


\subsubsection{Citizenship and Rights-Based Approach}

Yet another paradigm for framing dementia and one gradually gaining traction, in recent times, is the human rights perspective (WHO, 2015; DAI, 2016). This approach places an emphasis on the citizenship rights of the individual (Bartlett and O'Connor, 2010) including that person's civil, political, social, economic and cultural rights. A rights based approach is embedded in the WHO (2016) global action plan on the public health response to dementia, where explicit reference is made to the UN Convention on the Rights of Persons with a Disability (UN, 2006). Across the world, countries are encouraged by the WHO (2016) to cross check legislation, policy and guidelines to ensure compliance with the Convention (see Chapter 9).

Examining dementia through the lenses of citizenship and human rights broadens the contemporary debate and forces us to analyse some of the inequities in policy and practice people living with dementia are subjected to (Kelly and Innes, 2013). It questions discriminatory policies, which may deny people their fundamental right to basic interventions and supports (Swaffer, 2014). It asserts that the individual must be seen as legitimate part of mainstream society: must be supported to live in the community as a valuable citizen and must be treated with dignity and respect (Mental Health Foundation, 2015).

The human rights based approach places an emphasis on non-discrimination, empowerment, participation, accountability and legality (WHO, 2015) and concepts such as choice, control and consumer-directed care are central to the model. Accordingly, policies underpinned by rights based principles will guarantee entitlement to a timely diagnosis, its ethical and sensitive disclosure, and to a range of post-diagnostic services tailored to individual needs including drug treatments, cognitive rehabilitation and cognitive stimulation therapy. A rights based approach also means that the individual's right to access a range of inhome support services including the personal assistance necessary to support continued living and inclusion in the community will be upheld.

In Ireland, the right of the individual with dementia to remain living at home with in-home personal and social care supports is a controversial topic as, like in other countries, budget holders in Ireland worry about the cost of rights based approaches. At the time of writing a review of home care supports is being undertaken by the Department of Health to help inform the development of a new statutory scheme and system of regulation for home care services. Issues being explored in this review include the cost of home care and who pays for such services, eligibility criteria, training of care staff and national quality standards.

In Ireland, whilst murmurings of a rights based movement have over recent years begun to surface, see for example The Alzheimer Society of Ireland Irish Charter of Human Rights for people with dementia (Alzheimer Society of Ireland, 2016), there is still no legislative basis to community based care services. There is also an extremely limited range of residential support services such as housing with care (Convery, 2014), assistive living arrangements, group homes, care homes, and dementia specific units (Cahill et al., 2015) from which to choose. Under the Irish Human Rights and Equality Act (2014) the public sector has a duty to promote equality, prevent discrimination and protect the human rights of service users affected by government policies and plans. This legislation, along with the UN Convention on the Rights of Persons with Disabilities (UN, 2006), could be used by advocacy groups to campaign for statutory community based services for people living with dementia. Human rights legislation is also relevant to resource allocation for dementia care, given the public duty to protect human rights. 


\subsubsection{A Public Health Approach}

Finally and in recent years, the public health approach to framing dementia is also gaining increasing momentum as more information is coming on stream about the value of risk reduction programmes and primary prevention (ADI, 2014; Ngandu et al., 2015). Recent authoritative reports on dementia produced by the WHO (WHO, 2012; 2016), and the OECD (OECD, 2015) have contextualized dementia as a public health issue and have argued that by paying attention in early and mid-life to lifestyle factors and healthy living, some dementias may be either prevented or delayed. The public health approach considers the broader set of factors, social, economic and environmental likely to determine the health status of individuals or populations. In the context of dementia, a public health model considers the relevance of a range of critical actions (structural interventions) required to address its challenges. These include advocacy and consciousness raising, policy implementation, health and social care service response, capacity building, carer support and research (WHO, 2012). It takes a life course approach acknowledging that dementia can affect people of different age groups and is not merely an age related condition. It argues that brain health and cognitive health in ageing are rooted in physical and mental health in earlier years so that from the point of view of public policy, every stage in the life course is important (Wu et al., 2016). In severing the conventional association held between dementia and ageing and between mental health and dementia, the public health approach helps to address stigma and offers a paradigm of hope and optimism. The public health approach is strongly embedded in WHO's new global action plan on dementia (WHO, 2016).

The public health/health promotion approach acknowledges that many known diseases causing dementia e.g. Alzheimer's disease and Vascular Disease, share the same characteristics of other chronic diseases. These include, a complex aetiology, multiple risk factors, long latency period, prolonged illness trajectory and result in functional impairment or disability (Travers et al., 2015). This means that the health promotion interventions applied to other diseases such as coronary heart disease, stroke, diabetes, cancer and chronic obstructive pulmonary disease may also be applicable to dementia. This also means that economies of scale can be gained through the cross promotion of health promotion policies (Travers et al., 2015) and it also means that public health policies targeting whole populations such as risk reduction and health promotion are important for dementia.

Whilst the Irish National Dementia Strategy makes explicit reference to the importance of including dementia in all future health policies, dementia is not a listed illness included in the HSE's chronic disease management programme (Dept. of Health, 2017). Nor does dementia receive any significant coverage in the National Positive Ageing Strategy (Dept. of Health, 2013). This means that opportunities now exist for dementia to be more mainstreamed into such programmes in Ireland, for resource sharing and for new partnerships to be developed between organizations that promote similar risk reduction messages for other chronic diseases. 


\subsection{Lessons from Other Countries}

So what lessons can be learned from other countries now more advanced than Ireland in relation to their development of policy plans on dementia? From Luxembourg we learn that adopting a stand-alone silo approach to dementia policy is insufficient and what is needed is a whole of government cross-sectoral framework, which involves several different ministries (Mutsch, 2015). This makes sense especially given the public health approach to dementia now being adopted globally and the importance of contextualizing dementia within population health and life course approaches. From Sweden we see the importance of excellent leadership in dementia care, with her Majesty Queen Silvia now at the helm of dementia initiatives such as the Dementia Forum X (Dementia Forum X, 2015) and Sweden boasting the largest registry of dementia worldwide (Religa et al., 2015). The Swedish model is also clearly underpinned by a biopsychosocial, 'whole of community' approach where community based dementia care teams play an important role extending their specialist services into memory clinics and into the residential care sector. The new Norwegian Dementia Plan 2020 (Norwegian Ministry of Health and Care Services, 2016) is heavily embedded in rights based principles including dignity, self-respect and the right of the individual to choose how to live their own life. Like the Netherlands (Verbeek, 2013) the Norwegian Plan commits to ensuring that a sizeable proportion of new builds in the residential care sector (care homes and nursing homes) conform with best practice principles in dementia and are small-scale domestic-like group dwellings, which help to empower the individual, giving them a sense of control over their lives. The Finnish Strategy Creating a Memory Friendly Finland (Finnish Ministry of Social Affairs and Health, 2013) is committed to promoting brain health, preventing memory disorders and ensuring that rehabilitation services are made more readily available to people diagnosed with dementia and such services should be available across all care sectors.

\subsection{The Way Forward}

As discussed in this chapter, in a relatively short period, Ireland has witnessed a major shift in how dementia is framed. Evidence now exists of the gradual dismantling of what was formerly a firmly embedded biomedical model, which favored institutional care, and the emergence of a more person-centered community-based model of dementia services with a greater focus on subjectivity and personhood. This transformation has been driven and facilitated by funding made available through the Atlantic Philanthropies (O'Shea and Carney, 2016) and by a Dementia Strategy developed by the Department of Health and underpinned by principles of personhood and citizenship.

Building on this social model, some further recasting of dementia is now required where the optimal approach for future service development is through the adoption of a biopsychosocial model. This more holistic framework has significant implications for the practice of integrative medicine (O'Shea and Carney, 2016) and for a whole person multidisciplinary response to dementia. It legitimates the need to provide not only medical interventions but a broader range of services including multidisciplinary assessment services, rehabilitation/reablement services, including post diagnostic counseling, transport services, assistive technology, peer supports, dementia advisors, cognitive rehabilitation, cognitive stimulation therapy, reminiscence and so on.

As discussed here, the biopsychosocial approach is well aligned with the newly emerging philosophy of reablement: an approach designed to promote choice, dignity and independence and to give the individual as much control as they wish over their daily lives. This more positive approach moves the focus away from the disease model of brain atrophy, plaques, tangles, drugs, decline, no hope, no cure and acknowledges the interplay between the intrinsic capacity of the individual and that person's physical and social environment (Mishra and Barratt, 2016). The reablement approach also 'supports the human rights of people with dementia and their caregivers and focuses positively on what people can do with the appropriate support and interventions' (Mishra and Barratt, 2016 p.18). 


\subsection{Conclusion}

A significant shift has occurred in recent years in how dementia is understood and conceptualized in Ireland. In the past, dementia was viewed largely as a cognitive brain disorder, often hidden or when visible, managed by deficit based policies, focusing on medication and control. In contrast, today, dementia is being framed in broader more holistic terms and responded to by policies designed to preserve and promote personhood and engage and empower the individual. For the first time in its history, the country has received dedicated funding to deliver a community and home based model of dementia care. For the first time ever, it has a National Dementia Strategy over which the Department of Health has taken full ownership. What is also novel is evidence of good leadership and solidarity in the implementation of this Strategy through a newly established HSE national office for dementia resourced by dedicated staff determined to bring about change.

Future directions include the need for dementia to be more fully integrated into other health policy areas; the development and expansion of multidisciplinary assessment and post-diagnostic services with a greater emphasis on rehabilitation (Clare, 2017) and reablement approaches (Mishra and Barratt, 2016) for a whole of government response to dementia with strong political leadership and in line with the WHO's global action plan (2016) for greater recognition and promotion of the human rights of the individual and their family members.

Most importantly we need to continue to move away from an over-reliance on drugs, restraints, and asylum-type paternalistic care, which is dehumanizing, erodes personhood and is an affront to human rights. We must continue to personalise care, recognizing that people with dementia are active agents and citizens who need to remain socially engaged and involved in meaningful relationships and in activities, which promote their dignity and enhance quality of life. Finally if the principles of citizenship and personcentred care are to be implemented in Irish care settings, there is a need for clear guidelines to be developed on what exactly these principles mean to the individual, family members, health service professionals, front line care staff, and care regulators. For without guidelines, personhood and citizenship will remain vague, somewhat meaningless and unattainable concepts leading to sub-optimal care for people with dementia. 



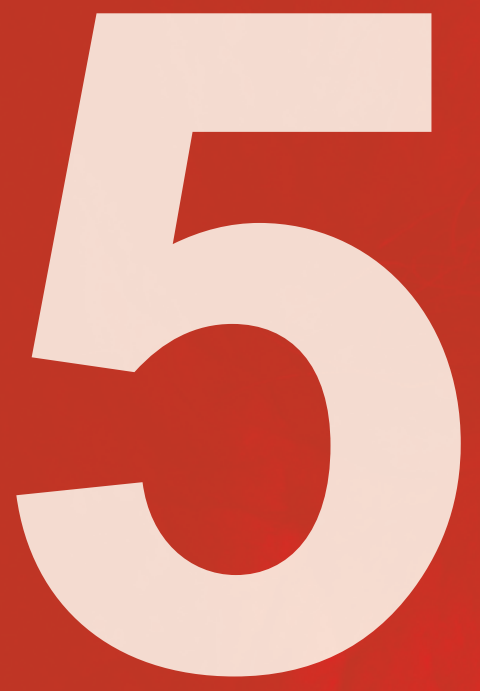

Personalised Care for People with Dementia in Ireland

Fiona Keogh and Maria Pierce 



\subsection{Introduction}

It is the wish of most people with dementia to continue living in their own homes for as long as possible. In December 2014, the Irish government published its first National Dementia Strategy (NDS), which supports this preference, stating that: "People with dementia should be facilitated to remain living in their own homes and to maintain existing roles and relationships for as long as possible ..." (Dept. of Health, 2014 p.24). This recommendation to support people with dementia to remain at home echoes many similar recommendations from policies for older people in Ireland from over three decades. Notably, The Years Ahead report recommended that the dignity and independence of older people could best be ensured by "...enabling them to continue to live at home with, if necessary, support services provided by the state" (Robins, 1988 p.iii). Yet, to date neither the service infrastructure nor the resources have been provided to achieve this espoused objective. The community care system for people with dementia in Ireland remains underdeveloped and fragmented, with a small range of services and patchy availability (Cahill et al., 2012). Resource allocation within health services budgets for older people is skewed toward residential care with the bulk of funding being allocated in this direction and not for community-based care (see Chapter 8). Home care services are rationed and because of scarcity, task oriented care is prioritised. This leaves little scope for services that support personhood, i.e. respects and encourages autonomy and empowerment and social connectivity through continued social participation and the maintenance of ability in people with dementia, or to support family carers who provide the bulk of care when the person remains at home. 


\subsection{HSE \& Genio Dementia Programme}

It was within this context of poor policy implementation, poorly developed community and home-based services and invisibility of personhood that a new initiative was developed in 2012. The HSE \& Genio Dementia Programme came about through an alignment of goals and funding from the Health Service Executive (HSE) and The Atlantic Philanthropies ${ }^{1}$, developed and delivered by Genio ${ }^{2}$. An initial innovation fund of $€ 4$ million was created to develop and test new service models in Ireland in order to improve the range and quality of community-based, person-centred supports for people with dementia; influence public policy and investment; and sustain leadership and innovation to support the implementation of the NDS (Genio, 2016b).

The focus of the programme was not just increasing the range of services, but on bringing about a deeper transformation in the service landscape for people with dementia. Core to the approach was the personalising of supports and services the promotion of personhood (Kitwood, 1997). Personhood was a fluid narrative underpinning the programme - a narrative that respects and encourages autonomy, empowerment and social connectivity for people living with dementia, to ensure that they can live fulfilling lives in their community in the face of declining cognitive abilities. The term personalised, as used in the programme, is a broad term used to describe the different ways to support the person with dementia to maximise their abilities and to remain living a full life. Personalised supports are based on the needs and the wishes of the person. While clinical and medical needs are attended to, equal weight is given to providing services that are required to support the person to live a full life.

The programme developed organically in response to learning and emerging needs, with five sites ${ }^{3}$ building on approaches developed in the first four sites ${ }^{4}$ to test, for example, the effectiveness of personalised community-based supports in enabling people with advanced dementia and/or complex needs to remain living at home (Genio, 2016a; Brady et al., 2017b; Brady et al., 2017a). A further three sites ${ }^{5}$ developed integrated care pathways in acute hospitals in order to improve the hospital experience and outcomes for people with dementia. In total, €6.3 million in combined funding has supported 12 sites and an associated learning and research programme in the period since 2012.

\subsection{Personhood and Personalised Supports}

Creating Excellence in Dementia Care described how policy and practice should be guided by people with dementia and their families noting that, "...for personhood to have real meaning it must be extended into citizenship whereby people with dementia are treated as full citizens with consequent rights and responsibilities." (Cahill et al., 2012 p.11-12). This was reflected in the NDS, with the inclusion of personhood and citizenship as underpinning values. Since Kitwood's seminal work, personhood has been increasingly recognised as a cornerstone of good quality dementia care (Downs, 2013; WHO, 2012). However, there is less consensus on how this concept is operationalised in service delivery (Wilberforce et al., 2017). What do 'personhood-based' services look like? What are their characteristics? Personhood is about more than providing a greater variety of services, although that is welcome, and it is more than a comprehensive needs assessment, although this is also necessary for effective service delivery. It involves a subtle but profound shift in how services providers interact with, and treat people with dementia; it involves a shift in the balance of power within dementia relationships and within the system of care. If the selfdetermination of the person is to be respected and promoted, people with dementia must be centrally involved in the design and delivery of the supports and services that address their priorities and those of their family. Their preferences must inform not only a wider choice-set, but more importantly the way services and supports are conceptualised, constructed, delivered and communicated. The current system

\footnotetext{
${ }^{1}$ The Atlantic Philanthropies is a private foundation founded by Irish American businessman Chuck Feeney in 1982. Between 2011 and 2015 Atlantic made an investment of $€ 33$ million in a number of dementia initiatives in Ireland.

${ }^{2}$ Genio is an Irish-based non-profit organisation working with government and philanthropy to transform social services.

${ }^{3}$ These five sites are Kilkenny/Carlow, Leitrim, Louth, Mallow and Roscommon.

${ }^{4}$ These four sites are Kinsale in Cork, Stillorgan/Blackrock in Dublin, Mayo and South Tipperary.

${ }^{5}$ Mercy Hospital in Cork, St James's Hospital in Dublin and Connolly Hospital in Dublin.
} 
is resourced and constructed to provide pre-determined forms of care primarily for physical care needs, through rigidly structured processes and settings that are determined by the funders, regulators and providers of care, resulting in a system that cannot take account of, or provide for, individual preferences and wishes.

The sites in the HSE \& Genio Dementia Programme have demonstrated personhood in action. A range of personalised supports were developed with the person and family carers, by eliciting their needs, preferences and priorities and developing appropriate responses based on the person's interests and which focused on enhancing their abilities. These supports avoided an exclusive focus on deficits, decline and risk and instead provided responsive, flexible supports that could, for example, support a person with dementia to come to terms with a diagnosis; help maintain a social life and relationships after diagnosis; and help with maintaining ability - all with a view to retaining quality of life and supporting personhood. A positive risk taking approach was adopted (Clarke, 2015), to address the 'silent harms' that can be done to people through being highly risk averse (Clarke et al., 2011), which can result in robbing the person with dementia of "the life yet to be lived" (Sabat et al., 2011). Personalised supports do not discount the range of clinical and medical services the person may need, but give equal weight to the range of supports and services required by the person in order to maintain ability for the person to remain living well at home and remain connected to their families and communities and live a full, meaningful life.

The initial and on-going dialogue with the person and their family is central to this approach and means that supports can change as the needs of the person and family change and that services can respond to crisis events. This collaborative and respectful interaction helps to establish a different dynamic between the person/family and the health and social care system. It is one in which option demand can function. In other words, people are more confident that a service is available to respond flexibly to individual social as well as medical needs if they need it in the future (O'Shea and Murphy, 2014).

In some of the literature, personalisation of services is unhelpfully conflated with the means of funding such supports in the form of personal budgets. A dominant discourse around personalisation has equated personalisation with giving people more autonomy and independence over their care, a wider choice of providers and services and extending their capacity for self-care (Wilberforce et al., 2017). However, personalised supports, as described here, are essentially about incorporating the principles of personhood, i.e. recognising the uniqueness, dignity and value of each human being irrespective of their dementia or its severity, into service delivery in a practical way, with an emphasis on interpersonal relationships and the interactional environment.

\subsection{Dementia Consortia - a Mechanism for Service Integration}

Adopting a personalised approach to services means that supports extend beyond formal health and social care services. A range of organisations is required to deliver such a variety of supports in a normalising, sustainable and integrated way. This has been recognised in other jurisdictions where responses such as the MAIA (Maison pour l'Autonomie et l'integration des maladies d'Alzheimer) in France, a high-profile action of the French Alzheimer Plan (Alzheimer Europe, 2016) and Dementia Networks in Germany (Laporte Uribe et al., 2017) have been developed. The response which underpinned the HSE \& Genio Dementia Programme was the development of Dementia Consortia (Keogh et al., 2016); a group of organisations, agencies and individuals who come together around the agreed goal of supporting people with dementia to live well in their local community. Dementia Consortia provide a structured way of using formal statefunded resources from health and other sectors in combination with resources from the community and voluntary sector and unpaid/voluntary contributions to create a holistic, sustainable and personalised 
response that meets a wide range of needs of people with dementia and family carers and is underpinned by values of personhood and citizenship. This 'care and support ecosystem' builds on existing infrastructure and informal carers, but also attracts and supports a variety of new and innovative responses to dementia (Keogh et al., 2016). Co-production in dementia consortia was a concrete expression of personhood in action; recognising the abilities and autonomy of people with dementia and involving them and family carers in a meaningful way in the design of supports and services. This focus on the individual was also a defining feature of the way in which the consortia worked. Rather than providing for the generality of 'people with dementia', the consortium focused on providing the individual with what they need as a person.

\subsection{Mobilising Community Support}

A supportive environment and community was recognised as a key precursor and enabler to the provision of a wider range of social supports that enable the person to remain living well in their community and that recognise the inherent value and uniqueness of the person.

Initial information and awareness-raising activities by the sites identified a gap to be bridged between awareness of dementia; to an understanding of personhood; and on to active participation. A deliberate strategy was needed to bridge that gap. This required more targeted actions around knowledge transfer and active participation, with specific outcomes in mind, including personhood-related outcomes. A deliberate strategy of moving from 'open' engagement to more 'targeted' engagement was needed to lead from the passive receipt of information to the active engagement of members of the community. This deliberate strategy was focused on both efforts to change attitudes (e.g. through de-stigmatising the 'loss of self' that is said to characterise the experience of a person with dementia) and efforts to change behaviour through stimulating active involvement of the community in a way that 'adds value' to the person's life and recognises their personhood and their citizenship (Bartlett and O'Connor, 2007) (see text box for example). This process moves work such as 'dementia friendly communities' to another level of active participation - i.e. 'dementia supportive communities' - where there is a strong recognition within the community of the role they can play in supporting people with dementia and can become actively involved. In effect a supportive 'community of interest' is created that contributes more broadly to building citizenship and social cohesion.

\section{Example of benefits of community mobilisation}

The recruitment of volunteers across several sites was a visible example of community mobilisation. Volunteers were trained and carefully matched to support people with dementia in a variety of ways based on the person's interests and wishes. Quotes from participants illustrate the process and benefits:

"Following the diagnosis the person can get withdrawn but slowly but surely when we make the right match we can get people back into the things [social activities] they were doing and should be doing" [Volunteer coordinator].

"We're absolutely a perfect match...we get on great. We play cards and we just have great fun and she lights up when I come through the door...so I get as much back as she gets" [Volunteer].

"The value of what the 40 volunteers have contributed is immeasurable because the greatest gift anyone can give to one another is your time." [Project lead].

(From film: Volunteers supporting people with dementia in the Living Well with Dementia project (2015) https://www.genio.ie/videos) 


\subsection{Community Supports Model}

A core imperative of the dementia programme was that what was learned from the demonstration sites would be distilled and act as a catalyst for change, and work to bring about the deeper change required to implement personalisation. Thus, a service design process, as described in Genio (2016a) was put in place to develop a comprehensive, evidence and practice based community supports model drawing on the most effective elements of the innovations across the community sites. An iterative consultative process included people with dementia; families; health and social care professionals; academics; third sector organisations; and an international expert panel. From this process the elements of the model were described as follows (see also Figure 5.1):

- Dementia consortium - a mechanism to support the provision of integrated and personalised services and supports.

- Dementia care coordinator - to act as a single point of contact, to co-ordinate services and support and to act as a specialist and recognised 'dementia resource' to a defined geographical area.

- Mechanisms to support timely diagnosis.

- Post-diagnostic supports.

- A range of personalised supports which are tailored and flexible to meet different needs at different times such as:

o Community connector(s) to support connection/reconnection.

o Supports to maintain ability.

o Responsive respite supports.

o Assistive technology/telecare.

- Underpinning 'Enablers' to create a supportive environment including community level awareness raising and multi-stakeholder training / education (training is described in more detail in Chapter 6). 
Figure 5.1 Community supports model
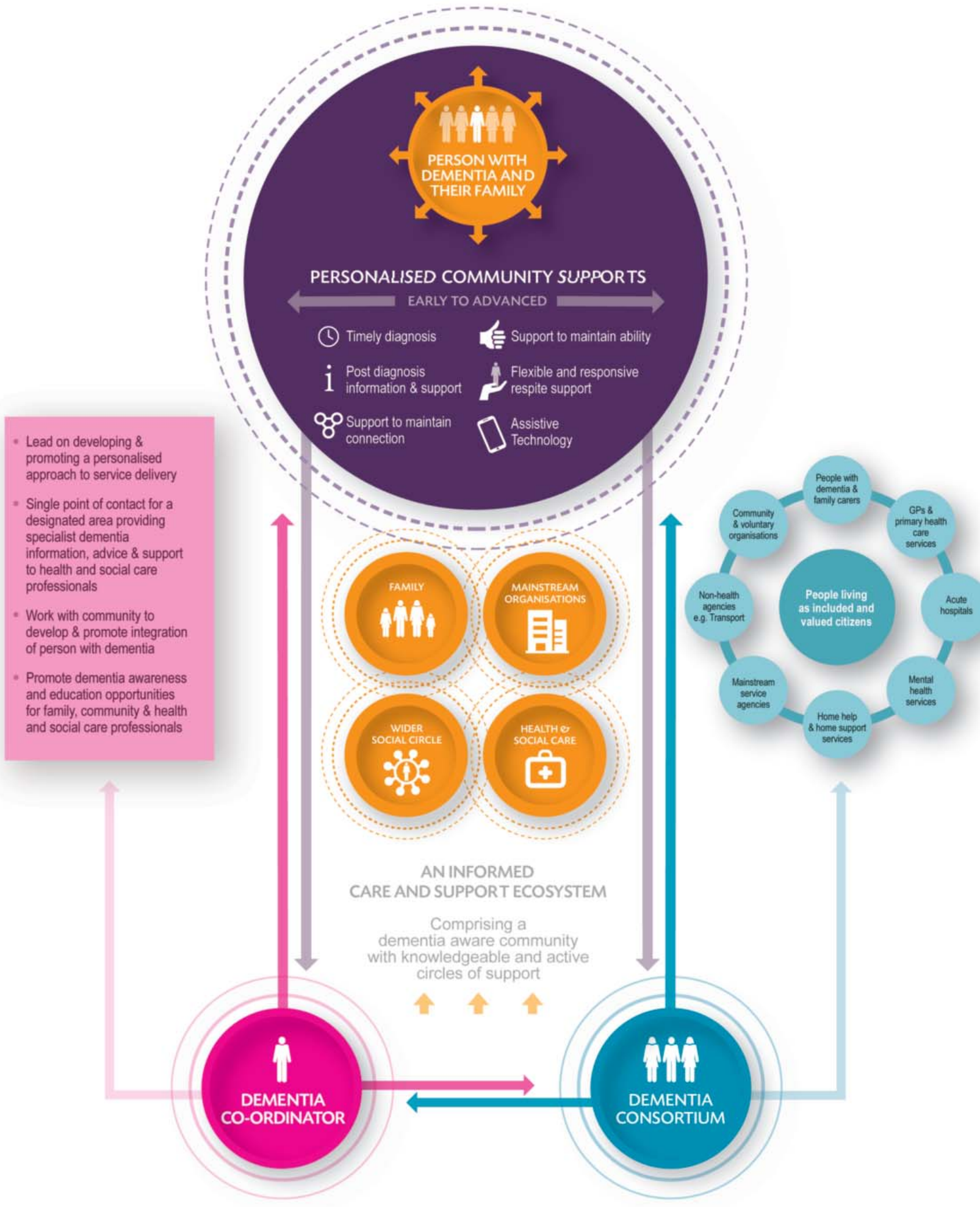


\subsection{Key Findings from the HSE and Genio Programme}

The outputs from the programme have demonstrated the practical feasiblity of this community supports model in nine sites in Ireland, both urban and rural and with different service configurations. Between 2012 and 2017, over 280 health and social care professionals, people with dementia, carers and community members worked together in nine dementia consortia; 3,299 people with dementia and carers received over 67,000 hours of personalised supports; and 180 telecare/technology packages were put in place.

Evaluations of personalised supports including innovative respite (Cahill et al., 2014b; a); assistive technology and telecare (Cullen et al., 2016); personalised home care (Brady et al., 2017a); and reablement (Brady et al., 2017b) reported a number of benefits for the person including opportunities to maintain abilities, social skills and independence, and for families the flexibility of the inputs was appreciated as changing needs were responded to; high levels of satisfaction with this approach were reported and families felt supported and better able to cope. Important differences between personalised supports and the usual mainstream services included the flexibility and responsiveness of the supports, the degree to which the person's autonomy was recognised or enhanced and the variety of activites or responses that could be provided in most sites, which meant that what the person and family received was more closely tailored to their wishes (Cahill et al., 2014a; b; O’Shea and Monaghan, 2016; Brady et al., 2017a; Brady et al., 2017b).

Economic analyses of six of the demonstration sites focused on persons with dementia on the margins of residential care (O'Shea and Monaghan, 2016; Brady et al, 2017a, b). The services and supports received were costed to determine the potential of the community supports model for delaying admission to residential care. O'Shea and Monaghan (2016) reported on 181 of 568 people with dementia (32\%). These people were located in four sites and were on the boundary of care between home care and residential care. The estimated average weekly cost of community care per person for this cohort, including standard HSE provision plus supports from the projects, was $€ 207$ per week, against an average cost per week of $€ 967$ for long-stay residential care. When the costs of housing and personal consumption for the person were included, the average cost per week increased to $€ 418$ per week. The overall estimated potential saving associated with the programme for this group of 181 people was over $€ 3$ million, when the comparison is made with HSE and project support costs.

Brady et al. (2017a), whose study focused on a cohort of people with advanced dementia and complex needs, reported an average cost per week of $€ 504$ for the HSE services plus supports provided by the Community Outreach Dementia Project Leitrim, compared to the average net cost of long-stay residential care of $€ 813$. For 27 of the 30 participants, the cost of additional, flexible and responsive home care hours was lower than the cost of care in a long-stay residential setting. Similarly, Brady et al. (2017b) reported an average cost per week of $€ 607$ for HSE supports plus the supports provided by the Memory Matters Project in Carlow/Kilkenny, compared to the average net cost of long-stay residential care of approximately $€ 1,200$. For 40 of the 49 participants the cost of reablement-focused home care was lower than the cost of care in a long-stay residential setting. If informal care is included in the cost comparison calculations from these studies, community care becomes more expensive than residential care, highlighting the central importance of family care for people with dementia living in the community and the need to provide sufficient support to families.

While there has been progress in moving the existing care system to a personalised model that respects and encourages personhood and autonomy (O'Shea and Monaghan, 2016), the evaluations identified important gaps and challenges to be addressed to ensure this model is available nationally. For example, the Dementia Coordinator was identified as a key role in facilitating integrated care and acting as a single point of contact, responsible for matching responses to need and coordinating the required supports (O'Shea and Monaghan, 2016; Genio, 2016a). While this role has been sustained in some sites it has not become embedded in others and has not been more widely adopted as yet. 
A key challenge in embedding personhood in service delivery is how to actively listen to the voice of the person with dementia (Cahill et al, 2012; O'Shea and Monaghan, 2015). The community sites demonstrated ways in which this can be done, such as local fora, membership of the dementia consortium and different approaches to needs assessment. However, on-going attention is required to achieve the necessary culture shift, not just amongst staff but also family members. Training has a role to play in this culture shift but we must also acknowledge that more time with the person is needed to really elicit their views and wishes; and resource and practical support is required to involve people with dementia on advisory forums or working groups.

Practical issues can also hinder the delivery of personalised supports. Transport is an issue and not just in rural areas (O'Shea and Monaghan, 2015). Matching the provider (care worker or volunteer) with the person is important if the maintenance of personhood and maximisation of capabilities is to be achieved but sometimes geography can create difficulties in ensuring that optimal matches occur (O'Shea and Monaghan, 2015). Similarly, shortages of care workers and a lack of appropriately trained care workers can mean that continuity of care is difficult to maintain or that the necessary skills are not available to promote and support personhood.

\subsection{Policy and Practice Implications of Personalisation}

The personalisation in services for people with dementia as demonstrated through the projects has gained traction in Ireland and some initiatives have led to changes in how dementia services are coordinated locally and how home care resources are used locally. The introduction of Intensive Home Care Packages for people with dementia is a further development and part of a process of introducing personalisation into the wider system. However, while demonstrations are very useful, systemic change requires more than 'tinkering' on the margins. We can learn from other sectors where moves towards personalisation have gone through a lengthy and incremental process over several decades, for example, the deinstitutionalisation and normalisation of disability services. It has been argued that disability services have struggled to become truly personalised as their core ethos and culture had not changed in spite of many infrastructural and other changes over three decades and that personalisation demands a revolution in our thinking about supports and services (McConkey et al., 2016). If we can learn from this experience a similar transformation in dementia care need not be so protracted.

For personalisation to work well, changes to the way in which resources are allocated are required. At a simple level, allowing people to 'bundle' their hours into one block rather than having short periods at times that do not suit them is a start. However, it is important to shift away from a sole focus on "hours of care', with little regard for what happens during those hours. Quality of care is very important as is continuity of care and familiarity with care workers. Also important are the deeper changes that are required to facilitate the person and family to have a much greater say in how their allocated resource is used. This, for example, could be through some form of personal budget, which have been shown to have benefits for people with dementia and their family carers if the right supports are in place (Lakey and Saunders, 2011). In some of the literature, personalisation of services is unhelpfully conflated simply with personal budgets (Spicker, 2013). However, personal budgets are just one mechanism for facilitating personalisation of service delivery. In the context of dementia care, the quality of the care relationship, the interaction with the person and the responsiveness to their wishes in terms of what is done, is central. A shift away from task-centred care with a sole focus on physical or personal needs is necessary. This is part of the deeper philosophical change that is required; where time spent adding value to a person's life is recognised and is regarded as equally important as time spent helping them with personal care. Relatively simple changes in service delivery, such as a reliable single point of contact and confidence in a timely response, has been shown to lead to a surprisingly low 'ask' from people with dementia and families (Genio, 2016a). 
There has been a significant change in culture and practice within many of the sites in the programme. These have been sustained to a variable extent and there is some evidence of adoption across wider service areas (for example, in $\mathrm{CHO} 6$ ). However, personalised supports are still not widely available throughout the country. Other initiatives supported by the National Dementia Office, ASI and others are creating a fertile environment for enhancing personhood in dementia. The Understand Together campaign (National Dementia Office, 2017), Dementia Friendly Communities (Alzheimer Society of Ireland, 2016), Dementia Elevator Training Programme (Dementia Elevator, 2017) and the Schools Project (Dementia Services Information and Development Centre, 2016) are all developing the underpinning enablers for the roll out of a community supports model.

However, much remains to be done. Workforce development is a neglected issue. Appropriate training and improved working conditions are essential to develop and grow a workforce that can deliver care which adds value to the person's life and which supports their personhood. While training programmes are being developed and provided (see Chapter 6), cross-departmental working will be necessary to fully address the issue of working conditions. The regulation of services for people with dementia so that personhood is incorporated and supported is a challenge, as the regulatory system is designed to deal with the prevailing service system which is predominantly built around predictable or rigid structures and processes such as physical buildings or staff rosters. The provision of sufficient resources to fund personalised care also needs serious consideration. While it is possible to add value to the current resource spent on home care, implementing personalised care more systemically will cost more and these resource implications are explored further in Chapter 8.

Fundamentally, however, personalisation requires a simple but profound change in how the service delivery structure, from front line personnel to senior managers, views and interacts with the person with dementia and their family. The simple but profound change involves listening closely, not relying solely on standardised needs assessments; respecting the uniqueness of the person and their circumstances, not providing a 'one-size-fits-all' response; and one that recognises the person and family as experts in what they need, involving them in co-producing the care they receive. 


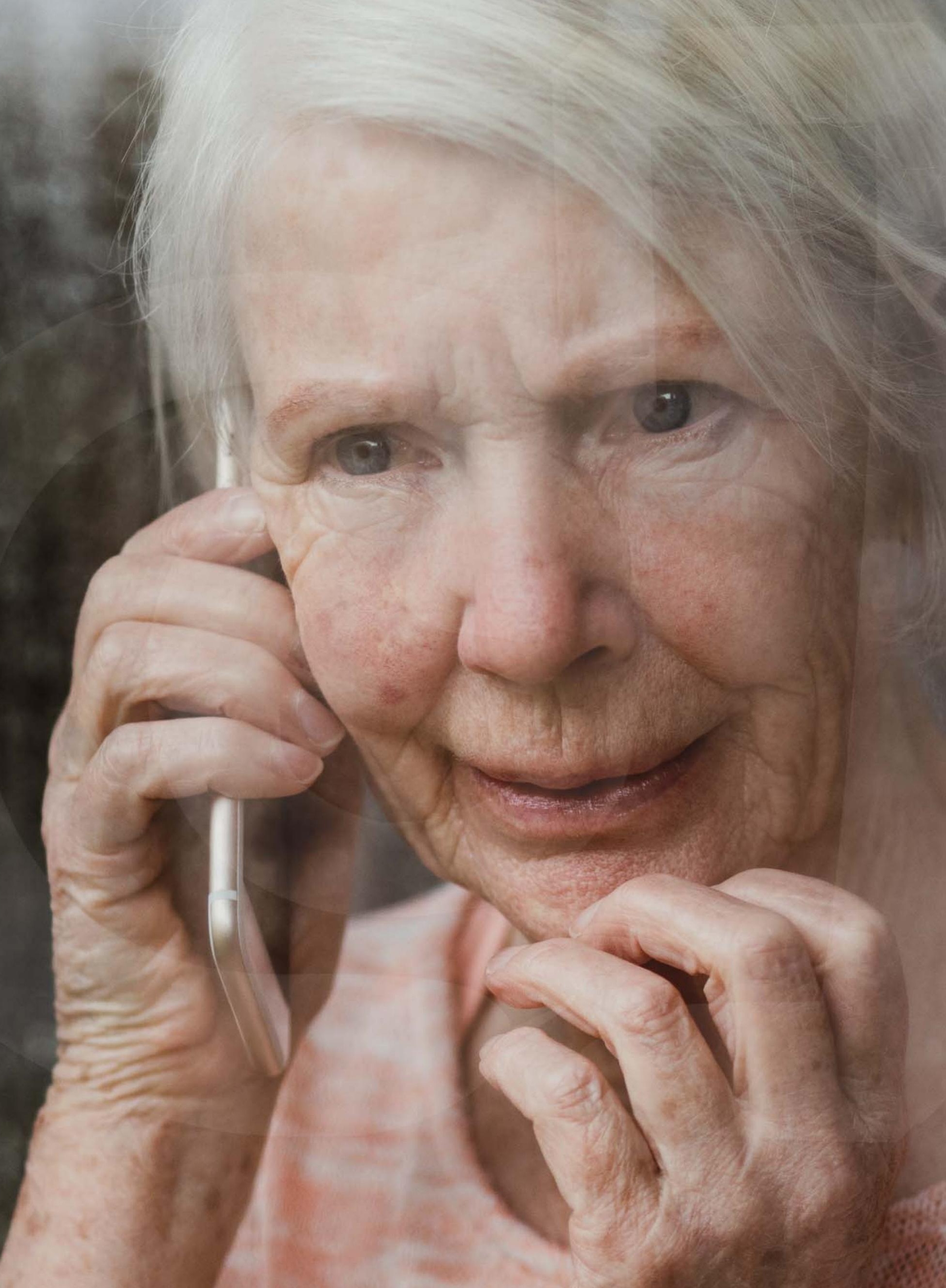




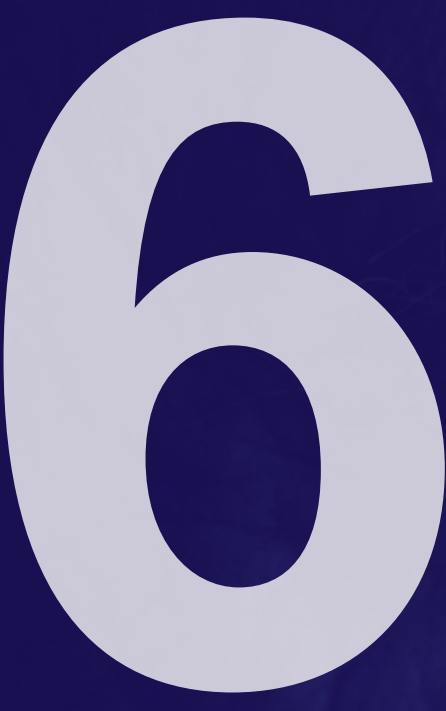

Education and Dementia

Kate Irving 



\subsection{Introduction}

This chapter is about education and training for people providing care and supports for people with dementia. There is an emerging consensus on the need for service change to realign care and provision with a kind of support that matches the wishes of people with dementia and their families (Dept. of Health, 2014; 2013). These wishes align with commonly expressed aspirations for how most people would like to be cared for if they/we had dementia in the future - to be cared for with humanity, empathy and dignity, in a way that recognises the self, protects identity and emphasises strengths and ageing in place (Brooker and Latham, 2016; Edvardsson et al., 2008). To achieve these aspirations, some fundamental shifts need to take place at every level of service provision, planning and in the values and beliefs about dementia held by providers of care and wider society. Education will be very important in bringing about that recalibration.

\subsection{Personhood and Person-Centred Care}

Kitwood defined personhood as: "... a standing or status that is bestowed on one human being, by others, in the context of relationship and social being. It implies recognition, respect and trust...." (Kitwood, 1997 p.8).

The relational aspect of personhood is most important in this definition. Many staff describe person centred care with an emphasis on having choice and personal agency, but when personhood is seen as relational, as a choice we make to bestow personhood on another human being, simply because they are one of us, then all aspects of care are affected. This is a subtle but important distinction. It is not the fact of having a choice about what to wear or eat that denotes our personhood, it is the fact that if we accept that all people should be accorded the status of personhood then we cannot treat people in ways that damage this in any way.

There is widespread agreement that person-centred care is a necessary condition for skilled dementia care (Brooker, 2004), but person-centred care is absent as often as it is present in dementia care, despite the widespread rhetoric of its importance (De Siún et al., 2014; Sjögren et al., 2013). There have been many recent care scandals and often less obvious but still malignant social psychologies (how the social and physical environment can make things more difficult for the person) evident in the care of people with dementia. It is clear, therefore, that there are a number of challenges ahead for dementia education in achieving person centred care. In that regard, Kitwood's (1997, p.133) warning twenty years ago about a superficial colonisation of the discourse of person centred care is still relevant today:

"It is conceivable that most of the advances that have been made in recent years might be obliterated, and that the state of affairs in 2010 might be as bad as it was in 1970, except that it would be varnished by eloquent mission statements, and masked by fine buildings and glossy brochures". 


\subsection{Changing Perceptions about Dementia}

There is a need for change in society as to how we see people with dementia, their personhood and their value. It is not always easy to identify and support strong person-centred ideals in dementia care and relationships. The following case study demonstrates the challenges people with dementia face in finding purpose and meaning in everyday relationships.

\section{Case study}

Anne is a woman of 75 who was diagnosed with Alzheimer's disease 4 years ago. She has always been a very kind and caring person. She lives alone after her husband died several months ago. She has a supportive family but they don't live nearby and a small but tight group of friends from over the years. One of these friends (Pauline's) husband is terminally ill and Anne wants to go and support her. Anne relates to how hard it must be for Pauline and what a good support she was to her when she was nursing her own husband. She calls round about every day or every second day for 30-60 minutes or so, has a coffee and leaves. Anne's daughter gets a call from Pauline saying, 'you have to stop your mum from coming over I can't cope with the stress and I have to look after my own husband now'. On examination, it seems the stress is caused because Anne now repeats herself and says things that are at odds with Pauline's reality. Pauline seems to feel responsible when Anne drives off - 'if anything should happen to her'.

It is very difficult to make a judgement of right and wrong in this case. Most people would probably put the needs of Pauline before Anne. A woman caring for a dying husband should have no additional demands on her, if at all possible. However, it is also unsatisfactory that a person with memory and orientation problems cannot now express meaningful concern and give support to someone - despite genuinely caring and meaning well - simply because expressions of empathy are punctuated with a number of memory slips and confusions. It is very difficult for Anne to maintain a sense of self and human dignity without being valued as a meaningful source of support. This happens thousands of times for people with dementia in different interactions and in different situations with both loved ones and strangers. But, it is equally clear that education and training could have an effect here in encouraging and facilitating empathy, reciprocity and understanding between the two friends, thus allowing Anne to offer support, maybe not the same as before, but in a manner, that would serve to protect her identity and personhood.

People with dementia are routinely subject to stigma, prejudice and systematic discrimination, far more obvious than that described in the case study presented above. The World Health Organisation (WHO) define stigma as 'resulting from a process whereby certain individuals and groups are unjustifiably rendered shameful, excluded and discriminated against' (WHO, 2002). Stigma occurs when the anticipated attributes we have assigned to someone in any interaction are not fulfilled so that when we meet someone who is outside the norm, a person with an undesirable attribute, then that person is "thus reduced in our minds from a whole and usual person to a tainted, discounted one" (Goffman, 1963 p.11-12).

McParland argues that the stigma attached to dementia is incredibly complex; "an interplay of many 'jeopardies' or labels, but also associated with existing perceptions of care, feelings of hopelessness or futility, and a profound fear of developing a condition that appears utterly arbitrary in selection, and totally beyond the control of the individual or the world of science and medicine." (McParland, 2014 p.265). In her research, the 'creaturliness' of people with dementia was emphasised, as can be seen in the following quote of someone describing their view of dementia:

'I certainly wouldn't want to be hanging about and not able to do, not able to see, just an entity, like an animal in a cage sort of thing'.

In this context of subtle and overt stigmatism, an education in ethics and moral courage, as much as evidence based practice, will be necessary to enhance dementia care and this needs to be fully acknowledged in any dementia training and education. 


\subsection{Delivering Person-Centred Care}

Improving the lives of people with dementia requires us to look at a complex system of interactions and multidisciplinary collaborations between formal and family carers, different services and public and private organisations. To date, we have had an overriding focus on separate parts of a system, for example, care recipient/care giver dyads, memory clinics, diagnosis, post diagnostic supports, primary care, day care, respite care, acute care, mental health services and residential long-stay care. We have focused on individual aspects of care rather than the continuum of care and the transition points along that continuum. Cross disciplinary education and training is central to bringing together all the various strands of care in a way that puts the person with dementia at the centre of decision-making in relation to their own care, including their connectivity to families and communities.

However, transitioning to a culture where person-centred care is the norm will require more than just the training of front line staff. Providing person-centred care will require increased flexibility and in some cases more time with the client. For instance, it may not always be possible to assist a person with dementia in the bath in the allocated time on a particular day. Unless the bath can be postponed, or more time can be allocated, person-centred care is likely to be compromised. Instead, a situation may arise that is potentially degrading and undermining to the self-esteem of the person with dementia, as well as impacting negatively on the person providing the care. Flexibility in relation to both provision and care structures is a necessary condition for person-centred care. The findings from the EU-funded Actifcare (Access to Timely Formal Care) programme showed a persistence of poor flexibility in relation to the care of people with dementia across all eight participating countries in that study (Hopper et al., 2016). The following quote is from an Irish participant, in relation to overnight respite care:

"But unfortunately, they'll only give you a block of three nights. If they said he could have one night, I would have been happy, but they are giving him three nights. So, at the end of, or the middle, of February he's coming here for three nights, and I really don't know what's going to happen." (Informal carer/IE).

It is essential that all those involved in the care and support of people with dementia understand the importance of person-centred care and are committed to its delivery, in the face of the very real challenges this presents, particularly in the absence of adequate resources. Education and flexibility in provision are required if we are to genuinely meet the needs of people with dementia. Even with education, people may find themselves working in cultures of care that do not have a person-centred ethos. Once lessons in selfawareness and empathy have been learnt, it is difficult to work in a system that has poor flexibility or structural issues that make person-centred provision difficult. If participants return after education to work in a system that values 'efficiency over empathy,' they may become demoralised in that environment.

Many people with dementia will exhibit challenging behaviours (BPSD) at some point (Banerjee, 2009). Challenging behaviours are frequently a result of difficulties in communication (Keady and Jones, 2010). Training can help to alleviate challenging behaviours through enhancing communication, resulting in an improvement in a range of outcomes for people with dementia and care workers (Spector et al., 2013). For people with dementia, improved outcomes can include reduced symptoms, reduced use of physical and chemical restraints and improved quality of life (Testad et al., 2005; Fossey et al., 2006; Spector et al., 2013). Magai et al. (2002) show that training in sensitivity to non-verbal-emotional signals can enhance mood in people with dementia. Staff education can also reduce care worker stress and improve work performance (Edvardsson et al., 2009). 


\subsection{Education and Training Needs}

In 2013, an educational needs analysis across the spectrum of professional groups found huge gaps in knowledge and awareness in relation to dementia (Irving et al., 2014). Only a small proportion of staff in the Irish health system had received dementia specific education and training. Those who had received training had usually only received a small amount. De Siún and Manning (2010) found that 83 per cent of nurses and 73 per cent of care attendants had no training in dementia. Where training was received, 14 per cent of nurses and 43 per cent of care attendants reported having only 1-2 hours of education. There were no data available for other health care professionals at that time.

Different levels of training are required depending on the frequency and the kind of interaction the person has with people with dementia. For the general public, a low level of awareness is required. For people who assist people with dementia on a daily basis in complex situations, a high level of training will be needed. The Dementia Skills Elevator Programme developed at Dublin City University provides a useful template to map the required skill range across the continuum of dementia: being aware; informed; skilled; and expert. The matrix shown in Appendix 1 characterises a range of different education requirements at different parts of the dementia journey from prevention and awareness to end of life care. Each level builds on the skills, knowledge and understanding of the column to the left.

The benefits of training apply both to people with extensive experience in dementia care, as well as those without any experience. For experienced health care professionals, interactive training courses provide a platform to explore their own professional practice in complex care situations. For family carers, practical information can be disseminated and the perspectives of people with dementia can be explored within caring relationships.

There have been no estimates of the optimal skill mix in different dementia care settings in Ireland, particularly in relation to what makes a difference to processes and outcomes for people with dementia. It makes intuitive sense that there should be at least one expert per nursing home, one expert per ward, several skilled people per expert and general dementia awareness in all facilities where people with dementia live. Table 6.1 is an attempt to provide various baseline skill mix estimates for a typical $\mathrm{CHO}$, that can be adjusted as more information becomes available. For example, in the Social Care Division in each $\mathrm{CHO}$, it is estimated that 30 dementia experts, 150 skilled staff in dementia and 1,000 informed practitioners in dementia are needed as a baseline provision. The indicative minimum training level for: i) an expert is a year-long course in dementia (c. 1,800 hours); ii) skilled practitioner is defined as having undertaken a substantial module of dementia training with formal assessment; and iii) an informed practitioner requires a short course in dementia awareness, in addition to practical experience of working with people with dementia (1 day to several days). 
Table 6.1: Estimated skill mix requirements for typical $\mathrm{CHO}$

\begin{tabular}{|c|c|c|c|c|}
\hline $\begin{array}{l}\text { Staffing ratio per } \\
\text { facility/setting in } \\
\text { typical CHO }\end{array}$ & Unit & Expert & Skilled & $\begin{array}{l}\text { Informed } \\
\text { practitioners }\end{array}$ \\
\hline $\begin{array}{l}\text { Social Care Division } \\
\text { (Home Help, Day } \\
\text { Care, Short Term } \\
\text { Beds, AHP) }\end{array}$ & $\mathrm{CHO}$ & 30 & 150 & 1000 \\
\hline $\begin{array}{l}\text { Mental Health } \\
\text { (POA, Psychiatric } \\
\text { Hospitals) }\end{array}$ & $\mathrm{CHO}$ & 10 & 50 & 500 \\
\hline $\begin{array}{l}\text { Primary Care } \\
\text { (Public Health } \\
\text { Nursing, AHP) }\end{array}$ & $\mathrm{CHO}$ & 10 & 50 & 500 \\
\hline General Practice & All GPs & 600 & 950 & 1,404 \\
\hline Acute Care & Hospital & 10 & 30 & 500 \\
\hline Nursing Homes & Nursing Home & 2 & 20 & 35 \\
\hline
\end{tabular}

* The numbers are averages and therefore do not take account of the size of facility or proportion of older people in the region.

In Table 6.2, baseline typical CHO estimates are aggregated to generate baseline skill mix requirements at a national level for various parts of the health and social care system. The exercise suggests that 2,608 dementia experts are required nationally, supported by 14,860 skilled dementia personnel and 64,869 informed dementia practitioners. While these estimates are subjective and fraught with uncertainties, they do demonstrate the scale of the potential effort that will be required to implement a national educational programme for people involved in the care of people with dementia in Ireland. Of course, up-skilling service providers is only the start of the process. It is equally important to ensure that what is learnt during training can be implemented, particularly if, at an organisational level, the 'culture of care' is firmly embedded and training is merely being done as a tick-box exercise.

Table 6.2: National estimates of skill mix requirements

\begin{tabular}{|c|c|c|c|c|c|c|}
\hline HSE Division & Expert & Skilled & $\begin{array}{l}\text { Informed } \\
\text { practitioners }\end{array}$ & $\begin{array}{l}\text { Total } \\
\text { Dementia } \\
\text { Trained }\end{array}$ & $\begin{array}{l}\text { Proportion } \\
\text { of Division } \\
\text { Staffing }\end{array}$ & Total Staff \\
\hline $\begin{array}{l}\text { Social Care } \\
\text { (Home Help, Day Care, } \\
\text { Short Term Beds, AHP) }\end{array}$ & 270 & 1350 & 9,000 & 10,620 & $55 \%$ & 19,485 \\
\hline Nursing Homes & 998 & 9,980 & 17,465 & 28,443 & $91 \%$ & 31,100 \\
\hline $\begin{array}{l}\text { Mental Health (Psychiatric } \\
\text { Hospitals) }\end{array}$ & 90 & 450 & 4,500 & 5,040 & $53 \%$ & 9,594 \\
\hline Primary Care (PHN/AHP) & 90 & 450 & 4,500 & 5,040 & $53 \%$ & 10,404 \\
\hline Primary Care (General Practice) & 600 & 950 & 1,404 & 2,954 & $100 \%$ & 2,954 \\
\hline Acute Care & 560 & 1,680 & 28,000 & 30,240 & $56 \%$ & 53,524 \\
\hline Total Required & 2,608 & 14,860 & 64,869 & 82,337 & $65 \%$ & 127,014 \\
\hline
\end{tabular}

It must be acknowledged that the provision of training has expanded in recent years, albeit from a low base. An estimated 25,421 people have now received short training courses, 2,292 people have received training to the "skilled level" and a further 275 people to the "expert level". While progress has been made, there remains a significant gap between the current and optimal levels of training, particularly at the higher levels of provision. The following section gives some details on current responses to meeting education needs in dementia care in Ireland. 


\subsection{Current Educational Responses}

\subsubsection{Dementia Awareness}

A wide range of training has been made available at a basic level by a number of different organisations. The promotion of personhood and person-centred care is a thread running through the range of educational and training initiatives described in this section. For example, the Dementia Skills Elevator in DCU and HSE developed many freely available online awareness resources for the general public. These are now being systematically disseminated by the Understand Together Campaign. A 2-day awareness programme has been widely disseminated in hospitals, nursing homes and community settings.

The Genio Dementia Learning Network developed in 2012 provides a mechanism where people can learn and share with colleagues about personalised working in dementia and how to implement this in practice. It provides a range of learning opportunities such as conferences, workshops and communities of practice. Learning resources such as themed papers and film resources from these events have been disseminated to a wide audience of people interested in this way of working (Genio, 2016). Training and education has also been a major focus of the HSE \& Genio Dementia Programme, with a diverse range of training programmes offered by projects.

The Department of General Practice in UCC, PREPARED, have developed a number of educational initiatives to support multidisciplinary dementia care in the community, including: peer-facilitated, small-group workshops for doctors facilitated by an experienced GP; CME Workshops run by the Irish College of General Practitioners (ICGP); and inter-professional education workshops for PCT members. Additional supports are available through the DementiaPathways website, a clinical resource for healthcare professionals including a county-by-county directory of dementia services and supports. A dementia reference guide is also available (Foley and Swanwick, 2014). GP Prepared are currently updating the ICGP e-learning dementia modules and developing master-classes, in conjunction with the ICGP.

The Irish Hospice Foundation (IHF) have well developed education material, focused on palliative and end of life care and dementia (Irish Hospice Foundation, 2016). There is a palliative care competence framework and the full impact of this needs to be cross referenced in planning education for dementia. Sonas apc has a popular annual international conference that includes a masterclass day for skills development, with a wide range of high quality speakers, attended by upwards of 450 participants, and a further range of psychosocial skills training such as life story work and Cognitive Stimulation Therapy. The Dementia Services Information and Development Centre (DSIDC) run regular training days both in-house and at St James's hospital for a wide variety of service providers. They also host annual conferences and co-host Ireland's national Memory Clinic Conference and have developed a suite of training materials including those targeting school children and educational DVD's. Their focus is on the development of a wide range of psychosocial skills to improve the care of people with dementia and their courses range from one hour to 5 day courses.

\subsubsection{Dementia Skilled}

Three standalone professional development modules in dementia for multidisciplinary health and social care staff were developed by DCU during the Elevator project. HSE and DCU have developed a 3-day module for home care workers to improve the skilled practitioners in that category. Roll out of this programme commenced in the autumn of 2017. UCC with the Prepared team have developed a 12-week university accredited blended learning dementia course for GPs. The Sonas Programme, a therapeutic activity for people with dementia, aims to provide an enjoyable, gently stimulating experience, activating each person's potential for communication. This programme has had a major impact on the Nursing Home environment, with about half of Irish Nursing homes having a certified Sonas programme practitioner. 


\subsubsection{Dementia Expert}

Third level education is well placed to contribute to skilled and expert practitioners. UL and TCD have a Masters programme in dementia, while other Universities offer dementia modules as part of their programmes. TCD in collaboration with DSIDC ran a very successful Living with Dementia programme that graduated six PhD and ten Masters students with specific expertise in dementia - many of whom are now leaders in dementia services here or in Europe. DCU is leading a proposal to roll out a National Dementia Certificate incorporating the learning from the Dementia Elevator project.

\subsection{Measuring Impact}

Measuring improvements in the quality of care provision as a result of education is challenging. The Kirkpatrick evaluation model outlines four levels at which a training programme can be assessed (Kirkpatrick and Kirkpatrick, 1994):

- Reaction. How satisfied are participants with the lesson?

- Learning. Has knowledge been transferred?

- Behaviour. Has behaviour changed in real life care situations?

- Results. Has training resulted in an improvement in patient experience?

As one moves down the list, it becomes harder to measure the impact of education with any great accuracy. However, research tools are available for this purpose and more effort needs to be made to measure the relationship between education and performance, using tools such as Quality of Interaction Schedule (QUIS) (Dean et al., 1993). HIQA have used this tool in their dementia inspections, as have regulatory agencies in other jurisdictions. A major piece of research in the UK called, Dementia Education: What Works?, outline a number of aspects for the successful delivery of education programmes in dementia (Surr et al., 2017).

"Common features of more efficacious educational programs included the need for educational programs to be relevant to participants' role and experience, involve active faceto-face participation, underpin practice-based learning with theory, be delivered by an experienced facilitator, have a total duration of at least 8 hours with individual sessions of 90 minutes or more, support application of learning in practice, and provide a structured tool or guideline to guide care practice." (Surr et al., 2017 p.1)

In Ireland, we require funded research on the impact of dementia-specific education on people with dementia and their caregivers. This should be carried out by researchers who are independent of, and external to, the educational initiatives, using mixed methods approaches, supported by theoreticallyinformed approaches to evaluation research. It would be useful to explore, for example, the extent to which training programmes are actually focused on educating staff to promote personhood and citizenship in dementia care. Moreover, it would be interesting to know whether structural and institutional factors impact on the ability of staff to deliver care in a more person-centred way following training. 


\subsection{Conclusion}

The spirit of collective activity in dementia care has increased nationally. Undoubtedly, considerable progress has been made in the number and diversity of dementia educational offerings available in Ireland since 2012, but it is also true that the majority of people with dementia still do not routinely receive personcentred care. Until education and training, in concert with other aspects of care organisation, are addressed, it is hard to see this changing for the majority of people with dementia. There are positive signs that improvements can be made in regard to education and training. However, there is a general paucity of educators with a level of knowledge about person-centred care that is useful to health and social care providers. We are also only at the beginning of the journey to challenge the general public's deeply entrenched views about dementia and people with dementia. A fundamental shift is required within each and every one of us, a shift that goes beyond the intellectual and challenges many of our values and beliefs.

At a systems level, that shift needs to be reflected in our thinking and planning. How do we make a deep and fundamental shift in thinking about dementia within the various agencies charged with responsibility for delivering care, policy and resources for people with dementia? How can we educate formal and informal care providers to move beyond the rhetoric of person-centred care. Education is much more than the simple transfer of information from people who have knowledge to those who don't. Collective ownership of reform is required, incorporating people with dementia, family carers, providers and the general public. Without shared ownership and responsibility, the realisation of person-centred care will take longer than it should. That would be a real shame, given the appetite for change in the country.

In this context, the following recommendations are made with a view to improving education for personcentred care:

- Any education in dementia must include an examination of personal values and self-awareness at all levels of service delivery.

- No student of any health and social care programme in the third level sector should graduate without a dementia-aware level of training (at least 3 hours of specific education per year of study).

- Leadership is required at senior management levels to ensure the roll out of the programmes that have been described in this chapter to staff and society.

- A dedicated team of dementia trainers should be employed nationally for a minimum of 5 years to deliver the high-quality programmes that have been invested in previously and to close the skill gap.

- Standards of training and guidelines need to be set nationally to increase service quality and ensure equity across private and public services.

- Independent research is required to evaluate the impact of training on the health and wellbeing of people with dementia and their caregivers.

- Training should, where possible, be cross-sectoral and interdisciplinary to encourage service integration.

- Dementia awareness training is needed for all stakeholders. Everyone needs to be getting the same message in relation to the importance of personhood and person-centred care.

Therefore, managers need to prioritise the release of all staff for dementia education, as well as ensuring that care structures are not antithetical to person-centred care once the education has been delivered. 
Appendix 1: Dementia Elevator Education Matrix - Prevention, Awareness and Assessment

\begin{tabular}{|c|c|c|c|c|}
\hline 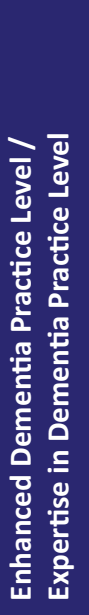 & 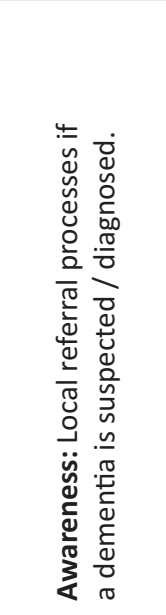 & 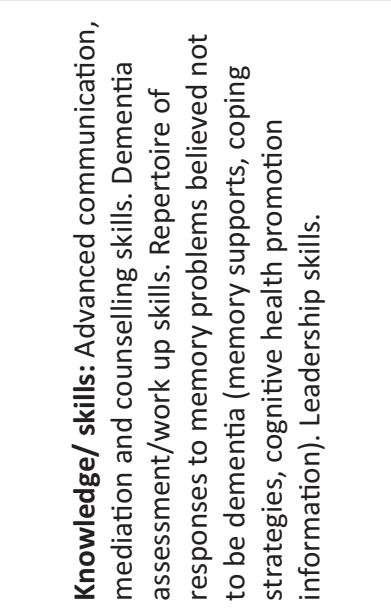 & 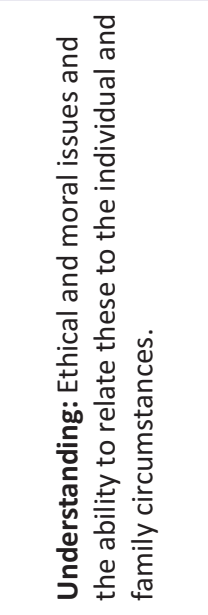 & 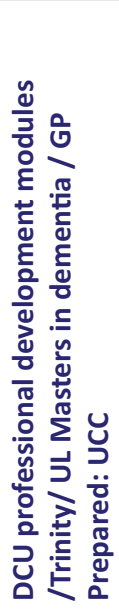 \\
\hline 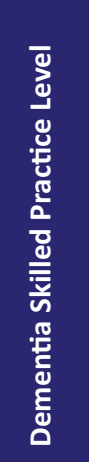 & 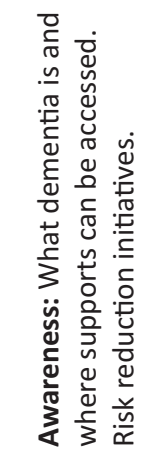 & 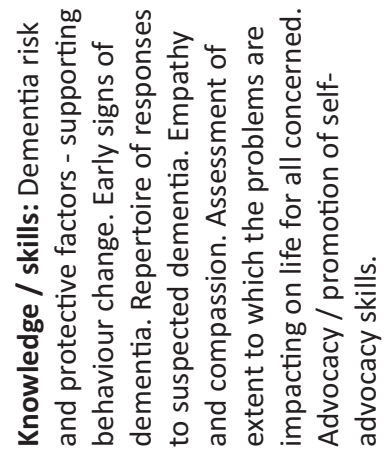 & 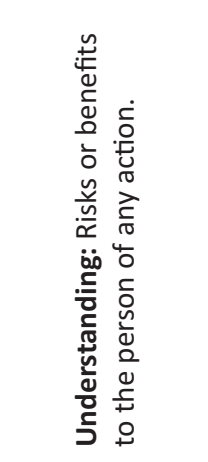 & 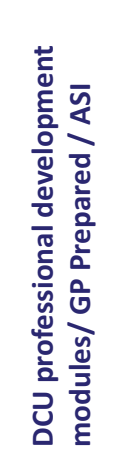 \\
\hline 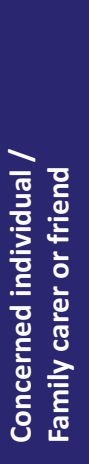 & 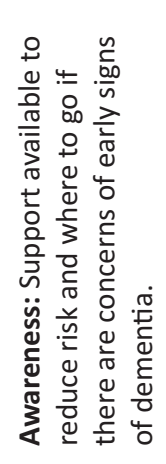 & 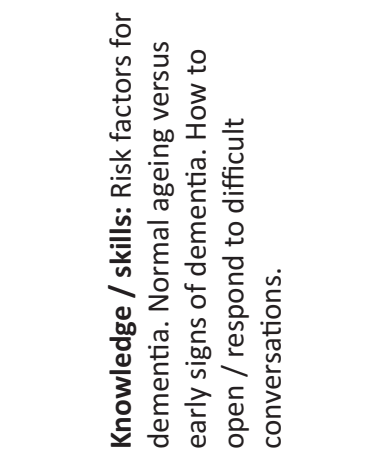 & 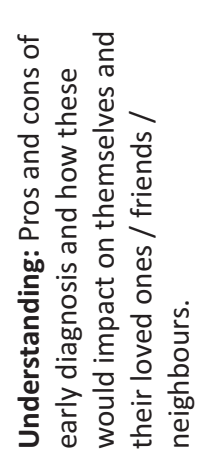 & 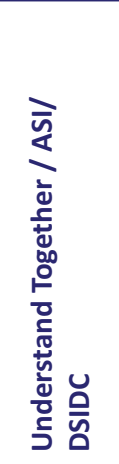 \\
\hline 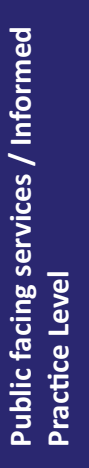 & 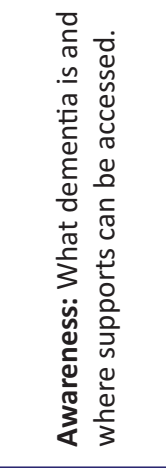 & 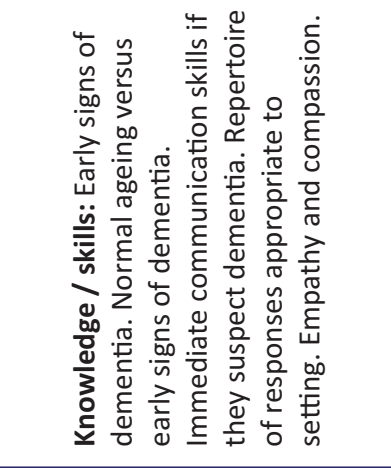 & 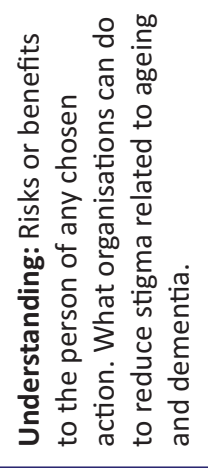 & 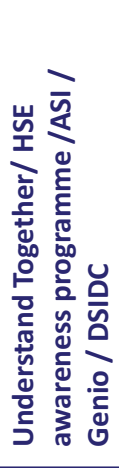 \\
\hline 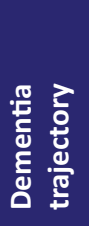 & 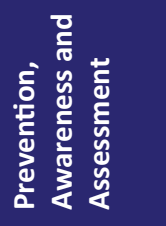 & & & 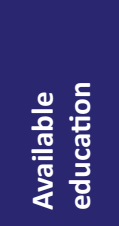 \\
\hline
\end{tabular}


Dementia Elevator Education Matrix - Diagnosis and Post Diagnosis

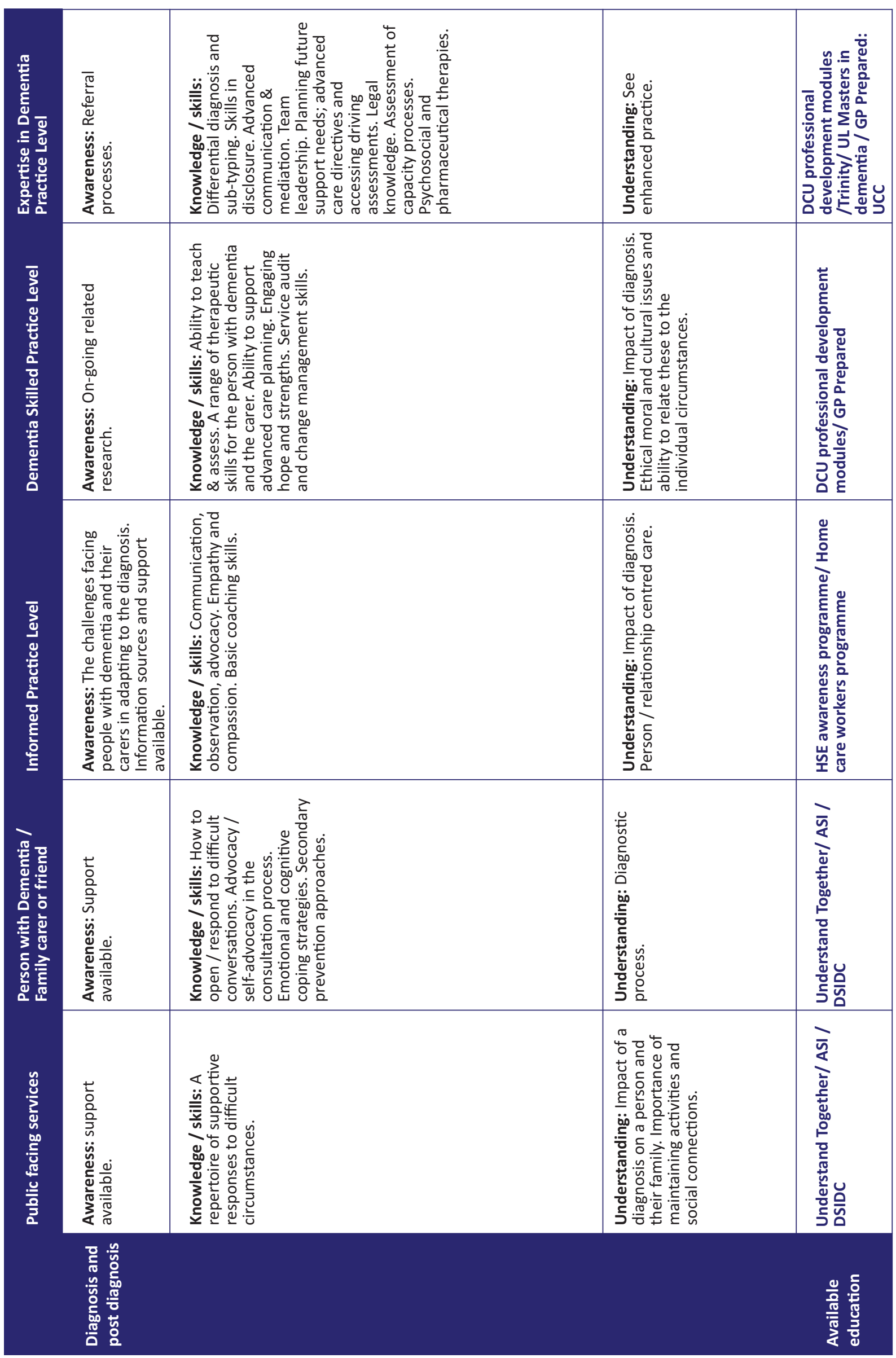




\section{Dementia Elevator Education Matrix - On-Going Support, Care and Review}

\begin{tabular}{|c|c|c|c|c|}
\hline 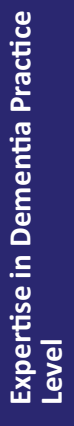 & 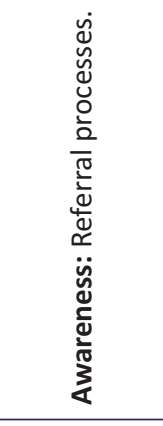 & 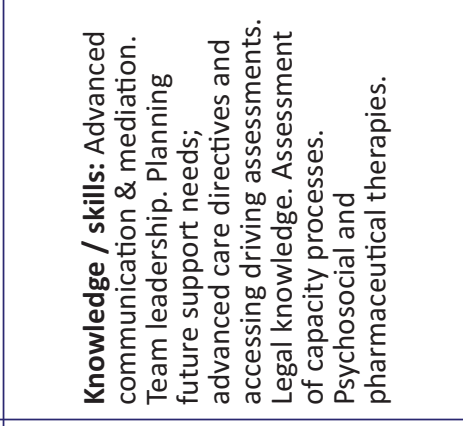 & 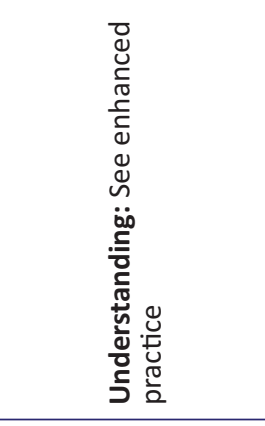 & 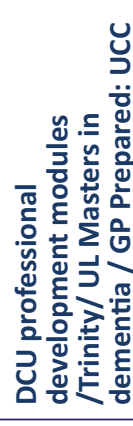 \\
\hline 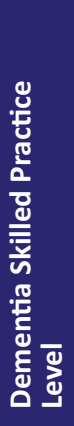 & 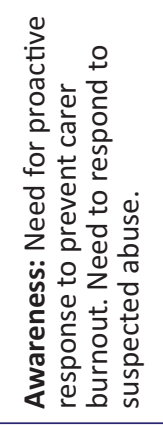 & 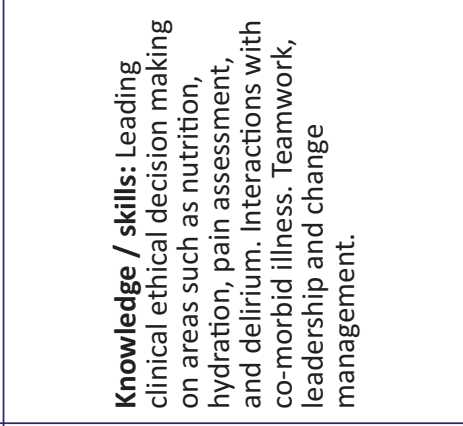 & 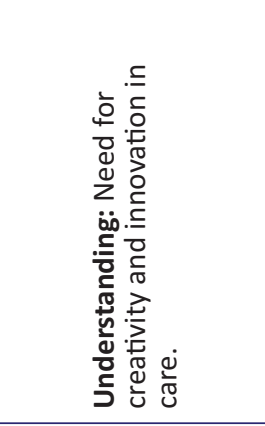 & 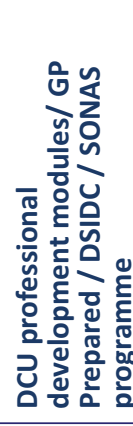 \\
\hline 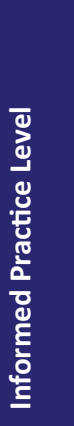 & 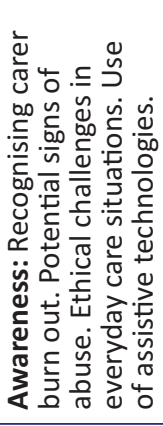 & 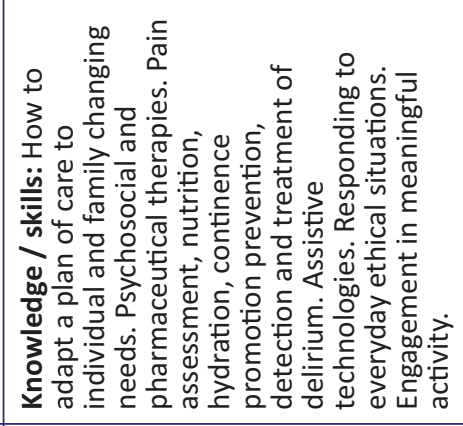 & 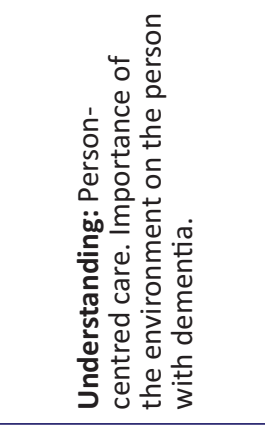 & 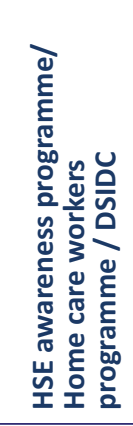 \\
\hline 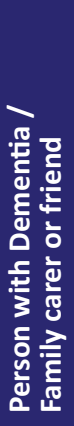 & 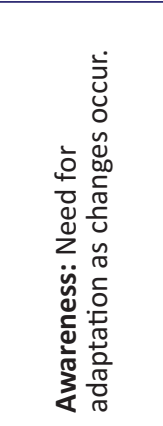 & 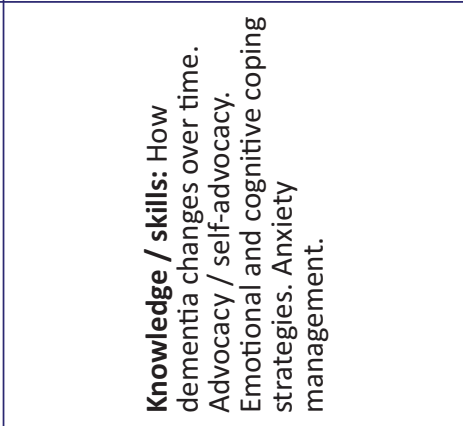 & 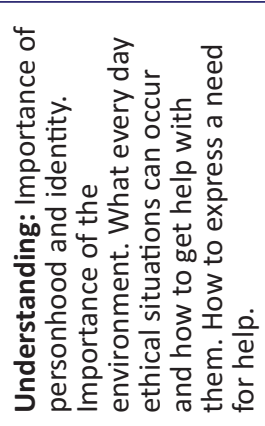 & 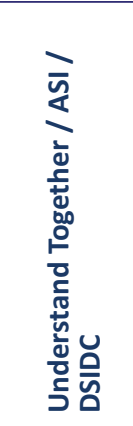 \\
\hline 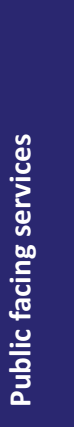 & 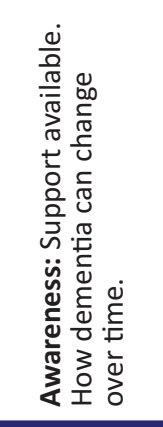 & 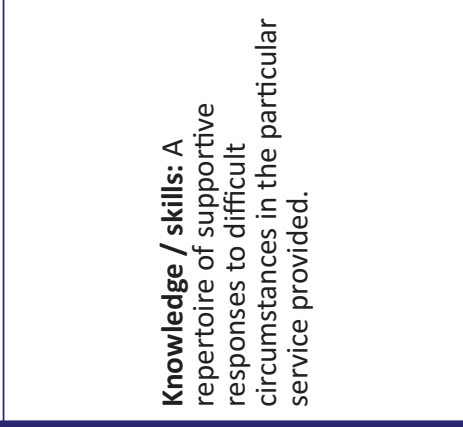 & 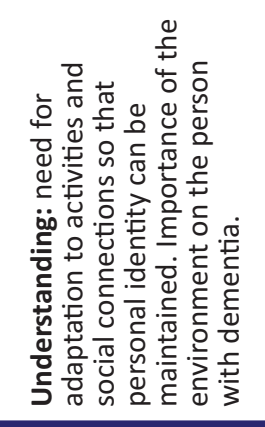 & 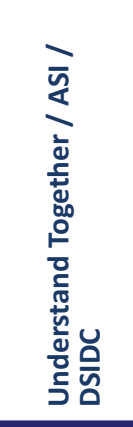 \\
\hline & 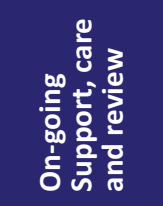 & & & 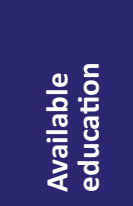 \\
\hline
\end{tabular}




\section{Dementia Elevator Education Matrix - End of Life}

\begin{tabular}{|c|c|c|c|c|}
\hline & $\begin{array}{l}\text { Person with } \\
\text { dementia, Lay carer } \\
\text { or friend }\end{array}$ & $\begin{array}{l}\text { Informed Practice } \\
\text { Level }\end{array}$ & $\begin{array}{l}\text { Dementia Skilled } \\
\text { Practice Level }\end{array}$ & $\begin{array}{l}\text { Expertise in Dementia } \\
\text { Practice Level }\end{array}$ \\
\hline \multirow[t]{3}{*}{ End of life } & $\begin{array}{l}\text { Awareness: Advanced } \\
\text { planning. Where to } \\
\text { access emotional and } \\
\text { practical support. }\end{array}$ & $\begin{array}{l}\text { Awareness: Needs of } \\
\text { carers and people with } \\
\text { dementia at the end of } \\
\text { life. }\end{array}$ & $\begin{array}{l}\text { Awareness: Needs / } \\
\text { wishes of carers and } \\
\text { people with dementia } \\
\text { at the end of life. }\end{array}$ & $\begin{array}{l}\text { Awareness: Personal } \\
\text { wishes and advanced } \\
\text { dplanning. Specialist } \\
\text { service referral } \\
\text { pathways. Spirituality. }\end{array}$ \\
\hline & $\begin{array}{l}\text { Knowledge / skills: } \\
\text { Human rights. Physical } \\
\text { body care. }\end{array}$ & $\begin{array}{l}\text { Knowledge / skills: } \\
\text { Empathy and } \\
\text { compassion. Opening } \\
\text { conversations. } \\
\text { Assessment of physical } \\
\text { and emotional needs. }\end{array}$ & $\begin{array}{l}\text { Knowledge / skills: } \\
\text { Empathy, compassion. } \\
\text { Assessment of physical } \\
\text { and emotional needs. } \\
\text { Advocacy. }\end{array}$ & $\begin{array}{l}\text { Knowledge / skills: } \\
\text { Empathy and } \\
\text { compassion. Advanced } \\
\text { assessment, } \\
\text { complementary } \\
\text { therapies, } \\
\text { pharmaceutical } \\
\text { symptom } \\
\text { management, grief } \\
\text { and bereavement } \\
\text { counselling. Clinical } \\
\text { and ethical decision } \\
\text { making in nutrition, } \\
\text { hydration, active / } \\
\text { palliative treatment } \\
\text { etc. Critical reflection } \\
\text { on practices. Self- } \\
\text { awareness. Advocacy. }\end{array}$ \\
\hline & $\begin{array}{l}\text { Understanding: } \\
\text { Person's wishes. How } \\
\text { to ask for support. }\end{array}$ & $\begin{array}{l}\text { Understanding: } \\
\text { Person-centred care. } \\
\text { The importance of the } \\
\text { environment at end of } \\
\text { life in death and } \\
\text { immediately after. }\end{array}$ & $\begin{array}{l}\text { Understanding: } \\
\text { Person-centred care } \\
\text { needs through dying, } \\
\text { death and } \\
\text { immediately after. } \\
\text { Needs of carers } \\
\text { through the dying } \\
\text { process and after } \\
\text { death. }\end{array}$ & $\begin{array}{l}\text { Understanding: } \\
\text { Acceptance that good } \\
\text { end of life care starts } \\
\text { well before the end of } \\
\text { life. Ethical decision } \\
\text { making around } \\
\text { treatment } \\
\text { alternatives. Person- } \\
\text { centred care. } \\
\text { Importance of the } \\
\text { environment on the } \\
\text { person with dementia } \\
\text { and their carer. }\end{array}$ \\
\hline $\begin{array}{l}\text { Available } \\
\text { education }\end{array}$ & $\begin{array}{l}\text { Understand Together } \\
\text { / ASI/ IHF /DSIDC }\end{array}$ & IHF / DSIDC & $\begin{array}{l}\text { DCU professional } \\
\text { development } \\
\text { modules/ GP } \\
\text { Prepared / IHF }\end{array}$ & $\begin{array}{l}\text { DCU professional } \\
\text { development modules } \\
\text { /Trinity/ UL Masters } \\
\text { in dementia / GP } \\
\text { Prepared: UCC] }\end{array}$ \\
\hline
\end{tabular}




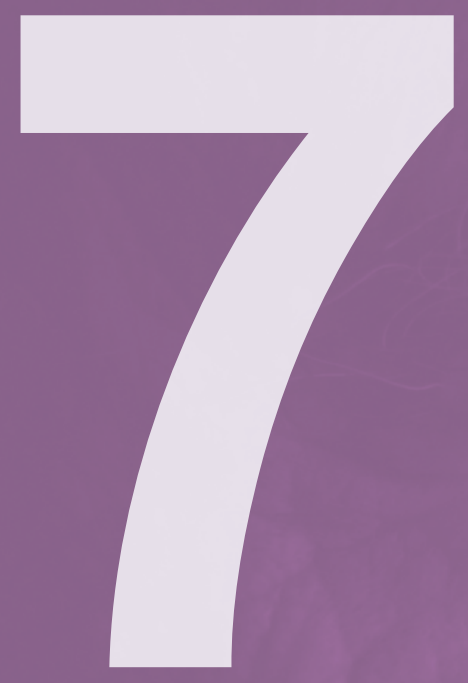

Post Diagnostic Support for People with Dementia

Eamon O'Shea and Fiona Keogh 
-1) the $\log ^{2}+2$

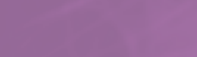
$4=$

$(x+y)$ trat

hing

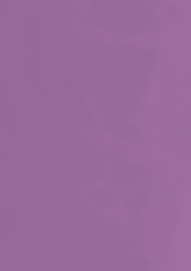

$1+1$

The

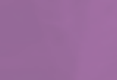

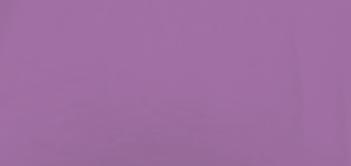
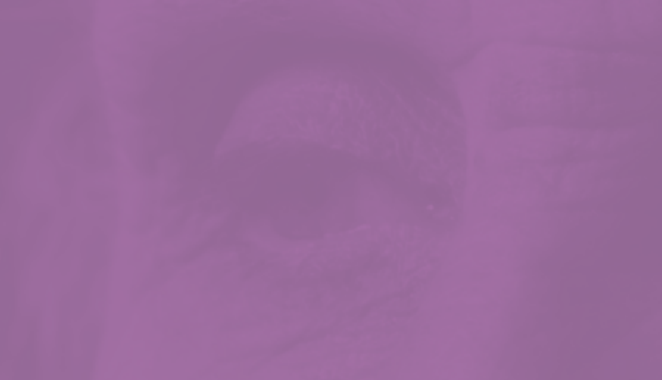

titititition

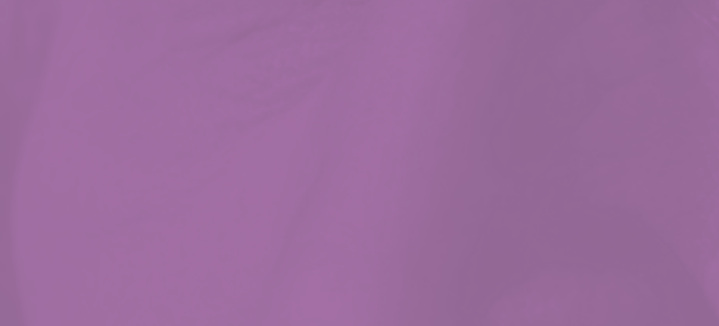

Alate

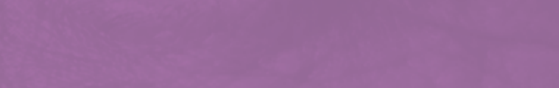

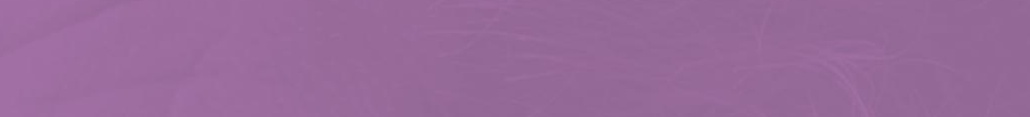

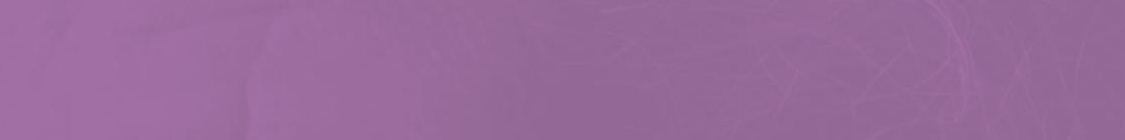
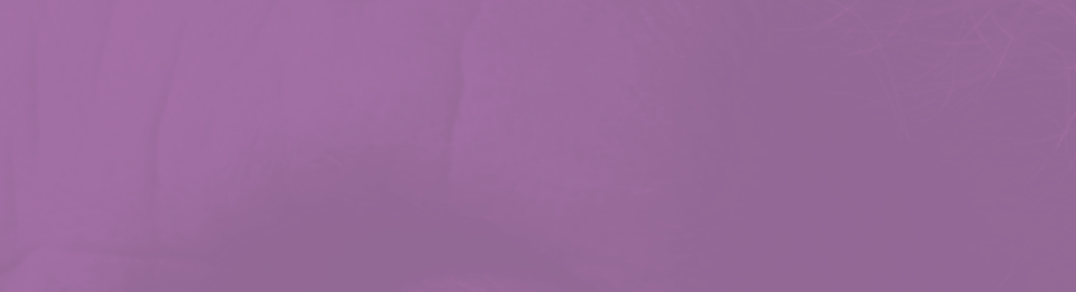

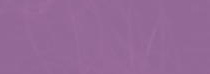

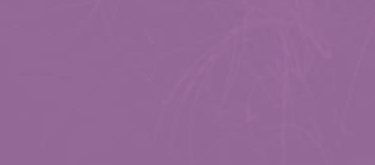

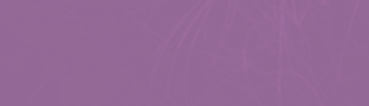

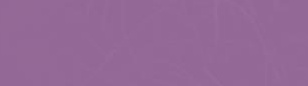

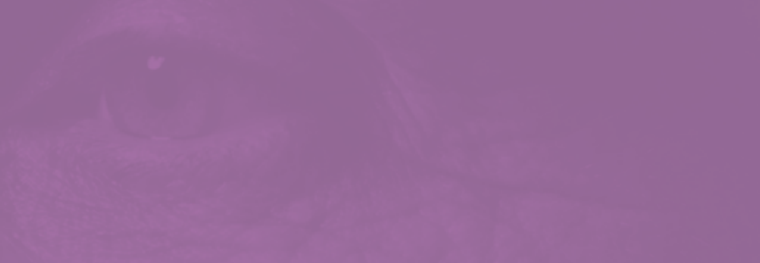

(1)

(x)

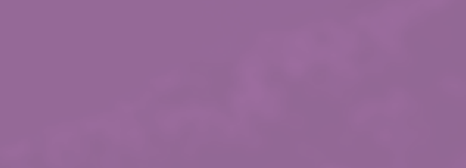

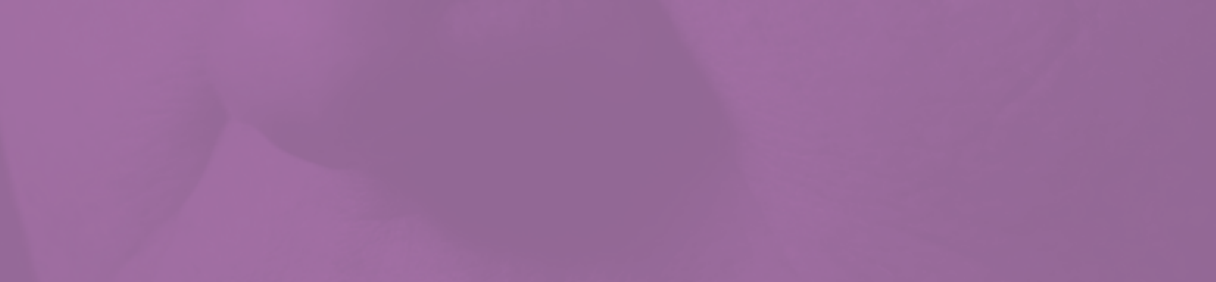

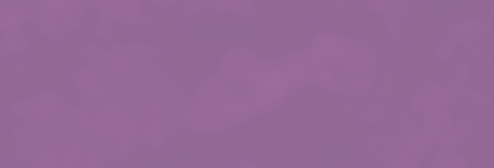

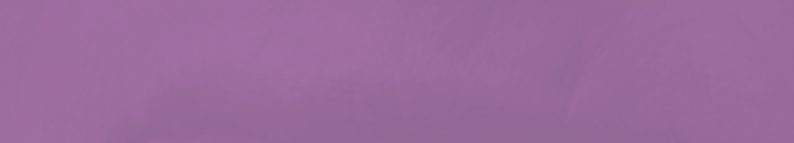

Whing

Whating

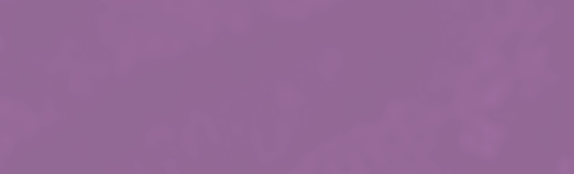

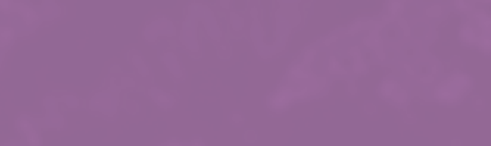

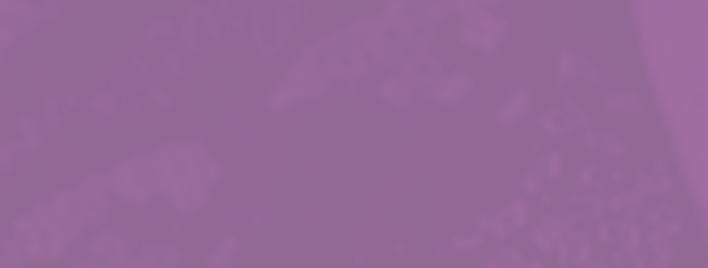

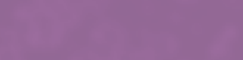

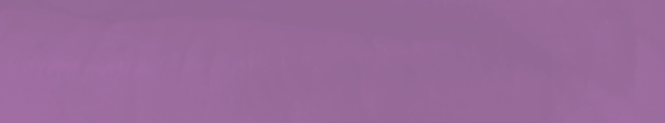

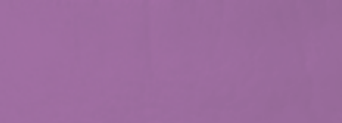

$1+1$

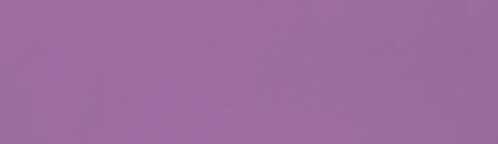

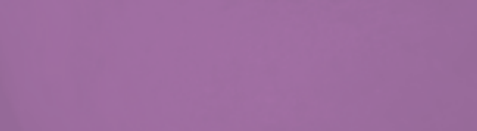

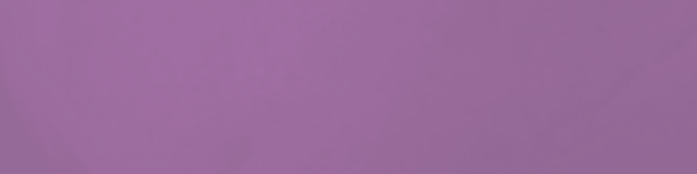

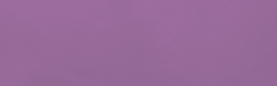




\subsection{Introduction}

Post diagnostic support (PDS) is increasingly recognised as an essential element in the care infrastructure for people with dementia and their carers. The World Alzheimer Report (ADI, 2009) and the World Health Organisation report Dementia: A Public Health Priority (WHO, 2012) directly reference post-diagnostic support in their seven-stage model for planning dementia services. Both the WHO and Alzheimer Disease International outline the importance of post-diagnostic support in enabling people with dementia and their caregivers to come to terms with the disease, plan for the future and make the best use of their current circumstances.

There is growing evidence about the value of early intervention for the well-being of people with dementia and their relatives (Jones et al., 2002; Moretti et al., 2003; Moniz-Cook and Manthorpe, 2009). Early intervention can help improve patient self-efficacy, as well as enhancing dementia symptom management and behavioural change (Dening and Thomas, 2013) and is supported by clinical guidelines (Foley and Swanwick, 2014). Early intervention in dementia has been shown to improve quality of life, and delay the need for institutionalisation (UK Dept. of Health, 2008; Banerjee et al., 2007), with early provision of support at home reported to decrease institutionalisation by 22 per cent (Gaugler et al., 2005). Similarly, carer support and counselling after diagnosis can reduce care home placement by 28 per cent (Mittelman et al., 2006). It is during the early stages that pharmacological and non-pharmacological interventions are likely to have maximum effect (Brooker et al., 2014; Milne, 2010a). PDS can lead to enhanced social contact, thereby helping to reduce isolation for people with dementia and family carers (Clare, 2002). It can also allow people to come to terms with the diagnosis. A care plan to be put into effect, thereby contributing to a better quality of life for the person with the disease (Moniz-Cook and Manthorpe, 2009). Supporting capacities such as self-efficacy and social skills is key to maintaining and enhancing personhood in dementia.

It is understandable, therefore, that the concept is enshrined, either directly or indirectly, in government thinking and policy narratives about appropriate responses to dementia both in Ireland and other jurisdictions. The Irish National Dementia Strategy incorporates post diagnostic supports in its priority actions, through its support for information and training, as well as named key workers within primary care services to co-ordinate care and provide continuity, thereby ensuring easy access to appropriate information and advice. The difficulty is, however, that there is little evidence to draw clear conclusions in regard to the usefulness of many of the PDSs that are currently available to people with dementia and their families (Kelly and Innes, 2016). While many interventions and supports come under the heading of PDS, the available evidence is stronger for some than for others. This chapter describes the main features of PDS, the challenges in creating a coherent framework for the consideration and study of PDS and the evidence for some selected PDS. 


\subsection{Post-diagnostic Support - Features and Definitions}

According to Clare (2002), post-diagnostic support should include: activities that enhance or provide social contact and peer support to reduce isolation; provide information and opportunities to overcome limitations imposed by the condition; and preserve or bolster self-worth by finding ways for people with dementia to make a contribution and to feel useful. The Social Care Institute for Excellence provides a more formal definition of PDS as follows: "to help people to continue living well in the community; provide information and support; help people to manage issues as a result of getting a diagnosis; and delay admission to longterm residential care" (SCIE, 2014 p.2). The targeting of PDS specifically at people with dementia is essential; when people with dementia feel that support is aimed at family members rather than at them, the result is often increased feelings of powerlessness and helplessness (Mountain and Craig, 2012). Post-diagnostic support should, therefore, be eclectic in its origins and ambitions, focusing on the disease, the people that have it and their carers; that means a focus on care relationships, social connectivity and the care pathway. There is a myriad of potential supports and choosing the most appropriate supports depends on the timing of the diagnosis and the stage of the disease when diagnosis occurs.

\subsection{The Importance of Diagnosis}

While there is convincing evidence of the benefits of a timely diagnosis (Woods et al., 2003; Knapp et al., 2007; lliffe et al., 2009; Banerjee and Wittenberg, 2009), dementia remains hugely undetected and underdiagnosed domestically and internationally (Cahill et al., 2012; ADI, 2011; Brooker et al., 2013). Alzheimer's Disease International (ADI) cite nine reasons for early identification and treatment, namely: (i) optimising current medical management; (ii) relief gained from better understanding of symptoms; (iii) maximising decision making autonomy; (iv) access to services; (v) risk reduction; (vi) planning for the future; (vii) improving clinical outcomes; (viii) avoiding or reducing future costs; and ix) diagnosis as a human right (ADI, 2011). Yet fewer than half of people with dementia in the UK ever receive a formal diagnosis (Banerjee and Chan, 2008; Milne, 2010b) and it is likely that the majority of the approximately 55,000 people living with dementia in Ireland do not have a diagnosis of dementia (Cahill et al., 2012). Moreover, even when diagnosis occurs, there are often significant delays from symptom onset to receiving a diagnosis. Some people may live with symptoms of dementia for months or even years, up to three years in Australia (Phillips et al., 2011) before a diagnosis is confirmed (Mountain and Craig, 2012);

While dementia is a condition that largely affects people over the age of 65 , younger people can also be diagnosed with young-onset dementia and the implications for them are very different, as are their needs. Those in middle age will frequently be in paid employment (Harris and Keady, 2004; Van Vliet et al., 2010), have different types of medium-to-long-term financial obligations (Flynn and Mulcahy, 2013; Harris and Keady, 2004), and may be involved in parenting children (Harris and Keady, 2004).

Diagnosis, therefore, does not occur at a set time for people with dementia; diagnosis may not come at all for some; for early onset dementia it can come very early in life; for the majority of people it comes later in life; and diagnosis without adequate support may be detrimental to people with dementia and families (Iliffe and Manthorpe, 2004; Manthorpe et al., 2013). People of different ages, at different stages of the disease will have different needs, some of them more immediate than others. Therefore, what might constitute a PDS for one person may not suit the needs of another. PDS works best, therefore, when it is personalised and responds to the expressed needs of the person diagnosed, depending on where the person is on the continuum of need. 


\subsection{Framework for Examining the Evidence}

It is difficult to establish a coherent framework that covers all of the potential elements of post diagnostic support for people with dementia and their carers given issues around the timing of diagnosis, comorbidities and the availability of and knowledge of existing services. Post-diagnostic support is currently focused mainly on supporting people in the early stages of the disease. For example, the NICE-SCIE Guidelines suggest that people with dementia have the right to be fully informed about care, through written information, and to make decisions in partnership with the care team (NICE-SCIE, 2007). The Guidelines suggest that people with dementia get information on: the type of dementia, symptoms and on-going development of the disease; treatments; local care services; support groups for dementia; advocacy services; and financial and legal advice. This is much easier to achieve if diagnosis occurs early in the disease.

The Scottish 5-pillar model for post-diagnostic support talks about: understanding the condition and managing symptoms; supporting community connections; peer support; planning for future care; and planning for future decision-making (Gilmour, 2011). This model is predicated on people remaining engaged and active with dementia and living well with the disease. It is based on a belief that self-management is possible with dementia provided people are immediately supported post-diagnosis. Keeping identity and the self intact following diagnosis is fundamental to this approach. To do this, people must understand the disease, remain physically and mentally well, maintain relationships, keep socially connected, build on their capabilities and have clear signposting and pathways to individualised services and supports. All of this will be more achievable if the community is made more dementia-friendly and the individual can access services, continue with their hobbies and former interests and live a regular life without feeling a sense of embarrassment or shame. Of course, there will be key transitions along the continuum of the disease, but the first stage is that people are supported to come to terms with the diagnosis and have the information, knowledge and support structures that allow them to make good early decisions that will influence future care trajectories for the better.

The diversity of care provision following diagnosis makes it impossible to compartmentalise interventions into neat and distinct categories. There is no clear agreement on the constituent elements of postdiagnostic support within the broad definitions that exist, nor on who should be the primary beneficiaries of those supports. For the purposes of this chapter, we have loosely divided post-diagnostic support into four categories:

1. Information, advice and peer support

2. Cognitive therapies

3. Psycho-educational supports for carers

4. Psychosocial supports 


\subsection{Information, Advice and Peer Support}

Consultations with people with dementia and carers have highlighted that timely, well-targeted information services are a key priority for enabling them to 'live well with dementia' (Corbett et al., 2012). Information, advice and peer support is the bulwark of post-diagnostic support for people with dementia and their carers. This was recognised in the Irish National Dementia Strategy and has led to the development of Understand Together, a comprehensive website and campaign offering easily accessible information on services, supports and a range of resources for people with dementia and the general public (National Dementia Office, 2017). What we know from the literature is that the information provided to people with dementia is often generic and of variable quality (Lauriks et al., 2007). It is often geared to the needs of carers rather than the person with dementia. Existing trials have not succeeded in identifying specificity in relation to the effectiveness of the information provided, so we do not know what type of information works best, for whom, in what circumstances. Much of the early information conveyed about dementia happens behind closed doors in a GP's surgery and it is difficult to capture data on the type of information communicated here. Moreover, the information needs of the individual and family members will vary over time. The information needs of the newly diagnosed person with dementia and family caregiver can be extensive and range from advice needed about prognosis and treatments (clinical and non-clinical), to support services (home care, peer supports and so on) to risk reduction, transport, driving, advanced care planning tools and other legal and financial supports. What is clear though is that people value individualised information, delivered as part of a complex multi-component programme for tackling dementia (Corbett et al., 2012).

There is support in the literature for the role of dementia key workers (Goeman et al., 2016), dementia coordinators (Genio, 2016) and dementia advisors and peer support networks within post diagnostic support systems, the latter drawn mainly from the Healthbridge project in the UK (Clarke et al., 2013). Independence, confidence, understanding, community awareness and social networks have all been enhanced through contact with dementia advisors and peer support programmes. Key elements of this role have been identified as: a single point of contact for a designated area providing specialised dementia advice; information and support; signposting to appropriate services; raising community awareness and understanding; and promoting and embedding a personalised approach to service delivery across primary care teams and associated services (Clarke et al., 2013; Genio, 2016).

Information networks have also been enhanced in recent years through peer support networks such as Alzheimer's cafés (Miesen and Jones, 2004). They were first developed about 20 years ago in the Netherlands. An Alzheimer's café is a regular (often monthly) post-diagnostic group intervention that provides education and information about dementia and various types of support in a relaxed social setting. People with dementia can visit a café and meet others in similar situations to themselves. By talking to people going through similar experiences, personal, relatable information and advice can be shared. Dementia cafes have been identified as having the potential to be an important part of peer support for people with dementia and their carers, providing an environment where people can come together in an informal way to receive advice, social support and signposting (Dow et al., 2011; Greenwood et al., 2017). 


\subsection{Cognitive Therapies}

CST has been shown to be effective as primary prevention for older people with good cognitive functioning and as secondary prevention for older people with mild-to-moderate dementia (Medical Advisory Secretariat, 2008). There is trials-based support for cognitive interventions for people recently diagnosed with dementia, especially people with mild to moderate dementia (Livingston et al., 2005; Olazarán et al., 2010). There is evidence of improvements in communication, cognitive scores, social interaction and quality of life for people with dementia (Woods et al., 2012; Spector and Orrell, 2010; Spector et al., 2003). Questions remain as to how long benefits last and there is always the caveat about the quality of the trials and the small sample sizes, but the results are credible. This is reflected in the inclusion of cognitive stimulation therapy (CST) in NICE guidelines for the care of people with dementia (NICE-SCIE, 2007). Orrell et al. (2014) found that cognitive functioning with maintenance CST was further enhanced when combined with early pharmacological interventions, particularly acetylcholinesterase inhibitors (AChELs). The limited cost effectiveness analysis that has been undertaken also supports CST for people with dementia (Knapp et al., 2006) and maintenance CST was found likely to be cost-effective for people with mild to moderate dementia (D’Amico et al., 2015).

Cognitive rehabilitation (CR), where ideas are drawn from cognitive and behavioural psychology, is an individual approach to improving cognitive functioning, focusing on implementing strategies to achieve personally identified everyday goals (Bahar-Fuchs et al., 2013). Kelly and O'Sullivan (2015) have recently produced a manual presenting healthcare professionals in Ireland with strategies and techniques that can be used to assist people with memory problems in optimising management of their daily lives and activities. Until recently, trials evidence on CR was limited, but early results from the GREAT trial suggest that personalised cognitive rehabilitation therapy can help people with early stage dementia significantly improve their ability to engage in important everyday activities and tasks (Clare, 2017). A trial that is underway on cognitive behavioural therapy for people with dementia and carers may provide evidence for the development of future guidelines for the psychological treatment of people with dementia and their caregivers (Forstmeier, 2011).

\subsection{Psychoeducational Interventions for Carers}

There is emerging and consistent evidence to suggest that participating in psycho-educational interventions, incorporating skills training, peer support programmes, psychological therapies and counselling, has positive effects on caregivers of people with dementia (Peacock and Forbes, 2003; Sörensen et al., 2006; Graff et al., 2006). The National Collaborating Centre for Mental Health's (2007) review of qualitative evidence suggested that psycho-educational interventions can be effective in reducing the risk of depression and bolstering coping skills amongst carers if offered early in the dementia trajectory (NICE-SCIE, 2007). The benefits of psycho-educational interventions are strongest where: the carer attends a separate group to that of their relative; support is tailored to the needs of a specific group of carers at a particular stage of caring; the intervention includes a combination of skill building, education and support; and it is easily accessible, low cost and time limited (Elvish et al., 2013; McHugh et al., 2012). While the quality of the evidence remains an issue, it is reasonable to say that practical educational supports for carers can impact on the quality of care of people with dementia and carer burden. While face-to-face interventions tend to yield the best results, telephone and web-based interventions can also provide cost-effective solutions to caregiver time constraints (Elliott et al., 2010; Nichols et al., 2011). Therefore, psycho-educational interventions which seek to reduce stress, depression and feelings of isolation among carers through the development of coping skills and resilience may be useful, as part of a comprehensive post-diagnostic support programme for people with dementia. 


\subsection{Psychosocial Interventions}

There is increasing consensus that psychosocial interventions make an essential contribution to the support of people with dementia and their carers and particularly in enhancing personhood. However, the fact that the term 'psycho-social intervention' incorporates a broad range of different service models and elements such as social activity, emotional support, and psychological therapy, makes evaluation difficult. Moreover, the timing of diagnosis and subsequent care trajectory can determine the relevance and effectiveness of any potential psychosocial support. Reminiscence is very popular as a response to dementia but the evidence with respect to its effectiveness is mixed, with some benefits shown (O'Shea et al., 2014; Chung, 2009), although a community-based joint reminiscence programmes for people with dementia and their carers was not found to be effective (Woods et al., 2016). Similarly, the evidence on cost-effectiveness in this area is not supportive of reminiscence. This is not to undermine reminiscence as part of post-diagnostic support system, simply to acknowledge that the evidence is not strong in relation to impact and effectiveness. The same could be said about life story work for people with dementia.

Music therapy is another potentially valuable therapeutic approach. Like many psychosocial interventions, music therapy groups are a social activity, which promote interaction and communication between participants. This can potentially contribute to improving social skills among participants and help to reduce the risk of isolation. Music can also tap into personhood and an individual's sense of self in relation to personal preferences. When asked about the value of music, people with dementia attest to its mental stimulating effects, emotional meaningful experience, its link to their personal identity and its ability to build and sustain relationships with others (McDermott et al., 2014). However, a recent Cochrane Review on the effects of music-based therapeutic interventions are not encouraging, with findings of little or no effect on emotional well-being and quality of life, overall behaviour problems and cognition, although there was some evidence of reduction in depressive symptoms (van der Steen et al., 2017).

Research has consistently demonstrated that exercise has the potential to improve physical health for older people in all types of settings (Hauer et al., 2012; Vreugdenhil et al., 2012; Steinberg et al., 2009). Unfortunately, the overall evidence on the impact of exercise in dementia is not compelling. The most recent Cochrane Review found some evidence that exercise programmes can improve the ability of people with dementia to perform activities of daily living, but evidence of other benefits was weak (Forbes et al., 2015).

A significant challenge in this area is that the quality of the evidence behind most of the results on many psychosocial interventions in dementia such as reminiscence therapy, music therapy and exercise, is very low. Sample sizes are small and compared with drug trials this type of research can be particularly challenging in terms of subject recruitment, obtaining consent/assent, attrition rates (if longitudinal), and the validity of research findings. There is also the further complication of identifying the main unit of analysis - is it the individual with dementia or the family caregiver? For example, an intervention that benefits the carer but has adverse effects for the individual living with dementia will be difficult to justify. It is also very difficult practically and logistically to evaluate the impact such psycho-social interventions have on people with a more advanced dementia given the severity of their cognitive impairment, including perhaps behavioural and psychological issues and associated language deficits. Systematic reviews, which only consider evidence from randomised controlled trials (RCTs), have identified few such trials, while the quality of the trials that have been done tends to be low, making it difficult to draw strong conclusions from the research. However, evidence from qualitative studies or evaluations, which do not meet the standard for systematic reviews, is often more positive, although quality of the studies is again an issue. Appropriate and robust studies can provide good evidence regardless of their design and all evidence, including practice-based experience, should be considered in making decisions about the most promising approaches in post-diagnostic supports. 


\subsection{Conclusion}

So what should post-diagnostic support for people with dementia look like in the future in Ireland? The trend towards earlier diagnosis should continue, even if the costs and benefits of this approach are still not fully settled. Information matters for people recently diagnosed with dementia, even if we are still unclear what aspects of information matter most. What is important however is that the right information needs to be given in the right way and at the right time in a supportive person-centred way and one which fosters hope (Fisk et al, 2007). Having a dedicated person to link directly with people newly diagnosed with dementia is important for continuity and the development of personalised care within an integrated system of provision. People with dementia and their carer need someone to help them navigate their way through existing services and supports. Whether that person is a dementia specialist from a clinical or social background requires further consideration, but, whatever their origins, they must have the leadership, expert knowledge and credibility to influence decision-making. The navigator should be a single point of contact for people with dementia within a specific geographical area, providing specialised dementia advice, information and support, as well as leading on the promotion of a personalised approach to service delivery across primary care teams and within the community care system.

Maintaining independence and personhood for people newly diagnosed with dementia should be the goal of the post-diagnostic support system. Keeping people connected to family, friends and social networks within local communities is really important. For that reason, education and psychosocial interventions, including peer support programmes, must become part of the care landscape to help people cope with the disease and its current and future implications. Cognitive stimulation should be central to any new post-diagnostic support system. This is one area where the evidence is clear and compelling in regard to potential benefits for people with dementia. The evidence on cognitive rehabilitation is also promising. Innovation in reminiscence, music therapy and exercise should be supported and evaluated as part of a wider strategy of developing the evidence base for the bio-psychosocial model of care in Ireland. 


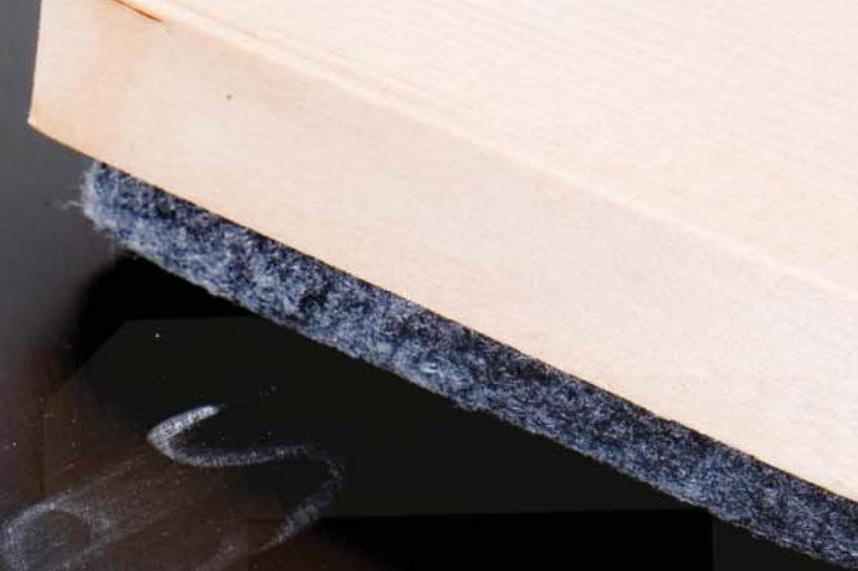




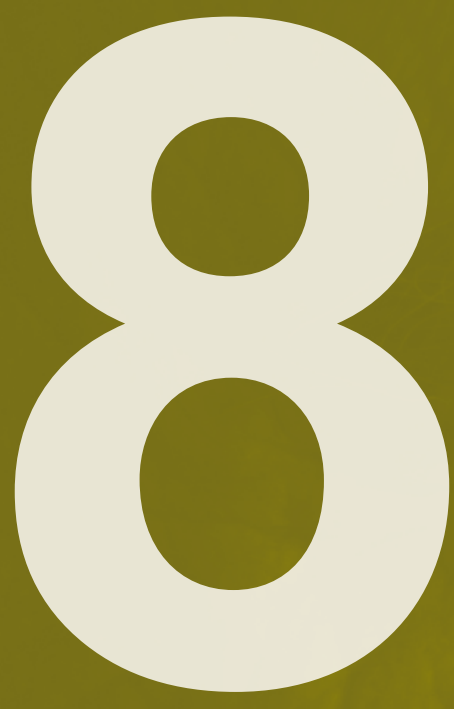

The Economics and Financing of Dementia in Ireland

Tom Pierse and Eamon O'Shea 


\subsection{Introduction}

Dementia has a huge economic impact. The estimated worldwide cost of dementia is US \$818 billion (ADI, 2015), and it will become a trillion dollar disease by 2018 (Rubinstein et al., 2015). Direct medical care costs are modest worldwide, accounting for roughly 20 per cent of global dementia costs, while direct social sector costs and informal care costs each account for roughly 40 per cent. Average total cost per incident case of dementia in the last five years of life $(\$ 287,038)$ in the USA is significantly greater than for people who die of heart disease $(\$ 175,136)$ or cancer $(\$ 173,383)$, driven mainly by out-of-pocket spending and informal care costs (Kelley et al., 2015). Putting a monetary value on informal care has a major impact on estimates of the cost of care for people with dementia. Although difficult to quantify, family care is an important and significant part of the support system for people with dementia, leading to significant opportunity costs for carers. If that component is included, the overall cost of care increases considerably.

Estimates of the overall economic cost of dementia are important benchmarks, but decision-makers charged with responsibility for resource allocation in this area are likely to be more interested in the economic evaluation of different care strategies and interventions for people with dementia. The majority of the economic evidence in dementia has been focused on pharmacological interventions aimed at alleviating behavioural, cognitive and functional symptoms. In a systematic review of evidence on dementia care costs and outcomes, Knapp et al. (2013) identified 56 literature reviews and 29 single studies offering evidence in dementia care, mostly focused on pharmacological therapies. Not only were the total number of available studies small, especially for non-pharmacological interventions, but the studies were of low methodological quality, particularly in relation to the assessment of costs and outcomes. That means that many of the major questions in relation to resource allocation in dementia remain unanswered, both internationally and in Ireland. In this chapter we bring together the economic evidence in relation to dementia care in Ireland, especially in relation to home care provision, pointing to the need for more information on costs and outcomes to support practice and policy for people with dementia in the country. Financing long-term care at home and in residential care is also important for people with dementia and we also address this issue in the chapter. 


\subsection{The Societal Impact of Dementia}

There are so many demands on the public purse for attention and financial coverage that it is difficult to know what services and supports should be prioritised for what categories of illness. One simple approach to assessing the relative impact of diseases is to aggregate the direct and indirect costs of the disease to generate a cost of illness study. These costs include primary and secondary medical care costs, the cost of providing formal and informal care and lost productivity costs associated with the illness and its treatment. This process allows different diseases to be compared in terms of the scale of the societal impact and also allows comparison in terms of the kind of costs that each disease group generates.

Cost of illness studies do not address economic efficiency or provide guidance to policy-makers on what interventions should be funded. What they do is provide magnitude effects in relation to various diseases, including where the burden of disease mainly falls. For example, dementia was found to have the lowest healthcare costs in the UK of $£ 1.4$ billion, compared with $£ 4.4$ billion for cancer, $£ 2.4$ billion for coronary heart disease (CHD) and $£ 1.8$ billion for stroke (Luengo-Fernandez et al., 2015). However, the costs placed by dementia on the social care system ( $£ 10.2$ billion) outweigh the social care costs of cancer, CHD and stroke combined. The combined costs of dementia to the UK health and social services was estimated to be $£ 11.6$ billion, compared with $£ 5.0$ billion for cancer, $£ 2.9$ billion for stroke and $£ 2.5$ billion for CHD.

The cost of dementia in Ireland has been estimated at $€ 1.69$ billion per annum, 48 per cent of which is attributable to informal care provided by family and friends to those living with dementia in the community (Connolly et al., 2014). A further 43 per cent is accounted for by residential long-stay care, while formal health and social care services only contribute 9 per cent to the total costs of dementia. These figures show that dementia is one of the major disease groups in terms of the intensity with which it affects family carers rather than formal provision in the health system. In comparison to other disease groups, the cost of dementia falls primarily on family carers. Informal care costs worldwide comprise 48 per cent of the cost of dementia compared to 10 per cent of cancer care costs (Luengo-Fernandez et al., 2012). This is due to the long hours of care needed by people with dementia and the low expenditures on treatments and therapies relative to cancer. In Ireland, it also reflects the paucity of provision for dementia, particularly within primary care and community-based care.

While spending on formal services for dementia in Ireland is relatively low, there is growing recognition of the impact of dementia on the acute care sector (Cowdell, 2010; Nolan, 2006). People in the same age group with a diagnosis of dementia tend to have a significantly longer length of stay in hospital than those without dementia. Applying European prevalence data for dementia to patients in the acute care sector in Ireland, suggest that the estimated additional cost of extended length of stay associated with dementia is almost $€ 200$ million per annum (Connolly and O'Shea, 2015). Adding this estimate to the most recent cost of illness figure for Ireland suggests an overall monetary burden of just under $€ 2$ billion for dementia in the country, based on 2010 data. This shows the importance of dementia in the budgetary process. The overall average cost per person with dementia in Ireland is estimated at $€ 35,000$, which is consistent with upper-bound per capita estimates in other industrial countries. In 2015, the mean cost per person with dementia was US $\$ 43,680$ in G7 countries, US $\$ 20,187$ in G20 countries, and US $\$ 6,757$ in countries that were members of neither G7 nor G20 (Wimo et al., 2017).

\subsection{Spending on Dementia Care}

The cost of dementia is important, but so too is overall government public expenditure on dementia. However, it is very difficult to estimate public expenditure on dementia care in Ireland due to the paucity of data in this area. We do not routinely collect aggregate data on government expenditure on dementia in Ireland, although we do have figures on overall public expenditure on dependent older people, many of whom have dementia. Figure 8.1 shows spending on long term care across OECD countries (OECD, 2017). In Ireland, we spend 1.8 per cent of GDP (2.2 per cent of GNI*) on long term care, which is above the OECD average of 1.4 per cent. 
Figure 8.1. Long term care spending as a percentage of GDP 2014.

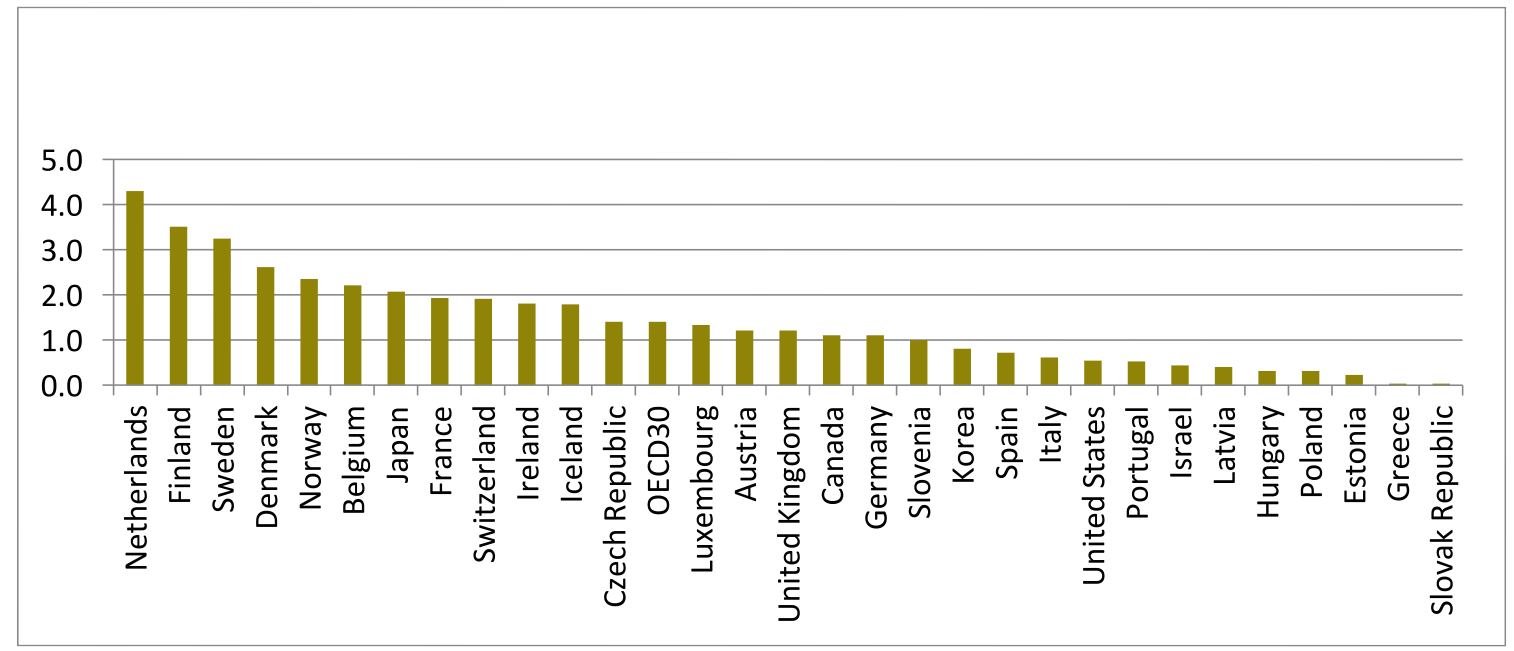

The locus of responsibility for the care of older people is a key indicator in relation to levels of public spending on long term care across countries. Surveys of European citizens show large differences in public preferences in relation to responsibility for long-term care across countries (Eurobarometer, 2007). Citizens in Nordic countries tend to favour the state as the main provider of care, while people in Southern European countries believe that care is largely a family matter. There is limited data on public preferences for spending on long term care in Ireland. Recently, the Citizens Assembly in Ireland (2017) considered this issue and 60 per cent of the Members voted that it is the family/older person who should be primarily responsible for providing required care for older people, but the State should have at least some responsibility (Citizens Assembly, 2017). One third of voters believed that the state should bear the primary responsibility for care, with the family/older person having at least some responsibility. Interestingly, given Ireland's relatively favourable position on the OECD continuum of spending and the majority view that families should have primary responsibility for care, 87 per cent of Assembly members still recommended an increase in public resources allocated for the care of older people, particularly in relation to home care services.

The latter vote is perhaps not surprising, given that spending on services and supports for older people in Ireland declined sharply on a per capita basis during the recession years. This decline was driven by a combination of cuts to nominal budgets arising from public expenditure constraints and annual increases in the number of older people, particularly in the last few years. Table 8.1 shows a 25 per cent decline in per capita spending from 2009 to 2017 (Dept. of Health, 2015; HSE, 2017a). While this decline relates to the overall population of older people, it does indicate that spending fell by about $€ 1,000$ per older person in the country over an eight year period.

Table 8.1: Spending on Services for Older People 2009 to 2017

\begin{tabular}{|l|c|c|c|c|c|c|c|c|c|}
\hline & $\mathbf{2 0 0 9}$ & $\mathbf{2 0 1 0}$ & $\mathbf{2 0 1 1}$ & $\mathbf{2 0 1 2}$ & $\mathbf{2 0 1 3}$ & $\mathbf{2 0 1 4}$ & $\mathbf{2 0 1 5}$ & $\mathbf{2 0 1 6}$ & $\mathbf{2 0 1 7}$ (est) \\
\hline Older People's Services $€ m$ & 1,739 & 1,684 & 1,433 & 1,366 & $\mathbf{1}, 366$ & $\mathbf{1 , 4 6 8}$ & $\mathbf{1 , 5 6 9}$ & $\mathbf{1 , 6 7 9}$ & 1,705 \\
\hline Per Capita over 65 $€$ & 3,514 & 3,299 & 2,720 & 2,509 & 2,429 & 2,528 & 2,612 & 2,688 & 2,648 \\
\hline
\end{tabular}

Public expenditure on older people is spread across a number of budget areas in the HSE and the Department of Social Protection - the latter through the Carer's Allowance, Carer's Benefit and the Carer Support Grant - making it difficult to estimate patterns of expenditure with any great precision. Within the HSE, spending on dependent older people falls mainly into the social care division; with additional services provided by the primary care, mental health and acute care divisions. The vast majority of services provided 
Table 8.2. Public Spending on Dementia Related Services (2016)

\begin{tabular}{|c|c|c|c|c|}
\hline Budget & & $\begin{array}{l}\text { Dementia } \\
\text { Related }\end{array}$ & $\begin{array}{l}\text { Total } \\
\text { Expenditure } € m\end{array}$ & $\begin{array}{l}\text { Dementia Related } \\
\text { Expenditure } € m\end{array}$ \\
\hline \multirow[t]{6}{*}{ HSE Social Care } & Nursing Home Support Scheme & $72 \%(1)$ & $€ 940$ & $€ 677$ \\
\hline & Home Care Schemes & $22 \%(2)$ & $€ 301$ & $€ 66$ \\
\hline & Intensive Home Care Packages & $33 \%(3)$ & $€ 6$ & $€ 2$ \\
\hline & ASI Home Care & $100 \%(4)$ & $€ 4$ & $€ 4$ \\
\hline & Dementia Day Care & $100 \%(4)$ & $€ 11$ & $€ 11$ \\
\hline & Short Stay Beds & $6 \%(5)$ & $€ 181$ & $€ 11$ \\
\hline \multirow[t]{2}{*}{$\begin{array}{l}\text { HSE Mental } \\
\text { Health }\end{array}$} & $\begin{array}{l}\text { Psychiatry of Old Age Community } \\
\text { Mental Health Teams }\end{array}$ & $35 \%(6)$ & $€ 25$ & $€ 9$ \\
\hline & $\begin{array}{l}\text { In-patient beds and community } \\
\text { residences }\end{array}$ & $12 \%(7)$ & & $€ 40$ \\
\hline \multirow[t]{3}{*}{ HSE Primary Care } & Primary Care (ex GP and Drugs) & $7 \%(8)$ & $€ 764$ & $€ 53$ \\
\hline & GP & $2.3 \%(9)$ & $€ 528$ & $€ 12$ \\
\hline & Drugs (AChE and Memantine) & $(10)$ & & $€ 12$ \\
\hline \multirow[t]{2}{*}{$\begin{array}{l}\text { HSE Health and } \\
\text { Well Being }\end{array}$} & Public Awareness Campaign & $100 \%(11)$ & $€ 2.7$ & $€ 2.7$ \\
\hline & GP Training & $(11)$ & $€ 1.2$ & $€ 1.2$ \\
\hline Acute Hospitals & All & $9 \%(12)$ & $€ 4,243$ & $€ 371$ \\
\hline $\begin{array}{l}\text { Dept. of Social } \\
\text { Protection }\end{array}$ & Carer supports (allowance etc.) & $22 \%(13)$ & $€ 500$ & $€ 110$ \\
\hline Total & & & & $€ 1,383$ \\
\hline
\end{tabular}

\section{Notes}

1. Nursing home prevalence rate based on CFAS II (Matthews et al., 2016); NHSS expenditure sourced from operational plans (HSE, 2017b).

2. Funding for $\mathrm{HH}$ and HCP based on HSE (2016c). Proportion of Carers Allowance recipients caring for person with dementia used as a proxy for dementia home care cost (Lafferty et al., 2014).

3. 142 people with dementia were in receipt of a Dementia-Intensive-HCP in 2016, at a cost of approximately €4 million (Genio, personal correspondence). Intensive HCP total funding sourced from HSE (2016c). Dementia-IHCPs are 50\% co-funded by Atlantic Philanthropies.

4. 61 per cent of ASI hours go on day care and 20 per cent on home care (Alzheimer Society of Ireland, 2015).

5. 6.2 per cent of short stay beds occupied by people with mental disorders (we assume all are dementia-related) (Long-Stay Activity Statistics 2013). Expenditure on short stay beds sourced from HSE (2016c).

6. 3 per cent of staff (303) of Mental Health Division work in the Psychiatry of old age mental health teams and, based on UK figures, 34.5 per cent of their time is allocated to dementia (Tucker et al., 2015; HSE, 2016a).

7. Based on 12 per cent of 2,278 inpatients charged at $€ 339$ per night; organic brain diseases in community residences: 2.6 per cent of $€ 228$ million (Daly and Craig, 2016; Cahill et al., 2012; Dept. of Health, 2011; 2006; HRB, 2006).

8. 43 per cent of PHN time was spent on older people (Begley, 2004), a more recent study of community nurse's in Dublin found that 16.4 per cent of older people who were referred to the service had a cognitive impairment (Ballard et al., 2013). This estimate assumes utilisation is the same as public health nursing in other parts of primary care. Primary care expenditure sourced from primary care plans (HSE, 2016b).

9. Based on a utilisation of 4.4 times per year in TILDA and the same utilisation rate as for non-dementia people of the same age (McNamara, 2013). Cost based on 55,000 people with dementia (Pierce, 2014) and a $€ 50$ session cost (Cahill, 2012).

10. Drug usage rates based on a UK study (Barnes et al., 2012). Average drug cost used from NMIC (2011).

11. Dail reports $(11 / 9 / 17)$

12. Calculated based on Connolly et al. (2014).

13. $€ 1.0$ billion was spent on carers allowance and other carers schemes (DPS, 2017). 50 per cent of carers allowance paid for care for older people and 22 per cent with a diagnosis of dementia (Lafferty et al., 2014). 
for older people in the HSE are not dementia specific, but are heavily used by people with dementia. Table 8.2 presents an outline of the main spending areas and our provisional estimates of the proportion of that expenditure accounted for by people with dementia. Overall expenditure based on our calculations suggest a public expenditure spend of just under $€ 1.4$ billion on dementia in Ireland in 2016, half of which relates to spending on the Nursing Homes Support Scheme (NHSS) (commonly referred to as the Fair Deal scheme) for residential nursing home care. The other two big spending items are acute care and the Carer's Allowance. Twenty-five per cent of older people admitted to six acute hospitals in Ireland were shown to have dementia, most of whom were undiagnosed (Timmons et al., 2015). Moreover, a study in Tallaght hospital found that the average length of stay was 31.0 days in the dementia group and 14.1 days in those over 65 years without dementia (Briggs et al., 2015).

\subsection{Home Care Provision}

One of the enduring criticisms of government policy for dependent older people in Ireland is the imbalance in public spending between residential care and community-based care. Currently, the government is spending more than twice as much on residential care than on community-based care for people with dementia. Historically, even when public resources were relatively plentiful, investment in community-based care was relatively poor (O'Shea and Carney, 2016). When budgets are curtailed, as happened in recent times, there is limited scope as to where these cuts can fall, due to two major constraints: the need to continue providing services that are mandated or have a legislative basis (as you can be brought to account if they are not provided); and the high level of fixed pay costs in the system. The only statutory scheme we have in place at present to care for older people is the Nursing Home Support Scheme (NHSS), so there is an element of protection in the residential care sector compared to home care provision, where there is no statutory protection. Fixed staff costs also affects decision-making in relation to cuts. Pay costs are significant; given the labour intensive nature of care provision, making it difficult to effect savings in this area should they be required. These constraints mean that if cuts are necessary, they tend to fall on what is termed 'discretionary' spending e.g. services which do not have a legislative underpinning. This is why home care is often one of the first budgets to get cut in times of adversity, even though most people realise that this is counter-productive in the long-term.

Community care service provision is based on a budget constrained, supply-driven model, partly due to the absence of a legal basis for many services, with provision determined more by the needs of the provider than the needs of the older person. The paradox is that the more successful the NHSS is in funding highly dependent older people, the more important it is that community care services are expanded to meet the needs of those who remain living in their own homes. The most important part of the care jigsaw, therefore, is investment in community care, which has always been residual to residential care in Ireland. It is no surprise, therefore, that the Government are now finally taking steps to develop a statutory response to deficiencies in this area, through a new Home Care funding scheme similar to the NHSS. One of the resounding weaknesses of home care provision in Ireland compared with those developed and delivered in other countries (such as the UK, Norway, Sweden, Denmark, France and Australia) is that services for people living at home are not underpinned by legislation. However, moving from the current fragmented system of community-based care to a rights-based model will take time and will be expensive to achieve. There is significant un-met need in the community that will draw heavily on the Exchequer following the implementation of a rights-based approach.

In Ireland, the Home Help service is a very important community-based support system for dependent older people living at home. Home Help services traditionally consisted of domestic assistance, such as help with cleaning, cooking and personal hygiene. However, since 2012, there has been more emphasis on assisting with personal care services (bathing, dressing, etc.). In 2016, the Health Service Executive (HSE) provided just over 10 million home help hours to 47,000 older people. The average number of home help hours is around 4 hours per week, excluding home care package hours. In comparison, Sweden, which operates a rights based system with a similar coverage rate, provides an average of 7 hours per week (NOSOSCO, 2014; Szebehely 
and Trydegård, 2012). The demand for public home care services will increase significantly in the future in Ireland (Wren et al., 2017), with or without a rights-based model of care, given the expected changes in demography in the country.

Of course, community-based care involves much more than just the provision of home help hours. Therefore, any improvements to the system should be more than simply providing an increase in hours in this area, important and all as that might be. There is a growing realisation of the importance of providing a rich and varied menu of home care options in response to individualised care needs (see Chapter 5). One of the difficulties in deciding on what should be funded in relation to community-based care, outside of the traditional services, is the absence of economic evaluation on alternative interventions for people with dementia. While a wide range of psychosocial interventions have been recommended for usage across Europe (Vasse et al., 2012), there is still only limited information on the cost effectiveness of these interventions.

Although the availability of studies on the effectiveness and cost effectiveness of psychosocial interventions is growing, the number of studies for each of the intervention types is still small (Knapp et al., 2013). Psychosocial interventions have been shown to be cost effective in reducing agitation among people with dementia using conventional cost per QALY metrics in care home residents, however, there is little evidence from other settings and other outcomes (Livingston et al., 2014). Cognitive stimulation therapy, tailored activity programmes and occupational therapy have been found to be more cost-effective than usual care for people with dementia (see Chapter 7). There is also some evidence to suggest that respite care in day settings and psychosocial interventions for carers can be cost-effective. Coordinated care management and personal budgets held by carers have also demonstrated cost-effectiveness in a limited number of studies (Knapp et al., 2013). Part of the reason for the lack of evidence is that any assessment of the effectiveness of psychosocial interventions for people with dementia is more problematic than for drug trials (Vernooij-Dassen and Moniz-Cook, 2014).

Recent innovations in community care in Ireland have focused on the introduction of designated home care packages (HCPs) for older people living at home. The latter are additional support measures over and above existing community based services and are designed to maintain an older person at home through home supports and rehabilitation services. They are targeted towards people on the margin of residential long-stay care or who need additional supports following discharge from an acute care bed. The most recent data suggests that 16,450 people benefited from a home care package during 2016 . The average weekly hours for HCPs are 6.5 hours at a cost of $€ 165$ per week.

An additional 142 people with dementia were in receipt of an intensive home care package in 2016. These were provided by the HSE and funded jointly by the HSE and The Atlantic Philanthropies under the National Dementia Strategy. These IHCPs are designed to support people with dementia with significant levels of needs to be discharged home from hospital or for those at home to remain living at home for longer. At the individual level, the intention was that the content and delivery of IHCPs would not just provide more support, but would provide a wider range of supports and be qualitatively different from usual home supports, building on the work of the Genio \& HSE Dementia Programme, which has been developing and testing personalised community-based supports for people with dementia (Genio, 2015). IHCPs are expensive; the 'marginal' costs, i.e. the costs of home care worker hours, are equal to or above the cost of residential care for about one-third of packages, and can require significant co-ordination and integration of care from a variety of sources. The economic evaluation of these packages is only beginning now in Ireland.

\subsection{Economics and the Boundary of Care in Dementia}

Many people with dementia will move into a nursing home at some stage (Sury et al., 2013). This an important transition point for people with dementia and family carers, and currently results in a large increase in the cost of formal care provided by the HSE. The 'Balance of Care' (BoC) approach can be used to identify the types of people with dementia who could equally be cared for at home or in a nursing home ( $O$ 'Shea and Monaghan, 2017; Tucker et al., 2016b; Challis et al., 2014). A large UK BoC study found that up to half of new care home entrants could be cared for in alternative settings (Challis et al., 2014). For each of these case-types, nursing home care could be delayed by 3-12 months with sufficient community supports. Similarly, O'Shea and 
Monaghan (2016) highlighted the potential of enhanced individualised supports for keeping people with dementia living in their own homes for longer in Ireland. The evidence on the impact of high quality community care on hospitalisations and the length of stay in hospital is also strong (Johri et al., 2003; Eklund and Wilhelmson, 2009). The key issue, therefore, is the adequacy of the community-based resources available to support dependent older people on the boundary of different care settings. The evidence base on the extent to which aggregate transition rates into nursing homes can be reduced significantly in the absence of sufficient community-based scale is not compelling, in contrast to when additional resources are provided (Spijker et al., 2008; Toot et al., 2017; Rothera et al., 2008).

The types of cases that have been identified as more suitable for community-based care rather than nursing home care, not surprisingly, are those that are less complex (Challis et al., 2014; Tucker et al., 2016a). Case types that are more likely to be viable for home care are those without a combination of high levels of physical dependency, cognitive impairment or challenging behaviours (Challis et al., 2014). All of the case types identified as being suitable for home care by Tucker et al. (2016a) had low levels of challenging behaviour. Women and younger people are also more likely to be viewed as suitable for home care (Challis et al., 2014). In practice, however, it may be difficult to target community supports at people who will be most affected by them. Incentives and various stimuli may be needed to change the behaviour of the providers in relation to home care provision. Care in the community tends to be generic rather than individualised and that needs to change to allow more people on the boundary of care to be looked after at home.

The cost of caring for people with dementia increases steadily as the condition progresses. Both informal and formal care costs have been observed to increase as the condition progresses (Gillespie et al., 2013). Decreases in cognition and functional status, and increases in behavioural symptoms are all correlated with increased care costs (Schaller et al., 2015). These costs are typically absorbed by family carers of people with dementia living at home. Higher levels of dependency are associated with higher levels of family care. The formal cost of providing community care for the case types identified in published balance of care studies ranges from parity to half the cost of nursing home care ( $O$ 'Shea and Monaghan, 2017; Tucker et al., 2016b; Challis et al., 2014). However, if informal care costs are included in the monetary calculations, community care can be much more expensive than residential care for people with dementia ( $\mathrm{O}$ 'Shea and Monaghan, 2017).

So what can be deduced from balance of care studies that can help policy-makers make better decisions about resource allocation in dementia care in Ireland? Currently, standard formal community-based care is cheaper than residential care for people with dementia in Ireland, but that is because supports are not individualised, nor are they properly scaled to keep people living at home who might otherwise be in residential care or acute care. When intensive home care packages are provided to people with dementia, the cost of community care rises accordingly. The cost of intensive home care packages can equal or exceed the cost of residential care placement for some people. When a monetary value is put on family care, the cost of community-based care will certainly exceed that of residential care, although it is still likely to be well below alternative acute care costs. At some stage, keeping people living in their own homes will no longer be cost-effective vis-à-vis residential care, unless the outcomes significantly exceed those associated with residential care. It is impossible to say at what level that happens, it is different for every person, mainly because we are at the very early stages of exploring the continuum of care in Ireland. But it is certain that budgets for home care can be expanded significantly before we reach the point of saturation in relation to community-based provision for the majority of people with dementia.

\subsection{Funding Long-Term Care}

Ireland has a well-established funding system for residential care in the country. The so-called Fair Deal scheme (NHSS) was introduced in October 2009, after a protracted gestation period, to address care and funding issues in residential care in the country. Cost sharing plays a significant role in the NHSS funding system for residential care. This is not surprising given the long-term budgetary implications of universal provision for long-stay care. For those who choose to avail of the Scheme, there is significant assessment of care needs and economic means as part of the qualification process. Under the NHSS, older people in 
residential care pay up to 80 per cent of their disposable income towards the cost of their care. They also pay up to 22.5 per cent of the value of their home, if their assets are over a certain limit, for the first three years of their care - a 7.5 per cent annual contribution. The payment can be deferred and collected posthumously. A recent review of the NHSS found that increased public funding will be necessary to sustain the system, even with significant co-payments. There is also recent survey evidence which indicates public support in Ireland for a co-responsibility approach to funding whereby individuals and the State combine to jointly finance long-term care (Amárach Research, 2016).

While there may be some scope for increased funding for long term care though co-payments for community care, the bulk of funding will still need to come from the State. Funding for long term care has historically come from general taxation. However, funding long-term care from this source has not delivered the funds necessary to support an optimal community-based response for dependent older people. General taxation has many advantages in that it is democratically accountable, universal, yields large amounts of money and it tends to be progressive, which means that the rich pay proportionately more than the less well off in society. But dependent older people seem to continually lose out in the allocation of scarce public resources collected through general taxation, particularly when it comes to funding communitybased care. And even when resources do trickle down to dependent older people, automatic entitlement is unusual and cost sharing is the rule rather than the exception. Co-payment is, however, not confined to Ireland and is a feature of general taxation systems all over the world.

An alternative option for funding the care needs of people with dementia is long-term care social insurance. Under a social insurance system, individuals would pay into a fund over the life cycle, in return for automatic entitlement should they need benefits at some time in the future. The Government can pay the premiums of those not in the labour market and inability to pay would not deny access to any new national scheme. A designated social insurance fund would allow for a more protected, community-based funding model than currently exists. It would also encourage transparency in priority-setting and service delivery. It would likely be more consumer oriented and consumer responsive than a general taxation system. Social insurance organised through the labour market would, however, draw from a smaller contributory pool than the general taxation system. Germany is an example of a select number of countries that fund long-term care through social insurance.

Back in 2002, when this was last examined in detail for Ireland, Mercer favoured a social insurance approach to funding long-stay care in this country arguing that a new social scheme would generate additional resources and would establish a clear link between contribution and benefit (Brown, 2016). Their calculations suggested a one percentage point increase in both employer and employee PRSI contributions would, for example, yield approximately $€ 725$ million, not an inconsiderable amount, then or now. The key advantages of introducing a long-term care social insurance contribution noted by Mercer were: the ability of social insurance to support a standardised needs assessment; the creation of a bias in favour of home care; the separation of financing and service delivery; the end to the welfare stigma associated with means tests; and the provision of long-term stability to the financing regime. Cost would obviously be an issue and they acknowledged that there could be potential adverse effects on overall economic competitiveness from raising PRSI rates.

The inter-departmental Report of the Long-term Care Working Group (Dept. of Health and Children, 2006) subsequently shied away from a social insurance model for Ireland, concluding that a co-payment scheme by nursing home residents based on ability to pay, the so-called Fair Deal system, taking both income and assets into account, was the optimal approach to funding residential care. The question of whether social insurance is now an option to support an enhanced statutory-based home care system for older people in this country, or more broadly could be used to support both home care and residential care, remains an interesting and important policy question for Ireland. The cost of any new and enhanced system is a problem, but if we want to develop high quality services and supports for older people we must find new sources of funding. General taxation has not succeeded in generating sufficient resources for home care, where demand continues to exceed supply. The problem will get worse as population ageing increases. The decision on an appropriate funding model for long-term care in Ireland is the most important policy question for older people if we really want to change the care system. 


\subsection{Conclusion}

There are two high level resource allocation questions arising from this chapter. First, with a wide range of competing resource pressures, is there a desire among the general public, politicians and policy-makers to put more resources into dementia care? If there is, where should the funding come from: increased taxation, internal transfers within the health care budget, a redistribution of resources within existing care budgets for older people, or a new social insurance funding model? Future research needs to establish the public's preferences for spending on social and health related programs for people with dementia taking account of the opportunity costs involved. What we do know at the moment is that family carers are the main providers of care in the community. The imminent increase in the number people with dementia will test the capacity and resolve of a potentially declining pool of family carers in the future and put increasing pressure on the government to allocate more resources to this area.

The second resource allocation question relates to priority-setting for people with dementia and their carers, namely how should dementia-specific resources be allocated in a cost-effective way. Diagnosis, post diagnosis supports, home care and psychosocial interventions are all under resourced in Ireland. We know that each of these services are beneficial, but we do not yet have a common decision-making framework that can be used to compare and prioritise expenditure for people with dementia. Balance of care studies are supportive of enhanced community-based investment for people on the margins between home and residential care, but good quality care will not come cheaply and could equal or surpass residential care costs. So far, economic evaluation has been under-utilised in dementia care, but it can provide some of the answers needed to support better decision-making in relation to the allocation of scarce resources for people with dementia. 


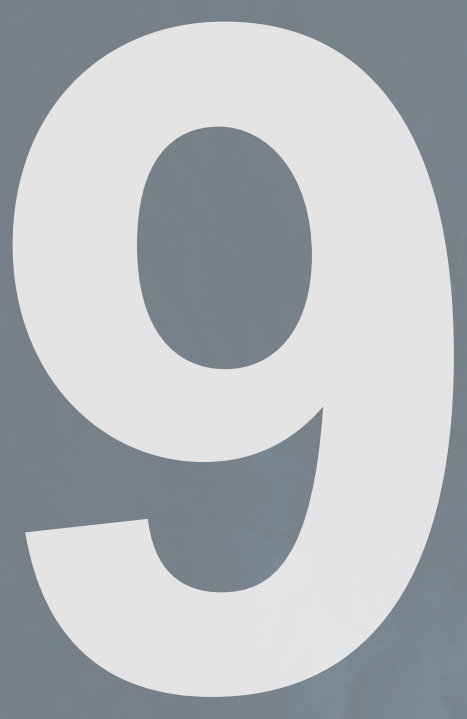

Dementia: an International Priority

Glenn Rees ${ }^{1}$ 

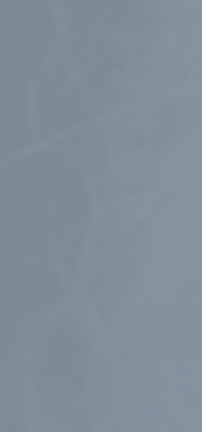

(8)

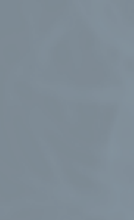




\subsection{Introduction}

Globally, about 47 million people are living with dementia, and this number is projected to triple by 2050. There is an increased understanding at the global level of the impact that this condition has both on the individual and their families and of the wider societal impact of dementia on health and social care. The 2015 global cost of dementia was estimated to be US\$818 billion, and this figure will continue to increase as the number of people with dementia rises (ADI, 2015). Nearly 85 per cent of costs are related to family carer and social costs, rather than medical care.

The response to this challenge at the international level is captured in the comprehensive Global Action Plan on the Public Health Response to Dementia (GDAP) which was adopted by the World Health Assembly in May 2017 (WHO, 2016b). For even the optimistic advocates this was barely a dream in 2000. This outcome is the result of the active commitment of governments, organisations, people with dementia, and family carers.

It was the equally dramatic initiatives taken by countries like France and Australia in the early years of this century that demonstrated the importance of national action through dementia plans and the commitment of resources to tackle dementia. Ireland has been among those countries that have subsequently made commitments to dementia through the Irish National Dementia Strategy. The evolving international consensus on dementia, as evidenced by national dementia plans and the work of the WHO, G7 and the Organisation Economic Cooperation and Development (OECD), has helped attract priority for dementia alongside other major chronic diseases in competing for scarce resources.

The platform for change internationally has been built on 10 years of advocacy by Alzheimer's Disease International (ADI), the international federation of 90 Alzheimer's associations around the world. The sea change in global action in the 12 months to May 2017 reflects the strong partnerships between ADI, Alzheimer's Europe, and Dementia Alliance International, the global body of people with dementia and governments and the exceptional work of the WHO.

The World Dementia Council (WDC) was created in February 2014, following the G8 Dementia Summit in London in December 2013 and it too has contributed to raising awareness of dementia as a priority for governments and society. The Summit resulted in an international commitment to accelerate progress towards effective treatments and cures. Central to this was an ambition to identify a cure or a diseasemodifying medicine for dementia by 2025 and a commitment to appoint a World Dementia Envoy to help achieve this goal (World Dementia Council, 2017).

This Chapter will explore dementia as a public health priority, the mobilizing of governments to act, key alliances that are making a difference at the international level and the task of moving from principles to action in relation to dementia care. We begin, however, with a brief discussion on prevention and risk reduction in dementia. 


\subsection{Dementia Risk Reduction}

The evidence that people may be able to reduce their risk of dementia has contributed to increased awareness of lifestyle as both a risk factor and a protective factor for dementia i.e. making a positive approach possible in relation to the prevention of dementia. Cognitive function in later life is influenced by physical and mental health from early in life, so every life stage matters. Although more research is needed there is enough evidence to support the potential of preventive strategies throughout life to enhance brain health and reduce the risk of dementia in later life.

It has been important to make the argument that the risk factors for dementia are the same as for other noncommunicable diseases such as cardiovascular diseases, cancers, chronic respiratory diseases and diabetes. Public awareness programs such as 'Your Brain Matters in Australia' (Your Brain Matters, 2015) have demonstrated how it is possible to inform the public that they may be able to reduce the risk of cognitive decline and dementia by being physically, socially and mentally active and by adopting balanced and healthy diets and by stopping smoking.

There is some evidence of a downward trend in dementia incidence in some countries in recent years (Wu et al., 2016). It is too early to draw firm conclusions about these trends but it is becoming increasingly clear that health factors in early life matter for dementia and primary prevention can have a major influence on the risk of dementia in later life. Governments who have not done so should consider including dementia risk reduction/management in public health policies and campaigns and their non-communicable disease strategies and invest in further research to build the evidence base on dementia risk reduction.

In 2017 the Lancet Commission on dementia prevention, intervention and care published an authoritative report that highlights new and existing risk factors for the development of dementia. The Commission calculated that "more than a third of dementia cases might theoretically be preventable" and concluded that "prevention or delay of dementia onset is a public health priority with potential not only to reduce the disability of individuals but the associated societal and economic burden" (Livingston et al., 2017 p.2,14). The interventions most likely to be beneficial were identified as increasing education in early life, increasing physical activity and social engagement, reducing smoking, treating hypertension, diabetes and hearing impairment.

\subsection{Global Action Plan on Dementia}

There is recognition at the international level that dementia is not a natural part of ageing and that dementia can and should be addressed as a priority within a public health framework. There is no cure or, more realistically, even disease-modifying medications for dementia. But there is an acceptance now that the quality of life of people with dementia can be improved through action to achieve: greater awareness; timely diagnosis; dementia risk reduction; rehabilitation; respect for the human rights of people with dementia; person centred community-based care and support services; and dementia friendly and inclusive communities.

The GDAP recognizes the need for a comprehensive response from the health and social care system whether through national dementia plans or through the development and coordination of policies, legislation, or frameworks. So, action could take the form of a dementia plan, or within existing policies relating to aged care, mental health or non-communicable diseases. Whatever the context, the ultimate requirement is implementation and national dementia plans assist in making the action specific and transparent. 
The GDAP identifies seven priority areas for action, with targets set for each as follows:

\begin{tabular}{|c|c|}
\hline Action 1 & Dementia as Public Health Policy \\
\hline Target & $\begin{array}{l}75 \text { per cent of countries will have developed or updated national policies, strategies, plans or } \\
\text { frameworks for dementia, either stand-alone or integrated into other policies, by } 2025 \text {. }\end{array}$ \\
\hline Action 2 & Dementia Awareness and Friendliness \\
\hline \multirow[b]{2}{*}{ Target } & $\begin{array}{l}100 \text { per cent of countries will have at least one functioning public-awareness campaign on } \\
\text { dementia to foster a dementia-inclusive society by } 2025 \text {. }\end{array}$ \\
\hline & $\begin{array}{l}50 \text { per cent of countries will have at least one dementia-friendly initiative to foster a } \\
\text { dementia-inclusive society by } 2025 \text {. }\end{array}$ \\
\hline Action 3 & Dementia Risk Reduction \\
\hline Target & $\begin{array}{l}\text { The relevant global targets defined in the Global Action Plan for prevention and control } \\
\text { of non-communicable diseases (NCDs) 2013-2020 and any future revisions are achieved } \\
\text { for risk reduction and reported }\end{array}$ \\
\hline Action 4 & Diagnosis, Treatment, and Care \\
\hline Target & $\begin{array}{l}\text { In at least } 50 \text { per cent of countries, as a minimum, } 50 \text { per cent of the estimated number of } \\
\text { people with dementia are diagnosed by } 2025 \text {. }\end{array}$ \\
\hline Action 5 & Support for Dementia Carers \\
\hline Target & $\begin{array}{l}75 \text { per cent of countries provide support and training programs for carers and families of } \\
\text { people with dementia by } 2025\end{array}$ \\
\hline Action 6 & Information Systems for Dementia \\
\hline Target & $\begin{array}{l}50 \text { per cent routinely collect a core set of dementia indicators through their national } \\
\text { health and social information systems every two years by } 2025 \text {. }\end{array}$ \\
\hline Action 7 & Dementia Research and Innovation \\
\hline Target & The output of global research on dementia doubles between 2017 and 2025 . \\
\hline
\end{tabular}


On the basis of the GDAP, ADI has identified three desirable outcomes:

1. Systemic change in mainstream health and long-term care services which results in services becoming as dementia-friendly as possible.

2. Access to dementia-specific services for people with dementia and their family carers who have health and social care needs beyond those that mainstream services provide.

3. Dementia risk reduction and new treatments.

\subsection{Mobilising Government}

The WHO cannot compel governments through the GDAP to act, but it is nonetheless a powerful agent for change. It commits the Ministry of Health, Social Care or other departments in each country to periodically report to the WHO on the progress of each area of the plan in 2020, 2023 and 2026. It also provides the necessary framework for more countries to introduce or revise their plans on dementia. For each action, the GDAP includes proposed actions for Member States, the WHO Secretariat and international, regional and national partners (e.g. World Bank, the OECD, ADI and Alzheimer's organisations) and detailed indicators for measuring progress towards the defined targets.

An important start has occurred in terms of commitments made by governments to plan for action on dementia. While it is encouraging that over 30 countries around the world have plans (ADI, 2017b) many will need revision and the commitment of additional resources. A total of 145 plans are needed to meet the GDAP target. Therefore, while the recent upsurge in international and intergovernmental focus and attention on dementia is welcome, the disease is still not a priority in the vast majority of countries in the world. This is partly due to lack of political leadership; a poor understanding of dementia and the lack of the resources necessary to prioritise dementia relative to pressing issues of poverty and inequality. Moreover community based services and home care services tend to receive a lower priority relative to medical and residential funding for people with dementia. What is common across countries is the key role played by family carers in the care of people with dementia, particularly in low to middle-income countries.

However, no country is now exempt from responding to the GDAP. Different responses will, however, be required in high and low-income countries dependent on the strength of their health and social support systems. In some high income countries such as Germany and Japan, it will be possible to act effectively through long-term insurance programs to improve access to dementia care and support. In low-income countries, the initial focus is likely to be on awareness, training and education, dementia friendly communities and support for caregivers.

\subsection{Agents of Change}

GDAP and national plans have been driven by strong political leadership, but they have also been influenced by multiple other factors. The most significant agents of change are as follows:

\subsubsection{The Human Face of Dementia}

One of the most important drivers at the international and national level has been the dramatic impact of people with dementia and their families telling their stories and self-advocating. At the international level the Dementia Advocacy and Support Network (DASN, 2000) was founded in 2000 by people with dementia to promote respect and dignity for persons with dementia.

More recently Dementia Alliance International (DAI, 2017) has been established as an independent selfadvocacy organisation of people with dementia. DAl seeks to represent, support, and educate others living with the disease, and the wider dementia community. A focus of their work has been on the human rights of people with dementia and protecting those rights through the Convention on the Rights of Persons with Disabilities (CRPD). 
At the national level, Scotland lead the way with the establishment of the Scottish Dementia Working Group in 2002 as an independent voice of people with dementia to campaign to improve services and challenge stigma (SDWG, 2017). Scotland has been and remains an inspiration to others including in more recent years Alzheimer's Europe, Alzheimer's Australia and the Alzheimer Society of Ireland. Others such as ADI and the Alzheimer's Argentina have a person with dementia on their board.

The participation of people with dementia has evolved from telling personal stories about their diagnosis, access to services and life experiences, to presenting on issues such as human rights and the importance of access to rehabilitation services. The power of the voice of people with dementia has a lasting emotional impact on us all. As the dementia experts they have helped shape the focus on human rights, policy development and services.

\subsubsection{Evidence Base}

The World Alzheimer's Reports published by ADI each year have sought to ensure that policy-makers know about the economic and social impact of dementia (ADI, 2016). ADI members for their part have sought a commitment from their governments to dementia plans that provide the basis for long term action for tackling dementia. To support this work ADI published in 2013 'Improving Dementia Care Worldwide' a review of existing national dementia plans from around the world, and puts forward recommendations for governments on what a best practice plan should include and how it should be developed and implemented (Pot and Petrea, 2013).

The WHO partnered with ADI to publish, 'Dementia: A public health priority' an authoritative and comprehensive overview of dementia worldwide (WHO, 2012). At the time, the release of the report highlighted the commitment of the World Health Organization to making dementia a global health priority by calling on national governments to address the increasing challenges dementia poses on a global, national, regional, and local level.

\subsubsection{Human Rights}

The GDAP makes 30 references to the rights of persons with dementia and 8 to the CRPD. The next step is to link the actions proposed in the plan to the articles of the CRPD and to monitor progress in regard to implementation. The Plan can then be monitored within the framework of the Convention. Relevant articles of the CRPD to dementia include: awareness and accessibility (Articles 8 \& 9); the right to health (Article 25); living independently and rehabilitation (Articles 19 \& 26); liberty and security (Article 14) and freedom from exploitation, violence and abuse (Article 16). The force for change is to bring legal and social action together to ensure that everything possible is done to protect the rights of people with dementia and to translate that into practical action. ADI with Dementia Alliance International has prepared a brief for members on the CRPD to help create a greater cohesion between dementia and disability (ADI, 2017a). The intention is that over the next few years, Alzheimer's organisations should partner with human rights and disability organisations to contribute to reporting processes on the Convention.

\subsubsection{Dementia-Friendly Communities}

Dementia-friendly communities have the power to achieve awareness and give practical expression to the human rights of people with dementia in everyday life. The dementia friends program was pioneered in Japan in 2005 with some government funding and there are currently 6.3 million dementia friends in Japan with a target of 8 million set for 2018. The dementia friends program aims to transform people's perception of dementia by creating 'dementia friends' - people drawn from all ages, cultures and lifestyles - who commit to learn what it is like to live with dementia though basic training and then turn that understanding into social actions that lead to the development of dementia-friendly communities. Since their inception in Japan, Dementia Friendly Communities have taken off across the world. The Dementia Friendly Community has been given expression in many practical ways - awareness through dementia friends, school programs, social engagement and activities through cafes, men's sheds, choirs, building capacity by dementia training in banks, retail services, health services; dementia champions in hospital services and improving the physical environment. 


\subsection{Key Alliances}

\subsubsection{WHO and National Governments}

The WHO has been significant both in bringing together its membership of governments to act and in the intellectual energy and commitment which the organisation itself makes to acting on the decisions of its Executive. Of major importance was the First WHO Ministerial Conference on Global Action Against Dementia in March 2015 which over 80 country representatives attended, including, Ministers from Switzerland, Japan, UK, Germany, Netherlands, Ethiopia, South Korea, Dominican Republic, Austria, USA, Luxembourg and Malta (WHO, 2016a). This meeting focussed concern on the human rights of people with dementia, the economic and social impact of dementia and issues in respect of access to services. This meeting set the scene for Switzerland and the Dominican Republic to take the lead in May 2016 to request the WHO Executive to develop the GDAP.

Political leadership at the national and international level has been decisive in setting the agenda for dementia. This is well demonstrated by the plans and additional resources that resulted from the first French Plan in 2001 under President Sarkozy, the implementation of the Dementia Plan by John Howard's Government in Australia in 2004 and the leadership of David Cameron in 2012 in the G8 and UK, Japan and the legacy meetings.

\subsubsection{ADI, WHO and DAI}

Alzheimer's Disease International was formed in 1984 by the USA, Canada, UK, and Australia. The mission of $A D I$ is to strengthen and support Alzheimer associations, to raise awareness about dementia worldwide, to make dementia a global health priority, to empower people with dementia and their care partners, and to increase investment in dementia research. ADI now has 90 members and is growing. ADI was invited to enter an Official Working Relationship with the WHO in 1996. The partnership at the international level between the WHO and ADI has been instrumental to change over the period since then, particularly in recent years.

ADI and DAI have also entered a Memorandum of Understanding which recognizes the independence of both organisations while both being committed to working together. Members of DAI have contributed significantly to ADI international conferences in recent years and they have actively advocated at international meetings and articulated the importance of addressing the human rights of people with dementia through the CRPD.

\subsubsection{Researchers}

Individually and collectively, the work of researchers and important conferences, such as the American Association International Conference, have been critical to promoting the awareness of dementia and a better understanding the condition. While the lack of new treatments this century has been a disappointment, research on new advances in thinking about dementia, including the potential for intervening much earlier in life, new approaches to diagnosis, the potential of dementia risk reduction and new models of dementia care give hope for the future.

\subsection{Principles to Action to Impact}

If people with dementia and their families and advocates can take some comfort from developments since the turn of the century, remain of the view I expressed in 2010, namely that the need is for revolution rather than evolution. Even Scotland, who have approached planning for dementia with great rigor, acknowledge in their third plan that the gap between "the policy commitments found in all three strategies and the real life experience of many people is far too wide". National Governments, including Ireland, must commit to all seven actions in the GDAP and in doing so give priority to timely diagnosis, post diagnostic support, support for family carers, dementia risk reduction, community and home-based services. 
Without a timely diagnosis the majority of people across the world with dementia will continue to be denied access to services. A post diagnostic guarantee on the model developed by the Scots (in their second and third plans) will assist those with a diagnosis to better plan their lives and the services they will need given their personal circumstances. Equally, if living in the community for as long as possible is to be a reality then the priority must be to provide flexible community and home-based services that respond to the individual needs of those with dementia and family carers.

Ensuring that services are person-centred and personalised is, therefore, key to progress. Service design should be flexible in terms of the type, timing, and location of delivery and some supports need to be available 24/7. Innovation in service design can contribute to the personalisation of care for people with dementia. OECD (2013) shows that more than two thirds of member countries have introduced userdirected support into their long term care systems, usually by offering choice of benefits in the form of cash payments, vouchers, or personal care budgets. Introducing mechanisms to improve the coordination of care within long term care and across health and care systems should also be a priority, especially for those with complex needs and those living alone.

As long ago as 2004, ADI identified in the Kyoto Declaration that there are strategies and interventions that governments (whether high, middle or low resourced) can adopt to tackle dementia from awareness to diagnosis to management and care to end of life. This was updated in the Dementia in the Asia Pacific Report. ADI has more to do at a number of levels (ADI, 2014), including: providing support to Alzheimer's associations in advocating to their governments for the preparation of dementia plans and commitments to action them; and providing support to member countries in monitoring the actions taken to implement the GDAP. Furthermore, the ADI will contribute to the monitoring undertaken by the WHO and the specific projects being undertaken by the WHO, including updating the dementia prevalence and incidence figures and those on the social and economic impact of dementia.

The WHO has put actions in place, or plans to do so, to address each of the seven action areas. For example, on Action 5, work has been done on the development and delivery of Support for Carers (WHO, 2017), a comprehensive e-tool to enhance self-help, skills, and support for caregivers of people living with dementia, including those in low and middle-income countries. On Action 6, the WHO has commenced a feasibility study with a group of Member States for a Global Dementia Observatory (GDO), a web-based data and a knowledge exchange platform to collect and disseminate key dementia information from WHO Member States. The study is expected to be completed by the end of 2017 and to result in a finalised framework for data collection.

The objectives of the GDO are: to help countries to support individuals with dementia; to reduce the disease burden and cost; to better understand countries needs for evidence based service planning and policies; and to strengthen their capacity to monitor progress within countries and globally; to share best practices; and create a knowledge exchange platform. At a much earlier stage the intention is to do an analysis of dementia plans, develop a dementia friendly tool kit, produce dementia risk reduction guidelines, develop clinical guidelines for non-specialised health workers and influence the agenda for dementia research.

The GDAP sets out much of what we need to do now in relation to dementia. What has been lacking at the national level in many countries is the resources or commitment to tackle dementia. The OECD has observed that there is a consistency in the policies embedded in dementia strategies but "ensuring that these policies are consistently implemented remains a challenge and there is too much uncertainty around which policy approaches are the most effective"(OECD, 2015 p.56). The GDAP combines what we know about dementia policies with a welcome determination to monitor and evaluate. But governments, including Ireland, will have to commit more resources to ensure that change can happen in a way that we know is necessary to improve the lives of people with dementia and their family carers. 


\subsection{Conclusion}

Each country has to establish their own priorities for dementia given the strengths and weaknesses of their health, long-term care and social support systems. But these priorities will, in the future, also have to reflect the actions and targets set in the GDAP. Even countries like Scotland, who are embarking on their third dementia plan, acknowledge that they still have a way to go in translating principles and actions into a better quality of life for people with dementia and their families. Therefore, governments must also focus on outcomes as well as process in relation to dementia care.

I suggest that there are four fundamental issues to address, as follows:

1. Diagnosis and post diagnostic support for people with dementia and their caregivers remain absolutely critical for all countries. The GDAP target requires: "In at least 50\% of countries, as a minimum, $50 \%$ of the estimated number of people with dementia are diagnosed by 2025". Diagnosis is, however, only the beginning of the process. People with concerns about dementia need to know that following a diagnosis they will get post-diagnostic support consisting of information, social supports and a care plan. Diagnosis and post-diagnostic supports provide the gateway to making informed personal life decisions and decisions about medical treatment.

2. The development of robust and sustainable community-based services and supports to allow people with dementia to live well at home is fundamental to future investment in dementia care. This must involve family carers as care partners, the integration of social and health systems and the provision of quality care and evidence-based interventions. ADI and Alzheimer's organisations need to develop strategies that allow people with dementia to make choices in relation to service delivery and to have those preferences respected. This requires the design of flexible and responsive services that reflect the expressed need of people with dementia and their caregivers.

3. Governments and civic society must make a commitment to monitor the rights of people with dementia through the United Nations Convention on the Rights of Persons with Disabilities. Dementia friendly communities must be developed and expanded to give those rights practical expression. In this way, we will not only improve care and support systems, but we will also value people with dementia and respect their rights to participation in society. Rights, and their monitoring, are particularly important for people with dementia living in acute and long-term care settings.

4. Finally, research funding has to be improved for the cure, prevention, treatment, and care of dementia. It may not be realistic to commit, as the G8 did in 2013, to finding a cure for dementia by 2025 , but it would be re-assuring to know that political leaders have a vision for the future that all stakeholders could work towards. While much has been achieved in dementia care practice and policy, there is still much to do. 

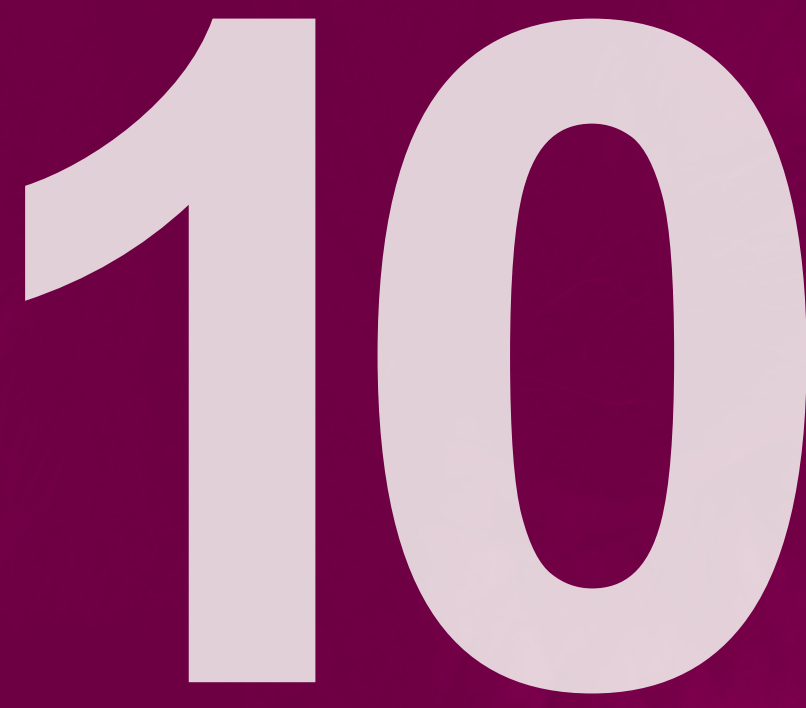

Conclusion: Towards a Second Dementia Strategy

Eamon O'Shea,

Suzanne Cahill and Maria Pierce 



\subsection{Dementia in Ireland}

There are currently an estimated 55,266 people with dementia in Ireland. This number is set to increase at a rate of 3.6 per cent per year in the coming decades. By 2031 there will be close to 100,000 people living with dementia in the country. There is significant regional and local variation in estimated dementia prevalence rates across Ireland due to differences in population age structures; the west of the country has the highest prevalence rates of dementia with some counties estimated to have up to $1.5 \%$ of their total population living with dementia. Commuter areas around Dublin have the lowest share of the population with dementia, with Dublin West currently having the very lowest share at 0.80 per cent. A tentative extrapolation of lower middle-range international incidence rates to the older population in Ireland suggests that there are 7,752 new cases of dementia arising in the general Irish population every year.

People with dementia are a heterogeneous group. They vary by disability, gender, age, marital status, education, socio economic status, co-morbidities and ethnicity. The diversity and variation in people with dementia is important in determining specific needs. There are an estimated 34,818 people with dementia currently living at home in the community; most of these people do not have a formal diagnosis. Indeed, many of these people are not aware that they have the disease and few are likely to be in contact with the health and social care system. There are an estimated 60,000 family carers in the community looking after someone with dementia in Ireland. Just over 20,000 people with dementia live in residential accommodation, the vast majority of those live in long-stay facilities, mainly in nursing homes.

The cost of dementia in Ireland has been estimated at just over $€ 1.69$ billion per annum. The average cost per person with dementia in Ireland is estimated at $€ 35,000$, which is consistent with per capita estimates from other countries. Just under half of the total costs of care are attributable to informal care provided by family and friends to people living with dementia in the community (Connolly et al., 2014). A further 43 per cent is accounted for by residential long-stay care, while formal health and social care services contribute only 9 per cent to the total costs of dementia. Increasingly, however, the burden on the acute care sector is being recognised. People with a diagnosis of dementia tend to have a significantly longer length of stay in hospital than those without dementia, a finding that holds across a number of comorbidities. Applying European prevalence data for dementia to patients in the acute care sector in Ireland, suggests that the estimated cost of this extended length of stay associated with dementia is almost $€ 200$ million per annum in Ireland (Connolly and O'Shea, 2015). 


\subsection{The National Dementia Strategy}

The National Dementia Strategy and its implementation through the National Dementia Office is supporting change and transformation in five key areas:

Better Awareness and Understanding of Dementia. Under the National Dementia Implementation Programme (NDIP), the Health Service Executive Health and Wellbeing Division in conjunction with the National Dementia Office and the National Communications in the Health Service Executive, are currently rolling out a nationwide education and support campaign for people with dementia and their family carers. The Understand Together campaign brings together a range of activities from various stakeholders, including: information and advice on dementia; information on services and supports; advocacy; dementia friendly communities; and dementia awareness.

Timely diagnosis and intervention. Under the NDIP, structures are currently being put in place to develop training, education and care pathways so as to optimize the individual's pathway through the system from initial presentation with worrying symptoms, through to diagnosis, including supporting different interventions appropriate to need at any given time. Timely diagnosis is considered important for a whole variety of reasons not least for treatments (clinical and non-clinical), for maximising individual autonomy and for enabling advanced care planning to take place (ADI, 2011). A key aim of the Strategy is to ensure that many more people will receive a timely diagnosis of dementia in Ireland. The School of General Practice at UCC, in collaboration with the Irish College of General Practitioners (ICGP) and Dublin City University (DCU), are developing a programme of education and training for general practitioners and primary care staff designed to impact on timely diagnosis. Dementia-specific reference material is now available to broaden the knowledge and skills base of practitioners. Guidance on national and local pathways to investigation and diagnosis is being provided. Post-diagnostic support is also being examined to identify optimal intervention strategies, focusing on information, signposting, peer-support, education, training, cognitive stimulation and rehabilitation, advice and care co-ordination.

Integrated Services and Supports. An integrated partnership approach is being developed to the planning, delivery, monitoring and evaluation of services for people with dementia, with the inclusion of all stakeholders from the public, private and voluntary sectors. The HSE-Genio program demonstrated the practical feasibility of responsive, flexible support system for people with dementia. Under the NDIP, 500 new intensive home care packages have been targeted for people with dementia. These packages were initially focused on people on the boundary of care between hospital care and community-based care, but have now been broadened to include people outside of the hospital sector living at home with significant care needs. This programme is being implemented and evaluated through a joint initiative between the Health Service Executive and Genio, supported by a budget of $€ 22$ million.

Training and Education. Caring for someone with dementia is challenging, both physically and emotionally. Apart from memory and cognitive problems, some people with dementia will experience behavioural and psychological symptoms such as depression, apathy, aggression, delusions and paranoia that will complicate care and pose ethical and moral dilemmas for formal carers. The skill and humanity with which help and support for everyday living is provided is critical to enabling a person retain their dignity and personhood and staff in all care settings need the appropriate specialist training and competencies to care effectively for people with dementia of all ages, all stages and of all sub-types. However, like in other countries, staff employed in Irish dementia care settings often have little formal dementia-specific training and education. Indeed some staff may have limited proficiency in English and may not have a good understanding of Irish culture. The Health Service Executive are now engaging with relevant professional and academic organisations to encourage and facilitate the provision of dementia-specific training, including continuous professional development, to relevant occupational and professional groups, including peer-led support and education for GPs and various staff within nursing homes. The priorities highlighted in the National Educational Needs Analysis completed by the Health Service Executive in 2009 and the on-going Dementia Skills Elevator programme run by Dublin City University are the key building blocks for current training and 
education programmes. Education and training programmes for family carers are also being developed as part of post-diagnostic support mechanisms; similarly education and training has been delivered to businesses and public agencies involved in meeting and dealing with people with dementia.

Research and Information Systems. Information on dementia is not routinely available through national databases and in the past it seems there has been a national reluctance to list dementia in much of the record keeping on older peoples' services. This has implications for the provision of evidence-based services and supports and for ensuring that resources for people with dementia are targeted effectively. Work has started on improving the information set on dementia in Ireland. For example, the Single Assessment Tool will address some of the information needs with regard to dependency and care in relation to people with dementia, while the NDO has recently establised a tender process to investigate the feasibility of a dementia register for Ireland. The evaluation of services is also taking place, most notably in relation to intensive home care packages and dementia advisors, funded by the NDO.

\subsection{Current Gaps}

For all the considerable progress associated with the National Dementia Strategy and the sterling implementation work currently being carried out by the National Dementia Office, significant gaps remain in relation to dementia in Ireland. One of the key deficiencies is that not enough attention was focused on prevention in the National Dementia Strategy, particularly in relation to the risk factors for dementia and lifestyle choices which can be adopted to minimise the risk of developing a dementia in later life. The risk of dementia may be reduced if one's general health is protected by controlling blood pressure, having a healthy diet, exercising regularly, not smoking, drinking moderate amounts of alcohol, and generally protecting the head from serious injury. The National Dementia Office through the Understanding Together campaign is addressing this issue currently through a focus on risk reduction and healthy living. Integrating dementia within the Healthy Ireland framework will be key to progress in this area and should be the cornerstone of more focused work on prevention against dementia. It requires a societal response to promoting healthy living, preventing dementia and preventing other co-morbidities which may further aggravate the symptoms of dementia (Travers et al., 2015). Consideration of other subpopulations including ethnic minority groups, as for example in Ireland, the Travelling Community is also a feature of the population health approach. The encouragement of alliances with and between organizations that promote similar primary prevention messages for other chronic diseases, such as the Irish Heart Foundation, is another feature of a population-based approach. An integrated population-based approach has the potential to impact on the incidence and prevalence of dementia in the future.

Another significant gap is the absence of entitlement to post-diagnostic social care supports to assist families sustain home care. The vast bulk of care in the community is provided free of charge by family caregivers, some of whom, as shown in Chapter 3, are frail and elderly themselves and do not enjoy good health. Caring for a person with dementia compared with other caring roles places much greater demands and strain on family members. The family caregiver of a person with moderate to severe dementia in Ireland is likely to be providing 24 hour care, sometimes struggling to cope with distressing challenging behaviours, leading to considerable emotional and psychological strain and sometimes complete burn out. Often these caregivers, especially spouses, become engulfed in the care role and feel guilty when they take any time out. Their social world shrinks and the only time spent away from caring, may be merely for grocery shopping or for attending GP or hospital appointments with their own or their relative's medical problems. Even at the earlier stages of dementia, supporting a family member who has dementia can result in enormous strain, as tensions arise between the autonomy needs of the individual, their safety and wellbeing and the interests and safety of others. Decisions about issues such as continuing to drive a car and hold a driver's licence and continuing to use money judiciously and do one's own banking independently are not easy to make, especially when, in the case of Alzheimer's disease, symptoms may fluctuate. 
Developing carer-specific post-diagnostic support structures would go some way to supporting families and acknowledging the role played by caregivers in Ireland. Several people with dementia and their families who participated in the National Dementia Summit in Ireland in 2011 (Alzheimer Society of Ireland, 2011 p.6) described how even after getting a diagnosis, they felt they were 'in an abyss'. Other Irish research has shown that once diagnosed, what people want most but what tends not to be available is follow up and information (Begley, 2009; Diaz-Ponce, 2014). It is clear that there is a need for more adequate and timely post-diagnostic support services for people with dementia and their families. While there is no consensus about what constitutes a good model for early support services for the carers of newly diagnosed people with dementia, information services, signposting, counselling and emotional supports are key elements in the early stages of the disease (O'Shea and Monaghan, 2017). Diagnosis should be followed by immediate access to a named and trained contact person that will: support and empower the individual; help that person maintain a level of independence and autonomy; avert future problems; and provide ongoing information and advice to their carer. It really does not matter what that person is called - connector, navigator, advisor, co-ordinator - but it does matter that the contact person is embedded in the care system, has the credibility and authority to act as an agent for the person with dementia within a well-defined geographical area and has the necessary skills and training to interact with family carers and formal providers of care. The use of a framework such as that developed in Australia, which incorporates components on overarching philosophies, organisational factors, role definition and contact person competencies, may be useful in guiding the development and implementation of such a role in Ireland.

In Ireland, community care for dependent older people is predominantly funded though the Home Help and Home Care Package schemes. These schemes fund home help and other home based care to assist older people, including those with dementia, to remain in their own homes for as long as possible. The Home Care Package Scheme has benefited considerably from investment through the National Dementia Strategy. However, one of the resounding weaknesses of home care services in Ireland compared with those developed and delivered in other countries (such as the UK, Norway, Sweden, Denmark, France and Australia) is that these services are not provided on a statutory basis. When resources are scarce, it is much easier to reduce services to people with dementia living at home, or not provide services at all, than it is to reduce hospital or residential care services. The latter are much more visible and politically sensitive. There are also significant inequities across the country in relation to home care delivery with considerable variation in the type and amount of services available. These inequities were not addressed in the National Dementia Strategy. Universal statutory entitlement to home care is a pre-requisite to the transformation of care for people with dementia in Ireland and should be a priority for government.

Another significant gap in the Irish National Dementia Strategy is the absence of attention given to autonomy for people with dementia. Personalised care has been shown to be important for people with dementia living at home (O'Shea and Monaghan, 2016; O'Shea and Murphy, 2014) and talking to the individual and family member about their respective care needs (Barnes and Brannelly, 2008), encouraging them to use retained abilities and make choices even in small areas of their lives can engender wellbeing in people living with dementia (Kitwood and Bredin, 1992). Autonomy which refers to an individual's capacity for self-determination and to be enabled to exercise choice and control (Kane, 2001) is an important component of quality of care (Nuffield Council on Bioethics, 2009). Yet for many people living with dementia, their rights to autonomy may be denied and their freedom for self-determination unduly restricted by the behaviours and actions of others (Parker and Penhale, 1998). Autonomy is not a binary concept (full autonomy or no autonomy) and although often associated with rational decision making, people with dementia can still retain the ability to value one thing over another even if they have lost the capacity to make and communicate a decision. Likewise, they can be helped to experience relational autonomy where they can be supported to communicate their wishes and preferences (Nuffield Council on Bioethics, 2009). A legacy of the old culture of care, however, and the biomedical model in particular, is the erroneous belief that once a person is diagnosed with dementia all rights to autonomy including decision making capacity should be removed. This perspective needs to change and, in our view, the autonomy needs of the individual with dementia have not received sufficient attention in the current iteration of the National Dementia Strategy. 
This legacy of the old culture of care has also percolated through to current systems of support and a major flaw with current home care provision in Ireland is the failure to recognise and respond to the individual and unique needs of the person with dementia. Current care is largely provided through a generic "one size fits all" approach, where people with dementia are rarely consulted or asked for their input about the care on offer. Personalised care is under-provided in Ireland and people are not given the opportunity to choose the kind of services that are most suited to their needs. This includes choice in relation to what services are provided, when they are delivered and by whom. For example, psychosocial care is weak in Ireland, mainly because it is not on the menu of choices available to people with dementia, which, is largely restricted to the provision of home help hours.

Neither does the current home care system prioritise a high level of communication between providers of care and people with dementia. There are no formal requirements for staff training in communication, an area that is critically important in dementia care (Powell, 2002). Session times for home help/home care are often short (Donnelly et al., 2016), which means that it is often easier and more expedient for formal home care staff to 'do things for' the individual rather than 'do things with' that person thereby disempowering the individual. Autonomy, flexibility and communication are key elements of personhood that are currently absent on a day-to-day basis in home care provision. Given Ireland's new Assisted Decision Making Act (2015), which places the will and preferences of people with impaired mental capacity at the heart of decision making for both their personal welfare and their property and affairs (Kelly, 2017); the absence of recognition of the autonomy rights of the individual and the lack of choice available to families in relation to service supports warrants urgent attention.

Fixing the home care system should be about more than simply expanding home help hours, helpful and all as that might be for some people. It requires a change in ideology, in how we think about and talk about dementia (Hughes, 2014) and in how we view those who experience the symptoms of the disease and in how services are developed and delivered. Instead of focusing on the person diagnosed with dementia as a 'patient' 'client', or 'target of care', it is crucial to see the individual as an 'agent' of his or her own life (Lindemann, 2014) who must be encouraged and supported to live a good life and one meaningful to him or her. Consequently real change needs to encompass support for a whole range of services that are of value to the person with dementia and promote that person's dignity and personhood. Moreover, it is not enough to talk about the principles of personhood and citizenship and have words like person-centred care enshrined in nursing home mission statements, they must also be regulated for if they are to become central to the care system. The current regulatory system of care for people with dementia is not sufficiently rooted in personhood or citizenship rights despite both being fundamental principles underpinning the National Dementia Strategy. This gap between the rhetoric of public policy on dementia and the reality of everyday practice needs to be addressed.

The absence of choice in service provision is also apparent when older people with dementia in Ireland need to move from their own home into long-term care. Compared with other countries, there are very few alternatives in Ireland outside of residential care settings available to people living with dementia. Moreover, the current funding system supports the residential care option ahead of all other choices - it is easier to navigate and provides greater certainty in relation to addressing need in times of crisis. Addressing this deficiency should be a major focus of policy in the coming years and Ireland should follow the example set by other countries like Norway and the Netherlands where a sizeable proportion (up to one third) of new build nursing homes must comply with best practice principles and must be designed as small scale dementia-specific units (Verbeek, 2013). 
The lack of alternatives to residential care in Ireland contrasts strongly with the US, UK, Australia, and other European countries where a range of alternate models to nursing home care exist, including: (i) housing with care; (ii) sheltered housing; (iii) hostels; and (iv) specialist care units. In Ireland, however, only a very small number of housing with care schemes exist that provide accommodation specifically to address the complex needs of people with dementia, and none of these are run by a statutory body. In section 6 , of the Irish National Dementia Strategy (Dept. of Health, 2014) which deals with 'integrated services, supports and care for people with dementia and their carers', reference is made to the need for a 'range of long term care options designed to comply with best practice and architectural principles' (p.24). Providing alternatives for people with dementia in relation to long-term care should be prioritised alongside the development of home care services.

What happens inside nursing homes in terms of how, where and with whom people spend their lives and the quality of their everyday living has not been given sufficient attention in Ireland and warrants future careful consideration. We know little, for example, in the Republic of Ireland about the use (excessive or otherwise) of antipsychotic medication and less about the use of physical restraints and assistive/ surveillance technologies which depending on why and how they are introduced, may be intrusive, restrictive, unethical and disempowering rather than emancipating (Astell, 2006; Welsh et al., 2003; Hofmann, 2013). The vast majority of people with dementia in Ireland living in residential care are still cared for within generic care facilities for older people, most of which are not purpose-built for dementia and many of which are not designed to cater for the complex, challenging and unique needs of residents with dementia. For front line care workers, this makes the task of providing care to two different cohorts of residents, those with and without dementia very difficult especially when residents with dementia are likely to require more time, need more individualized care and some will exhibit behaviours that challenge.

People with dementia are particularly sensitive to their environment and good environmental design is now widely regarded as critical to the care of people with dementia. Indeed, some people have argued that design is as vital to resident care as nursing care or the approach to the organisation of care within a facility (Fleming and Purandare, 2010). People with dementia should be connected to, and engaged with, the outside world. Therefore, segregated and remote nursing home care can never be justified and for some people may constitute a denial of the human rights of people with dementia (Ilinca, 2015). For that reason, we must stop designing nursing homes like hotels and locating them in socially marooned areas. We need to ensure that future builds are integrated into community areas and people living in these facilities feel socially connected and can enjoy the contacts and amenities available in their local surroundings.

In recognition of the special needs of people with dementia in residential care settings, the trend in many countries nowadays is towards providing specialist care in creatively designed small-scale units (Cahill et al., 2015). While some dedicated dementia-specific beds are available in public long-stay facilities in Ireland, these are still the exception rather than the rule. Very few people with dementia (about 11\%) gain access to specialist care units and even when they do, the size of these units does not always conform with best practice models. Moreover, there is no standard definition of what constitutes a special care unit in Ireland, nor is there an agreed meaning or definition for the term 'dementia specific bed' within a generic facility. Consequently, we do not have good information on where and how people with dementia are being looked after in residential care settings and where as they approach end of life they live out their final days. We suspect that some may be unnecessarily in some cases relocated to hospitals (Cahill et al., 2015). The availability of reliable data on the location and quality of special care units is all the more urgent given the significant concerns about the lack of good quality, dementia-specific-long-term-care facilities expressed by participants at the 2011 National Dementia Summit (Alzheimer Society of Ireland, 2011).

The care process within long-stay facilities is also important in allowing residents to live well with dementia. There is no doubt that the medical and functional needs of residents continues to dominate the care landscape within residential care settings. While, to some extent, this is understandable, psychosocial approaches are also needed to complement medical and neurological models of service delivery, but with 
some few exceptions, they are largely absent in residential care settings in Ireland or when used sometimes tacked on almost by way of an after-thought and often, as in the case of reminiscence, conducted by staff with no specialist expertise or training in the area (Parsons et al., 2015). In particular, psychosocial interventions can assist in developing meaningful communication with patients, using all of the senses, through reminiscence, music, art, dance and various therapeutic and time-intensive activities. Given the importance of connectivity for personhood within dementia, new ways of reaching into and out of longstay settings should be facilitated through various forms of social interventions. Very few facilities have connectivity programmes that link residents within residential care facilities to the communities that surround them, both within and outside the residential care setting. Exercise programmes can also be helpful for people with dementia living in long-stay settings. This emphasises again the need to regulate for personhood and person-centred care for people with dementia. The practice of personhood is not fully reflected in current inspections and reports on nursing home provision in Ireland.

\subsection{Future Directions for Policy and Practice}

There is no doubt that Ireland is increasingly being recognised internationally as a country where the narrative in regard to dementia is changing for the better. There has been a remarkable transformation in the discourse around dementia in Ireland in the last decade, some of which has been influenced by funding and support from the Atlantic Philanthropies. The country has witnessed a paradigm shift in policy towards personhood and the social model of care linked to evidence-based research. The practice of dementia care is also changing and there have been genuine attempts within the system to meet the objectives set out in the inaugural National Dementia Strategy. Significant progress has also been made in relation to combatting stigma, raising awareness and understanding, training and education, diagnosis and the development of services and supports on the boundary of care between home care and residential care

The process of transformation requires additional focus on a small number of key specific areas: prevention and risk reduction, post-diagnostic supports including access to both pharmacological and social and environmental interventions, statutory home care provision, personalised care with recognition of the autonomy rights of the individual, and the co-ordination and regulation of personhood and social citizenship especially within residential care settings. There is a strong desire for a bio psychosocial model of care of dementia among stakeholders in Ireland. The next iteration of the Strategy should be firmly rooted in the preferences, rights and potential of people with dementia and it should finally deliver on the long-standing aspiration of comprehensive home care provision for people with the condition. It should also ensure that training in dementia care becomes a mandatory requirement in all medical, nursing and allied health undergraduate and post-graduate education and that course accreditation is contingent on the inclusion of dementia modules. The next iteration should also set targets about quality long-term care and commit to ensuring that a sizeable proportion of new build nursing homes, or those being reconfigured, meet best practice design principles and features. The formula here is fairly simple: home like small scale units (accommodating up to 8 residents) in an easy to negotiate environment enabling direct access to outdoor areas and resourced by well trained motivated staff. Compared with large scale institutions, such units are likely to reduce the need for medication, increase social contact and reduce agitation, anxiety and depression (Norwegian Ministry of Health and Care Services, 2016). For the person with dementia, the goal must be to provide them with an individualised person-centred pathway of care from prevention, through early diagnosis to dignified end-of-life care. At the macro level, the objective should be to normalize dementia (WHO, 2012) and make the condition and those who experience it visible, in the same way as those with a physical disability are increasingly seen as part of normal society (Nuffield Council on Bioethics, 2009). The overall goal should be to make dementia a community-oriented public health priority, thereby placing people with dementia at the heart of local communities comfortable and secure in their own place and time. 
A key concern for the future is that resources will not be made available to fund the universal provision of services and supports for people with dementia. Those fears are not without foundation. It was only through support from the Atlantic Philanthropies that many of the recommendations in the first Strategy were funded. Implementation has been a problem for decades in relation to policies for dependent older people in Ireland. In particular, general taxation has not delivered the money necessary to support an optimal community-based response for people with dementia. General taxation has many advantages in that it is democratically accountable, universal, yields large amounts of money and it tends to be progressive, which means that the rich pay proportionately more than the less well off in society. However, people with dementia and their families seem to continually lose out in the allocation of scarce public resources collected through general taxation, particularly in relation to home care provision. It would be a real blow if new legislation for home care was enacted only to be stymied by the absence of funding to implement the changes most people agree are necessary to support people in their own homes.

Long-term care social insurance is an alternative option to general taxation and one used in other countries including Japan and Germany. Under a social insurance system individuals would pay into a fund over the life cycle, in return for automatic entitlement should they need benefits at some time in the future. The Government can pay the premiums of those not in the labour market and inability to pay would not deny access to any new national scheme. A designated social insurance fund would allow for the introduction of a statutory-based model of comprehensive home care services and supports for people with dementia in Ireland. A new funding model could also deliver appropriate support and regulation for personhood within residential care in Ireland. More generally, it would also facilitate transparency in priority-setting and service delivery, as well as being more consumer responsive than a general taxation system. The next phase of development for people with dementia cannot be achieved without a significant injection of money to support home care provision. Social insurance can be the financing mechanism to complete the transformation of care for people with dementia in Ireland. 


$$
\text { a }
$$




\section{References}




\section{REFERENCES}

\section{CHAPTER 1}

Alzheimer Europe (2016). France - national plans for Alzheimer and related diseases [Online]. Available: http://www.alzheimereurope.org/Policy-in-Practice2/National-DementiaStrategies/France. [Accessed 27th October, 2017].

Alzheimer Society of Ireland (2013a). 'Living With Dementia' Implications for the National Dementia Strategy: Summary of Roundtable Discussions. Dublin: Alzheimer Society of Ireland.

Alzheimer Society of Ireland (2013b). Multidisciplinary Clinicians Roundtable on the National Dementia Strategy. Dublin: Alzheimer Society of Ireland.

Banerjee, S. (2013). Developing Policy that Works for Dementia: National and Global Lessons in What Makes a Difference. Designing and Delivering Dementia Services, 119-125.

Bartlett, R. \& O'Connor, D. (2010). Broadening the dementia debate: Towards social citizenship, Bristol, Policy press.

Batsch, N. (2016). Conceptualizing empowerment from the perspectives of people with mild dementia. Unpublished Thesis, King's College London.

Boyle, G. (2008). Autonomy in long-term care: a need, a right or a luxury? Disability \& society, 23, 299-310.

Boyle, G. (2010). Social policy for people with dementia in England: promoting human rights? Health \& social care in the community, 18, 511-519.

Cahill, S. (2010). Developing a national dementia strategy for Ireland. International Journal of Geriatric Psychiatry, 25, 912-916.

Cahill, S., O'Shea, E. \& Pierce, M. (2012). Creating excellence in dementia care: A research review for Ireland's National Dementia Strategy. Dublin and Galway, Ireland: Trinity College Dublin and National University of Ireland, Galway.

Dept. of Health (2001). Quality and Fairness - A Health System for You. Dublin: Deptartment of Health.

Dept. of Health (2012a). Future Health A Strategic Framework for Reform of the Health Service 2012 - 2015. Dublin: Deptartment of Health.

Dept. of Health (2012b). National Strategy on DementiaSummary of Consultation Process Dublin: Deptartment of Health.

Dept. of Health (2014). The Irish National Dementia Strategy. Dublin: Deptartment of Health.

Haeffner-Cavaillon, N., Devos, P., Ledoux, S. \& Ménard, J. (2015) The Third French Alzheimer Plan: analysis of the influence of a national public health initiative on scientific research productivity and impact. Alzheimer's Research \& Therapy, 7, 60.

Hennelly, N. \& O'Shea, E. (2017). Personhood, dementia policy and the Irish National Dementia Strategy. Dementia.

HIQA (2008). National Quality Standards for Residential Care Settings for Older People in Ireland. Cork: Health Information and Quality Authority.

HSE (2015). Putting people at the heart of everything we do. Health Service Annual Report and Financial Statements. Dublin: Health Service Executive.
Inter-Departmental Committee on the Care of the Aged (1968). The Care of the Aged. Dublin, Ireland: The Stationery Office.

Kelly, F. \& Innes, A. (2013). Human rights, citizenship and dementia care nursing. International Journal of Older People Nursing, 8, 61-70.

Kitwood, T. (1997). Dementia reconsidered: The person comes first, Milton Keynes, Open University Press.

McLean, A. (2007). The person in dementia: A study of nursing home care in the US, University of Toronto Press.

O'Connor, D. \& Purves, B. (2009). Decision-making, Personhood and Dementia: Exploring the Interface, London, Jessica Kingsley Publishers.

O'Shea, E. (2007). Implementing policy for dementia care in Ireland: The time for action is now. Galway: National University of Ireland, Galway.

O'Shea, E., Cahill, S. \& Pierce, M. (2016). Reframing policy for dementia. In: Walsh, K., Carney, G. M. \& Ní Léime, A. (eds.) Ageing through austerity: Critical perspectives from Ireland. Bristol, UK: Policy Press.

O’Shea, E. \& Carney, P. (2016). Paying Dividends: A Report on The Atlantic Philanthropies Investment in Dementia in Ireland. Galway, Ireland: Centre for Economic and Social Research on Dementia.

O'Shea, E. \& O'Reilly, S. (1999). An action plan for dementia. Dublin: National Council on Ageing and Older People.

Robins, J. (1988). The years ahead: a policy for the elderly: report of the Working Party on Services for the Elderly. Dublin: Stationery Office.

Timonen, V. \& Doyle, M. (2008). From the workhouse to the home: evolution of care policy for older people in Ireland. International Journal of Sociology and Social Policy, 28, 76-89.

\section{CHAPTER 2}

ADI (2009). World Alzheimer Report 2009. London: Alzheimer's Disease International.

ADI (2015). World Alzheimer Report 2015: The Global Impact of Dementia. London: Alzheimer's Disease International.

AIB (2014). Long Term Care. Dublin: AIB in association with Nursing Home Ireland.

All-Party Parliamentary Group on Dementia (2013). Dementia Does Not Discriminate: The Experiences of Black, Asian and Minority Ethnic Communities. London: AAPG on Dementia.

Alzheimer's Society (2007). Dementia UK. London: Alzheimer's Society.

Alzheimer Europe (2009). EUROCODE: Report of WP 72006 Prevalence of Dementia in Europe.

Alzheimer Scotland (2007). The Dementia Epidemic - where Scotland is now and the challenge ahead. Edinburgh, Scotland Alzheimer Scotland.

Bamford, S. (2011). Women and Dementia: Not Forgotten. London: The International Longevity Centre. 
Blazer, D. G., Yaffe, K. \& Liverman, C. T. (2015). Cognitive Ageing: Processes in Understanding and Opportunities for Action, Washington (D.C), The National Academies Press (U.S.).

Boersma, F., Eefsting, J. A., van den Brink, W., Koeter, M. \& van Tilburg, W. (1998). Prevalence of dementia in a rural Netherlands population and the influence of DSM-III-R and CAMDEX criteria for the prevalence of mild and more severe forms. Journal of clinical epidemiology, 51, 189-197.

Bowen, M., Edgar, D., Hancock, B., Haque, S., Shah, R., Buchanan, S., Iliffe, S., Maskell, S., Pickett, J., Taylor, J. \& O’Leary, N. (2017). The Prevalence of Visual Impairment in People with Dementia (the PrOVIDe study): a cross-sectional study of people aged 60-89 years with dementia and qualitative exploration of individual, carer and professional perspectives Health Services and Delivery Research, 4

Boyle, G. (2013). Facilitating decision-making by people with dementia: Is spousal support genedered? Journal of Social Welfare and Family Law, 35, 227-243.

Browne, J., Edwards, D. A., Rhodes, K. M., Brimicombe, D. J. \& Payne, R. A. (2017). Association of comorbidity and health service usage among patients with dementia in the UK: a population-based study. BMJ open, 7.

Bunn, F., Burn, A.-M., Goodman, C., Rait, G., Norton, S. Robinson, L., Schoeman, J. \& Brayne, C. (2014). Comorbidity and dementia: a scoping review of the literature. BMC medicine, 12 , 192.

Bunn, F., Burn, A.-M., Robinson, L., Poole, M., Rait, G., Brayne, C., Schoeman, J., Norton, S. \& Goodman, C. (2017). Healthcare organisation and delivery for people with dementia and comorbidity: a qualitative study exploring the views of patients, carers and professionals. BMJ open, 7.

Cahill, S., Diaz-Ponce, A. M., Coen, R. F. \& Walsh, C. (2010). The underdetection of cognitive impairment in nursing homes in the Dublin area. The need for on-going cognitive assessment. Age and Ageing, 39, 128-131.

Cahill, S., O'Shea, E. \& Pierce, M. (2012). Creating Excellence in Dementia Care: A Research Review for Ireland's Forthcoming National Dementia Strategy. Dublin and Galway: Living with Dementia Priogramme, Trinity College Dublin and Irish Centre for Social Gerontology, National University of Ireland, Galway.

Cepoiu-Martin, M., Tam-Tham, H., Patten, S., Maxwell, C. \& Hogan, D. (2016). Predictors of long-term care placement in persons with dementia: A systematic review and meta-analysis. International Journal of Geriatric Psychiatry, 31, 1151-1171.

Corfield, S. (2017). Women and Dementia: A Global Challenge. London: Global Alzheimer's and Dementia Action Alliance.

CSO (2008). National Disability Survey.

Dublin: Stationary Office.

CSO (2013). Population and Labour Force Projections, 2016-2046. Cork: Central Statistics Office.

CSO (2016). Census 2016. Cork: Central Statistics Office.

de Witt, L. \& Ploeg, J. (2016). Caring for older people living alone with dementia: Healthcare professionals' experiences. Dementia: The International Journal of Social Research and Practice, 15, 221-238.
Dept. of Health (2013). Long-Stay Activity Statistics. Dublin: Deptartment of Health.

Diaz-Ponce, A. (2008). Qulaity of Life of People with Cognitive Imapirment Living in a Setting: The Subjective Views of Residents and Staff Masters, University of Dublin.

Duvvury, N., Ni Leime, A., Callan, A., Price, L. \& Simpson, M. (2012). Older Women Workers' Access to Pensions: Vulnerabilities, Perspectives and Strategies. Galway: Irish Centre for Social Gerontology, National University Ireland Galway.

Fanning, B. \& Pierce, M. (2004). Ethnic data and social policy in Ireland. Administration, 52, 3-20.

Ferri, C., Prince, M., Brayne, C., Brodaty, H., Fratiglioni, L., Ganguli, M. \& et al. (2005). Global prevalence of dementia: A Delphi consensus study. The Lancet, 366, 2112-2117.

Ferri, C. P., Prince, M., Brayne, C., Brodaty, H., Fratiglioni, L., Ganguli, M., Hall, K., Hasegawa, K., Hendrie, H. \& Huang, Y. (2006). Global prevalence of dementia: a Delphi consensus study. The Lancet, 366, 2112-2117.

Genio (2015). HSE and Genio Dementia Programme. Dublin: Genio.

Gordon, D., Carter, H. \& Scott, S. (1997). Profiling the care needs of the population with dementia: A survey of central Scotland. International Journal of Geriatric Psychiatry, 12, 753-759.

Helmer, C., Pérès, K., Letenneur, L., Guttiérez-Robledo, L. M., Ramaroson, H., Barberger-Gateau, P., Fabrigoule, C., Orgogozo, J.-M. \& Dartigues, J.-F. (2006). Dementia in subjects aged 75 years or over within the PAQUID cohort: prevalence and burden by severity. Dementia and geriatric Cognitive Disorders, 22, 8794.

Hurd, M. D., Martorell, P. \& Langa, K. (2015). Future monetary costs of dementia in the United States under alternative dementia prevalence scenarios. Journal of Population Ageing, 8, 101-112.

Jones, R. \& Trigg, R. (2007). Dementia and Serious Sight Loss. Occasional Paper No. 11. Bath: Research Institue for the Care of the Elderly, St Martin's Hosptial.

Kiejna, A., Frydecka, D., Asdamowski, T., Bickel, H., Reynish, E., Prince, M., Caracciolo, B., Fratiglioni, L. \& Georges, J. (2010). Epidemiological studies of dementia in Eastern and Middle Eastern European countries. International Psychogeriatrics, 26, 111-117.

Launer, L., Andersen, K., Dewey, M., Letenneur, L., Ott, A. Amaducci, L., Brayne, C., Copeland, J., Dartigues, J.-F. \& Kragh-Sorensen, P. (1999). Rates and risk factors for dementia and Alzheimer's disease results from EURODEM pooled analyses. Neurology, 52, 78-78.

Livingston, G., Sommerlad, A., Orgeta, V., Costafreda, S. G., Huntley, J., Ames, D., Ballard, C., Banerjee, S., Burns, A., Cohen-Mansfield, J., Cooper, C., Fox, N., Gitlin, L. N., Howard, R., Kales, H. C., Larson, E. B., Ritchie, K., Rockwood, K., Sampson, E. L., Samus, Q., Schneider, L. S., Selbæk, G., Teri, L. \& Mukadam, N. (2017). Dementia prevention, intervention, and care. The Lancet, s0140-6736, 31363-31366. 


\section{REFERENCES}

Manton, K., Gu, X. \& Ukraintseva, S. (2005). Declining prevalence of dementia in the US elderly population. Advances in gerontology= Uspekhi gerontologii, 16, 30-37.

Matthews, F. E., Arthur, A., Barnes, L. E., Bond, J., Jagger, C., Robinson, L., Brayne, C., Function, M. R. C. C. \& Collaboration, A. (2013). A two-decade comparison of prevalence of dementia in individuals aged 65 years and older from three geographical areas of England: results of the Cognitive Function and Ageing Study I and II. The Lancet, 382, 1405-1412.

MCCarron, M., McCallion, P., Reilly, E., Dunne, P., Carroll, R. \& Mulryan, N. (2017). A prospective 20-year longitudinal follow-up of dementia in persons with Down symdrome. Journal of Intellectual Disability Research.

Miranda-Castillo, C., Woods, B., Galboda, K., Oomman, S., Olojugba, C. \& Orrell, M. (2010a). Unmet needs, quality of life and support networks of people with dementia living at home. Health and Quality of Life Outcomes, 8, 132.

Miranda-Castillo, C., Woods, B. \& Orrell, M. (2010b). Peope with dementia living alone: What are their needs and what kins of supports are they receiving? International Psychogeriatrics, $22,607-617$

Misiak, B., Cialkowska-Kuzminska, M., Frydecka, D., Chladzinka-Kiejna, S. \& Kiejna, A. (2013). European studies on the prevalence of dementia in the elderly: time for a step towards a methodological consensus. International Journal of Geriatric Psychiatry, 28, 1211-1221.

Moriarty, J., Sharif, N. \& Robinson, J. (2011). Black and Minority Ethnic People with Dementia and their Access to Support and Services: Research Briefing No. 35. London: Social Care Institute for Excellence.

O'Shea, E. (2007). Implementing Policy for Dementia in Ireland: The Time for Action is Now. Dublin: Alzheimer Society of Ireland.

O'Shea, E. \& Monaghan, C. (2017). An Economic Analysis of a Community-based Model for Dementia care in Ireland: a Balance of Care Approach. International Psychogeriatrics, 29, 1175-1184.

ONS (2016). Deaths registered in England and Wales (Series DR): 2015

Pierce, M., Cahill, S. \& O'Shea, E. (2014). Prevalence and Projections of Dementia in Ireland 2011-2046. Mullingar: Genio.

Prince, M., Bryce, R., Albanese, E., Wimo, A., Ribeiro, W. \& Ferri, C. (2013). The global prevalence of dementia: A systematic review and metaanalyiss. Alzheimer's \& Dementia, 9, 63-75.

Prince, M., Knapp, M., Guerchet, M., McCrone, P., Prina, M., Comas-Herrara, A., Wittenberg, R., Adelaja, B., Hu, B., King, D., Rehill, A. \& Salimkumar, D. (2014). Dementia UK: Update. London: Alzheimer Society.

Sansoni, J., Duncan, C., Grootemaat, P., Capell, J., Samsa, P. \& Westera, A. (2016). Younger Onset Dementia: A Review of the Literature to Inform Service Development. American Journal of Alzheimer's Disease \& Other Dementias, 31, 693-705.

Schneider, J., Hallam, A., Islam, M., Murray, J., Foley, B., Atkins, L., Banerjee, S. \& Mann, A. (2003). Formal and informal care for people with dementia: variations in costs over time. Ageing and Society, 23, 303-326
Schrijvers, E. M., Verhaaren, B. F., Koudstaal, P. J., Hofman, A. Ikram, M. A. \& Breteler, M. M. (2012). Is dementia incidence declining? Trends in dementia incidence since 1990 in the Rotterdam Study. Neurology, 78, 1456-1463.

Tyrell, J., Cosgrave, M., McCarron, M., McPherson, J., Calvert, J., Kelly, A., McLaughlin, M., Gill, M. \& Lawlor, B. (2001). Dementia in people with Down's Syndrome. International Journal of Geriatric Psychiatry, 16, 1168-1174.

Wilberforce, M., Challis, D., Davies, L., Kelly, M., Roberts, C. \& Clarkson, P. (2017). Person-centredness in the community care of older people: A literature-based concept synthesis International Journal of Social Welfare 26, 86-98.

Wren, M.-A., Keegan, C., Walsh, B., Bergin, A., Eighan, J., Brick, A., Connolly, S., Watson, D. \& Banks, S. (2017). Projections of Demand for Healthcare in Ireland, 2015-2030: First Report from the Hippocrates Model. Dublin: ESRI.

Ziegler-Graham, K., Brookmeyer, R., Johnson, E. \& Arrighi, H. M. (2008). Worldwide variation in the doubling time of Alzheimer's disease incidence rates. Alzheimer's \& Dementia, 4, 316-323.

\section{CHAPTER 3}

ADI (2015). World Alzheimer Report 2015: The Global Impact of Dementia. London: Alzheimer's Disease International.

Andrén, S. \& Elmståhl, S. (2005). Family caregivers' subjective experiences of satisfaction in dementia care: aspects of burden, subjective health and sense of coherence. Scandinavian journal of caring sciences, 19, 157-168.

Argyle, E., Downs, M. \& Tasker, J. (2010). Continuing to Care for People with Dementia: Irish Family Carers' Experience of their Relative's Transition to a Nursing Home. Bradford, Dublin and Cork: Bradford Dementia Group, The Alzheimer Society of Ireland and St Luke's Home.

Bamford, C. (2013). Person- and care-centred respite care. Genio Learning Event. Bewley's Hotel, Dublin.

Banerjee, S., Murray, J., Foley, B., Atkins, L., Schneider, J. \& Mann, A. (2003). Predictors of institutionalisation in people with dementia. Journal of Neurology, Neurosurgery \& Psychiatry, 74, 1315-1316.

Barnes, M. \& Brannelly, T. (2008). Achieving Care and Social Justice for People with Dementia. Nursing Ethics, 15, 384-395.

Bobersky, A. (2013). "It's been a good move" Transitions into Care: Family Caregivers', persons with dementia, and formal staff members experiences of specialist care unit placement. PhD, Trinity College Dublin.

Brannelly, T. (2006). Negotiating Ethnics in Dementia Care: An Analysis of an Ethic of Care in Practice.

Dementia: The International Journal of Social Research I and Practice, 5, 197-212.

Brennan, S., Lawlor, B., Pertl, M. M., O'Sullivan, M., Begley, E. \& O'Connell, C. (2017). De-Stress: A study to assess the health and wellbeing of spousal carers of people with dementia in Ireland. Dublin: Alzheimer's Society of Ireland. 
Brodaty, H. \& Donkin, M. (2009). Family caregivers of people with dementia. Dialogues in clinical neuroscience, 11, 217.

Brouwer, W., van Exel, N., van der Berg, B., van den Vos, G. \& Koopmanschap, M. (2005). Process utility from providing informal care: the benefit of caring. Health Policy, 74, 85-99.

Cahill, S. (1999). Caring in families: What motivates wives, daughters and daughters-in-law to provide care?

The Australian Journal of Family Studies 5, 235-247.

Cahill, S. (2000). Elderly husbands caring at home for wives diagnosed with alzheimer's disease: Are male caregivers really different? Australian Journal of Social Issues, 35, 53-72.

Cahill, S. \& Shapiro, M. (1997). "At first I thought it was age": Family Carers Recognition and General Practitioners Diagnosis of Dementia. NEW DOCTOR-SYDNEY-, 19-23.

Cahill, S. \& Shapiro, M. (1998). The only one you neglect is yourself. The Australian Journal of Family Studies, 4, 87-101.

Cherry, M., Salmon, P., Dickson, J. \& Powell, D. (2013). Factors influencing the resilience of carers of individuals with dementia. Reviews in Clincial Gerontology, 23, 251-266.

Connolly, S., Gillespie, P., O'Shea, E., Cahill, S. \& Pierce, M. (2014). Estimating the economic and social costs of dementia in Ireland. Dementia, 13, 5-22.

Cooper, C., Balamurali, T., Selwood, A. \& Livingston, G. (2007) A systematic review of intervention studies about anxiety in caregivers of people with dementia. International Journal of Geriatric Psychiatry, 22, 181-188.

CSO (2010). Quarterly National Household Survey: Carers, Quarter 3 2009. Dublin: Stationary Office.

CSO (2012). Profile 8: Our Bill of Health.

Dublin: Stationary Office.

Dept. of Health (2014). The Irish National Dementia Strategy. Dublin: Deptartment of Health.

Draper, B. M., Poulos, C. J., Cole, A., Poulos, R. G. \& Ehrlich, F. (1992). A comparison of caregivers for elderly stroke and dementia victims. Journal of the American Geriatrics Society, 40, 896-901.

Elvish, R., Leaver, S., Johnstone, J., Cawley, R. \& Keady, J. (2013). Psychological interventions for carers of people with dementia: A systematic review of quantitative and qualitative evidence Counselling and Psychotherapy Research, 13, 106-125.

Eska, K., Graessel, E., Donath, C., Schwarzkopf, L., Lauterberg, J. \& Holle, R. (2013). Predictors of Institutionalization of Dementia Patients in Mild and Moderate Stages: A 4-Year Prospective Analysis. Dementia and Geriatric Cognitive Disorders Extra, 3, 426-445.

Fetherstonhough, D., McAuliffe, L., Bauer, M. \& Shanley, C. (2017). Decision-making on behalf of people with dementia: how do surrogate decision-makers decide? Journal of Medical Ethics, 43, 35-40.

Gaugler, J. E., Kane, R. L., Kane, R. A. \& Newcomer, R. (2005). Unmet Care Needs and Key Outcomes in Dementia. Journal of the American Geriatrics Society, 53, 2098-2105.
Gillespie, P., O'Shea, E., Cullinan, J., Lacey, L., Gallagher, D. \& Ni Mhaolain, A. (2013). The effects of dependence and function on costs of care for Alzheimer's disease and mild cognitive impairment in Ireland. International journal of geriatric psychiatry, 28, 256-264.

Gillespie, P., O'Shea, E., Cullinan, J., Buchanan, J., Bobula, J., Lacey, L., Gallagher, D., Mhaolain, A. N. \& Lawlor, B. (2015). Longitudinal costs of caring for people with Alzheimer's disease. International Psychogeriatrics, 27, 847-856.

Hilbrand, S., Coall, D. A., Gerstorf, D. \& Hertwig, R. (2016). Caregiving within and beyond the family is associated with lower mortality for the caregiver: A prospective study. Evolution and Human Behavior.

Hogstel, M. O., Curry, L. C. \& Walker, C. (2005). Caring for older adults: The benefits of informal family caregiving. Journal of Theory Construction \& Testing, 9, 55 .

Hux, M. J., O’Brien, B. J., Iskedjian, M., Goeree, R., Gagnon, M. \& Gauthier, S. (1998). Relation between severity of Alzheimer's disease and costs of caring. Canadian Medical Association Journal, 159, 457-465.

Jacobs, J. C., Lilly, M. B., Ng, C. \& Coyte, P. C. (2013). The fisca impact of informal caregiving to home care recipients in Canada: How the intensity of care influences costs and benefits to government. Social Science \& Medicine, 81, 102-109.

Jensen, M., Agbata, I., Canavan, M. \& McCarthy, G. (2015). Effectiveness of educational interventions for informal caregivers of individuals with dementia residing in the community: systematic review and meta-analysis of randomised controlled trials. International Journal of Geriatric Psychiatry, 30, 130-143.

Jones, R. W., Romeo, R., Trigg, R., Knapp, M., Sato, A., King, D., Niecko, T., Lacey, L. \& Group, D. I. (2015). Dependence in Alzheimer's disease and service use costs, quality of life, and caregiver burden: The DADE study. Alzheimer's \& Dementia, $11,280-290$.

Kamiya, Y., Murphy, C., Saava, G. \& V, T. (2012). Profile of Community-Dwelling Older People with Disability and their Caregivers in Ireland. Dublin: The Irish Longitudinal Study on Ageing.

Kitwood, T. (1997). Dementia reconsidered: The person comes first, Milton Keynes, Open University Press.

Kitwood, T. \& Bredin, K. (1992). Towards of Theory of Dementia Care: Personhood and Well-Being. Ageing and Society,

$12,269-287$.

Kramer, B. \& Kipnis, S. (1995). Eldercare and work-role conflict: towards an understanding of gender differences in caregiver burden. The Gerontologist, 35, 340-348.

Lafferty, A., Fealy, G., Teahan, A., McAuliffe, E., Phelan, A., O'Sullivan, L. \& O'Shea, D. (2016). Profiling Family Carers of People with Dementia: Results from a National Survey Age and Ageing, 45, ii13-ii56.

Lapatin, S., Gonçalves, M., Nillni, A., Chavez, L., Quinn, R. L., Green, A. \& Alegría, M. (2012). Lessons from the use of vignettes in the study of mental health service disparities. Health Services Research, 47, 1345-1362. 


\section{REFERENCES}

Lee, H. \& Cameron, M. (2004). Respite care for people with dementia and their carers. Cochrane Database of Systematic Review, 2004.

Leicht, H., König, H.-H., Stuhldreher, N., Bachmann, C., Bickel, H., Fuchs, A., Heser, K., Jessen, F., Köhler, M. \& Luppa, M. (2013). Predictors of costs in dementia in a longitudinal perspective.

Leng Woo, L., Thompson, C. \& Magadi, H. (2017). Monetary cost of family caregiving for people with dementia in Singapore. Archives of Gerontology and Geriatrics, 71, 59-65.

Livingston, G., Sommerlad, A., Orgeta, V., Costafreda, S. G., Huntley, J., Ames, D., Ballard, C., Banerjee, S., Burns, A., Cohen-Mansfield, J., Cooper, C., Fox, N., Gitlin, L. N., Howard, R., Kales, H. C., Larson, E. B., Ritchie, K., Rockwood, K., Sampson, E. L., Samus, Q., Schneider, L. S., Selbæk, G., Teri, L. \& Mukadam, N. (2017). Dementia prevention, intervention, and care. The Lancet, S0140-6736, 31363-31366.

Manthorpe, J., Iliffe, S., Samsi, K., Cole, L., Goodman, C., Drennan, V. \& Warner, J. (2010). Dementia, dignity and quality of life: nursing practice and its dilemmas. International Journal of Older People Nursing, 5, 235-244.

Mayor, M. S., Ribeiro, O. \& Paúl, C. (2009). Satisfaction in dementia and stroke caregivers: a comparative study. Revista Latino-Americana de Enfermagem, 17, 620-624.

Morgan, D. L. (1997). The focus group guidebook, Sage publications.

Motenko, A. K. (1989). The frustrations, gratifications and well-being of dementia caregivers. Gerontologist, 29, 166-172.

O'Shea, E. (2003). Costs and consequences for the carers of people with dementia in Ireland. Dementia: The International Journal of Social Research and Practice, 2, 201-219.

O'Shea, E. \& Monaghan, C. (2016a). An economic analysis of a community-based model for dementia care in Ireland: A balance of care approach. Galway, Ireland: National Centre for Economic \& Social Research on Dementia, NUI Galway.

O'Shea, E. \& Monaghan, C. (2016b). An Economic Analysis of a Community-Based Model for Dementia Care in Ireland: A Balance of Care Approach. Galway: Centre for Economic and Social Research on Dementia.

Olazaran, J., Reisberg, B., Clare, L., Cruz, I., Pena-Casanova, J., del Ser, T., Woods, B., Beck, C., Auer, S., Lai, C., Spector, A., Fazio, S., Bond, J., Kivipelto, M., Brodaty, H., Rojo, J., Collins, H., Teri, L., Mittelman, M., Orrell, M., Feldman, H. \& Muniz, R. (2010). Nonpharmalogical therapies in Alzheimer's Disease: A Systematic Review of Efficacy. Dementia and Geriatric Cognitive Disorders, 30, 161-178.

Opie, A., Fulcher, L., Hawke, G. \& Allen, N. (1992). There's Nobody There: Community Care of Confused Older People, Philadelphia, University of Pennsylvania Press.

Orgeta, V. \& Miranda-Castillo, C. (2014). Does physical activity reduce burden in carers of people with dementia? A literature review. International Journal of Geriatric Psychiatry,

29, 771-783.

Ory, M. G., Hoffman, R. R., Yee, J. L., Tennstedt, S. \& Schulz, R. (1999). Prevalence and impact of caregiving: A detailed comparison between dementia and nondementia caregivers. The Gerontologist, 39, 177-186.
Parker, D., Mills, S. \& Abbey, J. (2008). Effectiveness of interventions that assist caregivers to support people with dementia living in the community: A systematic review. International Journal of Evidence based Healthcare, 6, 137-172.

Pimouguet, C., Lavaud, T., Dartigues, C. \& Helmer, C. (2010). Dementia Care Management Effectivness on Health Care Costs and Resource Utilization: A systematic review of randomized controlled trials. The Journal of Nutrition, Health \& Aging, 14, 669-676.

Pusey, H. \& Richards, D. (2001). A systematic review of the effectiveness of psychosocial interventions for carers of people with dementia. Aging and Mental Health, 5, 107-119.

Qureshi, H. \& Walker, A. (1989). The Caring Relationship: Elderly People and their Families, London, Macmillan.

Rapp, T., Andrieu, S., Molinier, L., Grand, A., Cantet, C., Mullins, C. D. \& Vellas, B. (2012). Exploring the Relationship between Alzheimer's Disease Severity and Longitudinal Costs. Value in Health, 15, 412-419.

Rattinger, G. B., Schwartz, S., Mullins, C. D., Corcoran, C., Zuckerman, I. H., Sanders, C., Norton, M. C., Fauth, E. B., Leoutsakos, J.-M. S. \& Lyketsos, C. G. (2015). Dementia severity and the longitudinal costs of informal care in the Cache County population. Alzheimer's \& Dementia, 11, 946-954.

Reed, C., Belger, M., Dell'Agnello, G., Wimo, A., Argimon, J. M., Bruno, G., Dodel, R., Haro, J. M., Jones, R. W. \& Vellas, B. (2014). Caregiver Burden in Alzheimer's Disease: Differential Associations in Adult-Child and Spousal Caregivers in the GERAS Observational Study. Dementia and Geriatric Cognitive Disorders EXTRA, 4, 51-64.

Seavey, D. (2005). Family Care and Paid Care: Separate Worlds or Common Ground Better Jobs Better Care. Better Jobs Better Care, Issue Brief 15. Better Jobs, Better Care, Issue Brief 5.

Selwood, A., Johnston, K., Katona, C., Lyketsos, C. \& Livingston, G. (2007). Systematic review of the effect of psychological interventions on family caregivers of people with dementia. Journal of Affective Disorders, 101, 75-89.

Smebye, K., Kirkevold, M. \& Engedal, K. (2012). How do person with dementia participate in decision-making related to health and daily care? A multi-case study? . BMC Health Services Research 12, 241-250.

Son, J., Erno, A., Shea, D. G., Femia, E. E., Zarit, S. H. \& Parris Stephens, M. A. (2007). The Caregiver Stress Process and Health Outcomes. Journal of Aging and Health, 19, 871-887.

Sutcliffe, C. L., Giebel, C. M., Jolley, D. \& Challis, D. J. (2016). Experience of burden in carers of people with dementia on the margins of long-term care. International Journal of Geriatric Psychiatry, 31, 101-108.

Teahan, A., Lafferty, A., Fealy, G., McAuliffe, E., Phelan, A. O'Sullivan, L. \& O'Shea, D. (2017). An Exploration of Resilience Among Family Carers of People with Dementia. International Journal of Integrated Care, 17, A186.

Tronto, J. (1993). Moral Boundaries: A Political Argument for an Ethic of Care, London, Routledge.

Ungerson, C. (1987). Policy is personal: Sex, Gender and Informal Care, New York, Tavistock. 
Vandepitte, S., Van Den Noortgate, N., Putman, K., Verhaeghe, S., Faes, K. \& Annemans, L. (2016). Effectiveness of supporting informal caregivers of people with dementia: A systematic review of randomized and non-randomized controlled trials Journal of Alzhiemer's Disease 52, 929-965.

Vernooij-Dassen, M., Draskovic, I., McCleery, J. \& Downs, M. (2011). Cognitive reframing for carers of people with dementia. Cochrane Database of Systematic Review.

Wilberforce, M., Challis, D., Davies, L., Kelly, M., Roberts, C. \& Clarkson, P. (2017). Person-centredness in the community care of older people: A literature-based concept synthesis International Journal of Social Welfare 26, 86-98.

Windle, G. (2010). What is resilience? A review and concept analysis. Reviews in Clincial Gerontology.

Yaffe, K., Fox, P., Newcomer, R., Sands, L., Lindquist, K., Dane, K. \& Covinsky, K. E. (2002). Patient and caregiver characteristics and nursing home placement in patients with dementia. Jama, 287, 2090-2097.

Zhu, C. W., Scarmeas, N., Ornstein, K., Albert, M., Brandt, J., Blacker, D., Sano, M. \& Stern, Y. (2015). Health-care use and cost in dementia caregivers: Longitudinal results from the Predictors Caregiver Study. Alzheimer's \& Dementia, 11, 444-454.

Zwaanswijk, M., Peeters, J., van Beek, A., Meerveld, J. \& Francke, A. (2013). Informal caregivers of people with dementia: Problems, needs, and support in initial stage and subsequent stages of dementia: A questionnaire survey The Open Nursing Journal 7, 6-13.

\section{CHAPTER 4}

Irish Human Rights and Equality Act, (2014). Government of Ireland. Number 24

ADI (2014). World Alzheimer Report 2014: Dementia and risk reduction: An analysis of protective and modifiable risk factors. London: Alzheimer Disease International.

Alzheimer Society of Ireland (2016). A Charter of Rights for People with Dementia. Dublin: Alzheimer Society of Ireland

Bartlett, R. (2000). Dementia as a disability: can we learn from disability studies and theory? Journal of Dementia Care, 8, 33-36.

Bartlett, R. \& O'Connor, D. (2010). Broadening the dementia debate: Towards social citizenship, Bristol, Policy press.

Bobersky, A. (2013). "It's Been a Good Move"-Transitions Into Care: Family Caregivers', Persons' with Dementia, and Formal Staff Members' Experiences of Specialist Care Unit Placement. Trinity College Dublin.

Bond, J. (2001). Sociological perspectives. In: Cantley, C. (ed.) A handbook of dementia care. Buckingham Philadelphia: Open University Press.

Cahill, S., Pierce, M. \& Bobersky, A. (2014). An Evaluation Report on the Dementia Support Worker Initiative of the 5 Steps to Living Well with Dementia in South Tipperary Project. Trinity College Dublin: Genio.

Clare, L. (2017). Rehabilitation for people living with dementia: A practical framework of positive support. PLoS medicine, 14.
Convery, J. B. (2014). Here Today Gone Tomorrow: An Exploratory Study of Housing with Care Development for People with Dementia in Ireland. Trinity College Dublin.

DAI (2016). The Human Rights of People Living with Dementia: from Rhetoric to Reality. Ankeny: Dementia Alliance International.

Dementia Forum X (2015). [Online] Available: dementiaforumx.org [Accessed 06-11-17].

Dept. of Health (2013). The National Positive Ageing Strategy Dublin: Deptartment of Health.

Dept. of Health (2014). The Irish National Dementia Strategy. Dublin: Deptartment of Health.

Dept. of Health (2017).Tackling Chronic Disease: A Policy Framework for the Management of Chronic Diseases. [Online] Available: http://health.gov.ie/wpcontent/uploads/2014/03/tackling_chronic_disease.pdf [Accessed 07-11-17].

Donnelly, S., O'Brien, M., Begley, E. \& Brennan, J. (2016). 'I'd prefer to stay at home but I don't have a choice': Meeting Older People's Preference for Care: Policy, but what about practice? University College Dublin. Dublin: University College Dublin.

Finnema, E., Dröes, R.-M., Ribbe, M. \& Van Tilburg, W. (2000). A review of psychosocial models in psychogeriatrics: implications for care and research. Alzheimer Disease \& Associated Disorders, $14,68-80$

Finnish Ministry of Social Affairs and Health (2013). National memory programme 2012-2020: Creating a "memory-friendly" Finland. Helsinki: Finnish Ministry of Social Affairs and Health.

García-Iriarte, E. (2016). 'Models of disability',. In: Edurne García Iriarte, R. M., Robbie Gilligan (ed.) Disability and human rights. New York: Palgrave and Macmillan.

George, D. R. (2010). Overcoming the social death of dementia through language. The Lancet, 376, 586-587.

Hughes, J. C. (2011). Thinking through dementia, Oxford University Press.

Hughes, J. C. (2014). How we think about dementia: personhood, rights, ethics, the arts and what they mean for care, Jessica Kingsley Publishers.

Kelly, F. \& Innes, A. (2013). Human rights, citizenship and dementia care nursing. International Journal of Older People Nursing, 8, 61-70.

Kitwood, T. (1993a). Person and process in dementia. International journal of geriatric psychiatry, 8, 541-545.

Kitwood, T. (1993b). Towards a theory of dementia care: the interpersonal process. Ageing \& Society, 13, 51-67.

Kitwood, T. (1997a). Dementia reconsidered: The person comes first, Milton Keynes, Open University Press.

Kitwood, T. (1997b). The experience of dementia. Aging and Mental Health, 1, 13-22.

Livingston, G., Sommerlad, A., Orgeta, V., Costafreda, S. G., Huntley, J., Ames, D., Ballard, C., Banerjee, S., Burns, A. \& Cohen-Mansfield, J. (2017). Dementia prevention, intervention, and care. The Lancet. 


\section{REFERENCES}

Mental Health Foundation (2015). Dementia rights and the social model of disability: A new direction for policy and practice. London: Mental Health Foundation.

Mishra, V. \& Barratt, J. (2016). Reablement and older people. IFA Copenhagen Summit: IFA.

Mutsch, L. (2015). The Luxembourg National Dementia Plan. Paper presented at first WHO ministerial conference on global action against dementia, March 17th, Geneva, Switzerland.

National Dementia Office (2017). Understand Together. [Online] Available: http://www.understandtogether.ie/ [Accessed 06-1117].

Ngandu, T., Lehtisalo, J., Solomon, A., Levälahti, E., Ahtiluoto, S., Antikainen, R., Bäckman, L., Hänninen, T., Jula, A. \& Laatikainen, T. (2015). A 2 year multidomain intervention of diet, exercise, cognitive training, and vascular risk monitoring versus control to prevent cognitive decline in at-risk elderly people (FINGER): a randomised controlled trial. The Lancet.

Norwegian Ministry of Health and Care Services (2016). A more dementia-friendly society. . Oslo: Ministry of Health and Care Services.

O'Shea, E. \& Carney, P. (2016). Dementia Paying Dividends: A report on The Atlantic Philanthropies Investment in dementia in Ireland. NUI Galway: Centre for Economic and Social Research on Dementia.

OECD (2015). Addressing Dementia: The OECD response. OECD Health Policy Studies. Paris.

Religa, D., Seyed-Mohammad Fereshtehnejad, Pavla Cermakova Ann-Katrin Edlund, Sara Garcia-Ptacek, Nicklas Granqvist, Anne Hallbäck, Kerstin Kåwe, Bahman Farahmand, Lena Kilander, UllaBritt Mattsson, Katarina Nägga, Peter Nordström, Helle Wijk, Anders Wimo, Bengt Winblad \& Eriksdotter, M. (2015). SveDem, the Swedish Dementia Registry -A Tool for Improving the Quality of Diagnostics, Treatment and Care of Dementia Patients in Clinical Practice. PLOS ONE ,10.

Revolta, C., Orrell, M. \& Spector, A. (2016). The biopsychosocial (BPS) model of dementia as a tool for clinical practice. A pilot study. International Psychogeriatrics, 28, 1079-1089.

Sabat, S. R. (1994). Excess disability and malignant social psychology: A case study of Alzheimer's disease. Journal of community \& applied social psychology, 4, 157-166.

Sabat, S. R. (2012). A Bio-Psycho-Social model enhances young adults' understanding of and beliefs about people with Alzheimer's disease: A case study. Dementia, 11, 95-112.

Shakespeare, T., Zeilig, H. \& Mittler, P. (2017). Rights in mind: Thinking differently about dementia and disability. Dementia, 1471301217701506

Snowdon, D. (2001). Aging with Grace: The Nun Study and the Science of Old Age. London: The Fourth Estate.

Spector, A., Hebditch, M., Stoner, C. R. \& Gibbor, L. (2016). A biopsychosocial vignette for case conceptualization in dementia (VIG-Dem): development and pilot study. International Psychogeriatrics, 28, 1471-1480.

Stokes, G. \& Goudie, F. (2002). The essential dementia care handbook, Winslow Press.
Swaffer, K. (2014). Dementia: stigma, language, and dementiafriendly. London: Sage Publications Sage

Thomas, C. \& Milligan, C. (2015). How can and should UK society adjust to dementia? Joseph Rowntree Viewpoint.

Travers, C., Lie, D. \& Martin-Khan, M. (2015). Dementia and the population health approach: promise, pitfalls and progress. An Australian perspective. Reviews in Clinical Gerontology, 25, 60-71.

UN (2006). Convention on the Rights of Persons with Disabilities. GA Res, 61, 106.

Verbeek, H. (2013). Redesigning dementia care: Small scale homelike care environments. Paper presented at Living with Dementia Seminar, Trinity College, Dublin, Ireland, 5 April.

Vogt, H., Ulvestad, E., Eriksen, T. E. \& Getz, L. (2014). Getting personal: can systems medicine integrate scientific and humanistic conceptions of the patient? I Eval Clin Pract, 20, 942-952.

WHO (2012). Dementia: a public health priority, World Health Organization.

WHO (2015). Ensuring a Human Rights-Based Approach for People Living with Dementia. Geneva:

World Health Organisation.

WHO (2016). Draft global action plan on the public health response to dementia. Geneva: World Health Organsiation.

Wu, Y.-T., Fratiglioni, L., Matthews, F. E., Lobo, A., Breteler, M. M., Skoog, I. \& Brayne, C. (2016). Dementia in western Europe: epidemiological evidence and implications for policy making. The Lancet Neurology, 15, 116-124.

\section{CHAPTER 5}

Alzheimer Europe (2016). France - national plans for Alzheimer and related diseases [Online]. Available:http://www.alzheimereurope.org/Policy-in-Practice2/National-DementiaStrategies/France [Accessed 27th October, 2017].

Alzheimer Society of Ireland (2016). Creating Dementia Friendly Communities - A Guide. Dublin: Alzheimer Society of Ireland Bartlett, R. \& O'Connor, D. (2007). From personhood to citizenship: Broadening the lens for dementia practice and research. Journal of Aging Studies, 21, 107-118.

Brady, A., Bracken-Scally, M., H., G., , Keogh, B., Daly, L., Kennelly, B., Ciblis, A. \& McCarron, M. (2017a). Evaluation of the Community Outreach Dementia Project Leitrim Dublin: Trinity Centre for Practice and Healthcare Innovation, School of Nursing and Midwifery, Trinity College Dublin.

Brady, A., Ciblis, A., Hynes, G., Keogh, B., Daly, L., Kennelly, B., Bracken-Scally, M. \& McCarron, M. b. (2017b). Evaluation of the Memory Matters Carlow/Kilkenny Community Dementia Project. Dublin: Trinity Centre for Practice and Healthcare Innovation, School of Nursing and Midwifery, Trinity College Dublin.

Cahill, S., O'Shea, E. \& Pierce, M. (2012). Creating Excellence in Dementia Care: A research review for Ireland's National Dementia Strategy. School of Social Work and Social Policy: Trinity College Dublin. 
Cahill, S., Pierce, M. \& Bobersky, A. (2014a). An Evaluation Report on Flexible Respite Options of the Living Well with Dementia project in Stillorgan and Blackrock. Trinity College Dublin: Genio.

Cahill, S., Pierce, M. \& Bobersky, A. (2014b). An Evaluation Report on the Dementia Support Worker Initiative of the 5 Steps to Living Well with Dementia in South Tipperary Project. Trinity College Dublin: Genio.

Clarke, C. (2015). Learning paper on dementia and risk. Dublin: Genio.

Clarke, C. L., Keady, J., Wilkinson, H. \& Gibb, C. E. (2011). Risk assessment and management for living well with dementia, Jessica Kingsley Publishers.

Cullen, K., Delaney, S., P., S. \& Wynne, R. (2016). Telecare \& Assistive Technology Evaluation HSE \& Genio Dementia Programme (2012 - 2015). Dublin: Work Research Centre and Genio.

Dementia Elevator (2017). [Online] Available:

http://dementiaelevator.ie/ [Accessed 08-11-17].

Dept. of Health (2014). The Irish National Dementia Strategy. Dublin: Deptartment of Health.

Downs, M. (2013). Putting people-and compassion-first: The United Kingdom's approach to person-centered care for individuals with dementia. Generations, 37, 53-59.

Genio (2016a). Community Supports Model for People with Dementia: Service Design Summary Document. Dublin: Genio.

Genio (2016b). HSE \& Genio Programme 2012-2018.

Dublin: Genio.

Keogh, F., Howard, E., Maguire, M. \& De Suin, A. (2016). Dementia Consortia: Integrated Networks to Deliver Integrated Supports for People with Dementia and their Family Carers. Dublin: Genio.

Kitwood, T. (1997). Dementia reconsidered: The person comes first, Milton Keynes, Open University Press.

Lakey, L. \& Saunders, T. (2011). Getting personal? Making personal budgets work for people with dementia. London: Alzheimer's Society.

Laporte Uribe, F., Wolf-Ostermann, K., Wübbeler, M. \& Holle, B. (2017). Care Arrangements in Dementia Care Networks: Findings From the DemNet-D Study Baseline and 1-Year FollowUp. Journal of Aging and Health.

McConkey, R., Keogh, F., Bunting, B., Garcia Iriarte, E. \& Watson, S. F. (2016). Relocating people with intellectual disability to new accommodation and support settings: Contrasts between personalized arrangements and group home placements. Journal of Intellectual Disabilities, 20, 109-120.

National Dementia Office (2017). [Online]. Available: www.understandtogether.ie [Accessed 06-11-17].

O'Shea, E. \& Monaghan, C. (2015). Genio Dementia Programme Evalaution of Year 2. Mullingar: Genio.

O'Shea, E. \& Monaghan, C. (2016). An Economic Analysis of a Community-Based Model for Dementia Care in Ireland: A Balance of Care Approach. Galway: Centre for Economic and Social Research on Dementia.
O'Shea, E. \& Murphy, E. (2014). Genio Dementia Programme: Evaluation of year one. Galway: Irish Centre for Social Gerontology, NUI Galway.

Robins, J. (1988). The years ahead: a policy for the elderly: report of the Working Party on Services for the Elderly. Dublin: Stationery Office.

Sabat, S. R., Johnson, A., Swarbrick, C. \& Keady, J. (2011). The 'demented other'or simply 'a person'? Extending the philosophical discourse of Naue and Kroll through the situated self. Nursing Philosophy, 12, 282-292.

Spicker, P. (2013). Personalisation Falls Short.

The British Journal of Social Work, 43, 1259-1275.

WHO (2012). Dementia: a public health priority, World Health Organization.

Wilberforce, M., Challis, D., Davies, L., Kelly, M., Roberts, C. \& Clarkson, P. (2017). Person-centredness in the community care of older people: A literature-based concept synthesis International Journal of Social Welfare 26, 86-98.

\section{CHAPTER 6}

Banerjee, S. (2009). The use of antipsychotic medication for people with dementia: Time for action. London: Department of Health.

Brooker, D. (2004). What is person-centred care in dementia? Reviews in Clinical Gerontology, 13, 215-222.

Brooker, D. \& Latham, I. (2016). Person-centred dementia care: Making services better with the VIPS framework, Jessica Kingsley Publishers.

De Siún, A. \& Manning, M. (2010). National dementia education needs analysis report Febuary 2010.

De Siún, A., O'Shea, E., Timmons, S., McArdle, D., Gibbons, P., O’Neill, D., Kennelly, S. P. \& Gallagher, P. (2014). Irish National Audit of Dementia Care in Acute Hospitals. Cork: National Audit of Dementia Care.

Dean, R., Proudfoot, R. \& Lindesay, J. (1993). The quality of interactions schedule (QUIS): development, reliability and use in the evaluation of two domus units. International Journal of Geriatric Psychiatry, 8, 819-826.

Dept. of Health (2013). The National Positive Ageing Strategy. Dublin: Deptartment of Health.

Dept. of Health (2014). The Irish National Dementia Strategy. Dublin: Deptartment of Health.

Edvardsson, D., SANDMAN, P. O., Nay, R. \& Karlsson, S. (2009). Predictors of job strain in residential dementia care nursing staff. Journal of Nursing Management, 17, 59-65.

Edvardsson, D., Winblad, B. \& Sandman, P. O. (2008). Personcentred care of people with severe Alzheimer's disease: current status and ways forward. The Lancet Neurology, 7, 362-367.

Foley, T. \& Swanwick, G. (2014). Dementia: Diagnosis and management in general practice. Dublin: Irish College of General Practitioners. 


\section{REFERENCES}

Fossey, J., Ballard, C., Juszczak, E., James, I., Alder, N., Jacoby, R. \& Howard, R. (2006). Effect of enhanced psychosocial care on antipsychotic use in nursing home residents with severe dementia: cluster randomised trial. BMJ, 332, 756-761.

Genio (2016). HSE \& Genio Programme 2012-2018. Dublin: Genio.

Goffman, E. (1963). Behavior in Public Places. New York: The Free Press.

Hopper, L., Joyce, R., Bieber, A., Broda, A., Irving, K. \& Verhey, F. (2016). Experiences of providing formal home and community dementia care in ireland: advocating for a holistic systemic approach.

Irish Hospice Foundation (2016). Guidance Documents for Healthcare Staff [Online]. Dublin: Irish Hospice Foundation. Available: http://hospicefoundation.ie/healthcareprogrammes/dementia-palliative-care/guidance-documentsdementia/ [Accessed 08-11-17].

Irving, K., Piasek, P., Kilcullen, S., Coen , A.-M. \& Manning, M. (2014). National educational needs analysis report. Dublin: Dublin City University.

Keady, J. \& Jones, L. (2010). Investigating the causes of behaviours that challenge in people with dementia: Using a case study, John Keady and Lesley Jones show how a personcentred approach can reveal the individual behind the behaviour and help to tailor subsequent interventions. Nursing Older People, 22, 25-29.

Kirkpatrick, D. \& Kirkpatrick, J. (1994). Evaluating Training Programs: The Four Levels, San Francisco, Berrett-Koehler.

Kitwood, T. (1997). Dementia reconsidered: The person comes first, Milton Keynes, Open University Press.

Magai, C., Cohen, C. I. \& Gomberg, D. (2002). Impact of training dementia caregivers in sensitivity to nonverbal emotion signals. International Psychogeriatrics, 14, 25-38.

Mc Parland, P. (2014). Dementia: What comes to mind? An exploration into how the general public understands and responds to dementia. Unpublished Thesis. University of Stirling.

Sjögren, K., Lindkvist, M., Sandman, P. O., Zingmark, K. \& Edvardsson, D. (2013). Person-centredness and its association with resident well-being in dementia care units. Journal of Advanced Nursing, 69, 2196-2206.

Spector, A., Orrell, M. \& Goyder, J. (2013). A systematic review of staff training interventions to reduce the behavioural and psychological symptoms of dementia. Ageing research reviews, 12, 354-364.

Surr, C. A., Gates, C., Irving, D., Oyebode, J., Smith, S. J., Parveen, S., Drury, M. \& Dennison, A. (2017). Effective dementia education and training for the health and social care workforce: a systematic review of the literature. Review of Educational Research, 87, 966-1002.

Testad, I., Aasland, A. \& Aarsland, D. (2005). The effect of staff training on the use of restraint in dementia: a single-blind randomised controlled trial. International Journal of Geriatric Psychiatry, 20, 587-590.

WHO (2002). Reducing stigma and discrimination against older people with mental disorders. Geneva: World Health Organisation.

\section{CHAPTER 7}

ADI (2009). World Alzheimer Report 2009. London: Alzheimer's Disease International.

ADI (2011). World Alzheimer report 2011: The benefits of early diagnosis and intervention. London: Alzheimer's Disease International.

Bahar-Fuchs, A., Clare, L. \& Woods, B. (2013). Cognitive training and cognitive rehabilitation for mild to moderate Alzheimer's disease and vascular dementia. The Cochrane Library.

Banerjee, S. \& Chan, J. (2008). Organization of old age psychiatric services. Psychiatry, 7, 49-54.

Banerjee, S., Willis, R., Matthews, D., Contell, F., Chan, J. \& Murray, J. (2007). Improving the quality of care for mild to moderate dementia: an evaluation of the Croydon Memory Service Model. International journal of geriatric psychiatry, 22, 782-788.

Banerjee, S. \& Wittenberg, R. (2009). Clinical and cost effectiveness of services for early diagnosis and intervention in dementia. International journal of geriatric psychiatry, 24, 748754.

Brooker, D., Fontaine, J. L., Evans, S., Bray, J. \& Saad, K. (2014). Public health guidance to facilitate timely diagnosis of dementia: ALzheimer's COoperative Valuation in Europe recommendations. International Journal of Geriatric Psychiatry, 29, 682-693.

Brooker, D., La Fontaine, J., Evans, S. \& Karim, S. (2013). Timely Diagnosis of Dementia: Synthesis Report. ALzheimer COoperation Valuation in Europe (ALCOVE).

Cahill, S., O'Shea, E. \& Pierce, M. (2012). Creating Excellence in Dementia Care: A research review for Ireland's National Dementia Strategy. School of Social Work and Social Policy: Trinity College Dublin.

Chung, J. C. (2009). An intergenerational reminiscence programme for older adults with early dementia and youth volunteers: values and challenges. Scandinavian journal of caring sciences, 23, 259-264.

Clare, L. (2002). Developing awareness about awareness in early-stage dementia: the role of psychosocial factors. Dementia, 1, 295-312.

Clare, L. (2017). Rehabilitation for people living with dementia: A practical framework of positive support. PLoS medicine, 14.

Clarke, C., Keyes, S., Wilkinson, H., Alexjuk, J., Wilcockson, J., Robinson, L., Reynolds, J., McClelland, S., Hodgson, P. \& Corner, L. (2013). Healthbridge: The National Evaluation of Peer Support Networks and Dementia Advisers in implementation of the National Dementia Strategy for England.

Corbett, A., Stevens, J., Aarsland, D., Day, S., Moniz-Cook, E., Woods, R., Brooker, D. \& Ballard, C. (2012). Systematic review of services providing information and/or advice to people with dementia and/or their caregivers. International journal of geriatric psychiatry, 27, 628-636.

D’Amico, F., Rehill, A., Knapp, M., Aguirre, E., Donovan, H., Hoare, Z., Hoe, J., Russell, I., Spector, A. \& Streater, A. (2015). Maintenance cognitive stimulation therapy: An economic evaluation within a randomized controlled trial. Journal of the American Medical Directors Association, 16, 63-70. 
Dening, T. \& Thomas, A. (2013). Oxford textbook of old age psychiatry, Oxford University Press.

Dow, B., Haralambous, B., Hempton, C., Hunt, S. \& Calleja, D. (2011). Evaluation of Alzheimer's Australia Vic Memory Lane Cafés. International Psychogeriatrics, 23, 246-255.

Elliott, A. F., Burgio, L. D. \& DeCoster, J. (2010). Enhancing caregiver health: findings from the resources for enhancing Alzheimer's caregiver health II intervention. Journal of the American Geriatrics Society, 58, 30-37.

Elvish, R., Lever, S.-J., Johnstone, J., Cawley, R. \& Keady, J. (2013). Psychological interventions for carers of people with dementia: A systematic review of quantitative and qualitative evidence. Counselling and Psychotherapy Research, 13, 106125.

Flynn, R. \& Mulcahy, H. (2013). Early-onset dementia: the impact on family care-givers. British journal of community nursing, 18.

Foley, T. \& Swanwick, G. (2014). Dementia: Diagnosis and management in general practice. Dublin: Irish College of General Practitioners.

Forbes, D., Forbes, S. C., Blake, C. M., Thiessen, E. J. \& Forbes, S. (2015). Exercise programs for people with dementia. The Cochrane Library.

Forstmeier, S. (2011). Cognitive-behavioral treatment for mild alzheimer's patients and their caregivers (CBTAC): A case study of a comprehensive treatment approach. Alzheimer's \& Dementia: The Journal of the Alzheimer's Association, 7, S492.

Gaugler, J. E., Kane, R. L., Kane, R. A. \& Newcomer, R. (2005). Unmet Care Needs and Key Outcomes in Dementia. Journal of the American Geriatrics Society, 53, 2098-2105.

Genio (2016). Community Supports Model for People with Dementia: Service Design Summary Document. Dublin: Genio.

Goeman, D., Renehan, E. \& Koch, S. (2016). What is the effectiveness of the support worker role for people with dementia and their carers? A systematic review. BMC health services research, 16, 285

Graff, M. J., Vernooij-Dassen, M. J., Thijssen, M., Dekker, J., Hoefnagels, W. H. \& Rikkert, M. G. O. (2006). Community based occupational therapy for patients with dementia and their care givers: randomised controlled trial. Bmj, 333, 1196.

Greenwood, N., Smith, R., Akhtar, F. \& Richardson, A. (2017). A qualitative study of carers' experiences of dementia cafés: a place to feel supported and be yourself. BMC Geriatrics, 17, 164.

Harris, P. B. \& Keady, J. (2004). Living With Early Onset Dementia: Exploring the Experience and Developing Evidence-based Guidelines for Practice. Alzheimer's Care Today, 5, 111-122.

Hauer, K., Schwenk, M., Zieschang, T., Essig, M., Becker, C. \& Oster, P. (2012). Physical training improves motor performance in people with dementia: a randomized controlled trial. Journal of the American Geriatrics Society, 60, 8-15.

Iliffe, S., Jain, P., Wong, G., Lefford, F., Gupta, S., Warner, A. \& Kennedy, H. (2009). Dementia diagnosis in primary care: thinking outside the educational box. Aging Health, 5 .
Iliffe, S. \& Manthorpe, J. (2004). The hazards of early recognition of dementia: a risk assessment. Taylor \& Francis.

Jones, K., Cheston, R. \& Gilliard, J. (2002). Dementia voice group psychotherapy for people with dementia. Bristol: Dementia Voice.

Kelly, F. \& Innes, A. (2016). Facilitating independence: The benefits of a post-diagnostic support project for people with dementia. Dementia, 15, 162-180.

Knapp, M., Comas-Herrera, A., Somani, A. \& Banerjee, S. (2007) Dementia: international comparisons. Personal Social Services Research Unit, London School of Economics and Political Science and the Institute of Psychiatry, King's College London.

Knapp, M., Thorgrimsen, L., Patel, A., Spector, A., Hallam, A., Woods, B. \& Orrell, M. (2006). Cognitive stimulation therapy for people with dementia: cost-effectiveness analysis. The British Journal of Psychiatry, 188, 574-580.

Lauriks, S., Reinersmann, A., Van der Roest, H. G., Meiland, F. Davies, R. J., Moelaert, F., Mulvenna, M. D., Nugent, C. D. \& Dröes, R.-M. (2007). Review of ICT-based services for identified unmet needs in people with dementia. Ageing research reviews, 6, 223-246.

Livingston, G., Johnston, K., Katona, C., Paton, J., Lyketsos, C. G. \& Psychiatry, O. A. T. F. o. t. W. F. o. B. (2005). Systematic review of psychological approaches to the management of neuropsychiatric symptoms of dementia. American Journal of Psychiatry, 162, 1996-2021.

Manthorpe, J., Samsi, K., Campbell, S., Abley, C., Keady, J., Bond, J., Watts, S., Robinson, L., Warner, J. \& Iliffe, S. (2013). From forgetfulness to dementia: clinical and commissioning implications of diagnostic experiences. Br J Gen Pract, 63, e69-e75.

McDermott, O., Orrell, M. \& Ridder, H. M. (2014). The importance of music for people with dementia: the perspectives of people with dementia, family carers, staff and music therapists. Aging \& Mental Health, 18, 706-716.

McHugh, J. E., Wherton, J. P., Prendergast, D. K. \& Lawlor, B. A. (2012). Teleconferencing as a source of social support for older spousal caregivers: initial explorations and recommendations for future research. American Journal of Alzheimer's Disease \& Other Dementias, 27, 381-387.

Medical Advisory Secretariat (2008). Caregiver- and patientdirected interventions for dementia: an evidencebased analysis. Ontario Health Technology Assessment Series

Miesen, B. \& Jones, G. (2004). The Alzheimer Café concept: A response to the trauma, drama and tragedy of dementia. In: Jones, G. \& Miesen, B. (eds.) Care-giving in Dementia: Research and Applications. London: Brunner Routledge.

Milne, A. (2010a). The 'D'word: Reflections on the relationship between stigma, discrimination and dementia. Journal of Mental Health, 227-233.

Milne, A. (2010b). Dementia screening and early diagnosis: The case for and against. Health, risk \& society, 12, 65-76.

Mittelman, M. S., Haley, W. E., Clay, O. J. \& Roth, D. L. (2006). Improving caregiver well-being delays nursing home placement of patients with Alzheimer disease. Neurology, 67, 1592-1599. 


\section{REFERENCES}

Moniz-Cook, E. \& Manthorpe, J. (2009). Early psychosocial interventions: evidence based practice. In: Moniz-Cook, E. \& Manthorpe, J. (eds.) Early Psychosocial Interventions in Dementia: Evidence-based Practice. London: Jessica Kingsley.

Moretti, R., Torre, P., Antonello, R. M., Cazzato, G. \& Bava, A. (2003). Rivastigmine in subcortical vascular dementia: a randomized, controlled, open 12-month study in 208 patients. American Journal of Alzheimer's Disease \& Other Dementias ${ }^{\circledast}$, $18,265-272$.

Mountain, G. A. \& Craig, C. L. (2012). What should be in a selfmanagement programme for people with early dementia? Aging \& mental health, 16, 576-583.

National Dementia Office (2017). Understand Together. [Online] Available: http://www.understandtogether.ie/

[Accessed 06-11-17].

NICE-SCIE (2007). Dementia. A NICE-SCIE Guideline on supporting people with dementia and their carers in health and social care. Leicester: The British Psychological Society and The Royal College of Psychiatrists.

Nichols, L. O., Martindale-Adams, J., Burns, R., Graney, M. J. \& Zuber, J. (2011). Translation of a dementia caregiver support program in a health care system-REACH VA. Archives of Internal Medicine, 171, 353-359.

O'Shea, E., Devane, D., Cooney, A., Casey, D., Jordan, F., Hunter, A., Murphy, E., Newell, J., Connolly, S. \& Murphy, K. (2014). The impact of reminiscence on the quality of life of residents with dementia in long-stay care. International journal of geriatric psychiatry, 29, 1062-1070.

Olazarán, J., Reisberg, B., Clare, L., Cruz, I., Peña-Casanova, J., Del Ser, T., Woods, B., Beck, C., Auer, S. \& Lai, C. (2010). Nonpharmacological therapies in Alzheimer's disease: a systematic review of efficacy. Dementia and geriatric cognitive disorders, 30, 161-178.

Orrell, M., Aguirre, E., Spector, A., Hoare, Z., Woods, R. T., Streater, A., Donovan, H., Hoe, J., Knapp, M. \& Whitaker, C. (2014). Maintenance cognitive stimulation therapy for dementia: single-blind, multicentre, pragmatic randomised controlled trial. The British Journal of Psychiatry, 204, 454-461.

Peacock, S. C. \& Forbes, D. A. (2003). Interventions for Caregivers of Persons with Dementia: A Systematic Review Interventions auprès des aidantes naturelles dispensant des soins aux personnes atteintes de démence: une évaluation systématique. CJNR (Canadian Journal of Nursing Research), 35, 88-107.

SCIE (2014). Dementia Gateway: Support following diagnosis London: Social Care Institute for Excellence

Sörensen, S., Duberstein, P., Gill, D. \& Pinquart, M. (2006) Dementia care: mental health effects, intervention strategies, and clinical implications. The Lancet Neurology, 5, 961-973.

Spector, A. \& Orrell, M. (2010). Using a biopsychosocial model of dementia as a tool to guide clinical practice. International Psychogeriatrics, 22, 957-965.

Spector, A., Thorgrimsen, L., Woods, B., Royan, L., Davies, S., Butterworth, M. \& Orrell, M. (2003). Efficacy of an evidencebased cognitive stimulation therapy programme for people with dementia. The British Journal of Psychiatry, 183, 248-254.
Steinberg, M., Leoutsakos, J. M. S., Podewils, L. J. \& Lyketsos, C. (2009). Evaluation of a home-based exercise program in the treatment of Alzheimer's disease: The Maximizing Independence in Dementia (MIND) study. International journal of geriatric psychiatry, 24, 680-685.

UK Dept. of Health (2008). Transforming the Quality of Dementia Care: Consultation on a National Dementia Strategy. London: UK Deptartment of Health.

van der Steen, J. T., van Soest-Poortvliet, M. C., van der Wouden, J. C., Bruinsma, M. S., Scholten, R. J. \& Vink, A. C. (2017). Music-based therapeutic interventions for people with dementia. The Cochrane Library.

Van Vliet, D., de Vugt, M. E., Bakker, C., Koopmans, R. T. \& Verhey, F. R. (2010). Impact of early onset dementia on caregivers: a review. International journal of geriatric psychiatry, 25, 1091-1100.

Vreugdenhil, A., Cannell, J., Davies, A. \& Razay, G. (2012). A community-based exercise programme to improve functional ability in people with Alzheimer's disease: a randomized controlled trial. Scandinavian journal of caring sciences, 26, $12-$ 19.

WHO (2012). Dementia: a public health priority, World Health Organization.

Woods, B., Aguirre, E., Spector, A. E. \& Orrell, M. (2012). Cognitive stimulation to improve cognitive functioning in people with dementia. The Cochrane Library.

Woods, R., Moniz-Cook, E., lliffe, S., Campion, P., VernooijDassen, M., Zanetti, O. \& Franco, M. (2003). Dementia: issues in early recognition and intervention in primary care. Journal of the Royal Society of Medicine, 96, 320-324.

Woods, R. T., Orrell, M., Bruce, E., Edwards, R. T., Hoare, Z., Hounsome, B., Keady, J., Moniz-Cook, E., Orgeta, V. \& Rees, J. (2016). REMCARE: pragmatic multi-centre randomised trial of reminiscence groups for people with dementia and their family carers: effectiveness and economic analysis. PloS one, 11.

\section{CHAPTER 8}

ADI (2015). World Alzheimer Report 2015: The Global Impact of Dementia. London: Alzheimer's Disease International.

Alzheimer Society of Ireland (2015). Annual Accounts. Dublin: Alzheimer Society of Ireland.

Amarach Research (2016). Forum on Long-Term Care for Older People. Dublin: Sage.

Ballard, J., Mooney, M. \& Dempsey, O. (2013). Prevalence of frailty-related risk factors in older adults seen by community nurses. Journal of Advanced Nursing, 69, 675-684.

Barnes, T. R., Banerjee, S., Collins, N., Treloar, A., Mclntyre, S. M. \& Paton, C. (2012). Antipsychotics in dementia: prevalence and quality of antipsychotic drug prescribing in UK mental health services. The British Journal of Psychiatry, 201, 221-226.

Briggs, R., Coary, R., Collins, R., Coughlan, T., O’neill, D. \& Kennelly, S. (2015). Acute hospital care: how much activity is attributable to caring for patients with dementia? QJM: An International Journal of Medicine, 109, 41-44. 
Brown, M. (2016). Responding to the Support \& Care Needs of our Older Population. Dublin: Sage.

Cahill, S., O'Shea, E. \& Pierce, M. (2012). Creating Excellence in Dementia Care: A research review for Ireland's National Dementia Strategy. School of Social Work and Social Policy: Trinity College Dublin.

Challis, D., Tucker, S., Wilberforce, M., Brand, C., Abendstern, M., Stewart, K., Jasper, R., Harrington, V., Verbeek, H. \& Jolley, D. (2014). National trends and local delivery in old age mental health services: towards an evidence base: a mixedmethodology study of the balance of care approach, community mental health teams and specialist mental health outreach to care homes. Programme Grants for Applied Research, 2, 1-480.

Citizens Assembly (2017). How we best respond to challenges and opportunities of an ageing population [Online]. Available: https://www.citizensassembly.ie/en/How-we-best-respond-tochallenges-and-opportunities-of-an-ageing-population [Accessed 06-11-17].

Connolly, S., Gillespie, P., O'Shea, E., Cahill, S. \& Pierce, M. (2014). Estimating the economic and social costs of dementia in Ireland. Dementia, 13, 5-22.

Connolly, S. \& O'Shea, E. (2015). The impact of dementia on length of stay in acute hospitals in Ireland. Dementia, 14, 650 658.

Cowdell, F. (2010). The care of older people with dementia in acute hospitals. International Journal of Older People Nursing, 5, 83-92.

Daly, A. \& Craig, S. (2016). Activities of Irish Psychiatric Units and Hospitals 2016 - Main Findings. Statistics Series. Dublin: HRB

Dept. of Health (2006). The efficiency and effectiveness of longstay residential care for adults within the mental health services evaluation report prepared under the value for money and policy review initiative. Dublin: Dept. of Health.

Dept. of Health (2011). Department of Health Comprehensive Review of Expenditure. Dublin: Dept. of Health.

Dept. of Health (2014). Review of the Nursing Homes Support Scheme - A Fair Deal. Dublin: Department of Health.

Dept. of Health (2015). Health in Ireland - Key Trends 2015. Dublin: Department of Health

Dept. of Health and Children (2006). Report of the Interdepartmental Working Group on Long-Term Care. Dublin: Department of Health and Children.

DPS (2017). DSP Press Release Dublin: Dept of Social Protection.

Eklund, K. \& Wilhelmson, K. (2009). Outcomes of coordinated and integrated interventions targeting frail elderly people: a systematic review of randomised controlled trials. Health \& Social Care in the Community, 17, 447-458.

Eurobarometer, S. (2007). Health and long-term care in the European Union. Special Eurobarometer.

Genio (2015). HSE and Genio Dementia Programme. Dublin: Genio.
Gillespie, P., O'Shea, E., Cullinan, J., Lacey, L., Gallagher, D., N Mhaolain, A. \& Lawlor, B. (2013). The effects of dependence and function on costs of care for Alzheimer's disease and mild cognitive impairment in Ireland. International Journal of Geriatric Psychiatry, 28, 256-264.

HRB (2006). High support community residences census Dublin: Health Research Board.

HSE (2016a). Delivering Specialist Mental Health Services. Dublin: Health Service Executive.

HSE (2016b). Primary Care Division Operational Plans. Dublin: Health Service Executive.

HSE (2016c). Social Care Division Operational Plans. Dublin: Health Service Executive.

HSE (2017a). National Service Plan. Dublin: Health Service Executive.

HSE (2017b). Social Care Division Operational Plan. Dublin: Health Service Executive.

Johri, M., Beland, F. \& Bergman, H. (2003). Internationa experiments in integrated care for the elderly: a synthesis of the evidence. International Journal of Geriatric Psychiatry, 18, 222 235.

Kelley, A. S., McGarry, K., Gorges, R. \& Skinner, J. S. (2015). The Burden of Health Care Costs for Patients With Dementia in the Last 5 Years of LifeBurden of Health Care Costs for Patients With Dementia. Annals of Internal Medicine, 163, 729-736.

Knapp, M., lemmi, V. \& Romeo, R. (2013). Dementia care costs and outcomes: a systematic review. International Journal of Geriatric Psychiatry, 28, 551-561.

Lafferty, A., Fealy, G., Downes, C. \& Drennan, J. (2014). Family Carers of Older People: Results of a National Survey of Stress, Conflict and Coping. Dublin: National Centre for the Protection of Older People, University College Dublin.

Livingston, G., Kelly, L., Lewis-Holmes, E., Baio, G., Morris, S., Patel, N., Omar, R. Z., Katona, C. \& Cooper, C. (2014). A systematic review of the clinical effectiveness and costeffectiveness of sensory, psychological and behavioural interventions for managing agitation in older adults with dementia. Health Technology Assessment (Winchester, England), 18, 1.

Luengo-Fernandez, R., Leal, J. \& Gray, A. (2015). UK research spend in 2008 and 2012: comparing stroke, cancer, coronary heart disease and dementia. BMJ open, 5, e006648.

Luengo-Fernandez, R., Leal, J. \& Gray, A. (2012). UK research expenditure on dementia, heart disease, stroke and cancer: are levels of spending related to disease burden? European Journal of Neurology, 19, 149-154.

Matthews, F., Stephan, B., Robinson, L., Jagger, C., Barnes, L., Arthur, A., Brayne, C. \& Collaboration, A. S. C. (2016). A two decade dementia incidence comparison from the Cognitive Function and Ageing Studies I and II. Nature Communications, 7. NMIC (2011). Management Of Dementia. Dublin: National Medicines Information Centre, St. James Hospital. 


\section{REFERENCES}

Nolan, L. (2006). Caring connections with older persons with dementia in an acute hospital setting-a hermeneutic interpretation of the staff nurse's experience. International Journal of Older People Nursing, 1, 208-215.

NOSOSCO (2014). Social Protection in the Nordic Countries.

O'Shea, E. \& Carney, P. (2016). Dementia Paying Dividends: A report on The Atlantic Philanthropies Investment in dementia in Ireland. NUI Galway: Centre for Economic and Social Research on Dementia.

O'Shea, E. \& Monaghan, C. (2017). An Economic Analysis of a Community-based Model for Dementia care in Ireland: a Balance of Care Approach. International Psychogeriatrics, 29, 1175-1184.

OECD (2017). Public spending on long-term care (health and social components) in 2014 as a \% of GDP [Online]. Paris: OECD. Available: http://www.oecd.org/els/health-systems/long-termcare.htm [Accessed 07-11-17].

Rothera, I., Jones, R., Harwood, R., Avery, A. J., Fisher, K., James, V., Shaw, I. \& Waite, J. (2008). An evaluation of a specialist multiagency home support service for older people with dementia using qualitative methods. International Journal of Geriatric Psychiatry, 23, 65-72.

Rubinstein, E., Duggan, C., Van Landingham, B., Thompson, D. \& Warburton, W. (2015). A call to action. The global response to dementia through policy innovation. World Innovation Summit for Health.

Schaller, S., Mauskopf, J., Kriza, C., Wahlster, P. \& Kolominsky-Rabas, P. L. (2015). The main cost drivers in dementia: a systematic review. International Journal of Geriatric Psychiatry, 30, 111-129.

Spijker, A., Vernooij-Dassen, M., Vasse, E., Adang, E., Wollersheim, H., Grol, R. \& Verhey, F. (2008). Effectiveness of Nonpharmacological Interventions in Delaying the Institutionalization of Patients with Dementia: A Meta-Analysis. Journal of the American Geriatrics Society, 56, 1116-1128.

Sury, L., Burns, K. \& Brodaty, H. (2013). Moving in: adjustment of people living with dementia going into a nursing home and their families. International Psychogeriatrics, 25, 867-876.

Szebehely, M. \& Trydegård, G. B. (2012). Home care for older people in Sweden: a universal model in transition. Health \& Social Care in the Community, 20, 300-309.

Timmons, S., Manning, E., Barrett, A., Brady, N. M., Browne, V., O'Shea, E., Molloy, D. W., O'Regan, N. A., Trawley, S. \& Cahill, S. (2015). Dementia in older people admitted to hospital: a regional multi-hospital observational study of prevalence, associations and case recognition. Age and Ageing, 44, 993999.

Toot, S., Swinson, T., Devine, M., Challis, D. \& Orrell, M. (2017). Causes of nursing home placement for older people with dementia: a systematic review and meta-analysis. International Psychogeriatrics, 29, 195-208.

Tucker, S., Brand, C., Sutcliffe, C., Challis, D., Saks, K., Verbeek, H., Cabrera, E., Karlsson, S., Leino-Kilpi, H., Stephan, A. \& Soto, M. E. (2016a). What makes institutional long-term care the most appropriate setting for people with dementia? Exploring the influence of client characteristics, decision-maker attributes, and country in 8 European nations. JAMDA.
Tucker, S., Sutcliffe, C., Bowns, I., Challis, D., Saks, K., Verbeek, H., Cabrera, E., Karlsson, S., Leino-Kilpi, H. \& Meyer, G. (2016b). Improving the mix of institutional and community care for older people with dementia: an application of the balance of care approach in eight European countries. Aging \& Mental Health, 20, 1327-1338.

Tucker, S., Wilberforce, M., Brand, C., Abendstern, M., Crook, A., Jasper, R., Stewart, K. \& Challis, D. (2015). Community mental health teams for older people: variations in case mix and service receipt (I). International Journal of Geriatric Psychiatry, 30, 595604.

Vasse, E., Vernooij-Dassen, M., Cantegreil, I., Franco, M., Dorenlot, P., Woods, B. \& Moniz-Cook, E. (2012). Guidelines for psychosocial interventions in dementia care: a European survey and comparison. International Journal of Geriatric Psychiatry, $27,40-48$.

Vernooij-Dassen, M. \& Moniz-Cook, E. (2014). Raising the standard of applied dementia care research: addressing the implementation error. Taylor \& Francis.

Wimo, A., Guerchet, M., Ali, G.-C., Wu, Y.-T., Prina, A. M., Winblad, B., Jönsson, L., Liu, Z. \& Prince, M. (2017). The worldwide costs of dementia 2015 and comparisons with 2010. Alzheimer's \& Dementia, 13, 1-7.

Wren, M.-A., Keegan, C., Walsh, B., Bergin, A., Eighan, J., Brick, A., Connolly, S., Watson, D. \& Banks, S. (2017). Projections of Demand for Healthcare in Ireland, 2015-2030: First Report from the Hippocrates Model. Dublin: ESRI.

\section{CHAPTER 9}

ADI (2014). Dementia in the Asia Pacific Region. London: Alzheimer's Disease International.

ADI (2015). World Alzheimer Report 2015: The Global Impact of Dementia. London: Alzheimer's Disease International.

ADI (2016). World Alzheimer Reports [Online]. Available: https://www.alz.co.uk/research/world-report [Accessed 06-1117].

ADI (2017a). Brief for Alzheimer associations: Access to the United Nations Convention on the Rights of Persons with Disabilities by people living with dementia.

ADI (2017b). Canada becomes 30th country to launch national dementia strategy [Online]. Available:

https://www.alz.co.uk/news/canada-becomes-30th-country-tolaunch-national-dementia-strategy [Accessed 13-11-17].

DAI (2017). Dementia Alliance International. [Online] Available: https://www.dementiaallianceinternational.org/

[Accessed 05-11-17]

DASN (2000). Dementia Advocacy and Support Network.

[Online]. Available: http://www.dasninternational.org/].

Livingston, G., Sommerlad, A., Orgeta, V., Costafreda, S. G., Huntley, J., Ames, D., Ballard, C., Banerjee, S., Burns, A. \& Cohen-Mansfield, J. (2017). Dementia prevention, intervention, and care. The Lancet.

OECD (2013). A Good Life in Old Age? Monitoring and Improving Quality in Long-Term Care. Paris: OECD. 
OECD (2015). Addressing Dementia: The OECD response. OECD Health Policy Studies. Paris.

Pot, A. M. \& Petrea, I. (2013). Improving dementia care worldwide: Ideas and advice on developing and implementing a National Dementia Plan. London: Bupa/ADI,.

SDWG (2017). [Online]. Available:

http://www.sdwg.org.uk/videos/home/about-us-sdwg/ [Accessed 06-11-17].

WHO (2012). Dementia: a public health priority, World Health Organization.

WHO (2016a). Conference Report on First WHO Ministerial Conference on Global Action Against Dementia. Geneva.

WHO (2016b). Draft global action plan on the public health response to dementia. Geneva: World Health Organsiation.

WHO (2017). iSupport [Online]. Available:

https://www.isupportfordementia.org/en [Accessed 06-11-17].

World Dementia Council (2017). [Online]. Available:

https://worlddementiacouncil.org].

Wu, Y.-T., Fratiglioni, L., Matthews, F. E., Lobo, A., Breteler, M. M., Skoog, I. \& Brayne, C. (2016). Dementia in western Europe: epidemiological evidence and implications for policy making. The Lancet Neurology, 15, 116-124.

Your Brain Matters (2015).[Online]. Available:

https://yourbrainmatters.org.au/ [Accessed 06-11-17].

\section{CHAPTER 10}

ADI (2011). World Alzheimer report 2011: The benefits of early diagnosis and intervention. London: Alzheimer's Disease International.

Alzheimer Society of Ireland (2011). National Dementia Summit. Dublin: Alzheimer Society of Ireland.

Astell, A. (2006). Technology and personhood in dementia care. Quality in Ageing and Older Adults, 7, 15-25.

Barnes, M. \& Brannelly, T. (2008). Achieving care and social justice for people with dementia. Nursing Ethics, 15, 384-395.

Begley, E. (2009). "I Know what it is But how Bad Does it Get?" Insights Into the Lived Experience and Service Needs of People with Earlly-stage Dementia, Trinity College.

Cahill, S., O’ Nolan, C., O' Caheny, D. \& Bobersky, A. (2015). An Irish National Survey of Dementia in Long Term Residential Care. Dublin: The Dementia Services Information and Development Centre.

Connolly, S., Gillespie, P., O’Shea, E., Cahill, S. \& Pierce, M. (2014). Estimating the economic and social costs of dementia in Ireland. Dementia, 13, 5-22.

Connolly, S. \& O'Shea, E. (2015). The impact of dementia on length of stay in acute hospitals in Ireland. Dementia, 14, 650658

Dept. of Health (2014). The Irish National Dementia Strategy. Dublin: Deptartment of Health.
Diaz-Ponce, A. (2014). Quality of life and anti-dementia medication: An exploration of the experiences of people living with dementia and their care-partners. Unpublished thesis, Trinity College.

Donnelly, D. S., O’Brien, D. M., Begley, D. E. \& Brennan, M. J. (2016). "I'd prefer to stay at home but I don't have a choice" Meeting Older People's Preference for Care: Policy, but what about practice? . Dublin: University College Dublin.

Fleming, R. \& Purandare, N. (2010). Long-term care for people with dementia: environmental design guidelines. International Psychogeriatrics, 22, 1084-1096.

Hofmann, B. (2013). Ethical challenges with welfare technology: A review of the literature. Science and Engineering Ethics, 19, 389-406.

Hughes, J. (2014). How we think about dementia: Personhood, rights, ethics, the arts and what they mean for care, London, Jessica Kingsley Publishers.

Ilinca, S., Leichsenring, K. and Rodrigues, R. (2015). From care in homes to care at home: European experiences with (de)institutionalisation in long-term care. European Centre.

Kane, R. A. (2001). Long-term care and a good quality of life: Bringing them closer together. The Gerontologist, 41, 293-304.

Kelly, B. (2017). The Assisted Decision-Making (Capacity) Act 2015: what it is and why it matters. Irish Journal of Medical Science (1971-), 186, 351-356.

Kitwood, T. \& Bredin, K. (1992). Towards a theory of dementia care: personhood and well-being. Ageing \& Society, 12, 269287.

Lindemann, H. (2014). Second nature and tragedy of Alzheimer's. In: Hydén, L.-C., Lindemann, H. \& Brookmeier, J. (eds.) Beyond loss: Dementia, identity, personhood. Oxford: Oxford Scholarship Online, Oxford University Press.

Norwegian Ministry of Health and Care Services (2016). A more dementia-friendly society. . Oslo: Ministry of Health and Care Services.

Nuffield Council on Bioethics (2009). Dementia: ethical issues. London: Nuffield Council on Bioethics.

O’Shea, E. \& Monaghan, C. (2016). An Economic Analysis of a Community-Based Model for Dementia Care in Ireland: A Balance of Care Approach. Galway: Centre for Economic and Social Research on Dementia.

O'Shea, E. \& Monaghan, C. (2017). An Economic Analysis of a Community-based Model for Dementia care in Ireland: a Balance of Care Approach. International Psychogeriatrics, 29, 1175-1184.

O'Shea, E. \& Murphy, E. (2014). Genio Dementia Programme Evaluation of year one. Galway: Irish Centre for Social Gerontology, NUI Galway.

Parker, J. \& Penhale, B. (1998). Forgotten people: Positive approaches to dementia care, Arena.

Parsons, C., McCann, L., Passmore, P. \& Hughes, C. (2015). Development and application of medication appropriateness indicators for persons with advanced dementia: a feasibility study. Drugs \& aging, 32, 67-77. 


\section{REFERENCES}

Powell, J. (2002). Care to communicate: helping the older person with dementia, a practical guide for care workers. Journal of Dementia Care.

Travers, C., Lie, D. \& Martin-Khan, M. (2015). Dementia and the population health approach: promise, pitfalls and progress. An Australian perspective. Reviews in Clinical Gerontology, 25, 6071.

Verbeek, H. (2013). Redesigning dementia care: Small scale homelike care environments. Paper presented at Living with Dementia Seminar, Trinity College, Dublin, Ireland, 5 April.

Welsh, S., Hassiotis, A., O'mahoney, G. \& Deahl, M. (2003). Big brother is watching you -the ethical implications of electronic surveillance measures in the elderly with dementia and in adults with learning difficulties. Aging \& mental health, 7, 372375.

WHO (2012). Dementia: a public health priority, World Health Organization. 


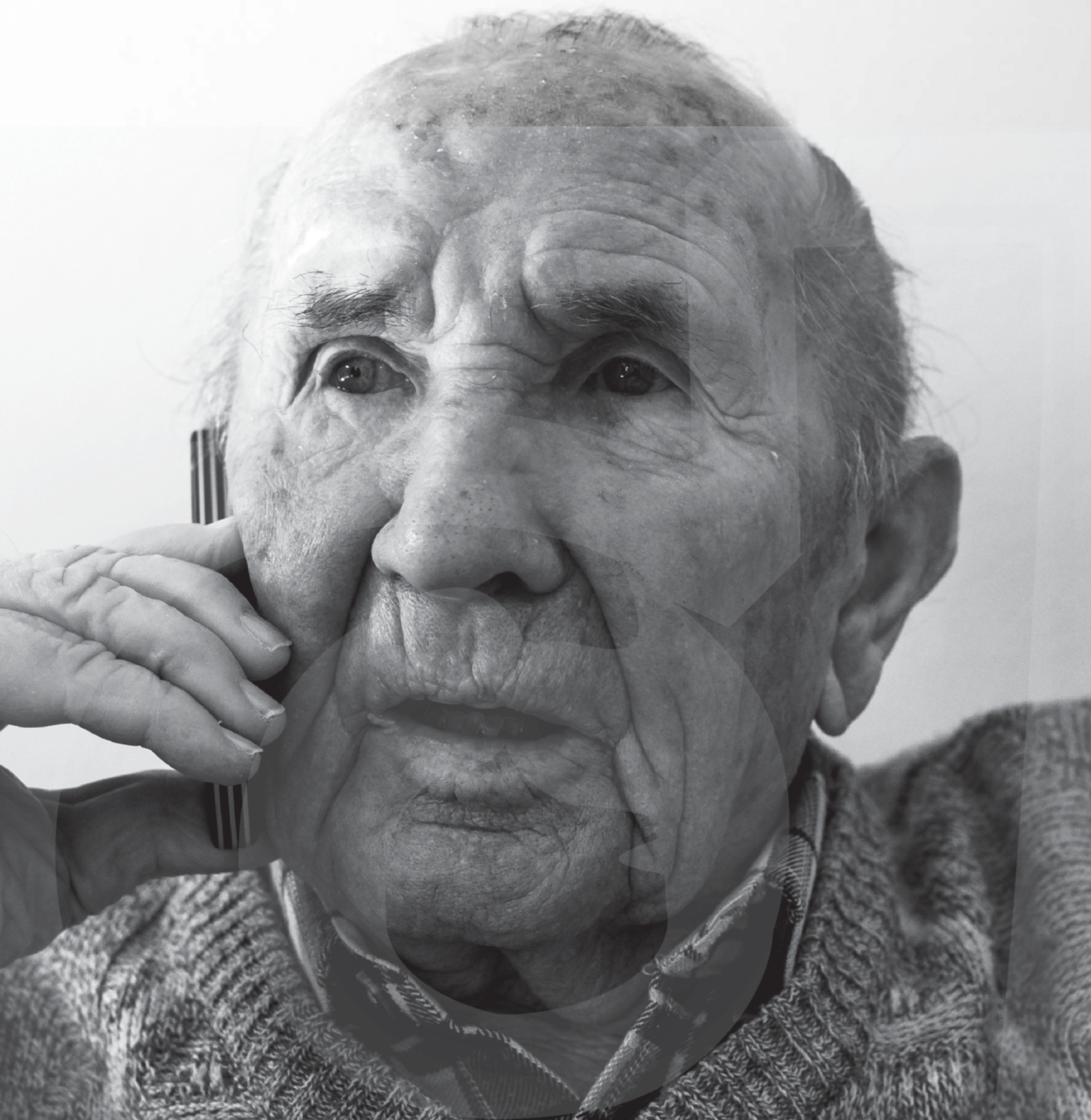

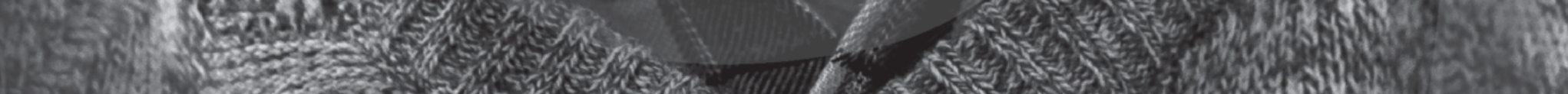

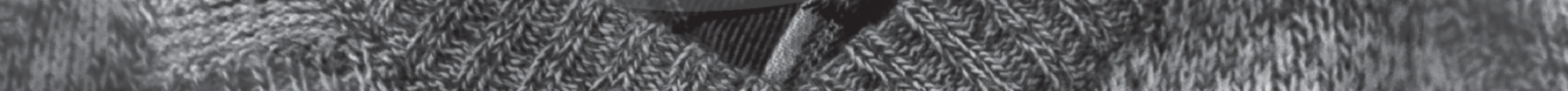
196.

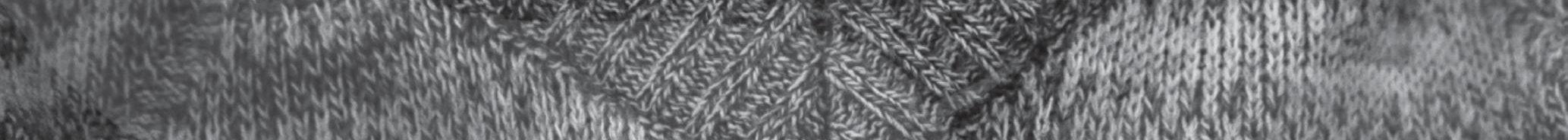

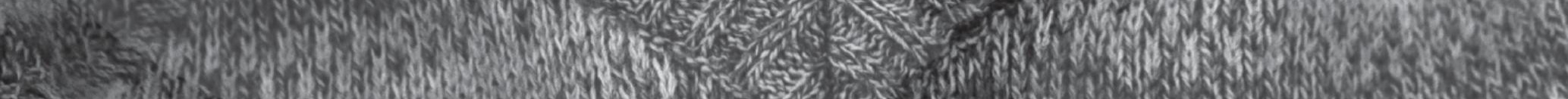
2.72 . 3.15)

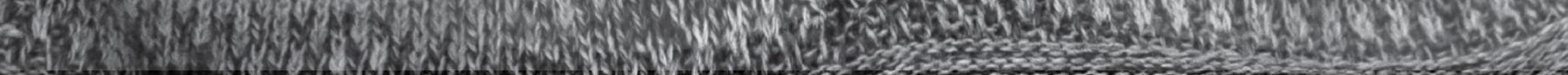
-

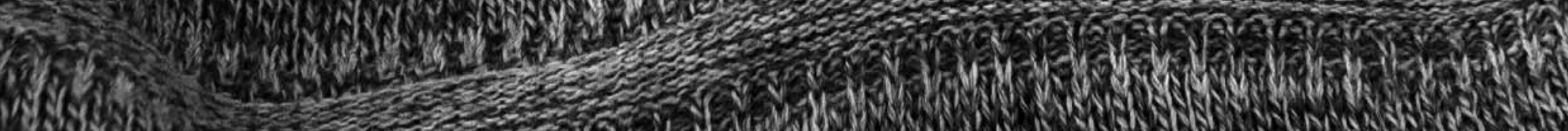

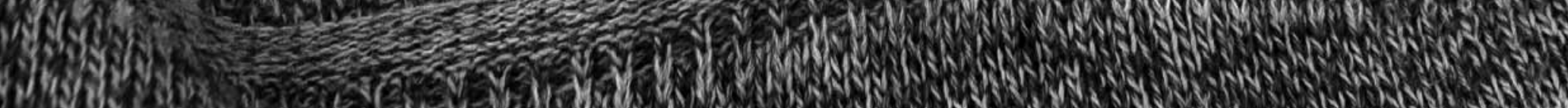

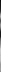




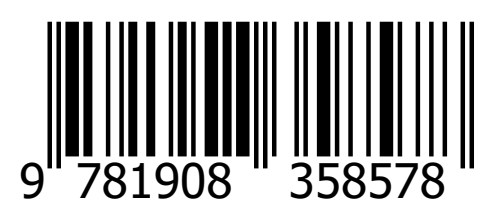

